Portland State University

PDXScholar

Winter 3-22-2016

\title{
Behavior of Prestressed Concrete Beams with CFRP Strands
}

Yasir Matloob Saeed

Portland State University

Follow this and additional works at: https://pdxscholar.library.pdx.edu/open_access_etds

Part of the Civil Engineering Commons, and the Structural Engineering Commons Let us know how access to this document benefits you.

\section{Recommended Citation}

Saeed, Yasir Matloob, "Behavior of Prestressed Concrete Beams with CFRP Strands" (2016). Dissertations and Theses. Paper 2726.

https://doi.org/10.15760/etd.2722

This Thesis is brought to you for free and open access. It has been accepted for inclusion in Dissertations and Theses by an authorized administrator of PDXScholar. Please contact us if we can make this document more accessible: pdxscholar@pdx.edu. 
Behavior of Prestressed Concrete Beams with CFRP Strands

by

Yasir Matloob Saeed

A thesis submitted in partial fulfillment of the requirement for the degree of

Master of Science

in

Civil and Environmental Engineering

Thesis Committee:

Franz Rad, Chair

Thomas Schumacher

Patrick McLaughlin

Portland State University

2016 
(C) 2016 Yasir Matloob Saeed 


\begin{abstract}
The high cost of repairing reinforced or prestressed concrete structures due to steel corrosion has driven engineers to look for solutions. Much research has been conducted over the last two decades to evaluate the use of Fiber Reinforced Polymers (FRPs) in concrete structures. Structural engineering researchers have been testing FRP to determine their usability instead of steel for strengthening existing reinforced concrete structures, reinforcing new concrete members, and for prestressed concrete applications. The high strength-to-weight ratio of FRP materials, especially Carbon FRP (CFRP), and their noncorrosive nature are probably the most attractive features of FRPs.
\end{abstract}

In this study, an experimental program was conducted to investigate the flexural behavior of prestressed concrete beams pre-tensioned with CFRP strands. The bond characteristics were examined by means of experimentally measuring transfer length, flexural bond length, and bond stress profiles. A total of four rectangular beams pretensioned with one 0.5-in. diameter CFRP strand were fabricated and tested under cyclic loading for five cycles, followed by a monotonically increasing load until failure. In investigating bond properties, the experimental results were compared to the equations available in the literature.

The results from the four flexural tests showed that the main problem of CFRP strands, in addition to their liner-elastic tensile behavior, was lack of adequate bonding between FRP and concrete. Poor bonding resulted in early failure due to slippage between FRPs and concrete. As a result, a new technique was developed in order to solve the 
bonding issues and improve the flexural response of CFRP prestressed concrete beams. The new technique involved anchoring the CFRP strands at the ends of the concrete beams using a new "steel tube" anchorage system. It was concluded that the new technique solved the bond problem and improved the flexural capacity by about $46 \%$.

A computer model was created to predict the behavior of prestressed beams pretensioned with CFRP. The predicted behavior was compared to the experimental results. Finally, the experimental results were compared to the behavior of prestressed concrete beams pre-tensioned with steel strands as generated by the computer model. The CFRP beams showed higher strength but lower ductility. 


\section{Dedication}

To my lovely parents,

To my wonderful sisters,

To my amazing brothers,

To the most beautiful wife in the world,

Thanks all for being there for me whenever 1 needed support ... 1 love you.

To my new little baby who will open his/ her eyes to this world soon,

Your "daddy" is trying to make this world a better place to live for you and your generation. 


\section{Acknowledgements}

First of all, many thanks to Allah (God) for giving me the faith and strength to finish this scientific work. I would like to express my deep gratitude to Professor Franz Rad, the supervisor and the chair of the thesis committee, for his generous help, support, and countless time of reviewing, reading, and advising. I also like to extend my appreciation to professors Thomas Schumacher and Patrick McLaughlin for serving as committee members and reviewing this paper. This piece of science became more informative and practically useful with their comments and recommendations. My deep gratitude to my parents, sisters, brothers, and wife for the emotional and financial support during my academic journey. Special thanks to all graduate students at Portland State University (PSU) who helped me with experimental work, especially Maysoun Hameed, Salam AlObaidi, Hayder Al-Khafaji, Karrar Al-Lami, Ali Al-Zerkani, Mohammad Murad, Salih Mahmood, Naowar Al-Abbas, Ranj Rafeeq, Ali Hafiz, Mohammed Al-Saedi, Bashar AlDomi, Anas Yosefani, Wisam Aules, Aqeel Al-Bahadily, Hamid Oqaili, and Sam Rediske. My gratitude to the Higher Committee for Education Development in Iraq (HCED) for funding this research. Tom Bennett, the lab expert and technician, is deeply thanked for his countless time and great efforts in instrumentation set-up and testing. Many thanks to Dr. Bill Wood, from the Department of Mechanical and Material Engineering/ PSU, and The University of Portland for helping with some material tests. Finally, I would like to thank John and Kerstin Hilton for their kind supports. 


\section{Table of Contents}

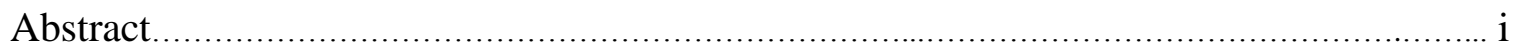

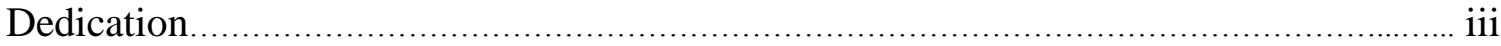

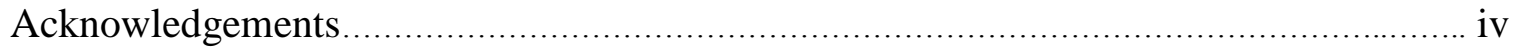

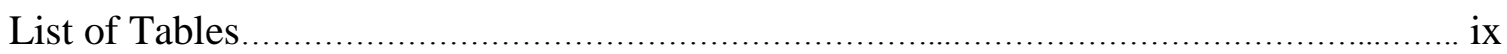

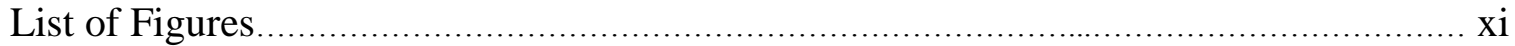

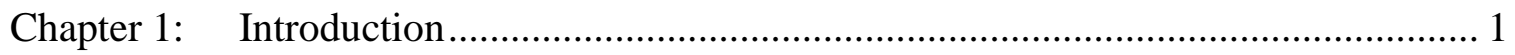

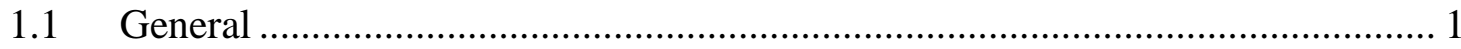

1.2 Fiber Reinforced Polymer Rebars or Strands .............................................. 2

1.3 Research Objective............................................................................... 4

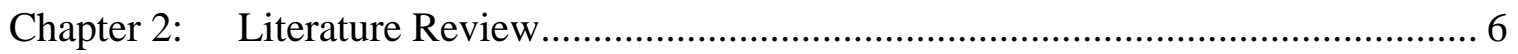

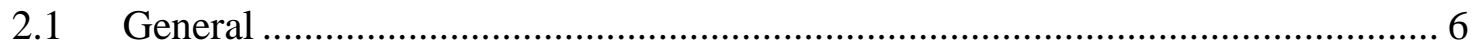

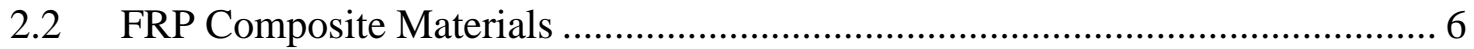

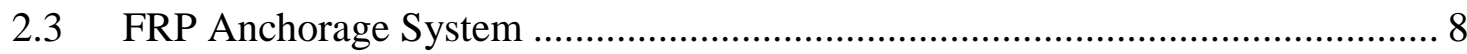

2.4 Bond Characteristics ......................................................................... 24

$2.5 \quad$ Flexural Behavior ........................................................................... 43

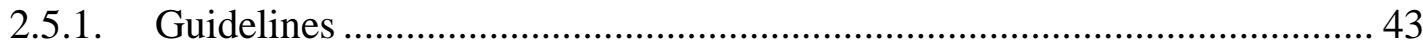

2.5.2. Flexural Response of FRP Prestressed Concrete Beams .......................... 50

Chapter 3: Experimental Program ........................................................................ 58

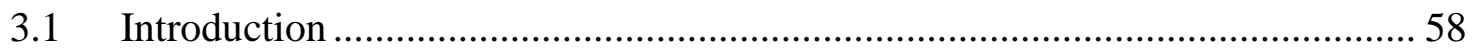

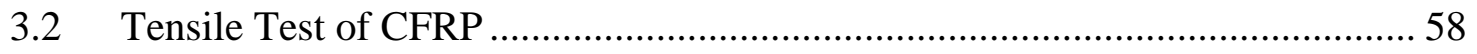




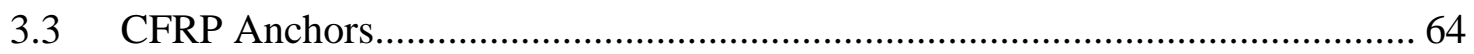

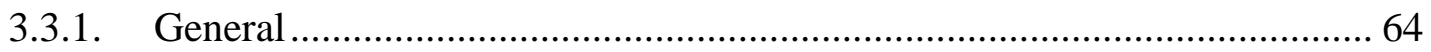

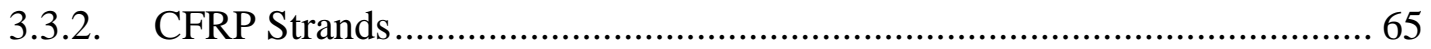

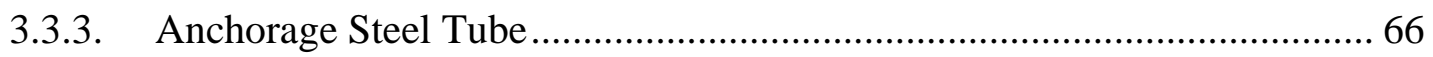

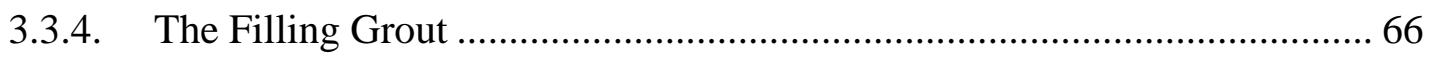

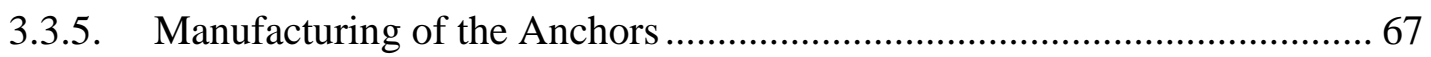

3.3.6. Test Setup and Instrumentation ................................................................. 71

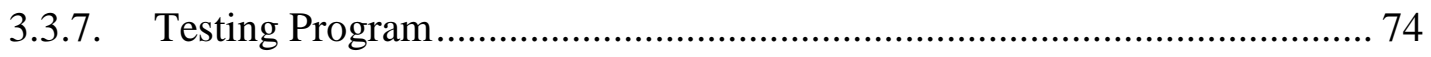

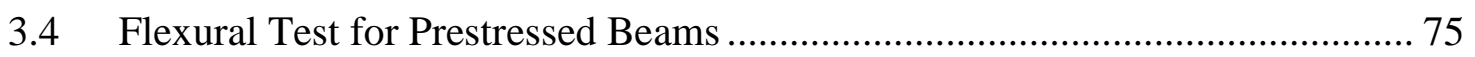

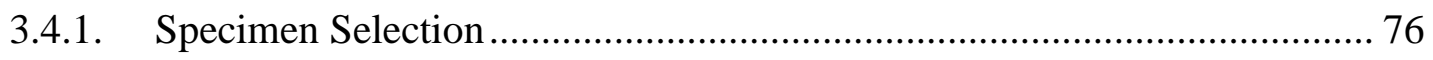

3.4.2. Material Properties ................................................................................... 79

3.4.3. Formwork, Casting, and Curing................................................................ 90

3.4.4. Instrumentations and test set up.......................................................... 95

Chapter 4: Results and Discussion of CFRP Prestressed Concrete Beams ................ 107

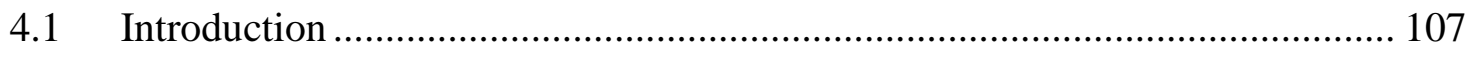

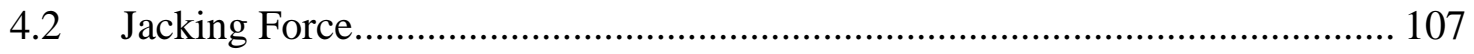

4.3 Force Releasing Results ............................................................................ 111

4.3.1. Transfer Length............................................................................... 112

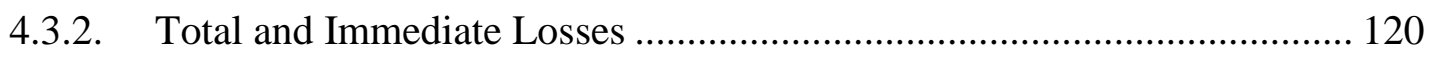


4.3.3. Average Bond Stress and Bond Stress Profile at Transfer

4.3.4. Theoretical Prediction of CFRP Transfer Length ................................. 129

4.4 Flexural Tests of the Prestressed Concrete Beams......................................... 130

4.4.1. Load Deflection Responses............................................................... 132

4.4.2. Tensile \& Bond Stress Development during Flexural Tests.................... 160

4.4.3. Moment-Deflection Response Comparison .......................................... 168

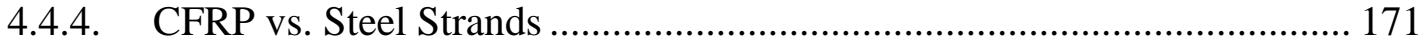

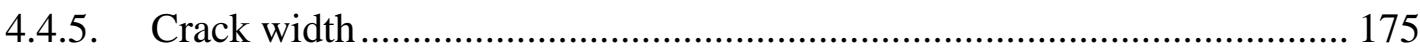

4.4.6. Bond Concrete Behavior of the D5 Steel Wire Embedded....................... 177

4.5 Test Results of the Anchorage System...................................................... 179

Chapter 5: Theoretical Prediction of Flexural Response of Beams Pre-tensioned with

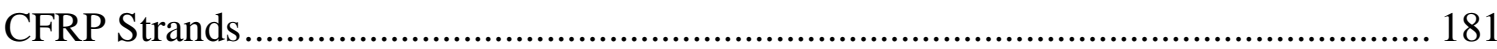

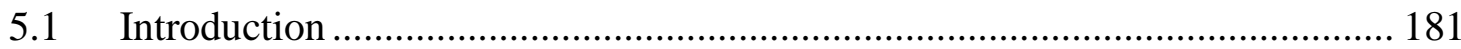

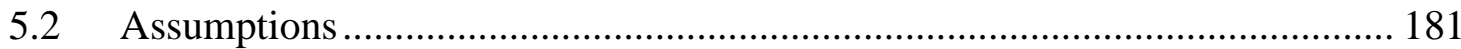

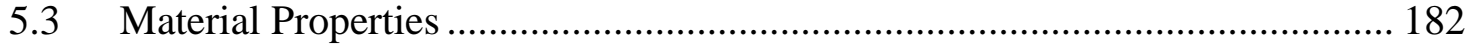

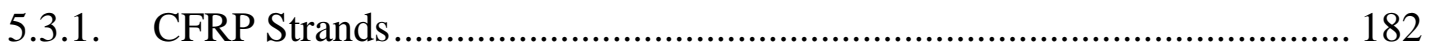

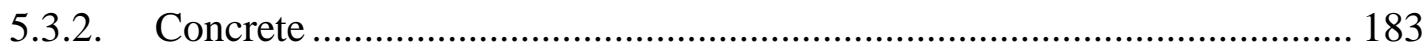

5.4 Analytical Procedure ............................................................................ 187

5.5 Theoretical vs. Experimental Moment-Deflection Curves ............................ 187 
Chapter 6: Conclusions and Recommendations

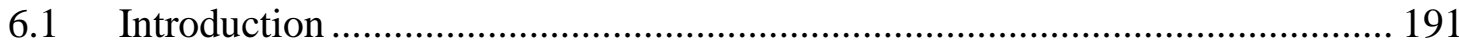

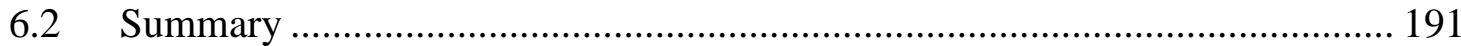

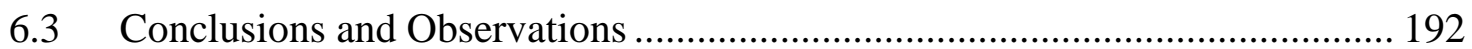

6.4 Recommendations for Future Work ......................................................... 195

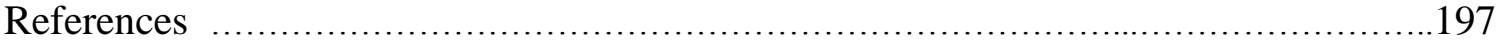

Appedix A: Development of a Computer Model to Predict Load-Deflection Response of Prestressed Beams with CFRP or Steel Strands................................................... 201 


\section{List of Tables}

Table 1-1 Typical mechanical properties of FRPs and steel (Schmidt et al., 2012).......... 3

Table 2-1 Advantages and disadvantages of FRP materials ...................................... 7

Table 2-2 Typical FRP mechanical properties..................................................... 8

Table 2-3 Transfer length results based on proposed model by Mahmoud et al. (1999) and

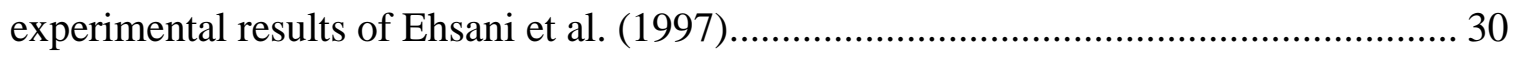

Table 2-4 Measured vs. predicted transfer lengths (Lu et al., 2000) ............................. 32

Table 2-5 Typical transfer and development lengths for AFRP and CFRP strands (ACI

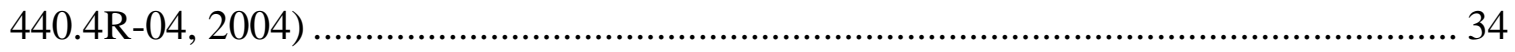

Table 2-6 Summary for the 209 beam tests (Wambeke \& Shield, 2006) ....................... 39

Table 2-7 Environmental reduction factor (ACI Committee 440.1R-06)....................... 44

Table 2-8 Flexural strength reduction factors (ACI 440.4R-04) .................................. 49

Table 2-9 Allowable stresses in FRP strands (ACI 440.4R-04) ................................. 49

Table 2-10 Allowable stresses in concrete for FRP-prestressed concrete beams (ACI

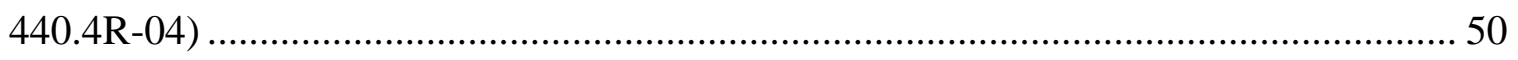

Table 2-11 Ductility or deformability indices for beams with AFRP and steel strands

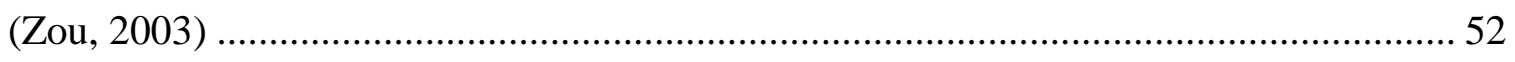

Table 2-12 Flexural responses of CFRP prestressed concrete beams (Krem, 2013)....... 55

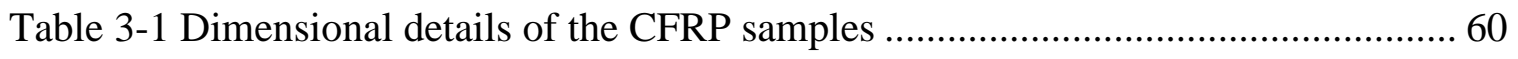

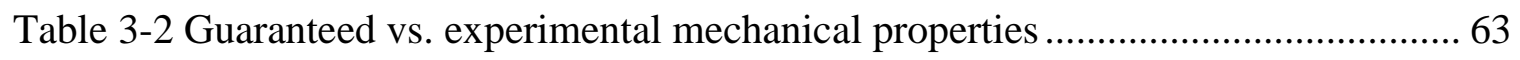

Table 3-3 Design details of the prestressed concrete beams...................................... 78

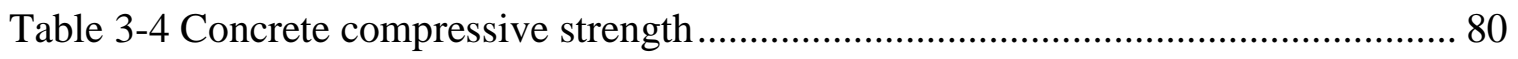




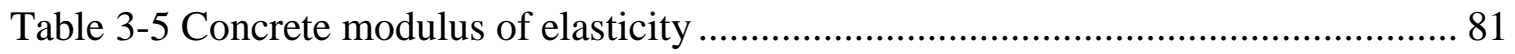

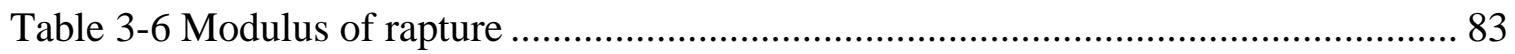

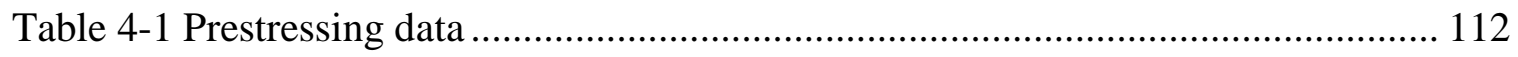

Table 4-2 Transfer lengths as a result of LVDTs' \& strain gauges' measurements....... 120

Table 4-3 Immediate and total losses.............................................................. 121

Table 4-4 Average bond stress at transfer......................................................... 122

Table 4-5 Theoretical vs. experimental transfer lengths......................................... 130

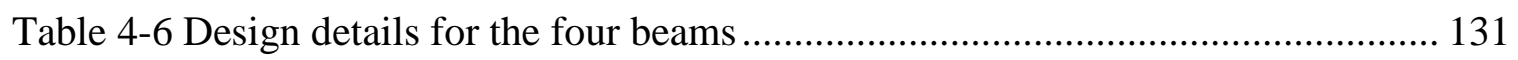

Table 4-7 Average bond stress at transfer and at flexural test ................................. 163

Table 4-8 Deformability comparison based on moment-deflection responses.............. 171

Table 4-9 CFRP beams vs. beams prestressed with steel strands .............................. 174

Table 4-10 The ratios of moments and deflections obtained from CFRP beams over the values obtained from beams prestressed with steel strands .................................... 174 


\section{List of Figures}

Figure 1.1 Typical stress-strain curves for steel and FRP composite bars ........................ 2

Figure 2.1 Steel/ FRP/ steel anchorage system (Lees et al., 1995) ............................... 10

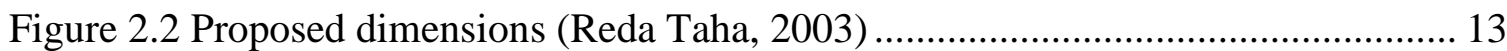

Figure 2.3 Dimensions of the bond-type anchorage system; (a) single-rode (b) multiplerod anchorage system. Dimensions are in mm. (Zhang \& Benmokrane, 2004) .............. 14

Figure 2.4 Typical load-slip curves (Zhang \& Benmokrane, 2004) .............................. 15

Figure 2.5 Straight-tube with inner-cone bond-type anchorage system (Cai et al., 2011) 17

Figure 2.6 Strain discontinuity between the four CFRP tendons at the same anchorage

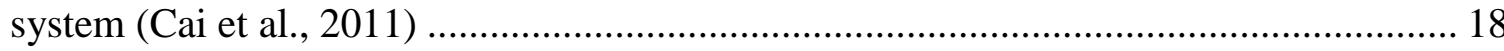

Figure 2.7 Multiple anchorage system for 9 CFRP rods proposed by (Fang et al., 2013) 19

Figure 2.8 The final design of the FRP mechanical anchor (Schmidt et al., 2010) ......... 21

Figure 2.9 Examples of mechanical anchorage systems (Schmidt et al., 2012) .............. 23

Figure 2.10 Transfer length results (Soudki et al., 1997) ........................................ 25

Figure 2.11 Long-term transfer for T-beams with 50\% prestressing level (Soudki et al.,

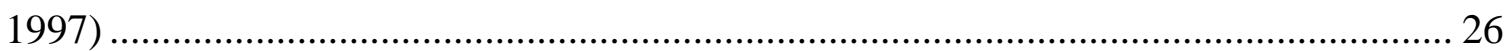

Figure 2.12 Predicted vs. test results of transfer length (Mahmoud et al., 1999)............ 29

Figure 2.13 Transfer length for steel strands (Mahmoud et al., 1999) ........................... 29

Figure 2.14 surface conditions of GFRP and steel bars (Harajli \& Abouniaj, 2010)...... 41

Figure 2.15 Modes of bond failures for beam specimens (Harajli \& Abouniaj, 2010).... 42

Figure 2.16 Bond stress-slip responses (Harajli \& Abouniaj, 2010)............................ 43

Figure 2.17 Flexural Strength Reduction Factor (ACI 440.1R-06) .............................. 47 
Figure 2.18 Sectional analysis of FRP-reinforced concrete members (ACI 440.1R-06) . 48 Figure 2.19 Sectional analysis of FRP-prestressed concrete members (ACI 440.4R-04) 48 Figure 2.20 Flexural response of prestressed concrete beams; FRP vs. steel strands (Zou, 2003) 52

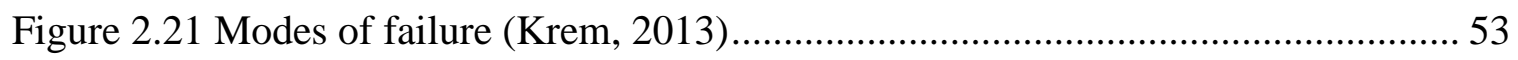

Figure 2.22 Effects of prestressing level on flexural response (Krem, 2013) ................. 54

Figure 2.23 Bonded vs. un-bonded tendons (Noël \& Soudki, 2013)............................ 56

Figure 2.24 Effects of prestressing tendons' number (Noël \& Soudki, 2013) ................ 56

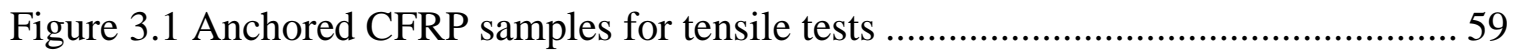

Figure 3.2 Test set-up for the CFRP tensile tests, performed at the University of Portland

61

Figure 3.3 Experimental vs. Manufacturer's stress-strain curves for \#3 CFRP strands ... 63

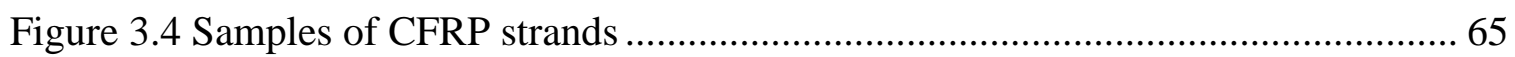

Figure 3.5 Expansive pressure vs. time. Retrieved from

(http://www.demolitiontechnologies.com/expanding-grout-technical-info).................... 67

Figure 3.6 Casting process to attach the anchorage steel tube ..................................... 68

Figure 3.7 A typical sample for anchorage testing .................................................. 71

Figure 3.8 Anchorage system - Test setup and instrumentations ................................ 72

Figure 3.9 Schematic drawing showing the test set-up for anchors tensile tests ............. 74

Figure 3.10 Loading procedure for anchors tensile tests ...................................... 75

Figure 3.11 Cross-sectional geometry and beam length profile of the prestressed concrete

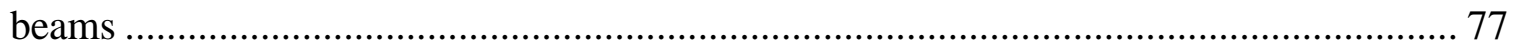


Figure 3.12 Casting of concrete cylinders 79

Figure 3.13 Schematic drawing for concrete flexural strength test ................................ 81

Figure 3.14 Mechanical tests for concrete ………………..................................... 83

Figure 3.15 Stress-strain relationship for CFRP strands during the pre-tensioning process -

Figure 3.16 Test set-up for D5 stress strain tests ................................................... 88

Figure 3.17 Stress-strain curve for D5 shear reinforcement ........................................... 89

Figure 3.18 Formwork, Casting, and Curing of the prestressed concrete beams ............. 91

Figure 3.19 Installation steps of the strain gauges on CFRP strands.............................. 96

Figure 3.20 Installation steps of concrete strain gauges …………................................. 97

Figure 3.21 Typical locations and number of strain gauges along the beam ................. 98

Figure 3.22 Prestressing bed system ................................................................... 100

Figure 3.23 Locking the CFRP strand with the load cell at the dead end....................... 101

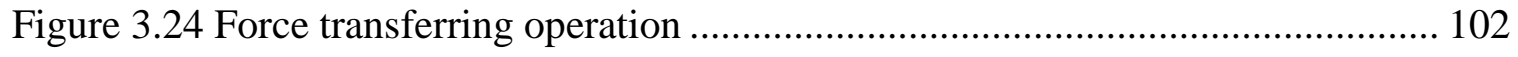

Figure 3.25 The reaction beam of the loading frame before and after upgrading......... 103

Figure 3.26 Upgrading of the loading frame ………………....................................... 104

Figure 3.27 Set-up for flexural tests .................................................................. 105

Figure 3.28 Flexural test set-up and instrumentations ............................................... 106

Figure 4.1 Stress-strain relationship for CFRP strands; comparing the tested samples to

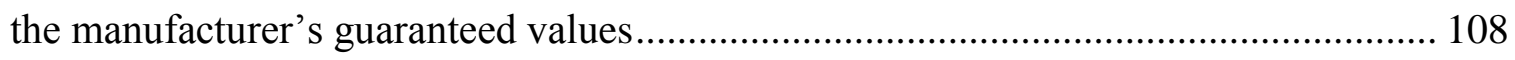

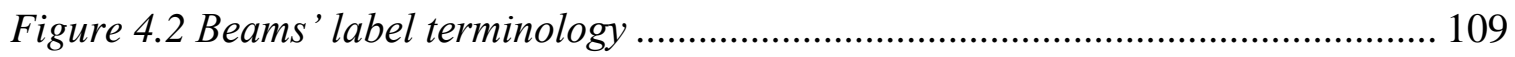

Figure 4.3 Stress-strain relationship for CFRP strands during prestressing process ...... 110 
Figure 4.4 Force releasing data; before \& after 115

Figure 4.5 Schematic drawing showing the stress development at the ends

Figure 4.6 CFRP tensile stress development and bond stress profile at transfer..... 123

Figure 4.7 Typical view for Beams \#1 to \#3 showing the un-bonded technique for CFRP

at the ends.

Figure 4.8 Typical view for Beam \#4 showing the anchoring technique of CFRP strand at the ends.

Figure 4.9 Moment vs. deflection for Beam \#1 - Mode of failure is CFRP slippage .... 135

Figure 4.10 Load vs. end slippage at the ends - Beam \#1 136

Figure 4.11 Moment vs. CFRP strain during flexural test - Beam \#1 137

Figure 4.12 Photos of the flexural test of Beam \#1 139

Figure 4.13 Moment vs. deflection for Beam \#2 - Mode of failure is CFRP slippage .. 143

Figure 4.14 Load vs. end slippage at the ends - Beam \#2. 145

Figure 4.15 Moment vs. CFRP \& concrete strains during flexural test - Beam \#2 ...... 146

Figure 4.16 Photos of the flexural test of Beam \#2

Figure 4.17 Moment vs. deflection for Beam \#3 - Mode of failure is concrete crushing

Figure 4.18 Load vs. end slippage at the ends - Beam \#3

Figure 4.19 Moment vs. CFRP \& concrete strains during flexural test - Beam \#3 ...... 150

Figure 4.20 Photos of the flexural test of Beam \#3 ................................................... 151

Figure 4.21 Moment vs. deflection for Beam \#4 - Mode of failure is concrete crushing 154 
Figure 4.22 Moment vs. CFRP \& concrete strains during flexural test - Beam \#4 ...... 156

Figure 4.23 Load vs. end slippage at the ends - Beam \#4 ........................................ 156

Figure 4.24 Photos of the flexural test of Beam \#4 ............................................... 158

Figure 4.25 Tensile stress and bond stress profiles - Beam \#1 .................................. 164

Figure 4.26 Tensile stress and bond stress profiles - Beam \#2 ................................ 165

Figure 4.27 Tensile stress and bond stress profiles - Beam \#3 ................................. 166

Figure 4.28 Tensile stress and bond stress profiles - Beam \#4 ................................ 167

Figure 4.29 Moment-deflection curves comparison ........................................... 168

Figure 4.30 Schematic drawing showing the points of interest for deformability

calculations

Figure 4.31 Comparison between prestressed concrete beams pre-tensioned with CFRP

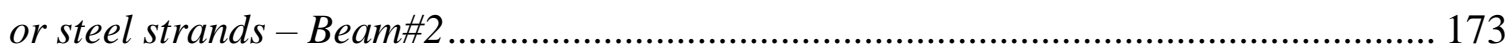

Figure 4.32 Comparison between prestressed concrete beams pre-tensioned with CFRP

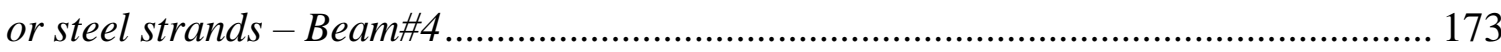

Figure 4.33 Moment vs. crack width for Beam \#2 ............................................... 176

Figure 4.34 Moment vs. crack width for Beam \#4 ............................................... 176

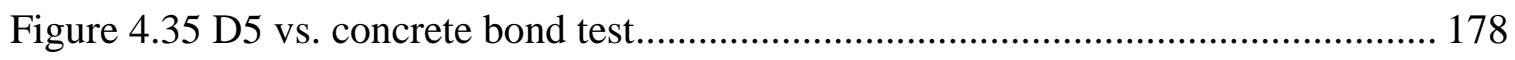

Figure 4.36 Pull-out load vs. extension of D5 rebar bonded in concrete....................... 178

Figure 4.37 Load vs. slip for the anchorage system tensile tests .............................. 180

Figure 4.38 Photos at instant of failure of the anchorage system tensile tests............... 180

Figure 5.1 Schematic drawing for typical concrete stress-strain relationship .............. 184

Figure 5.2 Concrete stress-strain relationships ... short time and creep effects ............ 185 
Figure 5.3 Theoretical vs. experimental moment-deflection curves........................... 189 


\section{Chapter 1: Introduction}

\subsection{General}

All over the world billions of dollars have been spent to solve the problems of corrosion associated with reinforced and prestressed concrete structures. Demolition of existing structures is a choice that is frequently used as a result of steel corrosion. Only in the United States, as reported by Lees, Gruffydd-Jones, and Burgoyne (1995), the cost of repairing the existing highway bridges was estimated in 1990s to be $\$$ US 50 billion. Furthermore, in Europe, the issues of corroded steel in concrete structures cost about \$US 1.5 billion a year. It is true that steel reinforcement is the most common and suitable material for concrete structures, but with the high cost of corrosion, structural engineers have to look for alternatives.

Over the last two decades, the use of a composite material called Fiber Reinforced Polymer (FRP) in concrete structures, whether reinforcing new structures or strengthening the existing ones, has been dramatically increased. FRP consists of a large number of fibers, which could be glass, aramid, carbon, or others, combined together and embedded in a resin matrix with different ratios based on the manufacturer. Unlike steel, there have not been any standards or guidelines for FRP production. As a result, every product of FRP has noticeable different properties from different providers. FRP composite can be in a form of rebars, strands (or tendons), sheets, or grids. For prestressed concrete industry, Carbon Fiber Reinforced Polymer (CFRP) strands or tendons are the most commonly used because of their high strength and high axial modulus of elasticity compared with glass or Aramid FRPs. 


\subsection{Fiber Reinforced Polymer Rebars or Strands}

What makes FRP attractive to structural engineers is its extremely high tensile strength, which is about four times that of conventional steel reinforcement rebars. Furthermore, FRPs are lightweight (about 20\% that of steel), are made up of corrosion resistant material, are non-magnetic, and are not sensitive to electricity. Compared to steel, FRP materials have higher strength-to-weight ratio, higher stiffness-to-weight ratio, lower life cycle costs, but higher initial costs. In terms of strength and modulus of elasticity, the stress-strain relationship for steel and different type of FRPs are presented in Figure 1-1.

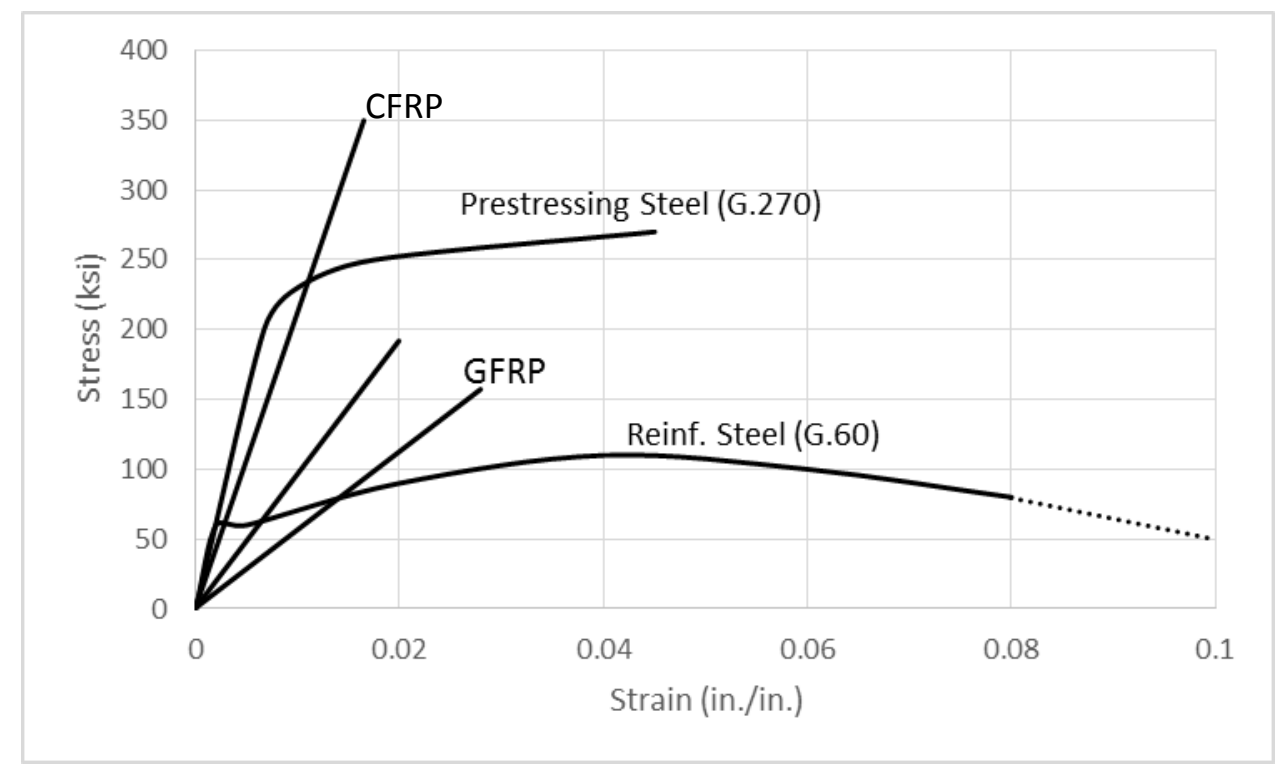

Figure 1.1 Typical stress-strain curves for steel and FRP composite bars

Despite all of the desired properties, FRP has some drawbacks. In general, the most common drawback of FRP is that it is extremely weak in transverse direction. The transverse tensile strength is as low as $2-4 \%$ of the longitudinal tensile strength, as shown 
in Table 1-1. Because FRP, unlike steel, is anisotropic material, one of the obstacles of using FRP in civil engineering practice is gripping this material, especially for prestressed concrete industry. In terms of flexural behavior of structural components, the linear-elastic behavior of FRP materials until failure causes a lack of ductility which leads to a nonpreferred performance for concrete elements reinforced or prestressed with FRP rods. Another disadvantage of FRP compared to steel is the very high initial cost. Table 1-1, which is derived from Schmidt, Bennitz, Täljsten, Goltermann, and Pedersen, (2012), summarizes the typical properties of the CFRP, GFRP, AFRP, and the prestressing steel (grade 270).

\begin{tabular}{|c|c|c|c|c|c|}
\hline & Units & AFRP & CFRP & GFRP & Prestressing steel \\
\hline Fiber & - & Aramid & Carbon & Glass & - \\
\hline Density & $\mathrm{g} / \mathrm{cm}^{3}$ & 1.28 & 1.53 & 2.1 & 7.85 \\
\hline Longitudinal tensile strength & Ksi & $181-203$ & $325-370$ & 157 & 270 \\
\hline Transverse tensile strength & ksi & 4.4 & 8.3 & 5.7 & 270 \\
\hline Longitudinal E-modulus & Ksi & 9800 & 21,170 & 5,660 & 30,000 \\
\hline Transverse E-modulus & Ksi & 800 & 800 & 1250 & 30,000 \\
\hline Major Poisson's ratio & - & $0.34-0.6$ & 0.27 & 0.28 & 0.3 \\
\hline Maximum Longitudinal strain & $\%$ & $2.0-3.7$ & $1.3-1.5$ & 2.8 & 4.0 \\
\hline Relaxation & $\%$ loss & 12.0 & $2.0-3.0$ & - & 8.0 \\
\hline
\end{tabular}

Table 1-1 Typical mechanical properties of FRPs and steel (Schmidt et al., 2012) 


\subsection{Research Objective}

The main objective of this study is to investigate the flexural behavior of prestressed concrete rectangular beams pre-tensioned with CFRP strands. The linear elastic behavior of CFRP strands until failure creates a major concern for design engineers in terms of safety. Since CFRP strands behaves linearly up to rupture, the prestressed beams using CFRP strands are considered not ductile members compared to those prestressed with steel strands. The aim of this study is to experimentally investigate the flexural response of rectangular beams prestressed with CFRP strands in order to observe their actual behavior. The experimental flexural response is then compared to the theoretical behavior based on flexural mechanics of prestressed concrete. Therefore, it is necessary to develop an analytical model to predict the flexural behavior of CFRP prestressed concrete beams.

Bonding behavior of CFRP strands embedded into prestressed concrete beams is also investigated. The transfer length and development length are also one of the main outputs of this study. It is known that the manufacturers of FRP rebars have not developed an adequate surface texture of the rebars that bonds with concrete as well as the steel strands do. As a result, this work focuses on the bonding problems and aims to develop a solution. Additionally, since this study is about prestressing systems using CFRP strands, development of a special anchor that can be used to sufficiently grip the CFRP strands is highly desirable.

The objective of this study can be summarized in the following points: 
a- Investigate the flexural behavior of prestressed concrete beams pre-tensioned with CFRP strands.

b- Examine the bond characteristics of the CFRP strands embedded in concrete for prestressed concrete applications.

c- Determine the transfer length and development length for CFRP strands and compare the results to those obtained from available equations from codes and guides.

d- Theoretically estimate the flexural behavior of prestressed concrete beams with CFRP strands represented by moment vs. mid-span deflection curves.

e- Develop and investigate a new anchorage system for CFRP strands.

f- Compare the flexural behavior of CFRP prestressed concrete beams to the behavior of concrete beams prestressed with steel strands. 


\section{Chapter 2: Literature Review}

\subsection{General}

Over the last two decades, engineering researchers have investigated a new material called Fiber Reinforced Plastic, or Polymer (FRP) as an alternative to steel reinforcement. Many studies have been carried out related to this material. Structural engineers are attracted to FRP materials due to their high strength to weight ratio compared to the conventional steel. Especially for prestressed concrete applications, the high strength of the material for applying the prestressing force is a big advantage. This chapter introduces a literature review of some studies related to using FRP materials in prestressed concrete applications. The following section presents the available material properties of FRP. Next, background information of the FRP anchorage systems is demonstrated. Section 2.4 covers the bond characteristics of FRP materials in contact with surrounding concrete. Finally, the previous research related to flexural behavior of prestressed concrete beams using FRP tendons are reviewed.

\subsection{FRP Composite Materials}

Historically, a number of studies of FRP bars for concrete reinforcement started between 1950s and 1970s (Bank, 2006). The studies started on smooth FRP rods until 1990s when deformed FRP bars were developed. Since then, many studies have been carried out to investigate this new technology in construction engineering. The use of FRP material for prestressed concrete structures was originally started in Germany and Japan in 1990s (Bank, 2006). The FRP materials are manufactured in different products like rebars, tendons, grids, and sheets. Each product is used for different applications. The interest of 
this paper is to focus on the FRP bars or tendons. The commonly known FRP bars are Aramid (AFRP), Carbon (CFRP), and Glass (GFRP). The most interesting material for prestressing concrete is CFRP as it has the strongest tensile capacity associated with higher modulus of elasticity. ACI 440.1R-06 summarized the advantages and disadvantage of using FRP materials for concrete reinforcement as shown in Table 2-1.

\begin{tabular}{ll}
\hline \multicolumn{2}{c}{ Advantages } \\
$\begin{array}{l}\text { High longitudinal tensile strength (varies with } \\
\text { sign and direction of loading relative to } \\
\text { fibers) }\end{array}$ & No yielding before brittle rupture \\
\hline $\begin{array}{l}\text { Corrosion resistance (not dependent on a } \\
\text { coating) }\end{array}$ & $\begin{array}{l}\text { Low transverse strength (varies with sign and } \\
\text { direction of loading relative } \\
\text { to fibers) }\end{array}$ \\
\hline Nonmagnetic & $\begin{array}{l}\text { Low modulus of elasticity (varies with type of } \\
\text { reinforcing fiber) }\end{array}$ \\
\hline $\begin{array}{l}\text { High fatigue endurance (varies with type of } \\
\text { reinforcing fiber) }\end{array}$ & $\begin{array}{l}\text { Susceptibility of damage to polymeric resins } \\
\text { and fibers under ultraviolet radiation exposure }\end{array}$ \\
\hline $\begin{array}{l}\text { Lightweight (about 1/5 to 1/4 the density of } \\
\text { steel) }\end{array}$ & $\begin{array}{l}\text { Low durability of glass fibers in a moist } \\
\text { environment }\end{array}$ \\
\hline $\begin{array}{l}\text { Low thermal and electric conductivity (for } \\
\text { glass and aramid fibers) }\end{array}$ & $\begin{array}{l}\text { Low durability of some glass and aramid } \\
\text { fibers in an alkaline environment }\end{array}$ \\
\hline & $\begin{array}{l}\text { High coefficient of thermal expansion } \\
\text { perpendicular to the fibers, relative to } \\
\text { Concrete }\end{array}$ \\
\hline & $\begin{array}{l}\text { May be susceptible to fire depending on } \\
\text { matrix type and concrete cover } \\
\text { Thickness }\end{array}$ \\
\hline & \\
\hline
\end{tabular}

Note: Adopted from Guide for the Design and Construction of Structural Concrete Reinforced With FRP Bars, P. 6, by ACI 440.1R-06, 2006, American Concrete Institute.

Table 2-1 Advantages and disadvantages of FRP materials 
In terms of engineering properties of FRP materials, many studies have been carried out to identify material properties of FRPs. The literature indicates that the properties are significantly varied from one product to the other. Small differences in the manufacturing process of FRPs leads to large differences in terms of tensile strength, modulus of elasticity, maximum elongation, and some other mechanical properties. In spite of that, ACI 440.4R04 provides typical properties for FRPs based on previous research as shown in Table 2-2.

\begin{tabular}{ccccccc}
\hline & $\begin{array}{c}\text { High-modulus } \\
\text { carbon }\end{array}$ & $\begin{array}{c}\text { Intermediate } \\
\text { modulus } \\
\text { carbon }\end{array}$ & $\begin{array}{c}\text { Standard } \\
\text { modulus } \\
\text { Carbon }\end{array}$ & Aramid & E-glass & S-glass \\
\hline $\begin{array}{c}\text { Tensile } \\
\text { strength, ksi }\end{array}$ & 305 to 348 & 752 to 914 & 506 to 711 & 421 to 435 & 493 & 711 \\
\hline $\begin{array}{c}\text { Tensile } \\
\text { modulus, ksi }\end{array}$ & $74965-119915$ & 42630 & 33350 & $10275-16240$ & 10484 & 12600 \\
\hline $\begin{array}{c}\text { Ultimate } \\
\text { strain, } \%\end{array}$ & 0.3 & 1.9 to 2.2 & 1.5 to 2.1 & 2.4 to 3.6 & 4.8 & 5.7 \\
\hline
\end{tabular}

Note: Adopted from Prestressed Concrete Structures with FRP Tendons, P. 3, by ACI 440.4R-04, 2004, American Concrete Institute.

Table 2-2 Typical FRP mechanical properties

\subsection{FRP Anchorage System}

One of the parameters that makes the FRP materials less common than steel for prestressed concrete applications is that it is difficult to anchor them. Whether pre-tensioned or posttensioned concrete systems are considered, FRPs have to be gripped for prestressing operation. As of yet, based on the author's knowledge, a sufficient FRP anchorage system 
that can be used in practice has not been developed yet. It is true that many studies have been carried out to develop different kinds of FRP anchors, but even if it is concluded that the anchor is sufficient, it cannot be considered in practice. The reason for this is that the anchorage system performance mainly depends on the FRP properties and the anchorage mechanism. The properties of FRP materials are different from different manufacturer. In addition, it was found that the same FRPs bought from same manufacturer have different properties(B. Zhang \& Benmokrane, 2004) (Zhang, Benmokrane, \& Chennouf, 2000; Zhang \& Benmokrane, 2004; Li, Zhao, Chen, Wang, \& Duan, 2010). Since FRP materials are very weak in the transverse direction, compared to their tensile strength, it is difficult to develop anchorage systems that do not produce a lateral force that causes damage to the FRP tendons. Even though some studies preferred mechanical anchorages as they are easier to install (Schmidt et al., 2012), the bond-type anchorage systems are widely recommended in order to avoid the stress concentrations and to uniformly and safely transfer the load from the anchor to FRP tendons (B. Zhang et al., 2000; Li et al., 2010; Cai, Zhang, Liang, $\& \mathrm{Tu}, 2011)$. This section focuses on previous research studies on bond-type anchorage systems for FRP tendons. At the end of this section, some studies about mechanical anchorage systems are presented.

Lees et al. (1995) conducted an experimental study to develop expansive cement couplers for FRP rebars. The goal of this study was to develop a FRP anchorage system that can be used for pre-tensioning FRP tendons. Initially, the couplers were tested using steel reinforcement bars. The research was then extended to include aramid FRP (AFRP) tendons anchored to prestressing steel wire using the proposed couplers, as shown in Figure 
2.1. The parameters for the steel tubes were tube wall thickness, tube inner diameter, and tube length. Bristar 100 was used as the cementitious material. The water cement ratio ranged from $25 \%$ to $30 \%$. Most specimens were tested after three days, except that some were left for long-term investigations. Some samples were tested until failure to determine the tensile capacity. The others were tested to measure the pressure development with time. The water-cement ratio effects were also investigated.

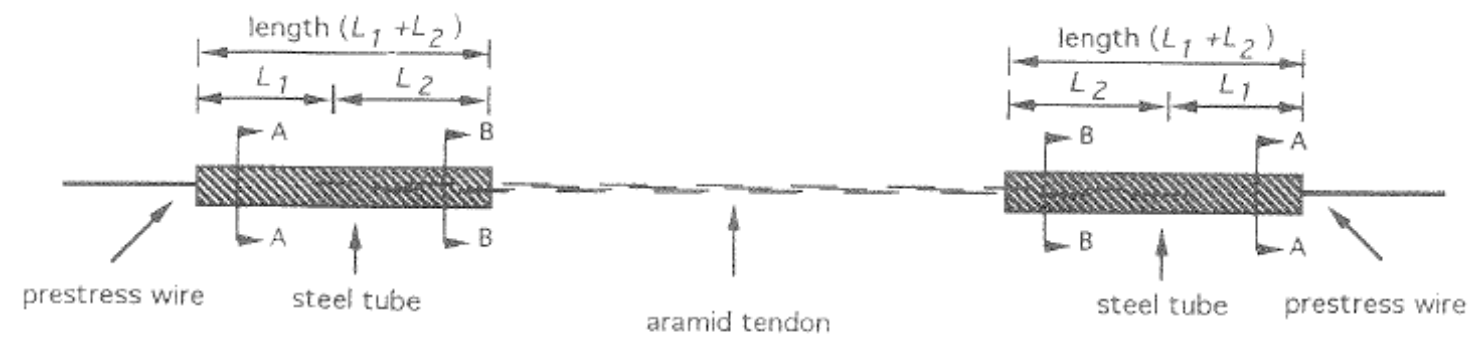

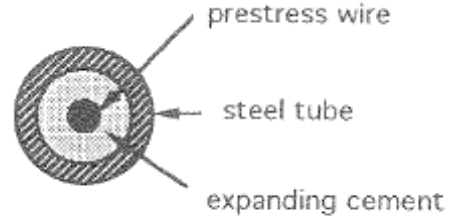

Section A-A

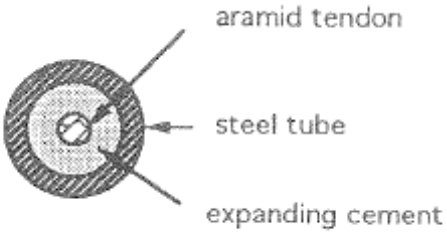

Section B-B

Figure 2.1 Steel/ FRP/ steel anchorage system (Lees et al., 1995)

The results of the steel reinforcement couplers show that with thick tubes and a w/c ratio of $27.5 \%$, the guaranteed pressure was $3.6 \mathrm{ksi}$ in $48 \mathrm{hrs}$. The pressure was found to be 3.8 
ksi at nine days. When smooth steel wires were used, all specimens failed because the prestressing wires were pulled out due to the poor bonding. However, when the steel wires were deformed, the failure mode was rupturing the steel wires by reaching their ultimate strength. Therefore, the couplers could achieve a tensile capacity more than the strength of the prestressing steel wires. After determining the coupler properties that can achieve the tensile capacity of the steel wires, the same couplers were tested including aramid FRP (AFRP) tendons.

Two types of AFRP tendons were investigated. The first was braided AFRP. The second was deformed AFRP, which has higher tensile strength than braided AFRP. The embedded lengths were $150 \mathrm{~mm}$ and $175 \mathrm{~mm}$ for braided AFRP, whereas, the embedded lengths for the deformed AFRP were $175 \mathrm{~mm}$ and $200 \mathrm{~mm}$. All the specimens failed due to FRP rupture, leading to the conclusion that the proposed anchors can develop the full strength of the AFRP. The research concluded that these results are only valid in laboratory conditions.

The tensile behavior of FRP-grouted anchors was also experimentally investigated in 2001 (B. B. Zhang, Benmokrane, Chennouf, Mukhopadhyaya, \& El-safty, 2001). To simulate the rock medium, a cement-sand based material was casted in a steel cylinder the diameter and height of which is $600 \mathrm{~mm}$ and $750 \mathrm{~mm}$, respectively. The compressive strength of this material was $13.2 \mathrm{ksi}$ after 90 days of curing. At the middle of the mortar cylinder, the ground anchor side consisted of a borehole of $32 \mathrm{~mm}$ in diameter for a single anchor and $50 \mathrm{~mm}$ borehole for multiple tendons. Neat cement grout was used as the filling grout. The cementitious material had already been tested in previous research. The other side of the 
tested specimens was the grouted anchor using a $750 \mathrm{~mm}$ long, and $5 \mathrm{~mm}$ thick steel tube. The tubes' external diameters are $35 \mathrm{~mm}$ for single tendon and $45 \mathrm{~mm}$ for multiple tendons.

The design load of the grouted anchor was set to $50 \%$ of the ultimate capacity of the FRP rods. The anchors were subjected to cyclic loading until reaching the maximum load. Some of the anchors were subjected to sustained load for long-term investigation. The effects of tendon type, embedded length, cross-sectional ratio of tendon to borehole, and loading history were investigated. The anchors for multiple FRP anchors showed an "acceptable" performance based on British Standard Institute criteria. It was recommended to use the proposed ground anchor for multiple FRP rods in practice. The design capacity was proposed to be $40 \%$ of the AFRP rod ultimate capacity and 50\% for CFRP.

Reda Taha (2003) developed a new concrete anchors for CFRP post tensioning tendons. The non-metallic concrete wedges were cast in a special mold as the dimensions had to be accurate. Two molds were required; one for the barrel and one for the wedges. The concrete was Ultra High Performance Concrete (UHPC) the compressive strength of which is more than $200 \mathrm{MPa}(29 \mathrm{ksi})$ at seven days. It was cured for five days in a 50-degrees-Celsius hot water. Then the samples were cured for two days at 200 degrees Celsius. The differential angle between the barrel and the wedges was 0.1 degree. As a result, any changes in the dimensions were crucial. A new feature of the proposed concrete anchor was that the concrete barrel was wrapped by CFRP sheets in order to improve the confinement without increasing the barrel thickness. The final design of the new concrete anchor is shown in Figure 2.2. 


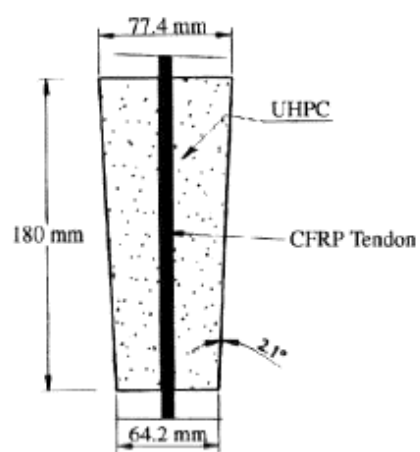

Wedges

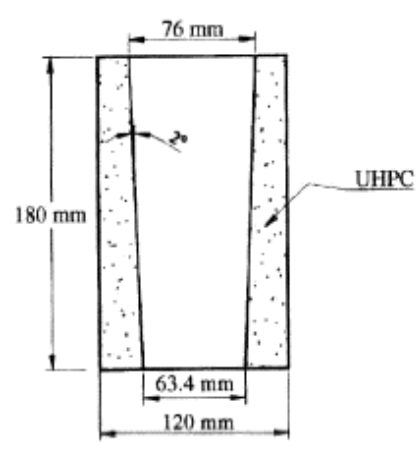

Barrel

Figure 2.2 Proposed dimensions (Reda Taha, 2003)

The following study was carried out to evaluate the proposed design of the concrete anchor. Reda Taha and Shrive (2003) conducted an experimental investigation to evaluate the concrete anchor under monotonic and cyclic loading. The parameters were the anchor geometry, number of layers of CFRP sheets, and the seating load. It was concluded that four layers of CFRP sheets were required to reinforce the concrete barrel. The results showed an outstanding performance of the concrete anchor whether a static or cyclic loading was applied. The anchor could achieve an efficiency factor of $99 \%$ under monotonic loading, and passed the efficiency criteria stated by Post-Tensioning Institute (1985) for long-term capacity and fatigue requirements. The authors estimated the cost of the concrete anchor to be as expensive as the stainless steel anchor, except that the concrete anchors do not need maintenance expenses. 
Zhang and Benmokrane (2004) developed a new bond-type anchorage system for FRP post-tensioning applications. Tensile and pull-out tests were carried out using single-rod and multi-rod FRP anchors. The parameters were the bond length and the type of steel tube. For anchors with a single FRP rod, three bond lengths were used; 250, 300, and $500 \mathrm{~mm}$. Nine CFRP rods were anchored by the multiple-rod anchorage system. The investigated bond lengths were 95 and $400 \mathrm{~mm}$. Two specimens were manufactured for each length. Commercially known as Leadline (Carbon FRP with a spiral helical impression on the surface), $7.9 \mathrm{~mm}$ in diameter rods were used in this study. For filling grout, a cementitious material was used to bond the CFRP to the steel sleeve. The grout's capacity was about 10 ksi at 28 days. The anchorage system dimensions and details are explained in Figure 2.3.
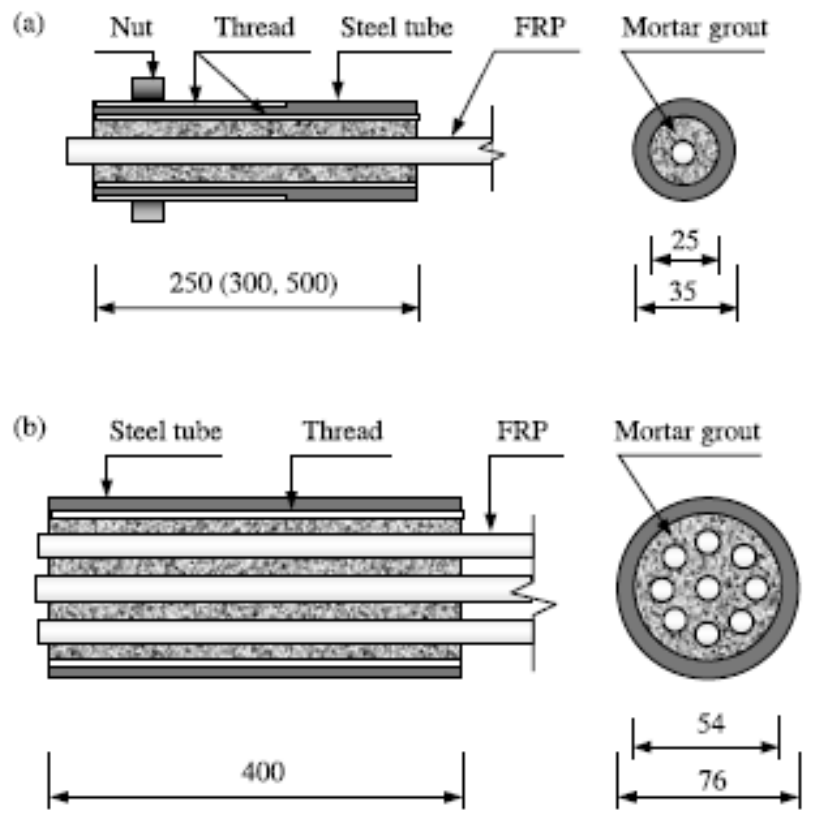

Figure 2.3 Dimensions of the bond-type anchorage system; (a) single-rode (b) multiplerod anchorage system. Dimensions are in mm. (Zhang \& Benmokrane, 2004) 
The results of the tensile tests of the mono-rod anchors proved that a bond length of 250 $\mathrm{mm}$ is adequate to develop the full capacity of the CFRP rods. It was also found that the stiffness of the anchorage system increased when the bond length increased. Figure 2.4 shows how the anchorage stiffness is affected by bond lengths.

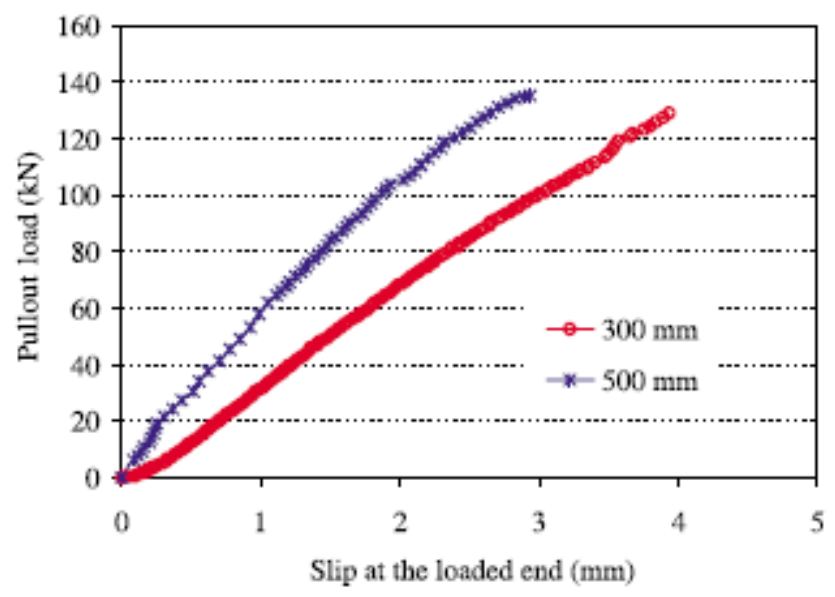

(a) single-FRP-rod anchorage system

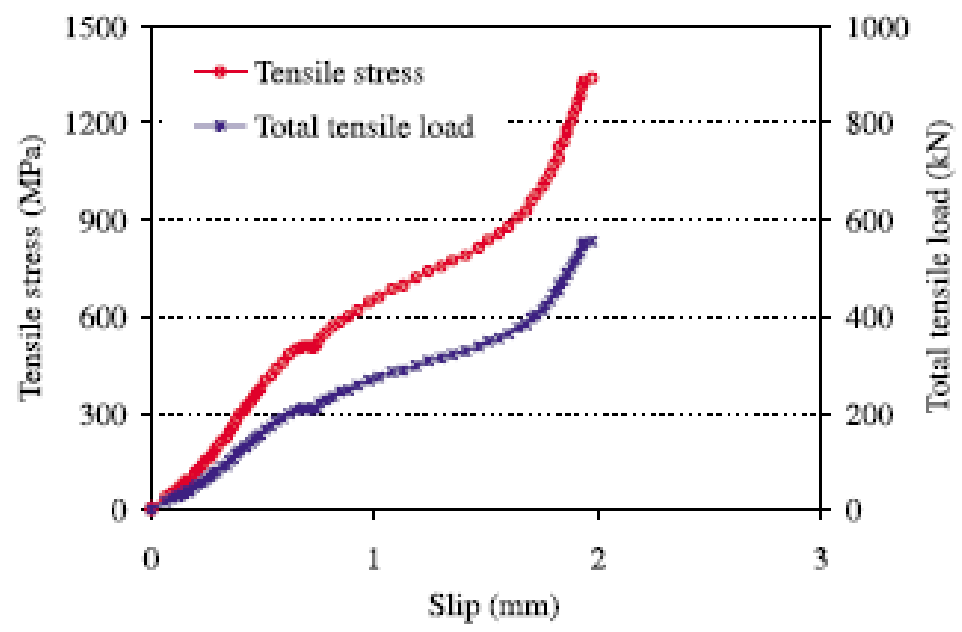

(b) 9-FRP-rod anchorage system

Figure 2.4 Typical load-slip curves (Zhang \& Benmokrane, 2004) 
For the multi-rod anchorage system, it was recommended that the tendons should be distributed evenly. A clear spacing of 5-to-10 mm between the rods was suggested. The inner face of the steel sleeve was recommended to be serrated in order to develop the bond characteristics between the filling material and the steel tubes. Figure 2.4 also shows that the stiffness of the 9-rod anchorage system, unlike that of single-rode one, increased with increasing applied load. Nonetheless, the bond strength of the 9-rod anchors was reported to be no more than $62 \%$ of that achieved by single-rod anchorage system. Although Zhang et al. (2001) found that the pull-out load was not distributed evenly among the CFRP rods, Zhang and Benmokrane (2004) reported, based on many strain gauges mounted on the CFRP surfaces, that the load was uniformly distributed. Finally, and based on long-time investigation (about nine weeks), it was concluded that the proposed anchorage systems showed acceptable performance.

In 2010, Li et al. (2010) conducted a study to predict the tensile capacity of bond anchorage for FRP tendons. Two bonded lengths were examined; 100 and $150 \mathrm{~mm}$. The thickness of surrounding grouting material was also investigated. The FRP rods were sand coated. The outer thickness of the steel tube was $46 \mathrm{~mm}$ and $26 \mathrm{~mm}$ with $3 \mathrm{~mm}$ wall thickness. After 28 days of curing, tensile tests were carried out. The results of the theoretical model were compared to experimental results. It was found that numerical model could predict the tensile capacity of the anchorage system. The thickness of the grout and the surface of the FRP rods were found to be the main factors affecting the bond strength and the anchorage stiffness. This was also reported by Zhang et al. (2000). Both Li et al. (2010) and Zhang et al. (2000) found that there was a good agreement between the theoretical and experimental 
results. For 100 -mm-long anchors, the difference was less than $20 \%$, but it was less than less than $10 \%$ for 350-mm-long (B. Zhang et al., 2000) and for 150-mm-long anchorage system (Li et al., 2010).

In 2011, a new bond type anchorage system combining the philosophy of straight-type anchors and inner cone anchors together in one anchor was developed (Cai et al., 2011). The author stated that it was efficient to combine the straight-type with the inner cone anchors to be straight plus cone anchors. The straight anchors usually have small diameter but larger length. The cone ones, however, have larger diameter but shorter length. As a results, Cai (2011) suggested that straight tube with inner cone anchors could have both advantages. The design of the proposed anchor is shown in Figure 2.5. Two kinds of CFRP rods were studied in this study. The parameters of the study were the surface of the CFRP rods and bond length. The bond lengths were 300 and $350 \mathrm{~mm}$.
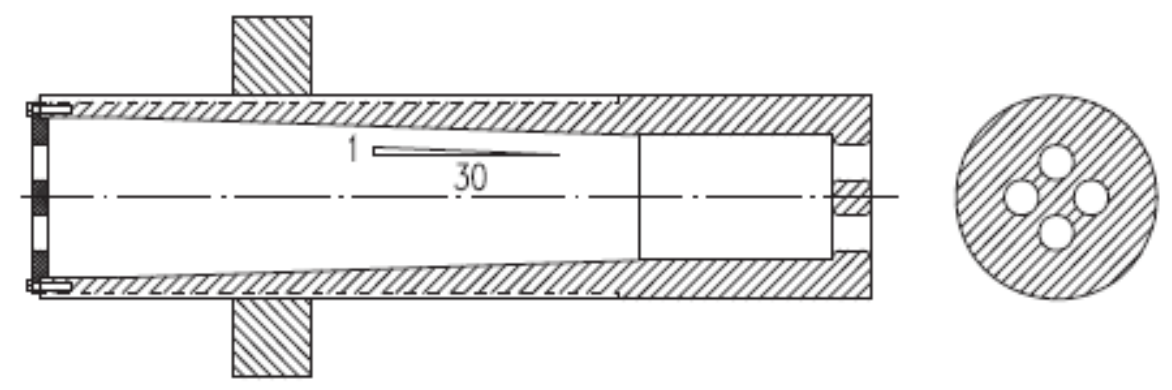

Figure 2.5 Straight-tube with inner-cone bond-type anchorage system (Cai et al., 2011) 
The results showed three types of failure modes; "pull-out destruction, the CFRP tendons fractured just in front of anchor, pull-off damage," (Cai et al., 2011). It was recommended that the failure mode at which pull-out destruction and the CFRP fraction close to the anchor simultaneously should be avoided. This was explained as the reason of discontinuity of CFRP properties or some eccentricity in the applied pull-out force. The load-slip curves were determined at the fixed end. The slip was measured at both sides of the fixed-end anchor. It was found that the slip at the tension-side of the anchor was much more than the end-side of the anchor. It was concluded that the tensile force was not uniformly distributed between the CFRP bars, as shown in Figure 2.6. Further research was recommended to avoid this problem.
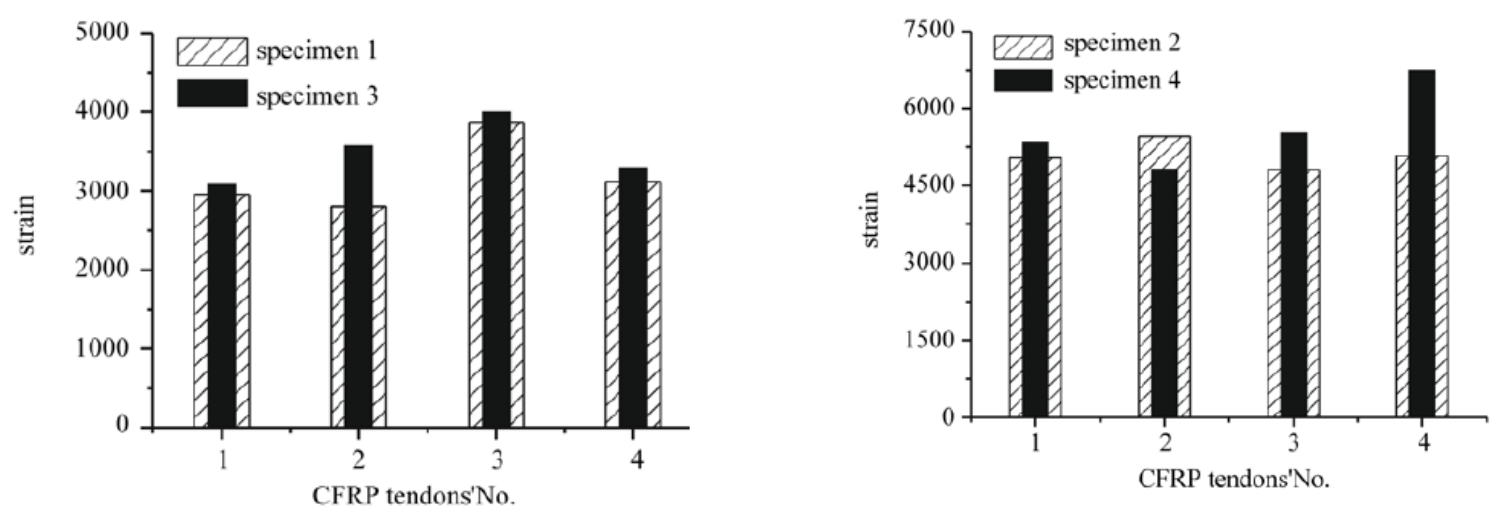

Figure 2.6 Strain discontinuity between the four CFRP tendons at the same anchorage system (Cai et al., 2011)

Another experimental study of a bond-type anchors was carried out for multiple FRP tendons (Fang, Zhang, \& Tu, 2013). The host part of the anchorage system was about a 
wide steel sleeve that can handle multiple FRP bars. The system consists of a steel tube, fasteners, and a mechanical locking tool. The length of the steel tube was considered as the embedded length. The out-side surface and part of the inner face of the steel sleeve were threaded. The FRP bars were distributed inside the anchorage system using a rubber seal. Based on the literature, the cover of the grout for each single FRP bar was neither less than $5 \mathrm{~mm}$, nor less than the bar diameter.

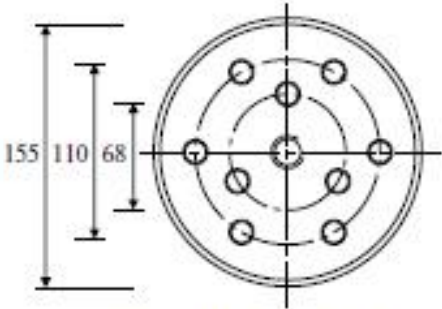

(a) Anchor plate in Anchor A

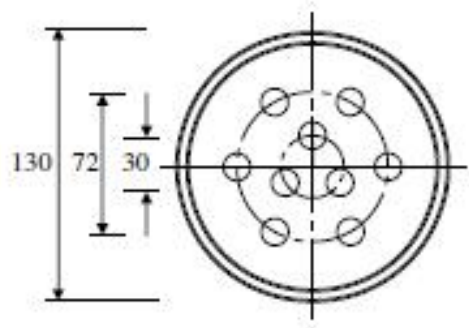

(c) Rubber seals

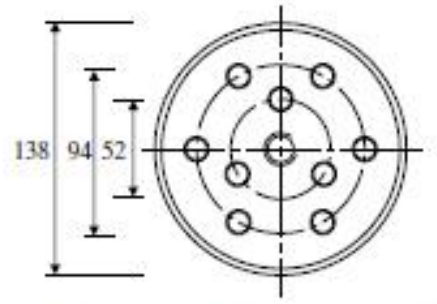

(b) Anchor plate in Anchor B

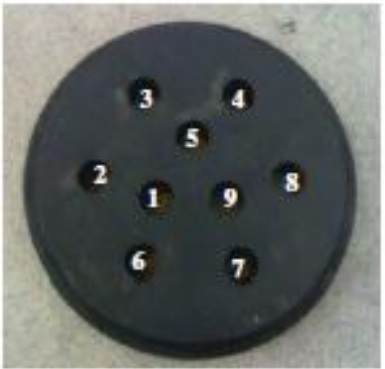

(d) Number of rods on rubber seal

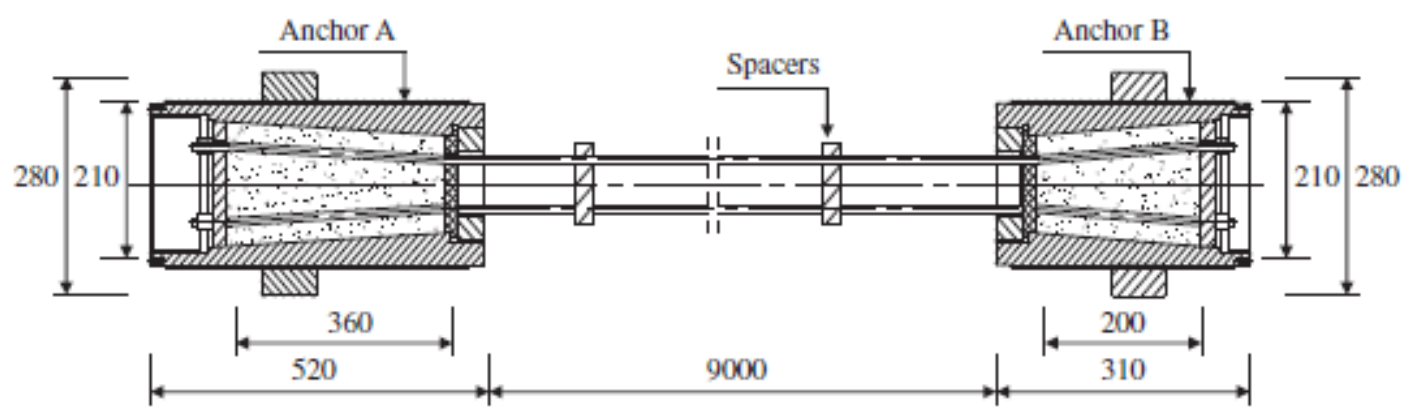

Figure 2.7 Multiple anchorage system for 9 CFRP rods proposed by (Fang et al., 2013) 
The filling grout was an ultra-high performance Reactive Powder Concrete (RPC). The full capacity of RPC can be achieved in three days using hot curing. For this investigation, 12.6mm Carbon FRP tendons, were used. Five specimens were easted cast using a single CFRP bar with the proposed anchors in order to determine the ultimate tensile strength of the CFRP bars and their modulus of elasticity. Different embedded lengths and RPC compressive strengths were investigated. Only two of the samples could develop the full capacity of CFRP rods (334 ksi). The multiple anchorage system consists of 9 CFRP bars as shown in Figure 2.7.

It was concluded that the load was not distributed uniformly among the CFRP rods. This was explained as a reason for the difference in material properties. It was also found that RPC was able to provide the bond strength needed for anchoring CFRP rods, whether single or multiple rods were used. The average bond strength of the multiple anchorage system was $3.29 \mathrm{ksi}$, assuming that the compressive strength of RPC was $18.85 \mathrm{ksi}$.

Even though the focus herein is on the bond-type anchorage systems, it is thought to include some studies about mechanical anchorage systems. Schmidt, Bennitz, Täljsten, and Pedersen (2010) developed a mechanical anchor for CFRP tendons using integrated steel sleeve. Figure 2.8 shows the final design of the proposed anchor. The integrated sleeve resulted in more confinement and friction with less lateral shear on the FRP rod. Strain gauges were mounted on the barrel surface and CFRP rod in order to investigate the stress development along the anchorage system. It was found that all anchors were able to achieve more than the guaranteed CFRP capacity, and some of the specimens showed barrel yielding without affecting the anchorage capacity. The integrated sleeves resulted in 
consistent failure mode and improved the ultimate capacity of the anchorage. To avoid stress concentration, it was highly recommended that a soft material be in contact with the FRP material. The authors advised an increase in the friction area between FRP bars and the integrated sleeve in order to uniformly distribute the load.
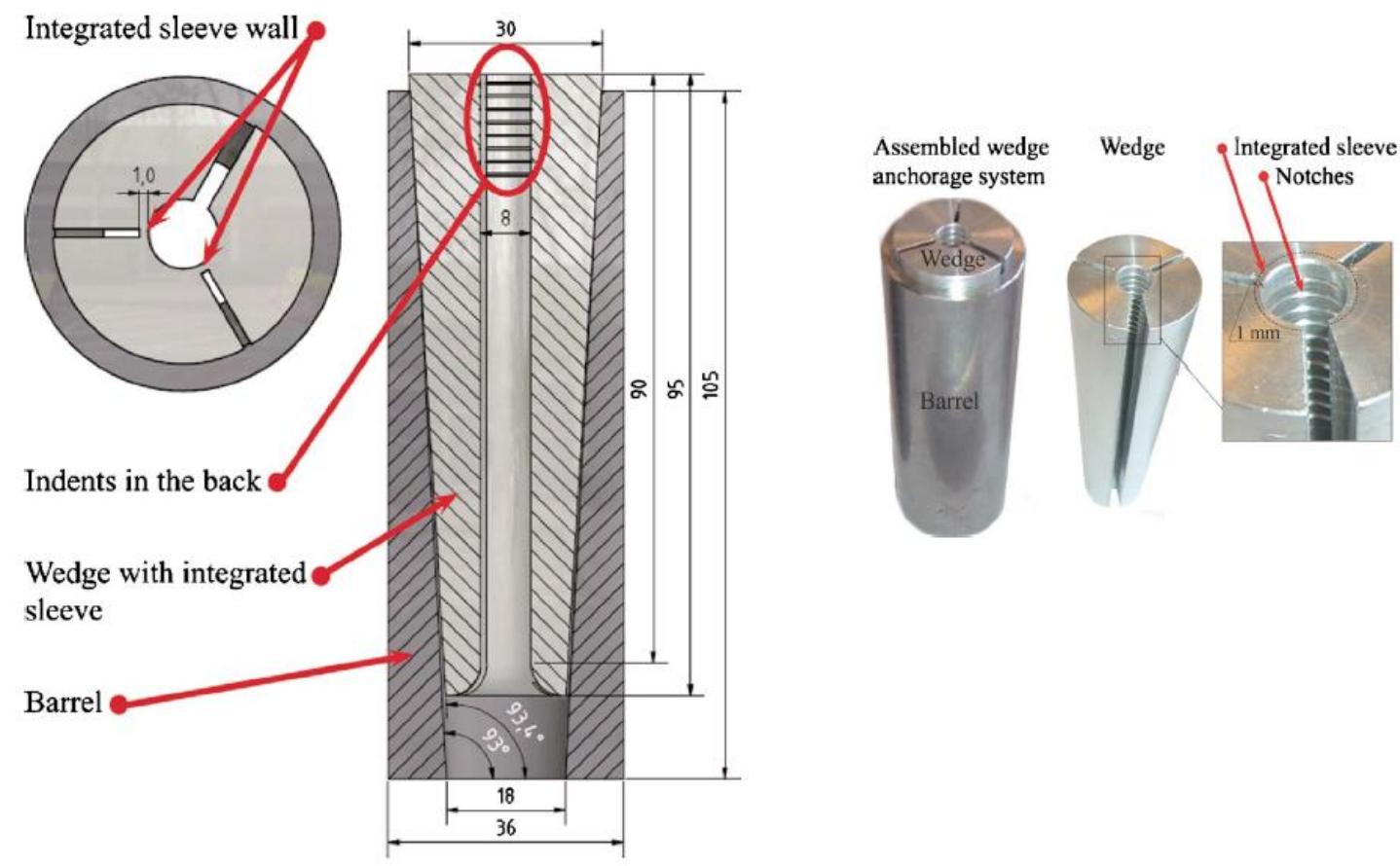

Figure 2.8 The final design of the FRP mechanical anchor (Schmidt et al., 2010)

In Schmidt et al's. (2012) interesting literature review about FRP anchorage systems focusing on the mechanical ones, it was stated that the main reasons for the lack of an anchorage system for FRP that are as reliable as what is available for steel are that FRPs are anisotropic, brittle, and very weak in the transvers direction. In terms of the bonded 
anchorages, the main issues that were reported were long curing time, creep of the grout, and anchorage length. The study divided the mechanical anchorage systems into three types: The "spike anchorage," which consists of a spike pushing the FRP fibers against the barrel; the "wedge anchorage," which consists of a barrel, wedges, and a sleeve. The load transfer depends on the compressive pressure applied by the wedges to the FRP rod. This pressure might cause a premature failure due to the weak transvers strength of FRPs as the stresses introduced at the loading end will high.

Schmidt et al. (2012) reported two ways to redistribute the stresses to the back of the anchorage. Both methods were based on changing the angle between the anchorage components. A number of researchers have developed mechanical anchorage systems to try and solve the issues by choosing different angles in order to reduce the principal stresses at the loaded end of the anchorage. The last kind of the mechanical anchorages is called "clamping anchorage." This type is generally large, hard to use, and not aesthetic. It consists of two steel plates, a sleeve, and several bolts. The gipping is applied by the edges of the bolts' heads. Figure 2.9 shows the three kinds of mechanical anchors.

It was concluded that there were no competitive FRP anchorage systems as there are for those available for steel. Also, that the difference between a successful and unsuccessful FRP anchorage system could be due to the small difference in the mounting procedure. Premature failure at the loaded end of the anchorage, local crushing, and interface sliding between FRP and sleeve were reported as the common failure modes. 
(a) Spike Anchorage

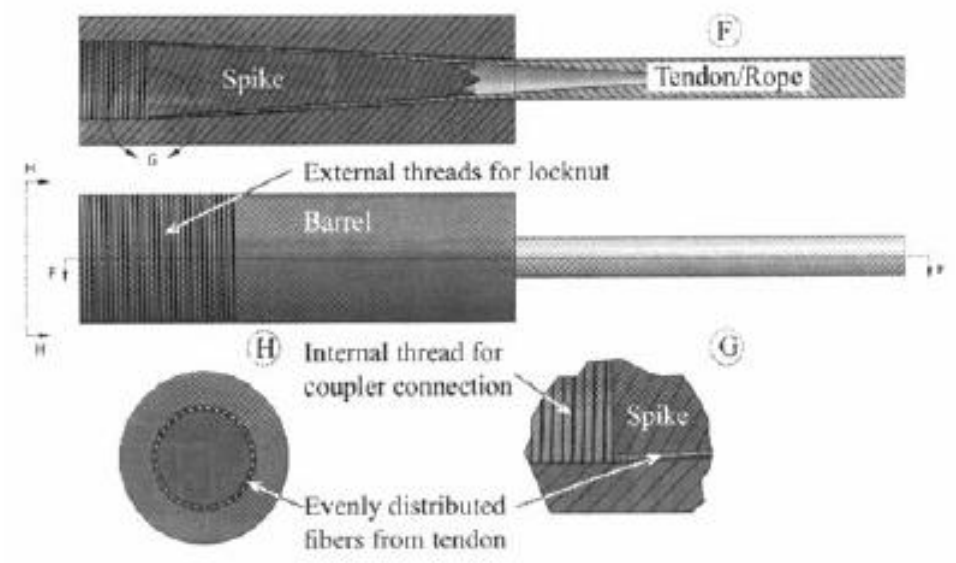

(b) Wedge Anchorage

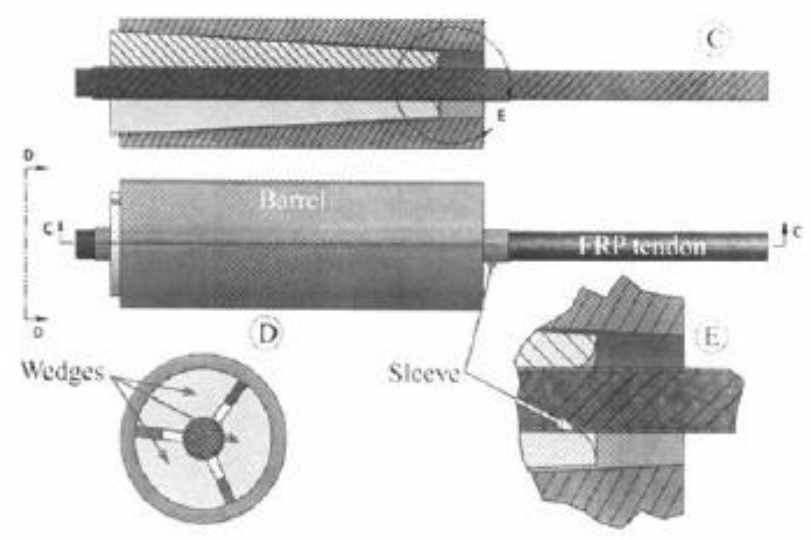

(c) Clamping Anchorage
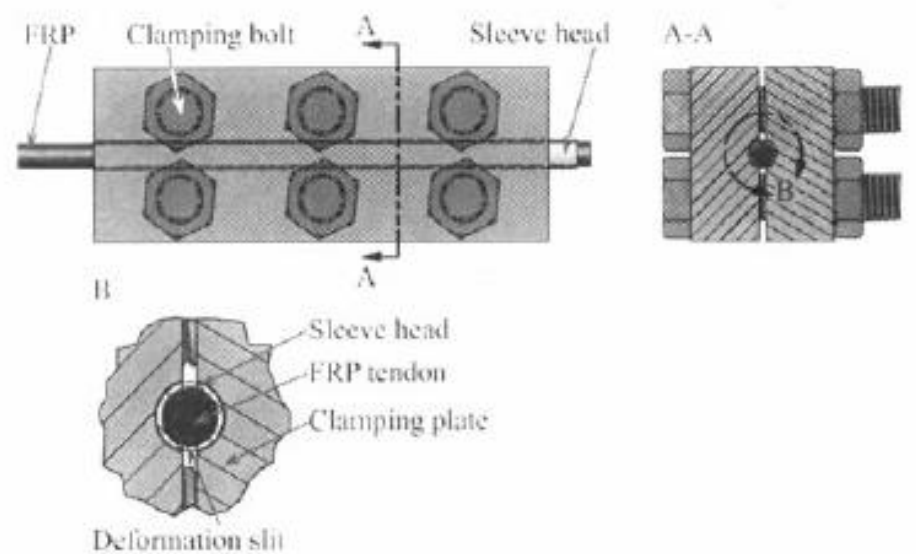

Figure 2.9 Examples of mechanical anchorage systems (Schmidt et al., 2012) 


\subsection{Bond Characteristics}

Bond characteristics crucially affect the flexural behavior of reinforced and prestressed concrete members. In order to design a concrete component reinforced or prestressed with FRP rods or strands, the bonding behavior between the FRP and concrete has to first be well understood. The work of this paper focuses on pre-tensioned prestressed concrete beams, so the literature work that is presented herein includes studies about transfer length, development lengths, and bond characteristics in general.

Nanni and Tanigaki (1992) conducted a study investigating the development and flexural bond lengths of pre-tensioned prestressed concrete beams. The transfer lengths for the same specimens used in this study were previously determined by the same author. One or two aramid FRP tendons were placed at $2 / 3$ of the section height for prestressing. The diameters of the tendons varied from $8 \mathrm{~mm}$ to $16 \mathrm{~mm}$. The results were compared to a conventional seven-wire steel strand, the diameter of which was $12.4 \mathrm{~mm}$. The average concrete compressive strength of the specimens was about 5000 psi.

Twenty-one beams were tested and two failure modes were observed: (1) flexural failure and (2) anchorage failure. The flexural failure occurred due to the concrete crushing in compression because all of the beams were designed so that the reinforcement ratio was more than the balanced ratio. The anchorage failure was basically a bond failure. Regarding the flexural bond length, it was concluded that (a) shorter flexural bond length is required for larger size of AFRP tendons, (b) small effects of using multiple tendons, and (c) larger flexural bond length is required for lower prestressing level. It was also found that shear reinforcement could significantly affect the bond results. Nanni and Tanigaki (1992) 
described the development length as more complicated because it depended on both the flexural and transfer lengths. The authors suggested that the development lengths were 120 $\mathrm{d}_{\mathrm{b}}, 100 \mathrm{~d}_{\mathrm{b}}$, and $80 \mathrm{~d}_{\mathrm{b}}$, for tendon diameters 8,12 , and $16 \mathrm{~mm}$, respectively. Finally, it was found that the seven-wire steel strand had a shorter development length.

The transfer length of CFRP in pre-tensioned concrete beams was investigated by Soudki, Green, and Clapp (1997). The experimental program included five large-scale T-beams and four rectangular beams. The T-beams were prestressed with four 5/16-in diameter CFRP strands, while the rectangular beams were prestressed with only one CFRP strand. The prestressing levels were 50,60 and $70 \%$ of the guaranteed capacity of CFRP strand. The rectangular beams were $9.8 \mathrm{ft}$. long, while the T-beams were $14.5 \mathrm{ft}$. long. Figure 2.10 shows the measured transfer lengths.

\begin{tabular}{|c|c|c|c|c|c|}
\hline \multirow{2}{*}{ Cast/Prestress level } & \multicolumn{2}{|c|}{$\begin{array}{c}\text { Electrical resistance } \\
\text { gauges }(\mathbf{m m})\end{array}$} & \multicolumn{2}{c|}{ DEMEC gauges $(\mathbf{m m})$} & \multirow{2}{*}{$\begin{array}{c}\text { Average } \boldsymbol{l}_{t} \\
\text { (mm) }\end{array}$} \\
\cline { 2 - 6 } & Range & Estimated $l_{t}$ & Range & Estimated $l_{t}$ & 650 \\
\hline T1 (50 percent) & 600 to 750 & 675 & 600 to 650 & 625 & 725 \\
\hline T2 (70 percent) & 650 to 800 & 725 & - & - & 675 \\
\hline T3 (50 to 70 percent) & - & - & 650 to 700 & 675 & 625 \\
\hline R1 to R4 (60 percent) & 500 to 900 & 625 & - & - & 675 \\
\hline
\end{tabular}

Note: 1 in. $=25.4 \mathrm{~mm}$.

Figure 2.10 Transfer length results (Soudki et al., 1997) 
The strains at the CFRP strands were measured at 25, 50, 75, and $100 \%$ of force release. It was found that the transfer lengths were about the same in all stages. The average transfer length of the rectangular beams was 24.6 inches associated with $60 \%$ prestressing. The results of T-beam indicated that the average transfer length was 25.6 for $50 \%$ prestressing level and 28.5 for $70 \%$ prestressing level. Some of the T-beams were kept for 200 days for long-term investigation. Figure 2.11shows the long-term transfer for T-beams with $50 \%$ prestressing level. The results, as presented in Figure 2.11, showed that the long-term transfer length was almost the same as that measured after one day. However, the concrete strains increased due to shrinkage, creep, and relaxation effects. Theoretically, it was observed that ACI equations used to predict the transfer length of steel strands could not be used for CFRP. Another researchers developed modifications that could be used to adjust ACI equations for better prediction of CFRP transfer length. The comparison and further discussion are available in Soudki et al. (1997).

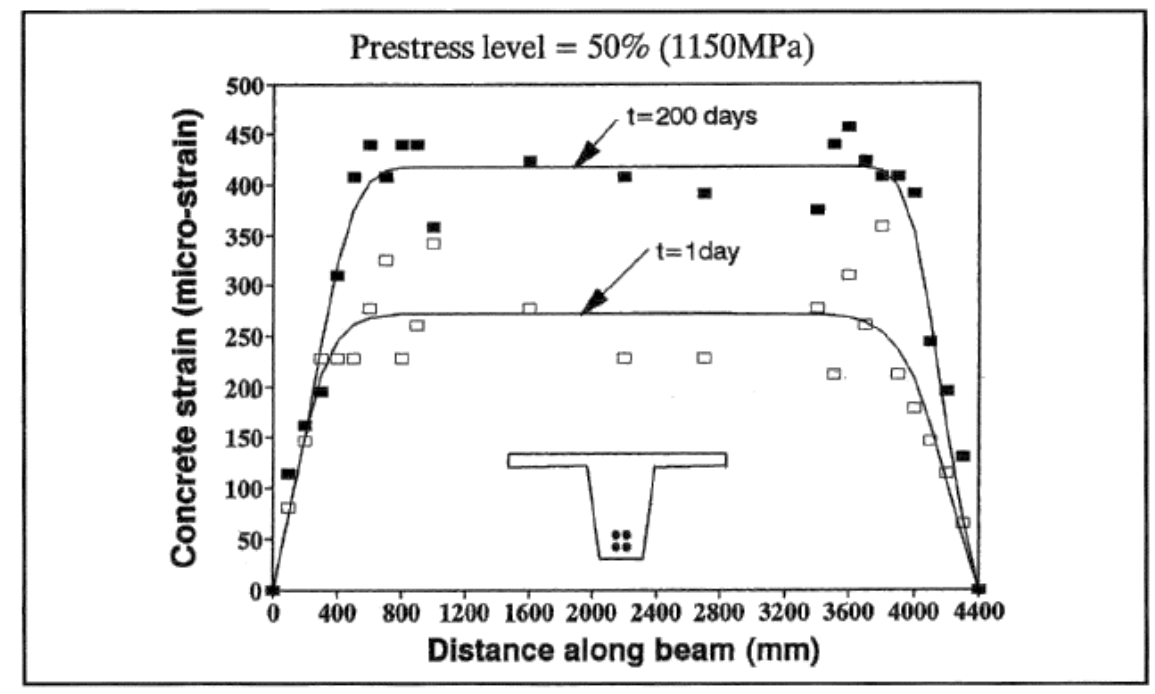

Figure 2.11 Long-term transfer for T-beams with 50\% prestressing level (Soudki et al., 1997) 
Domenico, Mahmoud, and Rizkalla (1998) conducted an experimental study on bond properties of CFRP strands in pre-tensioned concrete beams. The total number of specimens were ten T-beams and ten rectangular pre-tensioned beams. Different embedment lengths were investigated. The tendons were de-bonded at the ends of the beams in order to include only the clear span and to reduce the effects of the additional confinement provided by the supports. Based on the results, Domenico et al. (1998) proposed the following equations to predict the transfer, flexural bond, and development lengths of Carbon Fiber Composite Cables (CFCC):

$$
\begin{aligned}
& L_{t}=\frac{f_{p i} d}{4.8\left(f_{c i}^{\prime}\right)^{0.67}} \quad \ldots . E q \cdot(2-1) \\
& L_{f b}=\frac{\left(f_{p u}-f_{p e}\right) d}{2.8\left(f_{c i}^{\prime}\right)^{0.67}} \quad \ldots . E q .(2-2) \\
& L_{d}=L_{t}+L_{f b} \quad \ldots E q \cdot(2-3)
\end{aligned}
$$

Note: both equations are in MPa units.

These equations agreed with the experimental results. The bond stresses at transfer and flexural were $1.29 \mathrm{ksi}$ and $0.725 \mathrm{ksi}$, respectively, and were not affected by the strand diameter. Interestingly, it was found that the transfer length was affected by the prestressing level, while the bond strength at transfer was not.

Mahmoud, Rizkalla, and Zaghloul (1999) tested 52 pre-tensioned prestressed concrete beams in order to understand the bond properties of CFRP strands. Two kinds of CFRP 
were used; Leadline (Carbon FRP with a spiral helical impression on the surface), bars and CFCC strands. The strands were de-bonded at the ends of the beams to eliminate the additional confinement provided by the supports' zones. Ten beams were not reinforced for shear to investigate the effects of confinements. Another six beams were kept for longterm investigation. The results indicated that the typical elastic shortening losses were $3 \%$, but they were $15 \%$ due to shrinkage and creep of concrete after four weeks. Based on the results, it was found that the transfer length depended directly on the initial concrete strength, the prestressing level, and tendon's diameter, as proposed by Eq. (2-4).

$$
\begin{aligned}
& L_{t}=\frac{f_{p i} d_{b}}{\alpha_{t}\left(f_{c i}^{\prime}\right)^{0.67}} \quad \ldots . E q .(2-4) \\
& L_{f b}=\frac{\left(f_{p u}-f_{p e}\right) d_{b}}{\alpha_{f}\left(f_{c i}^{\prime}\right)^{0.67}} \quad \ldots . E q .(2-5)
\end{aligned}
$$

$\alpha_{t}$ is a coefficient obtained from transfer length results. The proposed coefficient values were 1.9, 4.8, and 2.4 (N/mm units) for Leadline, CFCC, and steel strands, respectively. This model was compared to two previous studies and was found to be within $7 \%$ to $9 \%$ for one study, but $20 \%$ lower than the results from the other study. Figure 2.12 shows the predicted vs. test results of transfer length, and Figure 2.13shows transfer length for steel strands. 


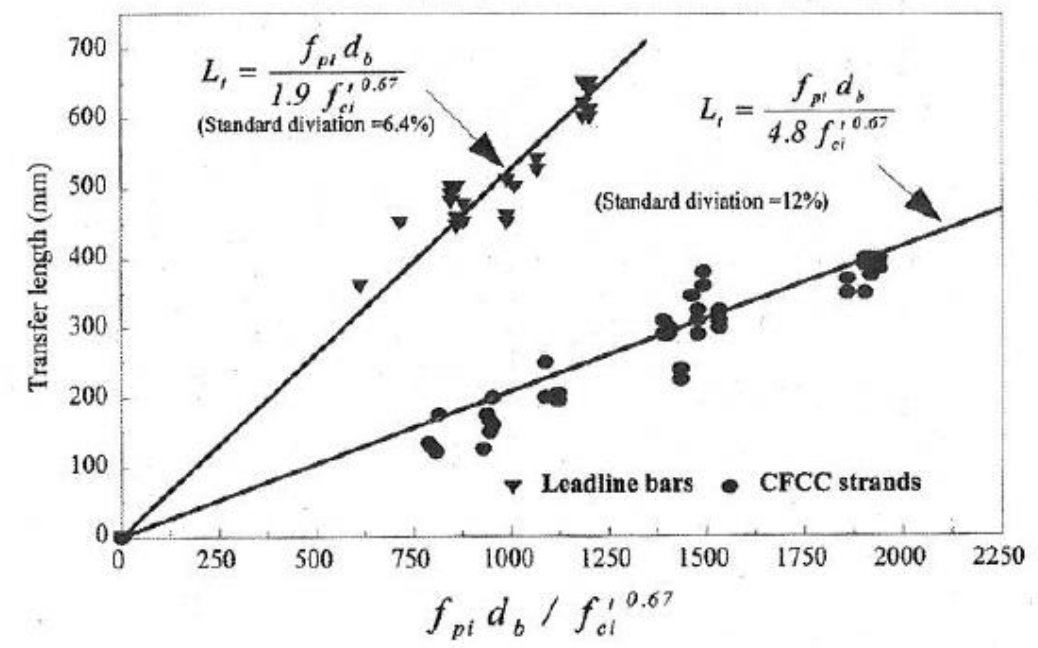

Figure 2.12 Predicted vs. test results of transfer length (Mahmoud et al., 1999)

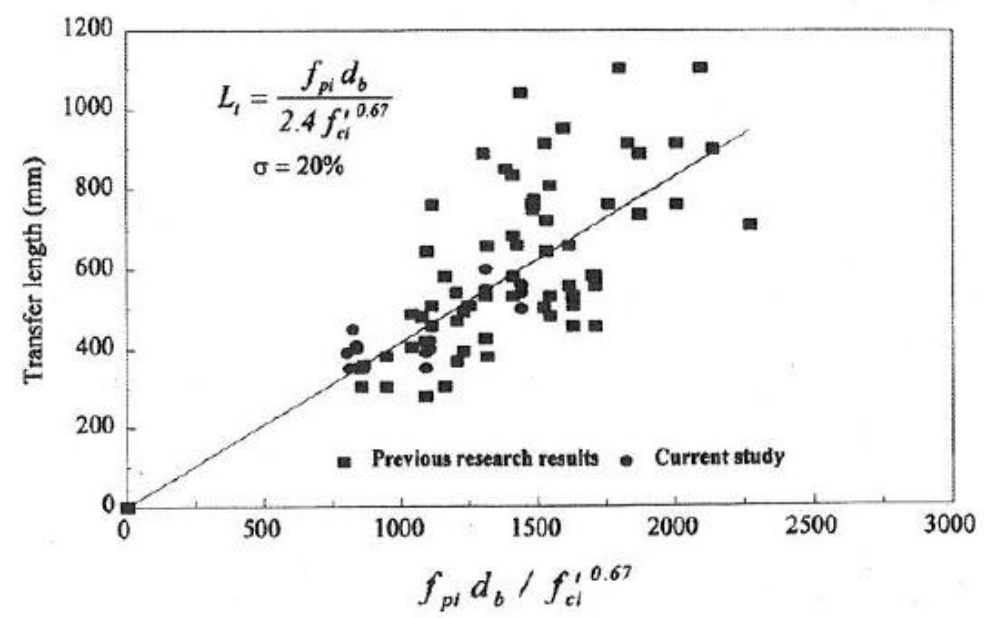

Figure 2.13 Transfer length for steel strands (Mahmoud et al., 1999)

Different shear spans were used to determine the development length, which was defined as the length required to change the mode of failure from slippage of CFRP to flexural failure due to CFRP rupture. Equation (2-5) above was proposed for flexural bond length. The coefficient $\left(\alpha_{f}\right)$ is based on experiment data analysis and equal to 1 and $2.8(\mathrm{~N} / \mathrm{mm}$ 
units) for Leadline and CFCC strands, respectively. Any CFRP slippage equal to or more than $0.025 \mathrm{~mm}$ was considered as bond failure.

In terms of confinement effects, it was observed that specimens without shear reinforcement had 10\% (Leadline) and 17\% (CFCC) larger transfer lengths than the transfer lengths predicted by the proposed model. However, there were no effects of shear reinforcement on the flexural bond length for Leadline. On the other hand, the flexural bond length was $25 \%$ larger due to the absence of shear reinforcement for specimens prestressed with CFCC strands. Mahmoud et al. (1999) explained this by assuming that a concrete cover of four times the strand diameter provided enough confinement for Leadline, but this cover was not enough for CFCC strands without concrete confinement steel. The proposed model was also compared to a previous experimental study which was done in 1997 (Ehsani, Saadatmanesh, \& Thompson, 1997). A development length of 1400 mm was recommended by Ehsani et al. (1997) for 8-mm Leadline strands. Whereas, the proposed model of Mahmoud et al. (1999) recommended a development length of 1060 $\mathrm{mm}$ for the same strand. Table -23 shows a comparison of transfer length results based on two proposed models.

\begin{tabular}{ccc}
\hline Specimen & $\begin{array}{c}\text { Model proposed by } \\
\text { Mahmoud et al. (1999) }\end{array}$ & $\begin{array}{c}\text { Experimental results } \\
\text { (Ehsani et al., 1997) }\end{array}$ \\
\hline 1 & 940 in. & $530 \mathrm{in.}$ \\
\hline 2 & 305 and $380 \mathrm{in}$. & $570 \mathrm{in.}$ \\
\hline 3 & 430 and $610 \mathrm{in}$. & $530 \mathrm{in}$.
\end{tabular}

Table 2-3 Transfer length results based on proposed model by Mahmoud et al. (1999) and experimental results of Ehsani et al. (1997) 
Finally, it was concluded that the model proposed by Mahmoud agreed with the available data. For long-term effects, the results showed that a $22 \%$ larger transfer length was required for Leadline after one year. However, the transfer lengths of CFCC and steel strands were not changed after one year. Regarding the concrete cover, it was concluded that a concrete cover of four times the strand's diameter could prevent concrete splitting at releasing of prestressing force.

In 2000, the transfer and development lengths of three kinds of FRP strands were experimentally investigated (Lu, Boothby, Bakis, \& Nanni, 2000). Thirty specimens for transfer length tests, twenty four specimens for development length tests, and nine prestressed concrete beams pre-tensioned with three different types of FRP strands were tested. The aim was to compare the experimental results with the existing theoretical models.

The average concrete capacity was 5570 at release, 6420 at 28 days, and 6550 at 90 days. Regarding prestressing strands, Leadline (Carbon FRP with a spiral helical impression on the surface), Technora strands (Aramid FRP with a rough surface provided by spiral aramid yarns), and CFRP non-commercial strands developed especially for this study were used for pre-tensioning operation. The strands were prestressed up to $62 \%$ or $64 \%$ of their ultimate strength. Table -24 shows the measured vs. predicted transfer lengths. It is interesting to note the wide range of values as predicted by various investigators. 


\begin{tabular}{|c|c|c|c|c|c|}
\hline \multicolumn{2}{|c|}{ Model (units in in.) } & \multirow{2}{*}{$\begin{array}{c}\mathrm{CL} \\
\text { (Leadline) } \\
-\end{array}$} & \multirow{2}{*}{$\begin{array}{c}\begin{array}{c}\text { AT } \\
(\text { Technora })\end{array} \\
14.2\end{array}$} & \multirow{2}{*}{$\begin{array}{c}\begin{array}{c}\text { CS } \\
\text { (Reference) }\end{array} \\
16.6\end{array}$} & \multirow{2}{*}{$\begin{array}{c}\begin{array}{c}\text { ST } \\
\text { (Steel) }\end{array} \\
18.2\end{array}$} \\
\hline Measured & $50 \%$ & & & & \\
\hline transfer & $100 \%$ & 16.6 & 14.5 & 16.0 & 19.1 \\
\hline & 28 days & 16.1 & 14.8 & 16.3 & - \\
\hline & 90 days & - & 14.8 & - & - \\
\hline \multicolumn{2}{|c|}{ Current ACI/ AASHTO } & $16.4 / 18.8$ & $11.8 / 18.8$ & $12.9 / 18.8$ & $15.0 / 18.8$ \\
\hline \multicolumn{2}{|c|}{ Zia and Mostafa } & 10.7 & 6.4 & 9.2 & 11.2 \\
\hline \multicolumn{2}{|c|}{ Cousins, Johnston, and Zia } & 23.6 & 18.1 & 21.4 & 18.8 \\
\hline \multicolumn{2}{|c|}{ Shahawy, Issa, and Batchelor } & 19.3 & 13.9 & 15.2 & 17.6 \\
\hline \multicolumn{2}{|c|}{ Russell and Burns } & 24.6 & 17.7 & 19.4 & 22.4 \\
\hline \multicolumn{2}{|c|}{ Mitchell, Cook, and Khan } & 13.7 & 9.6 & 19.4 & 22.4 \\
\hline \multicolumn{2}{|c|}{ Mahmoud, Rizkalla, and Zaghloul } & 17.6 & - & - & 13.3 \\
\hline
\end{tabular}

Table 2-4 Measured vs. predicted transfer lengths (Lu et al., 2000)

The transfer lengths were measured by Demec gauges placed at 4 in. on centers. The readings were taken at $50 \%$ and $100 \%$ of prestressing force after release, and 90 days after release. The transfer length results were based on the average transfer length on both ends of the specimens. On the other hand, the development lengths were measured by beams' flexural tests. The embedment length was varied by changing the load location relative to one of the supports.

Lu et al. (2000) concluded that the calculated transfer lengths were close to some of the models available in the literature. It was reported that the differences in FRP material properties and prestressing forces did not affect the results. However, FRP strands had slightely shorter transfer length than steel strands. Lu et al. (2000) suggested that the ACI 
equation for transfer length prediction could give a reasonable prediction only if the diameter of the strands was considered as a variable, especially if the initial prestressing level was low. The development length results were also the same for all three kinds of FRP and steel strands. The ACI prediction for FRP development length was reported as very conservative. In terms of bond stresses, the nominal bond stresses achived by all FRP beams were more than $450 \mathrm{psi}$, which is more than the nominal bond stress of steel strands. Finally, two points were recommended. The first one was that the transfer length should be equal or more than 50 FRP strand diameters. The second one was that the ultimate strength of FRP strands should be used in flexural bond length calculations instead of the nominal flexural strength. In addition, the higher bond stress achieved by FRP strands should be considered in order to overcome the over prediction of the development lengths.

It is important to mention that ACI Committee 440 (2004) (ACI 440.4R-04) adopted the following equations from the literature for transfer length, flexural bond length, and development length of CFRP strands:

$$
\begin{aligned}
& L_{t}=\frac{f_{p e} d_{b}}{\alpha_{t}\left(f_{c}^{\prime}\right)^{0.67}} \quad \ldots \quad E q \cdot(2-6) \\
& L_{f b}=\frac{\left(f_{p u-} f_{p e}\right) d_{b}}{\alpha_{f b}\left(f_{c i}^{\prime}\right)^{0.67}} \quad \ldots \quad E q \cdot(2-7) \\
& L_{d}=L_{t}+L_{f b} \quad \quad \ldots \quad E q \cdot(2-8)
\end{aligned}
$$


The above three questions were proposed by Mahmoud et al. (1999). Equation. (2-9), which was originally proposed by Lu et al. (2000), was also adopted by ACI 440.4R-04 to estimate the development length for carbon FRP strands.

$$
L_{d}=\frac{1}{3} f_{p e} d_{b}+\frac{3}{4}\left(f_{p u}-f_{p e}\right) d_{b} \quad \ldots . E q .(2-9)
$$

ACI 440.4R-04 provided typical values for transfer and development lengths for aramid FRP (AFRP) and carbon FRP (CFRP) strands. The values are presented in Table 2-5..

\begin{tabular}{c|c|c|c|c|c|c|c}
\hline \multirow{2}{*}{ Material } & Type & $\begin{array}{c}\text { Diameter, mm } \\
\text { (in.) }\end{array}$ & $\begin{array}{c}\text { Young's modulus, } \\
\mathrm{MPa}(\mathrm{ksi})\end{array}$ & $\begin{array}{c}\text { Tensile strength, } \\
\mathrm{MPa}(\mathrm{ksi})\end{array}$ & $f_{p e} / f_{p u}$ & $L_{t} / d_{b}$ & $L_{d} / d_{b}$ \\
\hline \multirow{4}{*}{ Aramid } & Arapree $^{8}$ & $9.9(0.39)$ & $127,600(18,500)$ & $2450(355)$ & 0.5 to 0.7 & 16 to 50 & 100 \\
\cline { 2 - 9 } & FiBRA & $10.4(0.41)$ & $48,270(7000)$ & $1430(208)$ & 0.4 to 0.6 & 20 to 50 & 90 \\
\cline { 2 - 9 } & Technora $^{(8)}$ & $7.4(0.291)$ & $68,600(9950)$ & $1720(250)$ & 0.6 & 50 & 140 \\
\hline \multirow{2}{*}{ Carbon } & Leadline $^{\mathrm{TM}}$ & $7.9(0.312)$ & $149,600(21,700)$ & $1980(287)$ & 0.5 to 0.7 & 50 to 80 & 175 \\
\cline { 2 - 9 } & CFCC $^{*}$ & $8.3(0.327)$ & $137,200(19,900)$ & $2220(322)$ & 0.5 to 0.7 & 50 & N/A \\
\hline
\end{tabular}

Table 2-5 Typical transfer and development lengths for AFRP and CFRP strands (ACI 440.4R-04, 2004)

Okelo and Yuan (2005) investigated the bond stress of FRP rebars in normal strength concrete. Four kinds of rebars were used, aramid FRP, carbon FRP, glass FRP, and steel rebars. The total number of specimens were 151 . The diameters of the rebars were $6,8,10$, 16, and $19 \mathrm{~mm}$. The surface of the FRP rebars were improved by sand coating, surface texture, helical wrapping with sand coating, deep dents, and resin deformations. Rebars were embedded in $203 \mathrm{~mm}$ concrete cubes. The embedment lengths were 5, 7, and 9 times 
the diameters of the rebars. Three identical specimens of each type were tested for certainty purposes.

The results showed that the average bond strength was higher when the embedment length was shorter. This could be explained by considering the actual stress distrbution rather than constant stress distribution. Most of the specimens failed due to pullout of rebars. Some other modes of failure occurred. Once the shear force exceeded the bond strength, the pullout failur occurred. The bond strength significantly depended on the surface configuration of the rebars. Based on the experimental results, the following Eq. 2-10 was proposed:

$$
u_{f}=\text { Average bond stress }=14.7 \frac{\sqrt{f_{c}^{\prime}}}{d_{b}}(M P a) \quad \ldots . E q \cdot(2-10)
$$

Okelo and Yuan (2005) found that surface texture like the ones on steel rebars, deformations or indentations as a result of stressing the helical yarns, deep dents, and sand coating were good ways to improve the bond strength between FRP rebars and normal strength concrete. The mode of failure was mainly affected by concrete compressive strength, the surface texture of the rebars, thickness of the concrete cover, and embedment length. It was also reported that for longer embedment length, a higher pullout load could be achieved, but a lower average of bond stress. In addition, lower average bond stress could be achieved for larger rebar's diameter. Overall, the bond strength for FRP rebars 
was 40 to $100 \%$ the bond strength of steel rebars. Finally, it was discovered that the bond strength was affected by the modulus of elasticity of FRP bars.

Wambeke and Shield (2006) evaluated the equations available for development length of glass FRP bars in concrete. The aim for this work was to collect and analyze the literature experimental data, compare them to the equation suggested by ACI committee 440, and propose new recommendations if necessary. The ACI committee 440.1R-03 suggested the equation below:

$$
l_{d}=\frac{d_{b} f_{f u}}{2700} \alpha k \quad \ldots . E q \cdot(2-11)
$$

Where;

$l_{d}$ is the development length (in.)

$d_{b}$ is the bar's diameter (in.)

$f_{f u}$ is the guaranteed tensile strength (psi)

$\alpha$ is a bar location modification factor

$k$ is a cover modification factor 
Wambeke and Shield (2006) thought that since this equation was based on the limited research data that was available at that time, it could be improved if more data were considered. The Japan Society of Civil Engineers (JSCE) recommended Eq. 2-12 in their design code of 1997. The equation is valid for a splitting controlled failure. For further information about determining each of the factors shown in the previouse equations, the technical paper of Wambeke and Shield (2006) could be reviewed.

$$
l_{d}=\alpha_{1} k \frac{f_{d} d_{b}}{4 f_{b o d}} \quad \ldots . E q .(2-12)
$$

Where;

$\alpha_{1}$ is a confinement modification factor

$k$ is a top bar modification factor

$f_{d}$ is the design tensile strength

$f_{b o d}$ is the design bond strength of concrete.

Wambeke and Shield (2006) followed the same procedure as that followed by the ACI Committee 318-02 in order to determine the development length of steel rebars. The data of 240 beam tests were collected from the literature and analyzed. The size of glass fiber reinforced polymer GFRP bars ranged from 0.5 in. to 1.128 in. Most of the GFRP bars considered in this study had either the same surface deformation as that of steel rebars or 
indentations around the GFRP bars. Furthermore, most of the considered embedment lengths were less than $30 \mathrm{~d}$. The concrete compressive strength ranged from 4000 to 6500 psi. It was reported that all of the specimens that exhibited splitting mode of failure had clear covers of one to three times bar diameters. On the other hand, about half of the specimens that exhibited pullout mode of failure had clear covers more than three times bar diameters. The analysis of the limited available data showed that there was no effect of the transverse reinforcement on the bond strength when the failure mode is splitting. Wambeke and Shield (2006) explained this as the GFRP rebar had a very low relative rib area. After statistical analysis, Wambeke and Shield (2006) proposed Eq. 2-13 to predict the development length of GFRP bars embedded in normal strength concrete, as the following:

$$
l_{d}=\frac{d_{b}\left(\frac{f_{f u}}{3.5 \sqrt{f_{c}^{\prime}}}-100\right) \alpha}{4+0.3 \frac{c}{d_{b}}} \geq \frac{f_{f u} d_{b}}{30.6 \sqrt{f_{c}^{\prime}}} \quad \ldots . E q \cdot(2-13)
$$

where $\alpha$ is equal to 1 except if there is a concrete cover more than $12 \mathrm{in.} \mathrm{below} \mathrm{the} \mathrm{GFRP}$ bars. The results of the proposed equation were compared to ACI $440.1 \mathrm{R}-03$ and the Japanese Design Guidelines. As shown in Table 2-6, the development lengths required by ACI 440.1R-03 were shorter than those required by either the proposed equation or the equation proposed by the Japanese Design Guidelines. Finally, it was concluded that when concrete strength was less than $8000 \mathrm{psi}$, the proposed equation (Eq. 2-13) suggested longer 
development length than ACI 440.1R-03. However, shorter development lengths were suggested by the proposed equation when concrete strength was more than 8000 psi.

\begin{tabular}{|c|c|c|c|}
\hline & & $l_{\text {embed }}<\boldsymbol{l}_{\boldsymbol{d}}$ & $l_{\text {embed }}>l_{d}$ \\
\hline & No. of tests & 156 & 54 \\
\hline \multirow[t]{4}{*}{$\begin{array}{l}\text { ACI 440.1R-03 } \\
\text { equation }\end{array}$} & $\begin{array}{l}\text { No. of pullout } \\
\text { failures }\end{array}$ & 77 & $4^{*}$ \\
\hline & $\begin{array}{l}\text { No. of splitting } \\
\text { failures }\end{array}$ & 43 & $24^{\dagger}$ \\
\hline & No. of tensile failures & 36 & 26 \\
\hline & No. of tests & 183 & 27 \\
\hline \multirow[t]{4}{*}{ Proposed equation } & $\begin{array}{l}\text { No. of pullout } \\
\text { failures }\end{array}$ & 81 & 0 \\
\hline & $\begin{array}{l}\text { No. of splitting } \\
\text { failures }\end{array}$ & 60 & $7 \ddagger$ \\
\hline & No. of tensile failures & 42 & 20 \\
\hline & No. of tests & 179 & 31 \\
\hline \multirow[t]{3}{*}{ Japanese equation } & $\begin{array}{l}\text { No. of pullout } \\
\text { failures }\end{array}$ & 81 & 0 \\
\hline & $\begin{array}{l}\text { No. of splitting } \\
\text { failures }\end{array}$ & 53 & $14 \xi$ \\
\hline & No. of tensile failures & 45 & 17 \\
\hline $50 \%$ reached $f_{f u}$ & ${ }^{1} 62 \%$ reached $f_{f u}$ & $* 100 \%$ reached $f_{f u}$ & ${ }^{\xi} 57 \%$ reached $f_{f u}$ \\
\hline
\end{tabular}

Table 2-6 Summary for the 209 beam tests (Wambeke \& Shield, 2006)

It is interesting to mention that the ACI Committee 440.1R-06 recommended the following equations in 2006. Equation (2-14) was for hooked FRP reinforcing bars, and Eq. (2-15) was for straight FRP bars. More details about the factors used in these equations could be found in ACI 440.1R-06. 


$$
\begin{aligned}
& l_{\text {bhf }}=\left\{\begin{array}{lll}
2000 \frac{d_{b}}{\sqrt{f_{c}^{\prime}}} & \text { for } f_{f u} \leq 75,000 p s i \\
\frac{f_{f u} d_{b}}{37.5 \sqrt{f_{c}^{\prime}}} & \text { for } 75,000 \leq f_{f u} \leq 150,000 p s i & \ldots . E q .(2-14) \\
4000 \frac{d_{b}}{\sqrt{f_{c}^{\prime}}} & \text { for } f_{f u} \geq 150,000 p s i
\end{array}\right. \\
& l_{d}=\frac{\alpha \frac{f_{f r}}{\sqrt{f_{c}^{\prime}}-340}}{13.6+\frac{C}{d_{b}}} d_{b}
\end{aligned}
$$

In 2010, the main bond parameters affecting the bond or development length of FRP bars adopted by the ACI Committee 440 were evaluated to see if they were truly crucial (Harajli \& Abouniaj, 2010). The study was specifically for two kinds of GFRP bars. The main parameters were the surface conditions of FRP bars, lateral steel confinement, and type of rebars. Beam tests and bond pullout tests were carried out. In terms of the surface conditions of GFRP bars, thread wrapped and ribbed GFRP bars were used. Both kinds were 0.47 -in.-diameter bars. The same size of steel bars were used to reinforce some of the samples. The embedment lengths were 15,20 , and $30 \mathrm{~d}_{\mathrm{b}}$ for beam specimens and $7 \mathrm{~d}_{\mathrm{b}}$ for pullout specimens. 


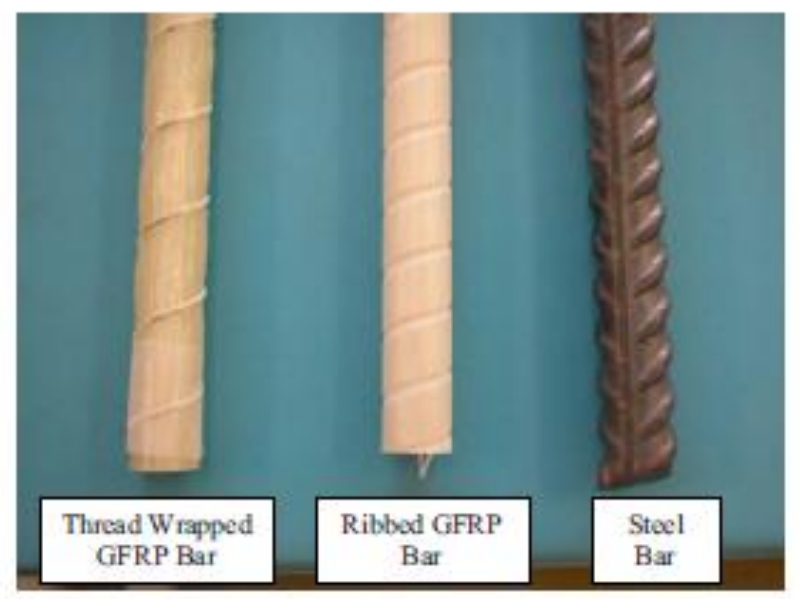

Figure 2.14 surface conditions of GFRP and steel bars (Harajli \& Abouniaj, 2010).

The results showed that pullout mode of failure was observed for all pullout specimens. This was as a result of a large concrete cover. In terms of surface condition effects, the thread was totally removed after the tests for the thread-wrapped bars. However, the notches on ribbed bars sheared off the concrete. On the other hand, the bond failure started with flexural cracks at the constant-moment zone for the beam specimens. The crack development was very quick, especially for beams reinforced with thread-wrapped GFRP bars. As a result, the pullout mode of failure was observed for all beams reinforced with thread-wrapped bars. Very wide flexural cracks (up to $20 \mathrm{~mm}$.) were associated with pull out mode of failure. In addition, beams failed with pullout had lower flexural strength. Finally, it was reported that the splitting mode of failure was observed for all beam specimens reinforced with ribbed GFRP or steel bars. Figure 2.15 shows the typical modes of bond failure in experimental beam tests. 

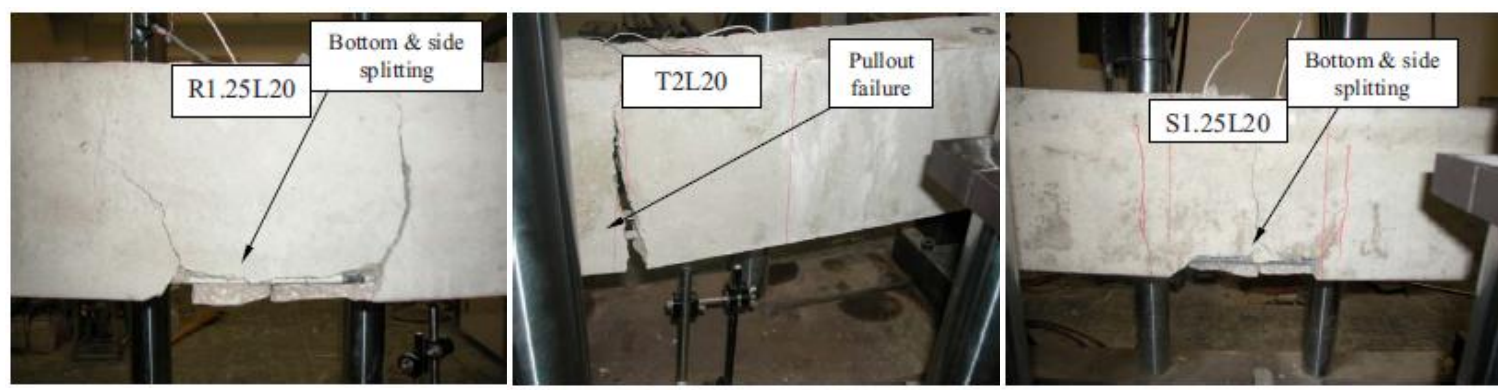

Figure 2.15 Modes of bond failures for beam specimens (Harajli \& Abouniaj, 2010).

Regarding the bond stress-slip response, the results showed that the thread-wrapped bars had the lowest stiffness and strength in all of the tests. The ultimate slippage values at failure were $5 \mathrm{~mm}$. and about $1 \mathrm{~mm}$. for thread-wrapped and ribbed GFRP bars, respectively. Although the ribbed GRPP bars showed better results than thread-wrapped bars, the GFRP bars could achieve significantly lower bond strength compared to steel bars. It was also found that the bond stress increased as the concrete compressive strength increased. As far as the concrete cover to the bar size ratio $\left(c / d_{b}\right)$ was considered, almost no effects were found by increasing the $\mathrm{c} / \mathrm{d}_{\mathrm{b}}$ for GFRP bars.

Harajli and Abouniaj (2010) concluded that the surface conditions had significant effects on bond strength and modes of failure for FRP bars, and that the ribbed GFRP bars could achieve larger bond strength. It was also concluded that the guidelines of the ACI Committee 440 (2006) for the development length of FRP bars resulted in bond strengths that were much higher than the experimental results. Therefore, Harajli and Abouniaj (2010) recommended that the ACI Committee 440 needed to reevaluate the equation to predict the development length of FRP bars. 

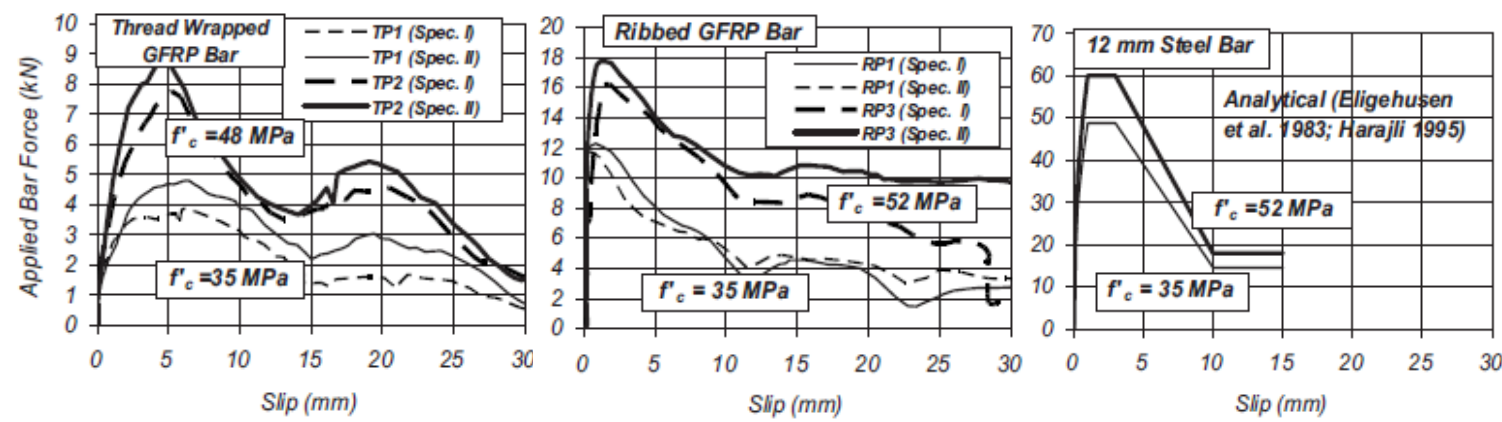

Figure 2.16 Bond stress-slip responses (Harajli \& Abouniaj, 2010).

\subsection{Flexural Behavior}

\subsubsection{Guidelines}

It is intended in this chapter to present the current design philosophy and considerations for concrete beams reinforced or prestressed with FRP bars or tendons. Up to 2006, a number of studies and research on flexural behavior of FRP beams were summarized and given as a design guidelines by ACI 440.1R-06 (Guide for the Design and Construction of Structural Concrete Reinforced with FRP bars) and ACI 440.4R-04 (Prestressed Concrete Structures with FRP Tendons). ACI Committee 440 considered strength design and working stress design methods, but the design strength was adopted as the design approach. Limit state design principles, fatigue, creep, and serviceability were used for design control. In terms of load, the load factors used in ACI 318-05 were adopted. In order to account for long term exposure to environment, equation 2-16 was recommended for the FRP tensile strength. The idea was that the guaranteed capacity provided by the manufacturer was reduced based on fiber type as shown in Table 2-7. 


$$
f_{f u}=C_{E} f_{f u}^{*} \quad E q \cdot(2-16)
$$

Where;

$f_{f u}=$ Design tensile strength, psi;

$C_{E}=$ Reduction factor based on Table 2-7

$f_{f u}^{*}=$ Guaranteed tensile strength $\left(f_{f u}^{*}=f_{u, a v g}-3 \sigma\right)$, psi;

$\sigma=$ Standard deviation of the test results.

\begin{tabular}{c|c|c}
\hline \multirow{2}{*}{\begin{tabular}{c} 
Exposure condition \\
\multirow{4}{*}{$\begin{array}{c}\text { Concrete not exposed to earth } \\
\text { and weather }\end{array}$}
\end{tabular}} & $\begin{array}{c}\text { Environmental } \\
\text { reduction factor } C_{E}\end{array}$ \\
\cline { 2 - 3 } & Fiber type & 1.0 \\
\cline { 2 - 3 } & Garbon & 0.8 \\
\hline \multirow{3}{*}{$\begin{array}{c}\text { Concrete exposed to earth and } \\
\text { weather }\end{array}$} & Aramid & 0.9 \\
\cline { 2 - 3 } & Carbon & 0.9 \\
\cline { 2 - 3 } & Glass & 0.7 \\
\hline
\end{tabular}

Table 2-7 Environmental reduction factor (ACI Committee 440.1R-06)

The same procedure would be considered if the design rupture strain were to be determined. However, it was suggested to take the modulus of elasticity as the average of the values reported by the manufacturer. In order to account for bending effects on the tensile strength of FRP bars, it is recommended to use equation 2-17, which was adopted from the Japan Society of Civil Engineers (1997).

$$
f_{f b}=\left(0.05 \frac{r_{b}}{d_{b}}+0.3\right) f_{f u} \leq f_{f u} \quad \ldots . E q \cdot(2-17)
$$


Where;

$f_{f b}=$ Design tensile strength considering bending in an FRP bar, psi

$r_{b}=$ radius of bending, in.

$f_{f u}=$ Design tensile strength as calculated in Eq. (2-15), psi

As stated in ACI 440.1R-06, the flexural design philosophy for concrete beams reinforced with FRP bars was the same as that for beams reinforced with steel bars. However, the linear stress-strain behavior of FRP bars should be considered. Therefore, the concrete section does not necessarily need to be under reinforced in order to get the desired ductile response due to the fact that FRP materials have brittle failure. As a result, concrete crushing is a more desired failure than FRP rupture. In both modes of failure, the strength reduction factor provides a larger reserved capacity compared to concrete sections reinforced with steel bars. Figure 2.17 shows the flexural strength reduction factor by (ACI 440.1R-06).

Similar to steel-reinforced concrete sections, the strength of the concrete member, which was calculated based on the equilibrium of the internal forces using strain compatibility principles, multiplied by a reduction factor, was limited to be larger than the applied factored load. Figure 2.18 shows the concrete section analysis for concrete beams reinforced with FRP bars. Equation 2-18 presents the balanced reinforcement ratio for FRP-reinforced concrete section and Figure 2.19 shows the section analysis for FRPprestressed concrete beams. Equation 2-19 can be used to determine the balanced 
reinforcement ratio for prestressed concrete beams using FRP tendons. Both figures and equations are retrieved from ACI Committee 440 (ACI 440.1R-06 \& ACI 440.4R-04). For more details about the parameters used in the equations, the resources mentioned above can be used.

For FRP-reinforced concrete sections;

Balanced ratio $=\rho_{f b}=0.85 \beta_{1} \frac{f_{c}^{\prime}}{f_{f u}} \frac{E_{f} \varepsilon_{c u}}{E_{f} \varepsilon_{c u}+f_{f u}} \quad \ldots$ Eq. $(2-18)$

For FRP-prestressed concrete sections;

Balanced ratio $=\rho_{b}=0.85 \beta_{1} \frac{f_{c}^{\prime}}{f_{p u}} \frac{\varepsilon_{c u}}{\varepsilon_{c u}+\varepsilon_{p u}-\varepsilon_{p e}-\varepsilon_{d}-\varepsilon_{p r}} \ldots$. Eq. $(2-19)$

Where:

$\varepsilon_{c u}=$ concrete Ultimate strain $(0.003)$

$f_{p u}=$ maximum CFRP tensile strength

$\varepsilon_{p u}=$ ultimate CFRP strain

$\varepsilon_{p e}=$ effective CFRP strain

$\varepsilon_{d}=$ strain due to decompression

$\varepsilon_{p r}=$ strain due to sustained load 
ACI 440.4R-04 suggested that the losses due to sustained loads $\left(\varepsilon_{p r}\right)$ and decompression $\left(\varepsilon_{d}\right)$ can be ignored in most cases. Therefore, Equation 2-19 can be written as seen in Equation 2-20;

Balanced ratio $=\rho_{b}=0.85 \beta_{1} \frac{f_{c}^{\prime}}{f_{p u}} \frac{\varepsilon_{c u}}{\varepsilon_{c u}+\varepsilon_{p u}-\varepsilon_{p e}} \quad$... Eq. $(2-20)$

The reinforcement ratio controlled the failure modes; whether it was concrete crushing or FRP rupture, and based on the failure mode, the flexural strength reduction factor changed.

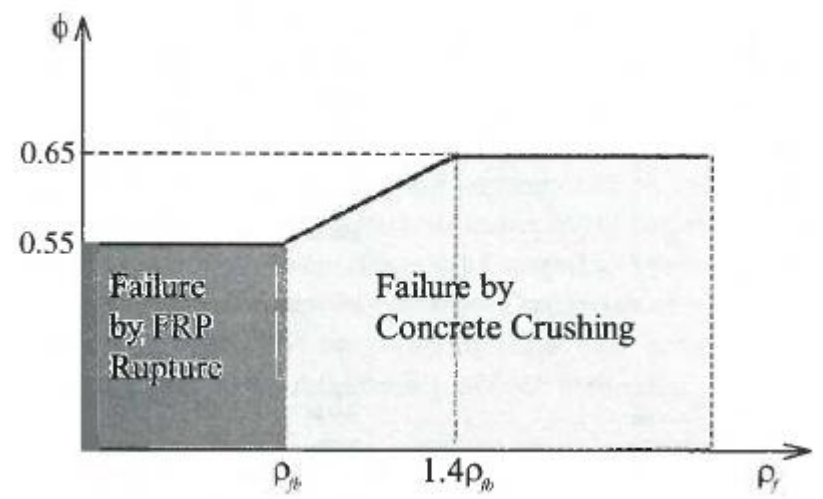

Figure 2.17 Flexural Strength Reduction Factor (ACI 440.1R-06) 


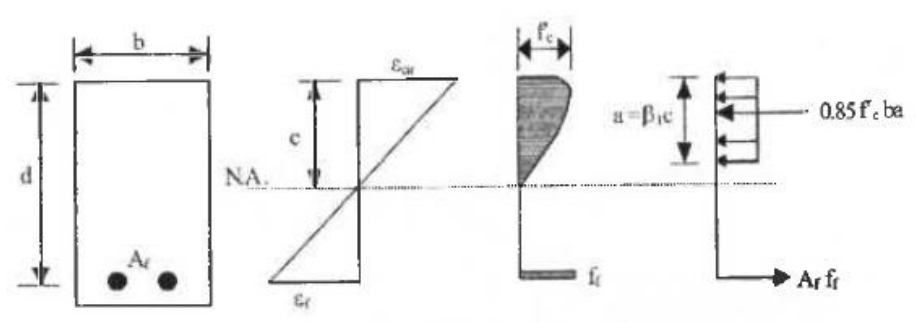

(a) Failure governed by concrete crushing

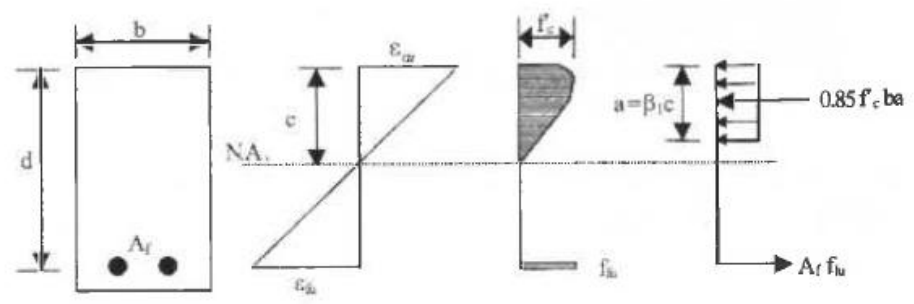

(b) Balanced failure condition

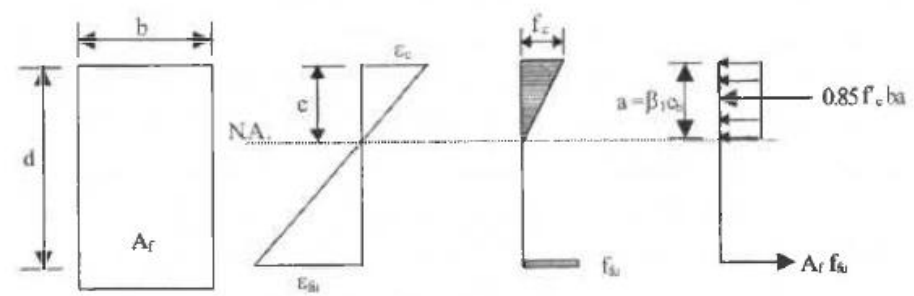

(c) Fuilure governed by FRP rupture (concrete stress may be nonlinear)

Figure 2.18 Sectional analysis of FRP-reinforced concrete members (ACI 440.1R-06)

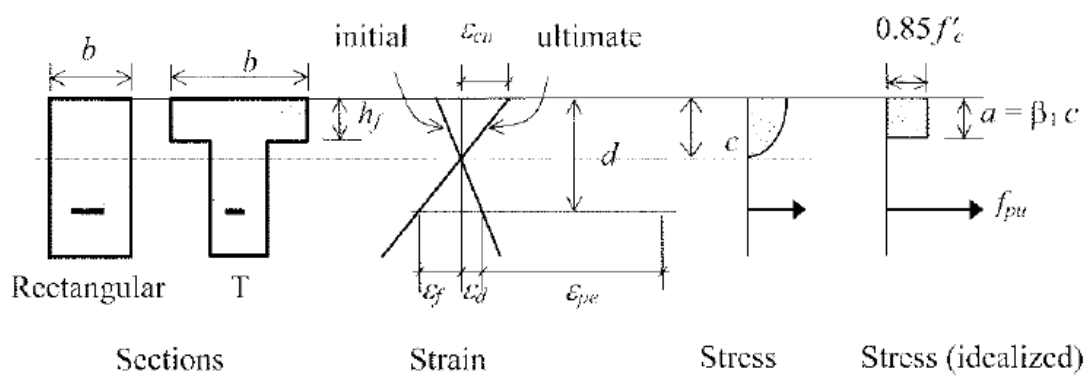

Note: Loss of strain capacity due to sustained load not shown

Figure 2.19 Sectional analysis of FRP-prestressed concrete members (ACI 440.4R-04) 
ACI 440.4R-04 recommends different flexural strength reduction factors. The ACI Committee 440 explained that the design philosophy of FRP-reinforced and prestressed concrete members significantly depended on the material properties. In reinforced concrete members, the dominant material used for reinforcing was GFRP, while CFRP was the most common in prestressed concrete members. AFRP was also used for prestressing. Based on Table 2-8, tension-controlled failure was thought to be safer in the design of prestressed concrete members.

\begin{tabular}{c|c|c}
\hline Tendon type & Strength reduction factor $\phi$ & Condition \\
\hline Aramid & 0.70 & $\begin{array}{c}\text { Tension-controlled } \\
\text { behavior }\end{array}$ \\
\hline Carbon & 0.85 & $\begin{array}{c}\text { Compression- } \\
\text { controlled behavior }\end{array}$ \\
\hline
\end{tabular}

Table 2-8 Flexural strength reduction factors (ACI 440.4R-04)

In terms of allowable stresses in concrete and FRP strands at jacking, transfer and service loading, the ACI 440 Committee recommends the values shown in Table 2-9 and Table 210.

\begin{tabular}{c|c}
\hline \multicolumn{2}{c}{ Allowable jack stresses } \\
\hline Carbon & $0.65 f_{p u}$ \\
\hline Aramid & $0.50 f_{p u}$ \\
\hline Allowable stress immediately following transfer \\
\hline Carbon & $0.60 f_{p u}$ \\
\hline Aramid & $0.40 f_{p u}$ \\
\hline
\end{tabular}

Table 2-9 Allowable stresses in FRP strands (ACI 440.4R-04) 


\begin{tabular}{c|c}
\hline Allowable stress at transfer of prestress (before losses) & $\mathrm{Units,} \mathrm{MPa} \mathrm{(psi)}$ \\
\hline (a) Extreme fiber stress in compression & $0.6 f_{c i}^{\prime}\left(0.6 f_{c i}^{\prime}\right)$ \\
\hline (b) Extreme fiber stress in tension except for (c) & $0.25 \sqrt{ } f_{c i}^{\prime}\left(3 \sqrt{ } f_{c i}^{\prime}\right)$ \\
\hline (c) Extreme fiber stress in tendon at ends & $0.5 \sqrt{ } f_{c i}^{\prime}\left(6 \sqrt{ } f_{c i}^{\prime}\right)$ \\
\hline $\begin{array}{c}\text { Allowable stresses under service loads (after losses) } \\
\text { plus sustained loads }\end{array}$ & $\mathrm{Units,} \mathrm{MPa}(\mathrm{psi})$ \\
\hline $\begin{array}{c}\text { (a) Extreme fiber stress in compresion due to press } \\
\text { plus total loads }\end{array}$ & $0.45 f_{c}^{\prime}\left(0.45 f_{c}^{\prime}\right)$ \\
\hline $\begin{array}{c}\text { (b) Extreme fiber stress in compression due to prestress } \\
\text { (c) Extreme fiber stress in precompressed tensile zone }\end{array}$ & $0.6 f_{c}^{\prime}\left(0.6 f_{c}^{\prime}\right)$ \\
\hline
\end{tabular}

Table 2-10 Allowable stresses in concrete for FRP-prestressed concrete beams (ACI 440.4R-04)

Regarding the ductility of FRP-members, due to brittleness of both concrete and FRP materials, desired ductility of FRP-reinforced concrete members is a more challenging issue. Instead of ductility, deformability is the common terminology used for concrete members reinforced with FRPs (ACI Committee 440, 2007). Because FRP materials do not yield, researchers have suggested a comparison of the ultimate deflection at failure to the deflection at cracking. Because of that, distinguished deformability might be achieved for concrete members reinforced or prestressed with FRP materials. Finally, in order to achieve favorable deformability in FRP-prestressed concrete members, it was recommended to reduce the initial tensile stress in FRP strands.

\subsubsection{Flexural Response of FRP Prestressed Concrete Beams}

This section presents some of the previous studies that have been conducted on prestressed concrete beams using FRP strands. Based on the author's knowledge, there is no work so 
far that has been done using Aslan 200 CFRP strands in prestressed concrete beams. The closest properties to Aslan 200 is what is commercially known Leadline (carbon FRP). Therefore, the author did not collect all the studies that were conducted, but only the most related papers. The focus of this section is mostly on the flexural response and modes of failure of beams in the previous studies that can be compared to the work of the current study.

Zou (2003) investigated the behavior and deformability of FRP prestressed concrete beams. The Aramid (AFRP) and Carbon FRP (CFRP) beams were compared to the beams prestressed with 7-wire steel strands. Normal and high strength concrete were used. In order to compare the flexural behavior for beams prestressed with FRPs with the beams prestressed with steel strands, the same prestressing force was applied for beams that would be compared. It was found, as expected, that the behaviors of beams prestressed with FRP and steel strands were identical up to the cracking moment. After cracking, as shown in Figure 2.20, the beams with steel strands showed nonlinear behavior with larger deflection and little increase in load. On the other hand FRP beams showed almost linear postcracking behavior with larger gain in load. Zou (2003) concluded that FRP prestressed concrete beams could handle larger load experience but with less deflection, which means less ductility, or deformability. However, when the ductility or deformability indices took in account the maximum and cracking moment values, the FRP beams showed ductility indices close to steel, as presented in the last column of Table 2-11. 


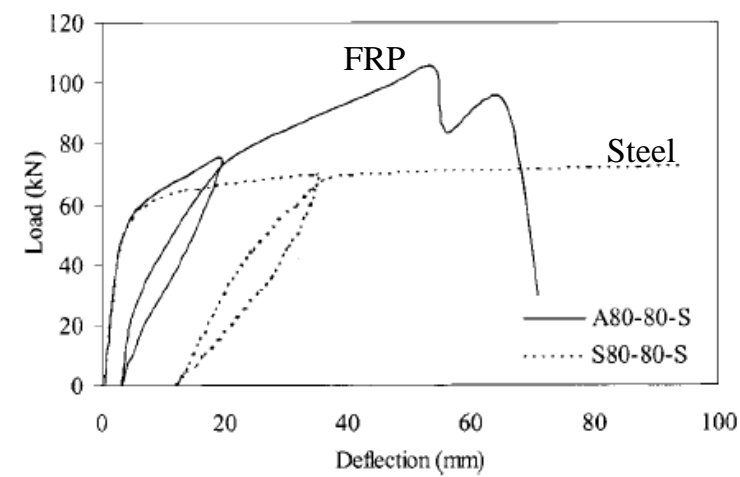

a) High strength concrete

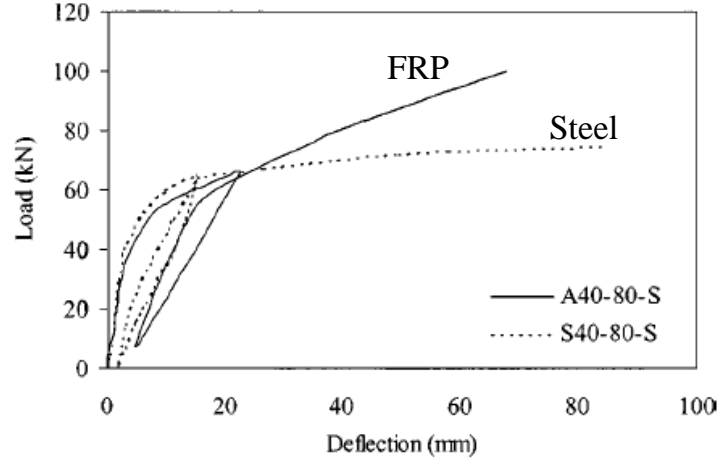

b) Normal strength concrete

Figure 2.20 Flexural response of prestressed concrete beams; FRP vs. steel strands (Zou, 2003)

\begin{tabular}{|c|c|c|c|c|c|}
\hline Beam & $\Delta \boldsymbol{u} / \boldsymbol{L}$ & Eq. (3) & Eq. (4) & Eq. (5) & Eq. (8) \\
\hline designation & & $\Delta \boldsymbol{u} / \Delta \boldsymbol{y}$ & $0.5\left(E^{E_{t o t}} / E_{\text {ela }}+1\right)$ & $\Delta_{u} / \Delta_{\boldsymbol{l}}$ & $(\Delta \boldsymbol{u} \boldsymbol{M u}) / \Delta_{c r} M_{c r}$ \\
\hline A50-80-S1 & $1 / 47$ & $\mathrm{n} / \mathrm{a}$ & $\mathrm{n} / \mathrm{a}$ & 9.2 & 56.0 \\
\hline A50-80-S2 & $1 / 52$ & $\mathrm{n} / \mathrm{a}$ & $\mathrm{n} / \mathrm{a}$ & 9.8 & 55.0 \\
\hline S50-80-S & $1 / 30$ & $\mathrm{n} / \mathrm{a}$ & $\mathrm{n} / \mathrm{a}$ & 16.4 & 51.6 \\
\hline A40-80-S & $1 / 44$ & $\mathrm{n} / \mathrm{a}$ & 1.37 & 9.0 & 43.7 \\
\hline S40-80-S & $1 / 35$ & 3.7 & 3.10 & 22.1 & 59.5 \\
\hline A80-80-S & $1 / 65$ & $\mathrm{n} / \mathrm{a}$ & 1.35 & 9.0 & 33.3 \\
\hline S80-80-S & $1 / 32$ & 2.7 & 4.24 & 19.9 & 41.5 \\
\hline A40-80-L & $1 / 44$ & $\mathrm{n} / \mathrm{a}$ & 1.46 & 5.2 & 23.5 \\
\hline S40-80-L & $1 / 36$ & 3.4 & 2.72 & 14.2 & 41.9 \\
\hline A80-80-L & $1 / 59$ & $\mathrm{n} / \mathrm{a}$ & 1.42 & 5.1 & 18.2 \\
\hline S80-80-L & $1 / 32$ & 3.1 & 3.44 & 12.5 & 17.6 \\
\hline A80-120-L & $1 / 52$ & $\mathrm{n} / \mathrm{a}$ & 1.46 & 4.5 & 15.4 \\
\hline S80-120-L & $1 / 31$ & 2.5 & 1.45 & 5.1 & 10.7 \\
\hline
\end{tabular}

Note: Beam designation starting with A means AFRP strands. Designation starting with $S$ means steel strands.

Table 2-11 Ductility or deformability indices for beams with AFRP and steel strands (Zou, 2003) 
Krem (2013) did a-study on concrete beams reinforced and prestressed with CFRP bars. The research covered many areas of interests, most of them related to bond characteristics. In addition to the concrete beams reinforced with glass FRP (GFRP) and steel bars, Krem tested sixteen concrete beams prestressed with CFRP. Two modes of failure were observed in this study: 1) CFRP rupture and 2) bond pullout failure. The mode of failure was considered pullout if a slippage of $0.25 \mathrm{~mm}$. occurred at the ends. Usually, the bond pullout failure occurred between the sand coating layer and the fiber interface of CFRP bars. While the FRP rupture mode of failure generally happened at the mid-span region, the bond pullout failure occurred between the end of the transfer length and the point load, as shown in Table 2.21. It was concluded that the development length of $1500 \mathrm{~mm}$ was enough if the prestressing level was less than $45 \%$. However, when the prestressing level was $60 \%$, the development length went over $1700 \mathrm{~mm}$.

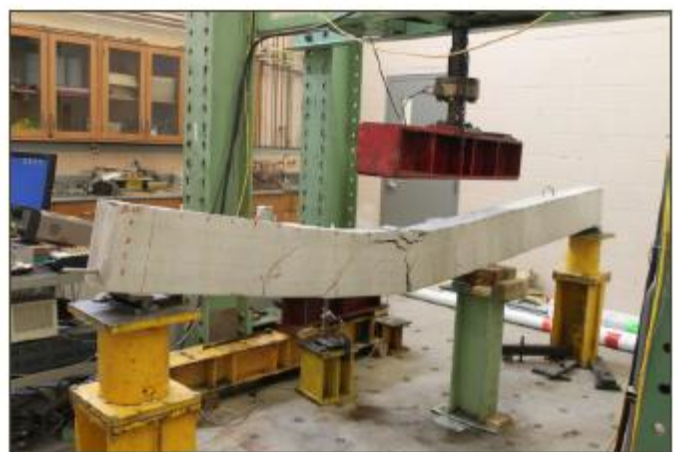

a) CFRP rupture

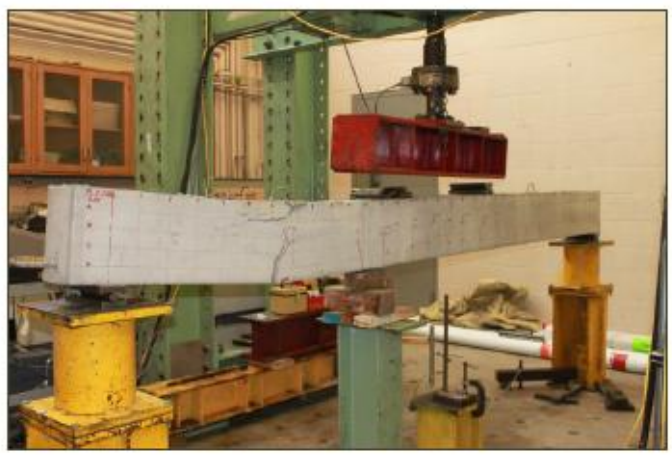

b) Bond pullout - slippage

Figure 2.21 Modes of failure (Krem, 2013) 
The mode of failure for all beams prestressed with $60 \%$ was bond pullout failure. It is noted from Table 2-12 that more than half of the beams failed in bond pullout. Therefore, Bond pullout failure was a common mode of failure in this study. Krem (2013) also addressed the effects of prestressing level on the flexural response of prestressed concrete beams pretensioned with CFRP bars, as presented in Figure 2.22. The conclusion of this study was that the prestressing level mostly affected the ultimate ductility of prestressed concrete beams and had a small influence on the flexural strength, especially for over-reinforced sections. This observation also agreed with the results of nine beams tested by $\mathrm{Du}, \mathrm{Zuohu}$, and Jingbo (2011).

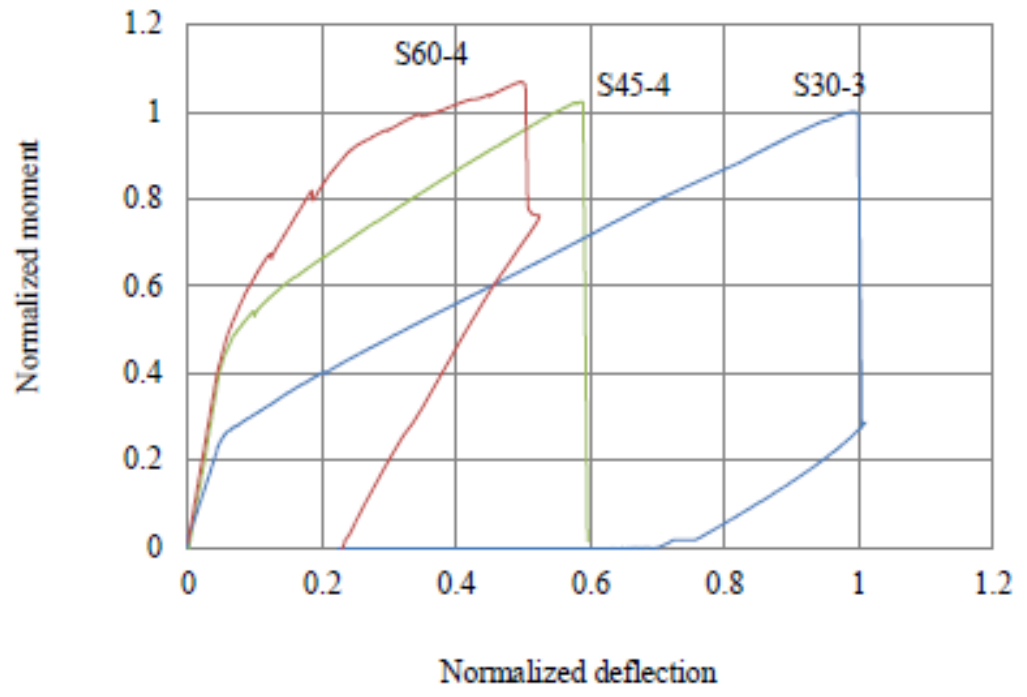

Figure 2.22 Effects of prestressing level on flexural response (Krem, 2013) 


\begin{tabular}{|c|c|c|c|c|c|c|c|}
\hline \multirow[b]{2}{*}{ Group } & \multirow{2}{*}{$\begin{array}{l}\text { Beam } \\
\text { label }\end{array}$} & \multirow{2}{*}{$\begin{array}{c}\text { Shear } \\
\text { span, mm }\end{array}$} & \multicolumn{2}{|c|}{ Cracking } & \multicolumn{2}{|c|}{ Failure } & \multirow[b]{2}{*}{ Type of failure } \\
\hline & & & $\begin{array}{l}\text { Moment, } \\
\mathrm{kN} . \mathrm{m}\end{array}$ & $\begin{array}{c}\text { Deflection, } \\
\mathrm{mm}\end{array}$ & $\begin{array}{l}\text { moment, } \\
\mathrm{kN} . \mathrm{m}\end{array}$ & $\begin{array}{c}\text { Deflection, } \\
\mathrm{mm}\end{array}$ & \\
\hline \multirow{4}{*}{ I } & S30-1 & 1100 & 12.8 & 3.7 & 16.7 & 11.9 & Pullout \\
\hline & S30-2 & 1250 & 10.7 & 3.6 & 42.4 & 69.2 & Rupture \\
\hline & S30-3 & 1350 & 10.1 & 3.1 & 33.9 & 52.5 & Pullout/Rupture \\
\hline & S30-4 & 1500 & 12.5 & 3.6 & 17.8 & 25.4 & Rupture* \\
\hline \multirow{4}{*}{ II } & S45-1 & 1100 & 17.1 & 4.7 & 34.0 & 35.9 & Pullout \\
\hline & S45-2 & 1250 & 16.8 & 4.6 & 36.8 & 35.7 & Pullout \\
\hline & S45-3 & 1350 & 14.6 & 3.4 & 36.9 & 31.5 & Pullout \\
\hline & S45-4 & 1500 & 18.7 & 3.7 & 43.5 & 40.6 & Rupture \\
\hline \multirow{4}{*}{ III } & S60-1 & 1100 & 16.7 & 5.1 & 26.3 & 12.9 & Pullout \\
\hline & S60-2 & 1350 & 22.9 & 5.2 & 31.4 & 19.2 & Pullout \\
\hline & S60-3 & 1500 & 16.9 & 4.9 & 26.7 & 21.2 & Pullout \\
\hline & S60-4 & 1700 & 17.2 & 6.3 & 33.2 & 22.3 & Pullout/rupture \\
\hline \multirow{4}{*}{ IV } & $\mathrm{N} 30-1$ & 1350 & 10.5 & 4.2 & 42.3 & 68.8 & Rupture \\
\hline & $\mathrm{N} 60-2$ & 1250 & 20.9 & 4.1 & 29.4 & 12.5 & Pullout \\
\hline & $\mathrm{N} 60-3$ & 1350 & 17.5 & 3.6 & 44.6 & 48.5 & Rupture \\
\hline & N60-4 & 1500 & 17.9 & 3.9 & 43.7 & 49.4 & Rupture \\
\hline
\end{tabular}

* This beam failed by premature bar rupture failure. The flexural test results of this beam were excluded from any further discussion

Table 2-12 Flexural responses of CFRP prestressed concrete beams (Krem, 2013)

Noël and Soudki (2013) investigated GFRP-reinforced concrete slabs prestressed with CFRP strands. Generally, the GFRP-reinforced concrete members experience larger deflection compared to members reinforced with conventional steel rebars due to the fact that GFRPs have low modulus of elasticity. As a result, prestressing these members would improve the flexural performance significantly. Probably the most benefit would be by preventing cracks under service loads, which is very difficult to achieve by GFRP reinforcing only. Noël and Soudki (2013) tested a total of ten slab strips; one with steel 
reinforcement and nine with GRRP reinforcement. Seven of the GFRP-reinforced concrete slabs were prestressed with CFRP tendons.

Noël and Soudki (2013) found that the specimens reinforced with GFRP showed the lowest flexural stiffness with very wide cracks. However, prestressing them with CFRP tendons remarkably improved the serviceability of GFRP-reinforced slabs. They also examined the effects of different numbers of tendons. It was found, as shown in Figure 2.24, the more numbers of prestressing tendons, but same prestressing force, increased the post cracking stiffness and maximum strength. However, since the prestressing force was the same, no improvement in serviceability was gained. Increasing the prestressing force to a double, but the same number of prestressing tendons resulted in higher moment capacity (Figure 2.24). The results of Figure 2.23 compared the effects of bond between CFRP tendons and concrete on flexural response. It could be clearly seen that specimens with bonded and unbonded tendons had the same pre-cracking flexural response. However, slabs with the bonded CFRP showed higher strength but less ductility.

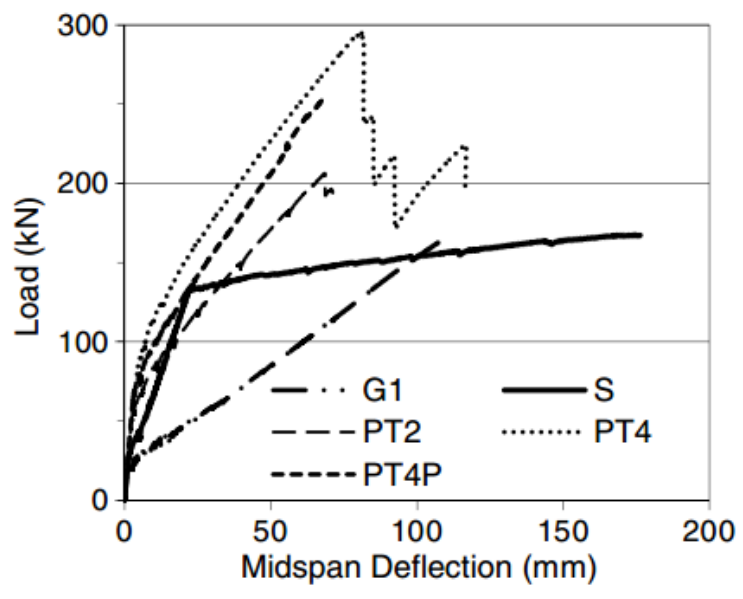

Figure 2.24 Effects of prestressing tendons' number (Noël \& Soudki, 2013)

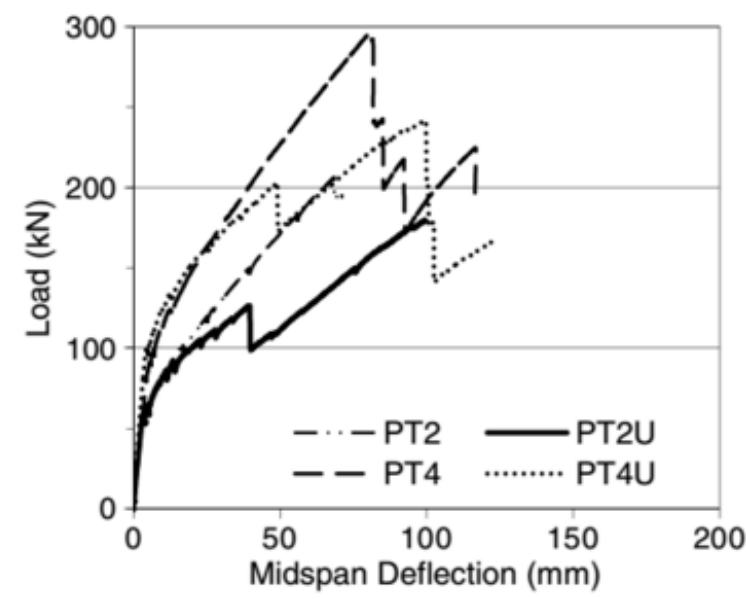

Figure 2.23 Bonded vs. un-bonded tendons (Noël \& Soudki, 2013) 
Where;

S: slab specimens reinforced with conventional steel rebars,

G1: slab specimens reinforced with GFRP rebars,

PT2: slab specimens reinforced with GFRP rebars and prestressed with two bonded CFRP tendons.

PT2U: slab specimens reinforced with GFRP rebars and prestressed with two un-bonded CFRP tendons.

PT4P: slab specimens reinforced with GFRP rebars and prestressed with four bonded CFRP tendons, but the prestressing force was almost the same as PT2.

PT4: slab specimens reinforced with GFRP rebars and prestressed with four bonded CFRP tendons.

PT4U: slab specimens reinforced with GFRP rebars and prestressed with four bonded CFRP tendons. 


\section{Chapter 3: Experimental Program}

\subsection{Introduction}

The main focus of the experimental study was to investigate the flexural behavior of the prestressed concrete beams pre-tensioned with Carbon Fiber Reinforced Polymer (CFRP) strands. A total of four CFRP prestressed concrete beams were tested and evaluated under cyclic loading. All the materials used to create the composite prestressed concrete beams were tested so that the mechanical properties of each material were determined. The transfer and the development lengths for CFRP strands embedded in concrete were also investigated. Additionally, the study included developing a new bond-type anchorage system for CFRP strands in order to overcome the bonding issues. Several tests were conducted to evaluate the efficiency of the anchors.

\subsection{Tensile Test of CFRP}

Although Carbon Fiber Reinforced Polymer (CFRP) strands are very strong in longitudinal direction, they are extremely week in their transvers direction. Unlike steel, CFRP is anisotropic material. This feature creates a challenge for engineers to think about a way for gripping this material for testing or application purposes. Different ways for gripping have been developed by other investigators. Some of the gripping methods are mechanical, however, previous studies suggested that the most efficient methods are bond-type anchors. In this study, a total of eight samples, four of \#3 and four of \#4 strands, were purchased from the manufacturer. Mechanical-type anchors were already attached to both ends of the strands, as shown in Figure 3.1. The manufacturer guarantees that these anchors can 
develop the guaranteed tensile capacity of the CFRP strands before failure. The total length, steel anchor dimensions, and CFRP free length of the samples are shown in Table 3.1.
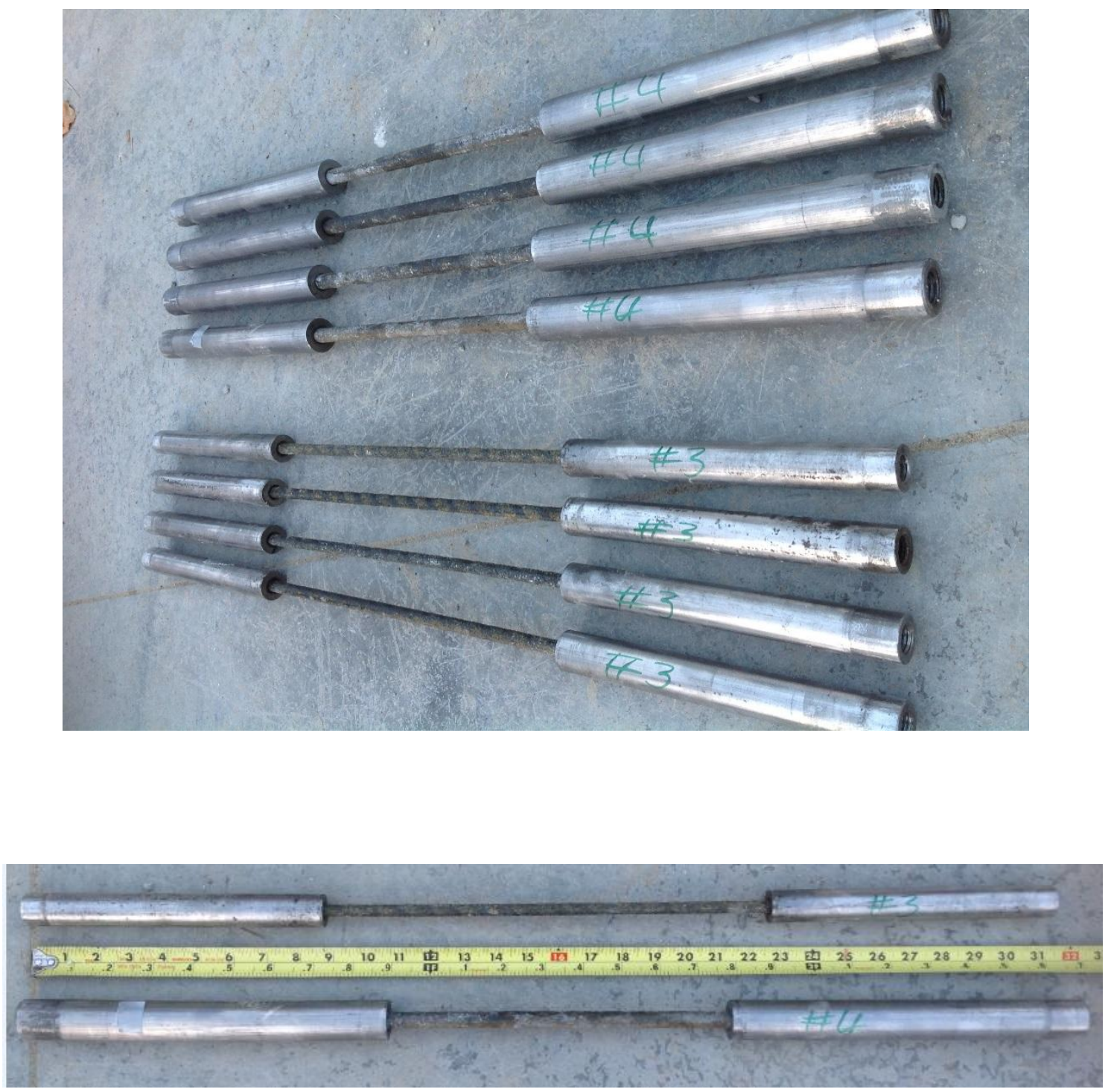

Figure 3.1 Anchored CFRP samples for tensile tests 


\begin{tabular}{ccccc}
\hline \multirow{2}{*}{$\begin{array}{c}\text { Samples based on the } \\
\text { size of CFRP }\end{array}$} & $\begin{array}{c}\text { Total length } \\
\text { (inch) }\end{array}$ & $\begin{array}{c}\text { Steel anchor } \\
\text { (inch) }\end{array}$ & $\begin{array}{c}\text { CFRP free length } \\
\text { (inch) }\end{array}$ & $\begin{array}{c}\text { Diameter } \\
\text { between anchors }\end{array}$ \\
\hline \#3: 3/8 CFRP strands & 31.25 & 8.75 & 1.00 & 13.75 \\
\hline \#4: 4/8 CFRP strands & 32.00 & 10.75 & 1.25 & 10.5 \\
\hline
\end{tabular}

Table 3-1 Dimensional details of the CFRP samples

Eight samples were tested in the Mechanical Laboratory at the University of Portland. Figure 3.2 shows the test setup for the tensile test. A 200-kilopound capacity computercontrolled testing frame was used. A hydraulic gripping system provided enough pressure to hold the smooth surface of the steel anchors from both ends. It was very important to keep the eccentricity of the samples at the minimum. ASTM Standard D7205/D7205M (2011) was adopted for providing the guidelines for this tensile test. The speed of testing, as recommended by this guideline, "shall be selected so as to produce failure within 1 to 10 minutes from the beginning of force application."

Another suggested strain rate by this guideline, in case the ultimate strength of the material is not known, is $0.01 /$ minute. Herein, a strain rate of $0.005 /$ minute was decided to be used for both two groups of specimens, \#3 and \#4 strands. An extensometer of 2- inch initial separation was used to measure the strain in the CFRP strands. Figure 3.2 shows the test setup for the tensile test. 

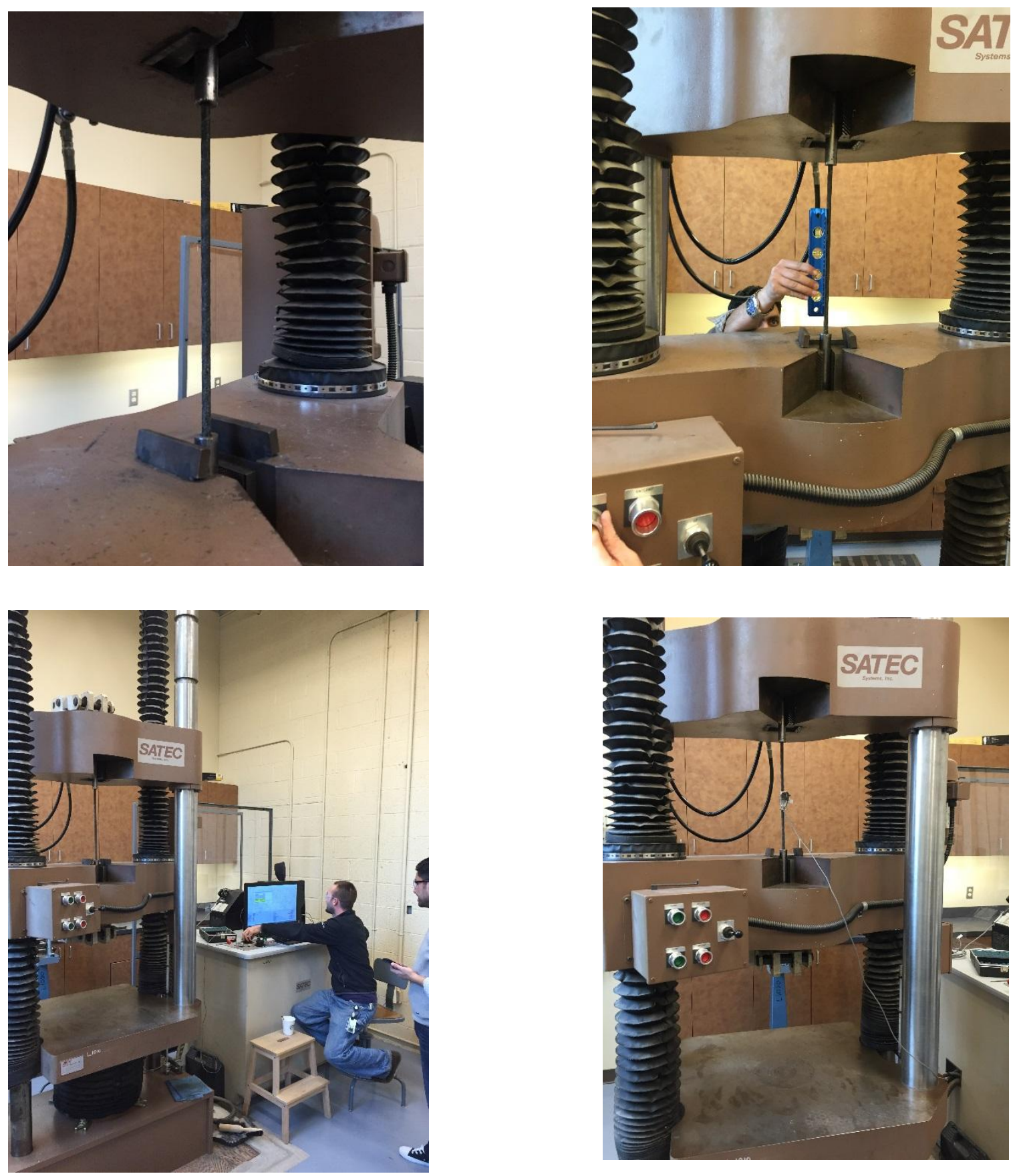

Figure 3.2 Test set-up for the CFRP tensile tests, performed at the University of Portland 
All eight samples were tested until failure. Table 3-2 shows the mechanical properties of both \#3 and \#4 strands based of the test results and compared to the guaranteed values of the manufacturer (Aslan 250). The manufacturer guaranteed capacity, at the time of purchasing, is 315 and 300 for \#3 and \#4 CFRP strands, respectively. The tensile capacity of the strands is calculated by dividing the peak load to the cross sectional area. The modulus of elasticity is determined based on ASTM Standard D7205/D7205M (2011), depending on the slope between the strain of $0.1 \%$ and $0.3 \%$ from the stress-strain relationship. The extensometer was removed when the load reached $70 \%$ of the guaranteed capacity. As a result, the maximum strain was estimated from the peak load and the modulus of elasticity based on the assumption that the CFRP behaves linearly until failure. Figures 3.3 and 3.4 show the test results and the guaranteed values.

In terms of the modulus of elasticity, there is a strong agreement between the guaranteed values and the test results. Although the average maximum capacity of \#4 strands is higher than the guaranteed capacity, the maximum capacity of \#3 strands is lower. The cause was thought to be due to the anchorage system that is used by the manufacturer. Therefore, it was decided to retest the strands while doing the anchorage system investigation, as explained in the following section. 


\begin{tabular}{|c|c|c|c|c|c|c|c|c|}
\hline \multirow{2}{*}{$\begin{array}{l}\text { Strand } \\
\text { size }\end{array}$} & \multirow{2}{*}{$\begin{array}{l}\text { Cross- } \\
\text { sectional } \\
\text { area } \\
\left(\mathrm{in}^{2}\right)\end{array}$} & \multirow{2}{*}{$\begin{array}{l}\text { Avg. } \\
\text { failure } \\
\text { load } \\
\text { (kips) }\end{array}$} & \multicolumn{3}{|c|}{$\begin{array}{l}\text { Avg. max. capacity } \\
\text { (ksi) }\end{array}$} & \multirow{2}{*}{$\begin{array}{l}\text { Avg. max. strain } \\
\text { (in./in.) } \\
\text { Guaranteed }\end{array}$} & \multirow{2}{*}{\multicolumn{2}{|c|}{$\begin{array}{l}\text { Avg. modulus of } \\
\text { elasticity (ksi) } \\
\text { Test Guaranteed }\end{array}$}} \\
\hline & & & Test & Guaranteed & Test & & & \\
\hline$\# 3$ & 0.11 & 31.1 & 283 & 315 & 0.0148 & 0.0175 & 19000 & 18000 \\
\hline$\# 4$ & 0.196 & 64.9 & 330 & 310 & 0.0162 & 0.0167 & 20500 & 18000 \\
\hline
\end{tabular}

Table 3-2 Guaranteed vs. experimental mechanical properties

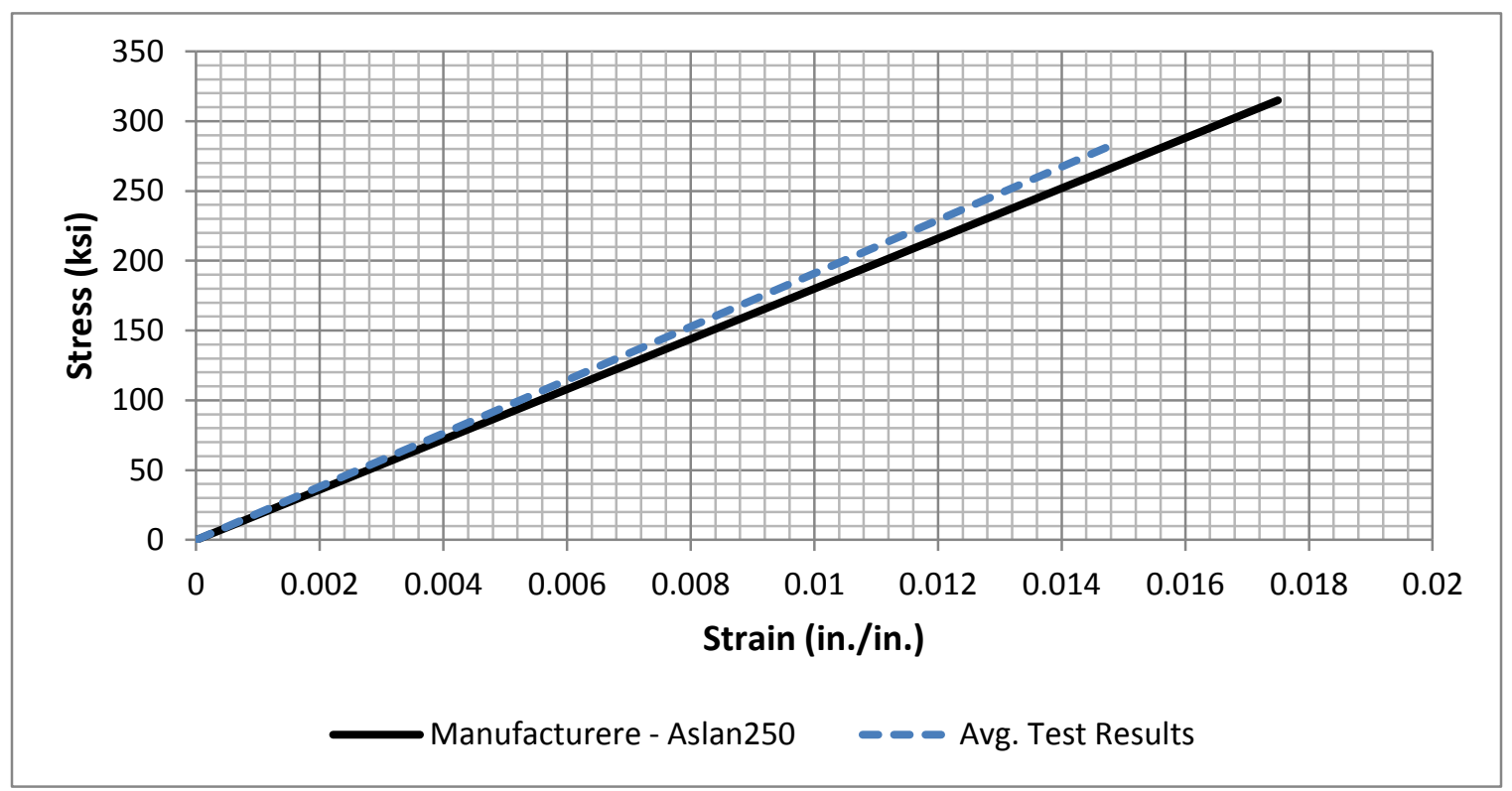

Figure 3.3 Experimental vs. Manufacturer's stress-strain curves for \#3 CFRP strands 


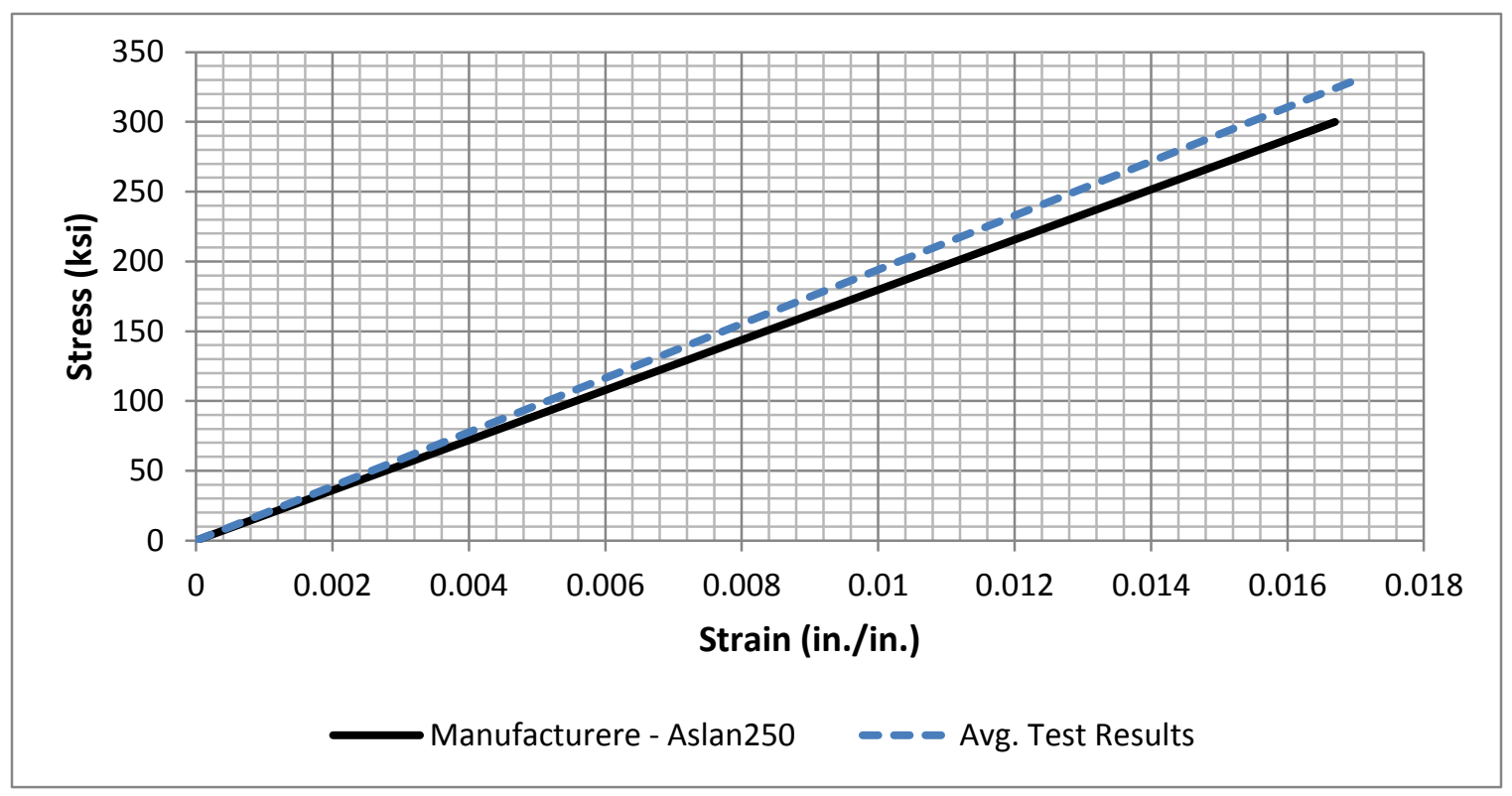

Figure 3.4 Experimental vs. Manufacturer stress-strain curves for \#4 CFRP strands

\subsection{CFRP Anchors}

\subsubsection{General}

For the anchorage system, eleven samples were fabricated and tested in the laboratory. The goals of these tests were to evaluate the efficiency of the anchors to be used in pretensioning applications as a solution for bonding issues. Since only \#4 strands were used for the flexural tests, the results of only the \#4 strands are presented in this paper. The bonded lengths, represented by the length of the steel tubes, were $12 \mathrm{in.}$ and $15 \mathrm{in}$. The main goal related to the work of this paper was whether the proposed anchors were capable of developing to the full capacity, or at least to the guaranteed capacity of the carbon fiber reinforced polymer CFRP strand. 


\subsubsection{CFRP Strands}

The CFRP strands are called Aslan 200 Rebar, and they were purchased from Hughes Brothers, Inc., Nebraska, USA. This company produces Aslan200 for concrete reinforcement and Aslan 250 for prestressed concrete applications. The only difference between Aslan200 and Aslan 250 is that Aslan 250 rebars have steel anchors at the ends. The carbon fibers and resin represent about 55\% and 45\%, by volume, of the CFRP rods, respectively. These ratios are based on the information given by the company representative at the World of Concrete 2015, Las Vegas, USA. Regarding the surface treatment, Aslan rebars and tendons have both a sand coating and helical wrap. The guaranteed capacity of the CFRP strands is $315 \mathrm{ksi}$ and $300 \mathrm{ksi}$ for the \#3 and the \#4 strands, respectively. According to the manufacturer, the guaranteed values are determined based on ACI Committee 440 definition, the "Guaranteed Tensile Strength," $f^{*}$ fu. The tensile testing is based on ASTM Standard D7205. Fig. 3.4 shows Aslan 200 CFRP bars.

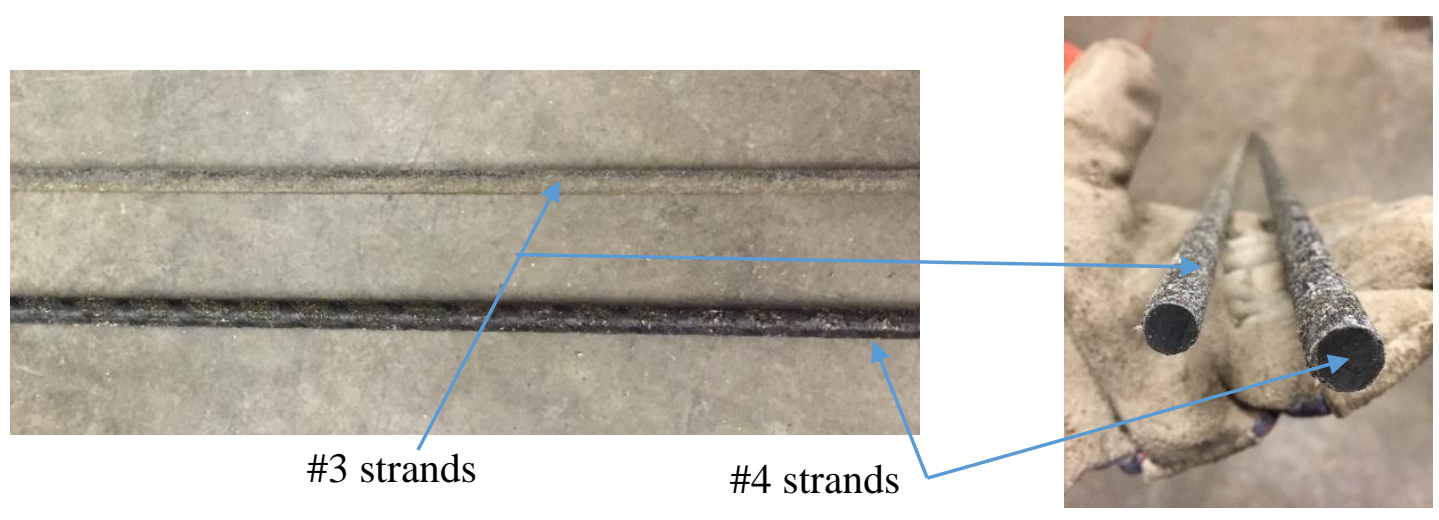

Figure 3.4 Samples of CFRP strands 


\subsubsection{Anchorage Steel Tube}

The steel tube that was used for anchorage system in this study was originally manufactured to be used as a geo-drill injection anchor system for soil-anchorage applications. It is a continuously threaded steel tube with an average inner diameter of 0.787 inch. The outer diameter is 1.25 " with a minimum net area through threads of 0.556 $\mathrm{in}^{2}$. The ultimate and the yield strengths are $58.4 \mathrm{kips}$ and $47.2 \mathrm{kips}$, respectively. The length of steel tube represents the bond length, or the anchor length. Two different lengths, 12 " and 15 " were investigated for this study. The ratio of the cross sectional area of the CFRP strands to the inner cross sectional area of the steel tubes is $40.4 \%$ for \#4 strands.

\subsubsection{The Filling Grout}

Expansive grout commercially called "Bustar" was used as the filling material for the anchors. This grout is produced by Demolition Technologies Inc., Alabama, USA. Bustar expansive grout is used for concrete and rock non-explosive demolition projects. In this

study, Bustar was used as a filling material to provide enough pressure to hold the CFRP strands inside the steel tube. The water/cement ratio of 0.3 is recommended by the manufacture. The mixing time is two to three minutes. The pouring time should be within five minutes. As stated on the manufacturer's instructions, the seven day curing will produce a pressure of $9.94 \mathrm{ksi}$. Figure 3.5 shows the relationship between the time and the expansive pressure as provided by the manufacturer. This product was first used for this purpose by Alobaidi (2015). 


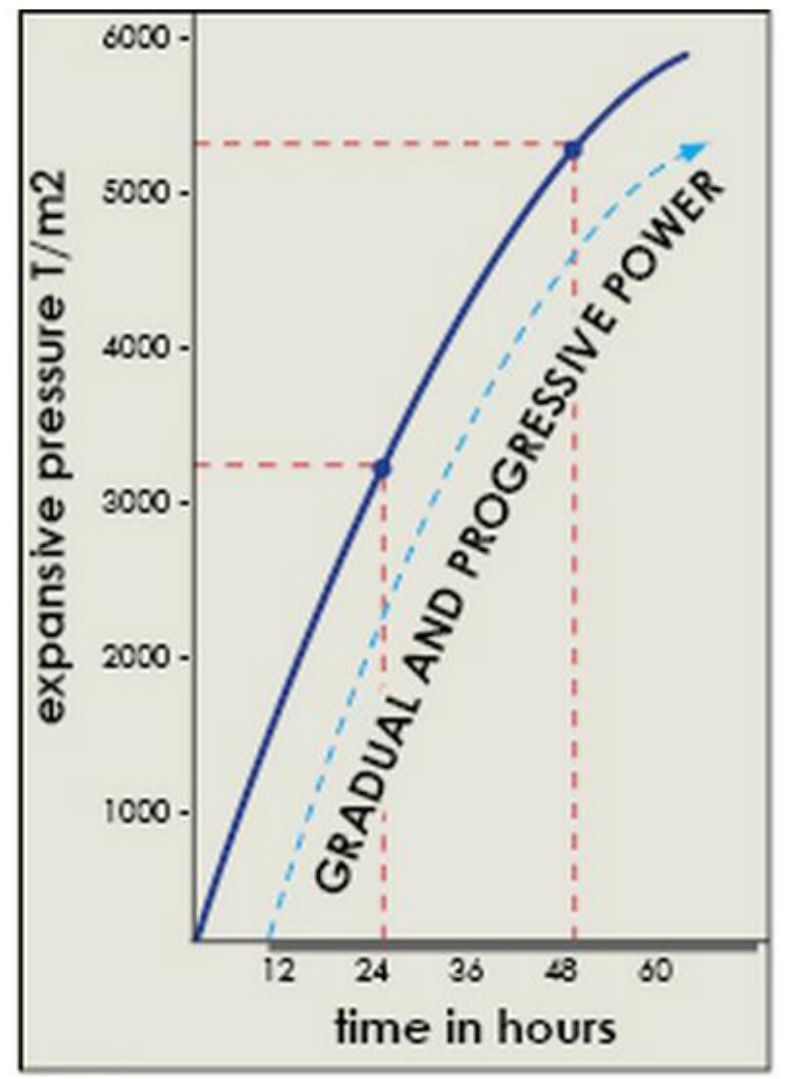

Figure 3.5 Expansive pressure vs. time. Retrieved from (http://www.demolitiontechnologies.com/expanding-grout-technical-info).

\subsubsection{Manufacturing of the Anchors}

Below is a list of the items and tools that were used to connect the anchorage tube:

- $\quad$ A CFRP strand of four to five feet long depending on the investigated bond length.

- A steel tube that is continuously threaded from outside and smooth from inside. The length of the tube is the bond length.

- Enough expansive grout to fill the room between the CFRP strand and the internal walls of the steel tube. 
- Water: the w/c ratio is 0.3 .

- A PVC cup at the bottom of the steel tube. The PVC cup should have a hole at the center.

- A plastic cup at the top of the steel tube: This is used for alignment purposes.

- A wood frame: to hold the steel tube vertically.

- Thermometer: to make sure that the temperature and the humidity are appropriate.

- Plastic gloves.

- Duct tape.

- Weighing scale.

Figure 3.6 shows photos of the casting process to attach the anchorage steel tube.

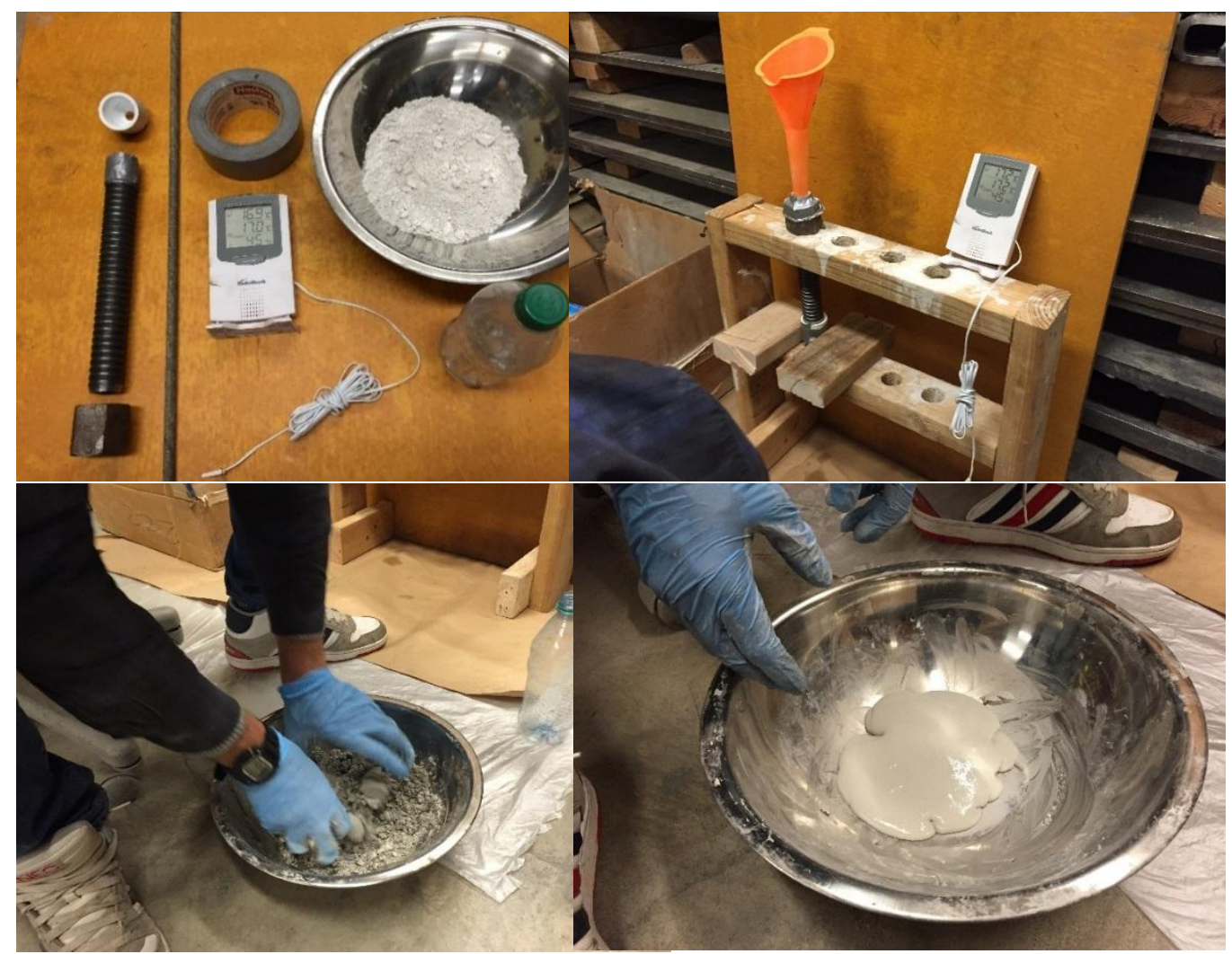

Figure 3.6 Casting process to attach the anchorage steel tube 

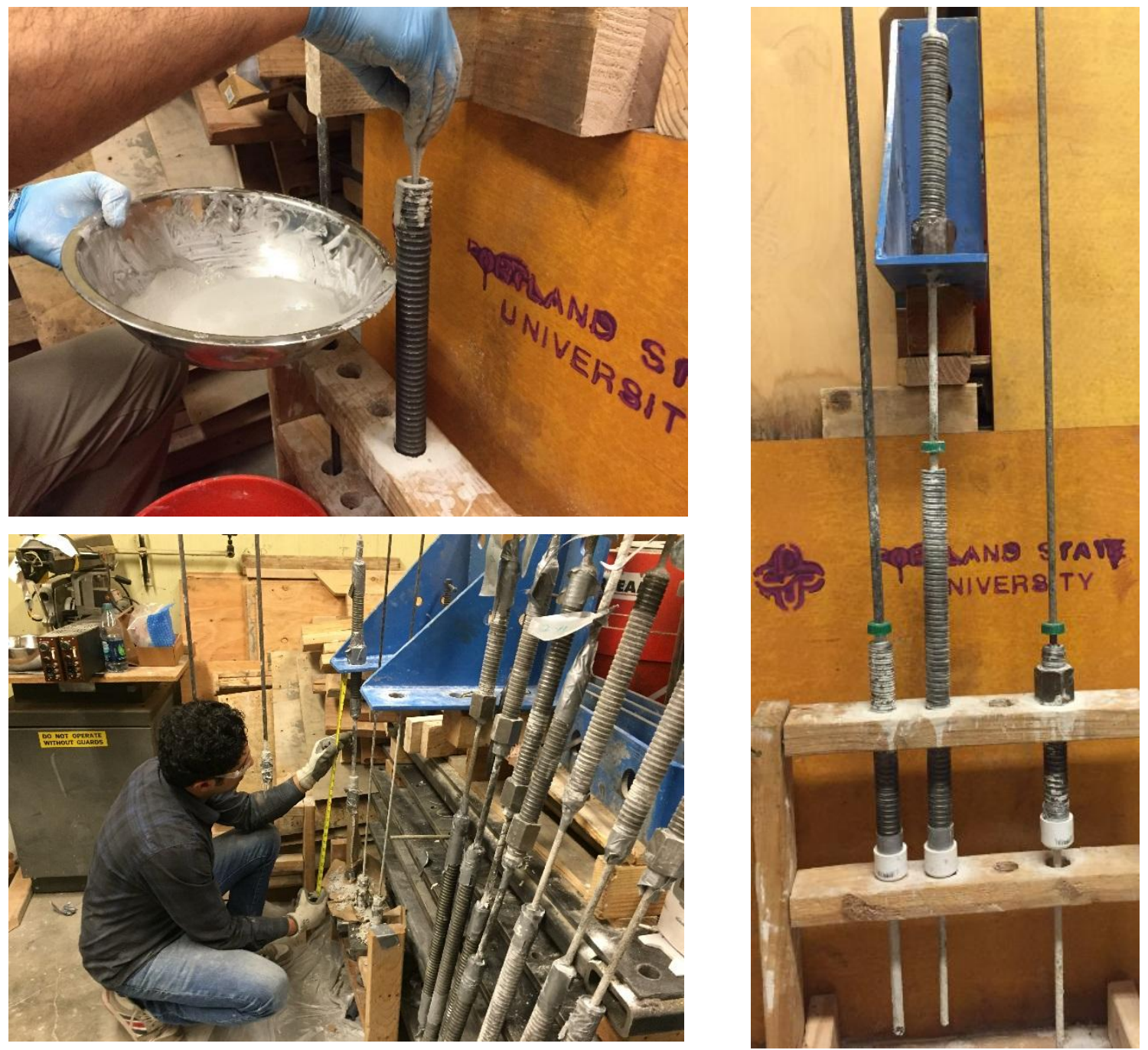

Figure 3.6 Continued

The work started with cleaning the internal wall of the steel tube with a wet piece of paper.

When the steel tube was ready, it was placed vertically in the wood frame. The steel tube sat on a PVC cup, which was supported by the wood frame. The PVC cup had a hole at the center where the CFRP strand went through. The PVC cup was very important because it kept the CFRP strand centered, and it held the expansive gout while it was in the liquid 
stage. Duct tape was used to provide good confinement between the PVC cup and the steel tube. The mixing of the expansive grout and the water started after everything was set-up and ready. A predefined weight of the expansive grout and water was placed in a metal bowl. It was the preferred method in this study to add the water to the grout in two to three stages. This made it easier to mix, and made it less likely that some drops of water would be lost during mixing. The mixing time was two to three minutes until the mixture looked very soft, and the feature of expansion was clearly visible. Then, the steel tube was filled with the water-grout mixture. After filling the steel tube with the grout, the CFRP strand was inserted all the way to the bottom of the steel tube going through the hole of the PVC ensuring that the CFRP strand was in the center at the bottom. A plastic cup was used at the top of the steel tube to ensure that the CFRP strand was also at the center at the top side. The anchorage system was then left for curing. Usually, and depending on the manufacture data, it was flipped over to anchor the other end of the CFRP strand after three days.

Two bond lengths for the \#4 strands were investigated in this study. The bond lengths are 12 " and 15". The other ends of all the samples were anchored with $20 \mathrm{in.}$ bond length. The CFRP free length between the steel tubes was 9" for all the specimens because that was the only dimension that fit the testing set-up. Approximately 5 in. to 10 in of the CFRP strand were left at the ends as a free length to hold the LVDT that was used for slippage measurements. Fig.3.7 shows a typical specimen for anchorage system investigation. 


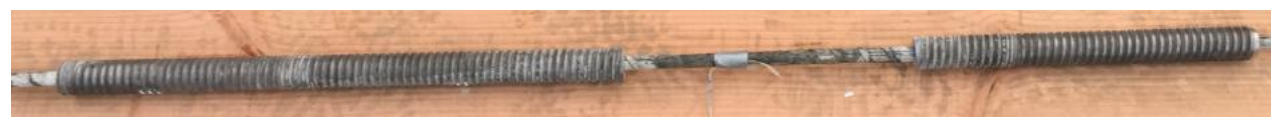

CFRP

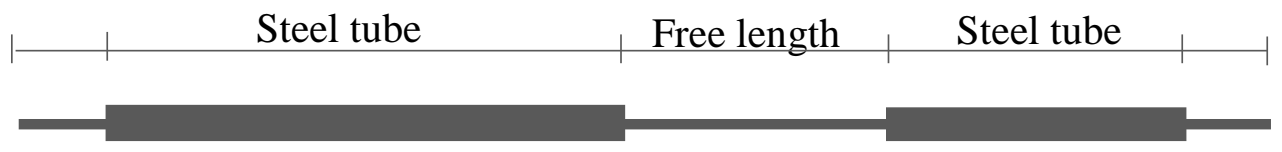

\begin{tabular}{llllll} 
(a) & (b) & (c) & (d) & (a) \\
\hline
\end{tabular}

(a): Free length of CFRP at the ends (5 in. to $10 \mathrm{in.})$

(b): Steel tube anchor; fixed end (20 in.)

(c): Free length of CFRP at the middle (9 in.)

(d): Steel tube anchor; the focused area (12 in. and 15 in.)

Figure 3.7 A typical sample for anchorage testing

\subsubsection{Test Setup and Instrumentation}

The aim of this part of the experimental tests was to investigate the efficiency of the anchorage system before using it in the prestressed concrete beams. In addition, further information about the material properties of the CFRP strands could be obtained from this test. This part of the experiment also provided a good start for future experiments using this anchorage system for pre-tensioned and post-tensioned prestressed concrete applications. Figure 3.8 shows the anchorage system, test setup and instrumentation.

The loaded end of the prestressing bed, which was used for casting the prestressed concrete beams, was used to test the anchors. The loaded end was designed as two 20-in. long and 1/2-in. thick steel plates welded longitudinally to the wide-flange steel beam (casting bed), 
see Figure $3.8(\mathrm{G})$. The other two 1-in.-thick steel plates, as shown in Figure $3.8(\mathrm{H})$, were welded transversely across the longitudinal two steel plates. This created a kind of a box of steel plates in the middle of the system. The extension of plates worked like stiffeners for the transverse plates, and provided a house for the hollow-core ram, which was used to apply the jacking force. The two transverse plates had a hole at the center allowing the steel anchors to go in and out from the hollow-core ram to the locking end. The hollow-core ram was placed to push against a 1.5-in.-thick plate that transferred the load to the two longitudinal plates. The distance between the 1.5-in.-thick plate and steel box of the transverse plates provided a space for locking the load using a hex nut. On the other end, a hex nut was also used to provide a fixed end against the force applied by the ram. A number of pictures, showing the test set-up and instrumentations, are provided in Figure 3.8.

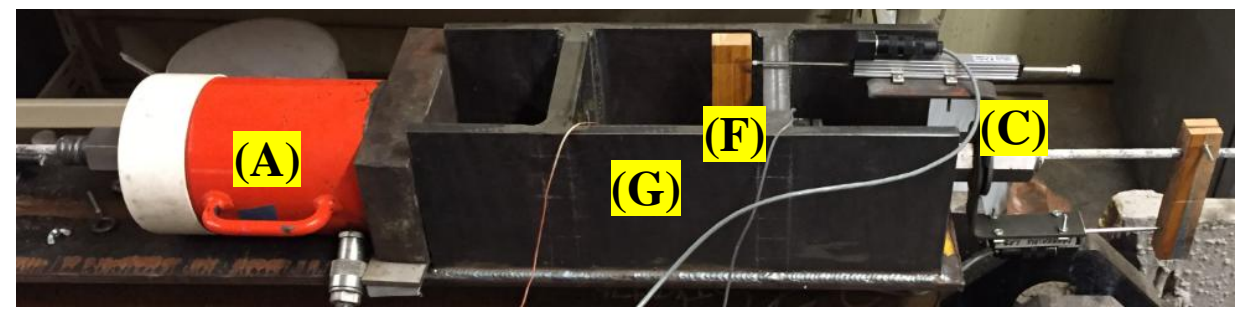

(1)
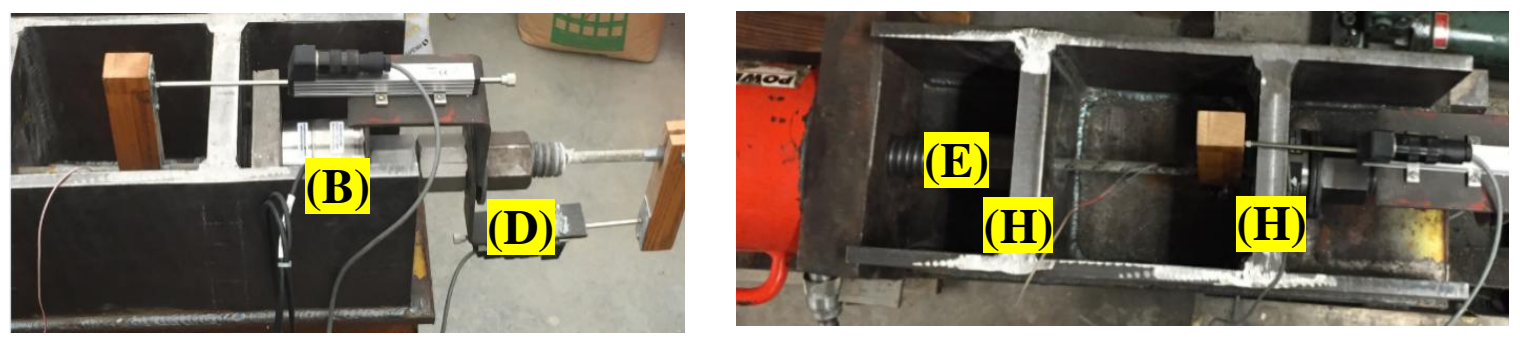

Figure 3.8 Anchorage system - Test setup and instrumentations 
Where;
(A): Hollow core ram
(B) : Load cell
(C) : LVDT-1
(D): LVDT-2
(E) : Hex nut
(F) : Piece of hard wood transferring the movements of the CFRP to the LVDTs.
(G) : Longitudinal steel plate; 20 x 7 x 0.5 ".
(H): Transverse steel plate; 7 x 6 × 1".

Figure 3.9 shows a schematic drawing of test set-up for anchors tensile tests. The load was applied using a hollow-core ram (10000 psi). The ram was connected to a hand-controlled hydraulic pump. The load was recorded using a through-hole compression load cell, the capacity of which was equal to $150,000 \mathrm{Ib}$. It was a strain gauge based load cell converting the pressure into an electrical output. The manufacturer, Omega Engineering Inc., promises that the accuracy of this load cell is within $0.03 \%$ to $0.25 \%$. The axial strain in the CFRP rods was measured using linear, 20-mm long, $120 \Omega$, pre-wired strain gauges. One strain gauge, attached at the middle of the free length of the CFRP rod between the dead and loading ends, was used for each sample. The slippage was measured using Linear Variable Differential Transformers (LVDTs). LVDT-2 was used to measure the end slip, while LVDT-1 was used to measure the slippage where the force was applied as shown in Figure 3.9. All of the data, like force, strain, and slippage, were collected using USB-type voltage data loggers. The data loggers were connected to the computers to present and save the collected data using their special software program. 


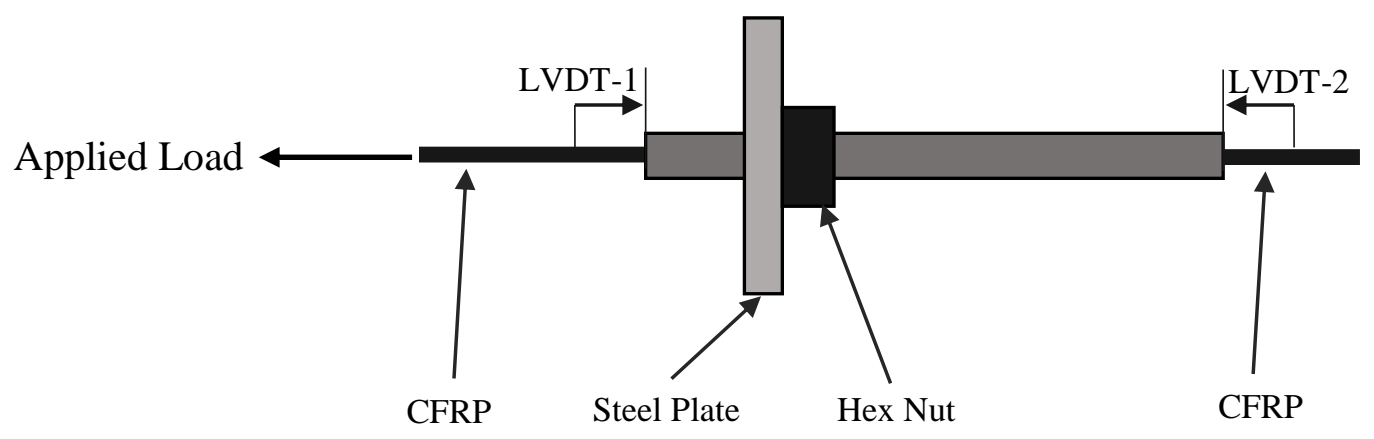

Figure 3.9 Schematic drawing showing the test set-up for anchors tensile tests

\subsubsection{Testing Program}

The load was applied using the hollow-core ram and the hand-controlled pump. A load rate of $1 \mathrm{~mm} / \mathrm{min}$ was used for this short-term test. Many guidelines are available for testing the anchorage systems for FRP, but for this study the procedure recommended by Schmidt et al. (2010) was adopted. This procedure recommends to go from zero load to $20 \%$ of the maximum capacity of the CFRP strands, and then stop for five minutes. Then, the load is increased with constant load rate to $50 \%$. After waiting another five minutes, the load should be increased to $70 \%$. The load of $70 \%$ of the maximum capacity should be kept constant for an hour. After that, the load should be increased monotonically until failure. The loading procedure is shown in Figure 3.10 below. 


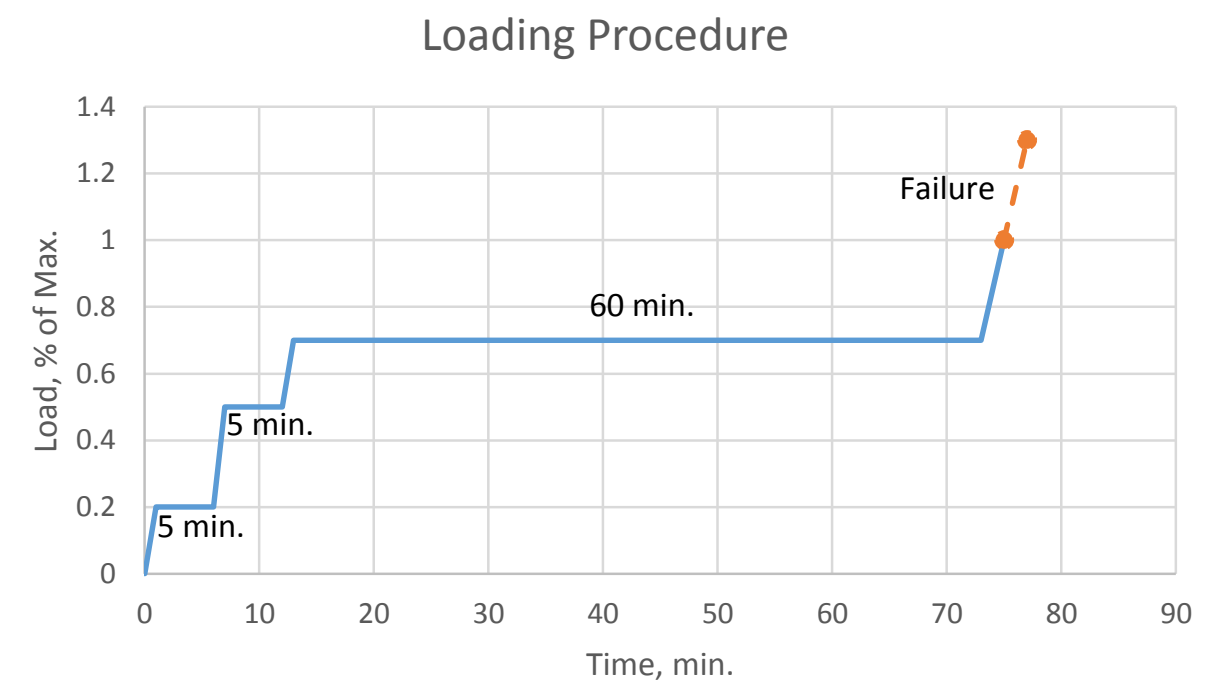

Figure 3.10 Loading procedure for anchors tensile tests

\subsection{Flexural Test for Prestressed Beams}

The experimental program was carried out to investigate the flexural performance of prestressed concrete beams pre-tensioned with CFRP strands. The study focused on experimentally determining the load deflection curves of the CFRP prestressed concrete beams. These responses were compared to the predicted response of prestressed concrete beams pre-tensioned with CFRP strands. Moreover, the flexural tests also provided more knowledge about the bond properties between CFRP strands and the surrounding high strength concrete. 


\subsubsection{Specimen Selection}

Approximately third-scaled rectangular prestressed concrete beams were designed and fabricated in the laboratory. The geometry of the third scale specimens, which were fabricated in the laboratory, is as shown in Figure 3.11. The total length and the clear span of all of the specimens was $14 \mathrm{ft}$. and $13.5 \mathrm{ft}$., respectively. Each specimen represented a prototype prestressed concrete beam with a clear span equal to $40.5 \mathrm{ft}$. The cross section width and height of the prototype beam was $16.5 \mathrm{in}$. and 30 in., respectively. All the beams were reinforced with one \#4 CFRP strand. The eccentricity of the CFRP strands was 3.5 in., which corresponded to an effective depth (d) equal to $8.5 \mathrm{in}$. This provided a prestressing reinforcement ratio of 0.0042 . The balanced ratio is defined as the prestressing ratio where the concrete strain reaches 0.003 and the FRP reaches its maximum tensile strength simultaneously. The balanced ratios for the four beams were less than 0.0042 , as shown in Table 3-3. Therefore, the expected failure was concrete crushing in the compression zone. It has been recommended by previous researchers, including the ACI guidelines for FRP reinforcement, that the desired mode of failure is concrete crushing in compression because it is more ductile than CFRP rapture. The ratio, though, was kept close to the balanced ratio because it was beneficial for this research to push the CFRP close to its ultimate strength for investigation purposes. 

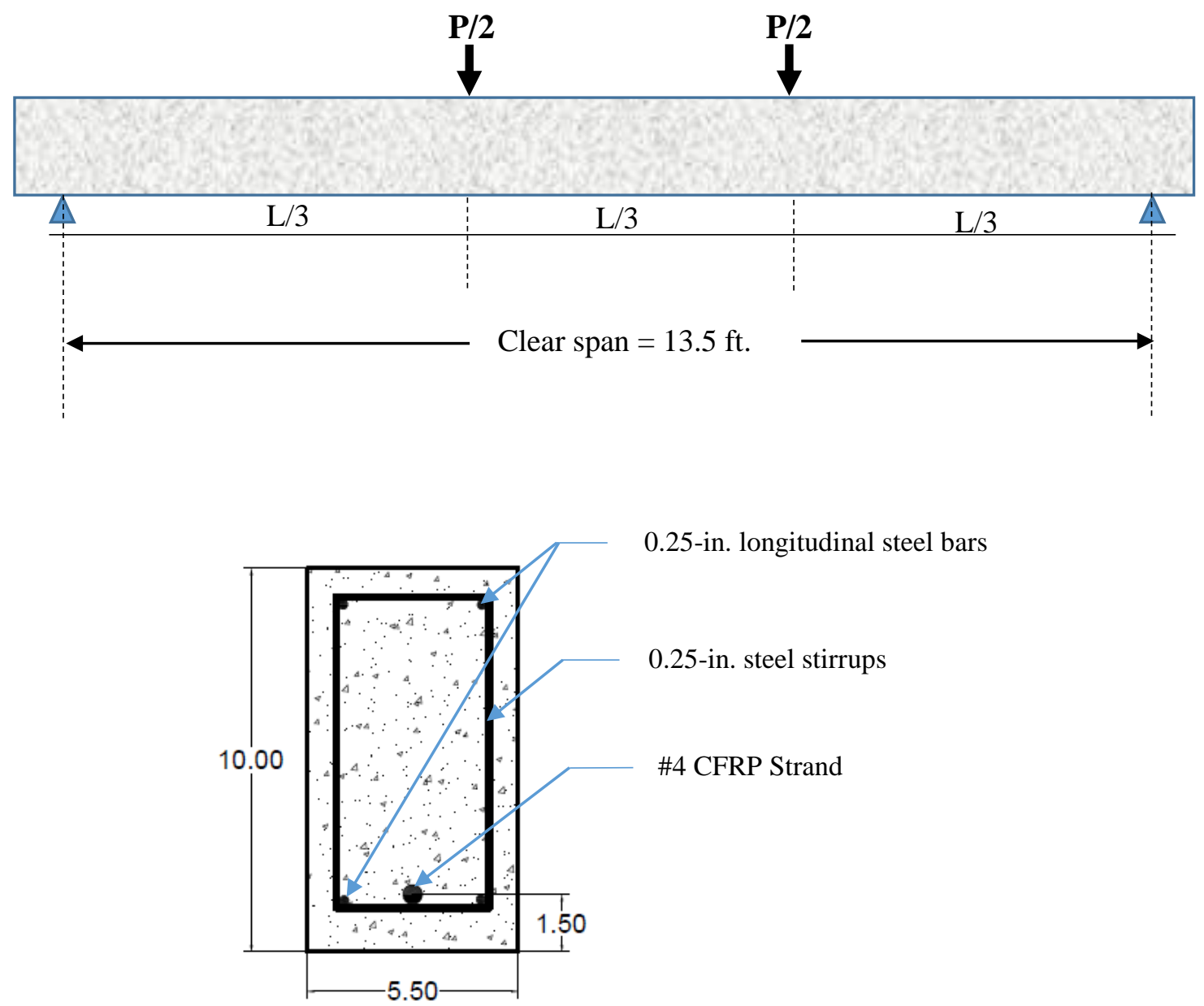

Figure 3.11 Cross-sectional geometry and beam length profile of the prestressed concrete beams 


\begin{tabular}{cccccccccc}
\hline Beam & Actual cross & \multicolumn{4}{c}{ Prestressing Reinforcement } & \multicolumn{3}{c}{ Shear Reinforcement } \\
\cline { 3 - 9 } label & section & Prestressing & $\mathrm{d}$ & $\rho$ & $\rho_{b}$ & Size & S @ shear & S @ mid- \\
& b x h (in.) & level (\%) & (in.) & & & (in.) & zone (in.) & span (in.) \\
& & & & & & & & & 6 \\
\hline B1-4-65 & $5.5 \times 9.75$ & 65 & 8.25 & 0.0043 & 0.0039 & 0.25 & 6 & 6 \\
\hline B2-4-55 & $5.5 \times 10.0$ & 55 & 8.5 & 0.0042 & 0.0035 & 0.25 & 3 & 6 \\
\hline B3-4-60 & $5.5 \times 10.0$ & 60 & 8.5 & 0.0042 & 0.0036 & 0.25 & 2 & 6 \\
\hline B3-4-60 & $5.5 \times 10.0$ & 60 & 8.5 & 0.0042 & 0.0038 & 0.25 & 3 & 6 \\
\hline
\end{tabular}

Table 3-3 Design details of the prestressed concrete beams

The shear reinforcement design for the first beam was based on ACI 318-14 Building Code. The design based on the minimum shear reinforcement for prestressed concrete beams with steel strands called for spacing between the stirrups to be $75 \%$ of "d." Herein, " $0.75 * \mathrm{~d}$ " is equal to 6.4 in. on centers (O.C.). A spacing of 6.00 in. O.C. was used for the first beam. On the other hand, the shear reinforcement for the second beam was twice as much as the first beam (Spacing = 3 in., c-t-c). The spacing of the stirrups was changed only at the shear span. The spacing at the maximum moment region, between the point loads, was always 6 in. for all beams because the shear force was equal to zero in this region. In order to improve the bond characteristics, the spacing between stirrups was reduced to 2 in. for Beam \#3. For comparison reasons, a new technique was developed for Beam \#4 to solve the bond issues, so that the shear reinforcement was made exactly the same as for Beam \#2. 


\subsubsection{Material Properties}

\subsubsection{Concrete}

For each beam and its cylinders, four to five concrete batches were made because the capacity of the concrete mixer in the laboratory is $2.25 \mathrm{ft}^{3}$. At least two cylinders were taken for each mixture. On average nine cylinders were cast for each beam. Figure 3.12 shows casting of concrete cylinders. The design of the concrete mixtures was based on PCA (2002)/ Designing and Proportioning Normal Concrete Mixtures. It was preferred in this study to test the beams when the concrete capacity was not less than $7000 \mathrm{psi}$. The mixture was designed to achieve 8000 psi on the 28th day. However, all of the beams were tested at an age of less than 28 days, mostly at 21 days. The desired slump, which provided good workability and did not reduce the capacity, was 6.5 in.

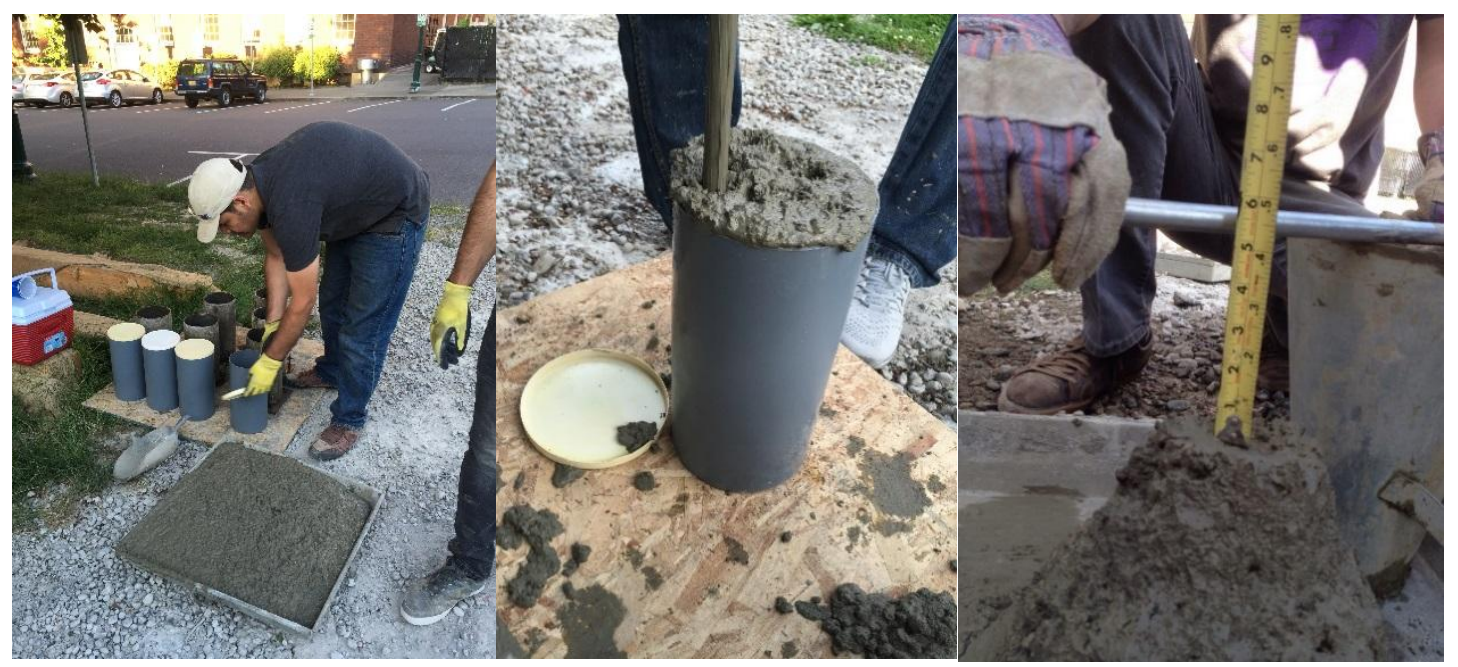

Figure 3.12 Casting of concrete cylinders

Three groups of experimental tests were conducted for concrete material: 


\section{(A) Concrete compressive strength}

(B) Modulus of Elasticity

\section{(C) Flexural Strength of Concrete}

The concrete compressive strength for each mixture is presented in Table 3-4. For each beam, at least three cylinders were tested on the day of releasing the prestressing force, and the other three cylinders were tested on the day of the flexural test. The rest of the cylinders were used to determine the modulus of elasticity of the concrete.

The modulus of elasticity was experimentally determined based on ASTM Standard C469 (2002), "Standard Test Method for Static Modulus of Elasticity and Poisson's Ratio of Concrete in Compression." The strain of the concrete was measured using two LVDTs attached by compressometer frame. The results were compared with the modulus of elasticity predicted by ACI Committee 318 (2014). Table 3-5 presents the results for experimental and theoretical modulus of elasticity of concrete.

\begin{tabular}{|c|c|c|c|c|c|c|c|c|c|c|}
\hline Beam & At fo & release & & & & At the & ay of $t$ & & & \\
\hline label & Mix1 & Mix2 & Mix3 & Mix4 & Avg. & Mix1 & Mix2 & Mix3 & Mix4 & Avg. \\
\hline B1-4-65 & 6703 & - & 6817 & 6224 & 6581 & 7056 & 7009 & - & 7484 & 7183 \\
\hline B2-4-55 & 6950 & 6900 & 7000 & - & 6950 & 7600 & 7409 & 7945 & 7593 & 7637 \\
\hline B3-4-60 & 7430 & 7140 & - & 5800 & 6790 & 7600 & 7363 & 7041 & 7070 & 7269 \\
\hline B4-4-60 & 7337 & 7365 & - & - & 7351 & 7726 & - & 7342 & 7726 & 7518 \\
\hline
\end{tabular}

Table 3-4 Concrete compressive strength 


\begin{tabular}{|c|c|c|c|c|c|}
\hline Beam & Avg. Unit & Avg. $\boldsymbol{f}_{\boldsymbol{c}}^{\prime}$ & Avg. & ACI 318-11/ Eq.1 & ACI 318-11/ Eq.2 \\
\hline label & weight $\left(\mathrm{lb} . / \mathrm{ft}^{3}\right)$ & (psi) & Experimental & $(\mathrm{ksi})^{*}$ & $(\mathrm{ksi}) * *$ \\
\hline \multicolumn{6}{|c|}{ Modulus E (ksi) } \\
\hline B1-4-65 & 138.26 & 7183 & 5921 & 4547 & 4831 \\
\hline B2-4-55 & 138.88 & 7637 & 6040 & 4720 & 4981 \\
\hline B3-4-60 & 139.90 & 7269 & 6000 & 4656 & 4860 \\
\hline B4-4-60 & 141.84 & 7518 & 6122 & 4833 & 4942 \\
\hline
\end{tabular}

*ACI 318-14/Eq.1: $E=W c^{1.5} 33 \sqrt{f c^{\prime}}$ (psi)

$* * A C I$ 318-14/Eq.2: $E=57000 \sqrt{f c^{\prime}}$ (psi)

\section{Table 3-5 Concrete modulus of elasticity}

The flexural strength of the concrete was determined by testing a simple concrete beam with third-point loading. The beam dimensions ( $\mathrm{b} \times \mathrm{h} \times \mathrm{L})$ are $6 \times 6 \times 18$ in. ASTM Standard C78 (2008), "Standard Test Method for Flexural Strength of Concrete (Using Simple Beam with Third-Point Loading)" was used as a guideline for this test. Figure 3.13 shows the schematic drawing of concrete flexural strength test.

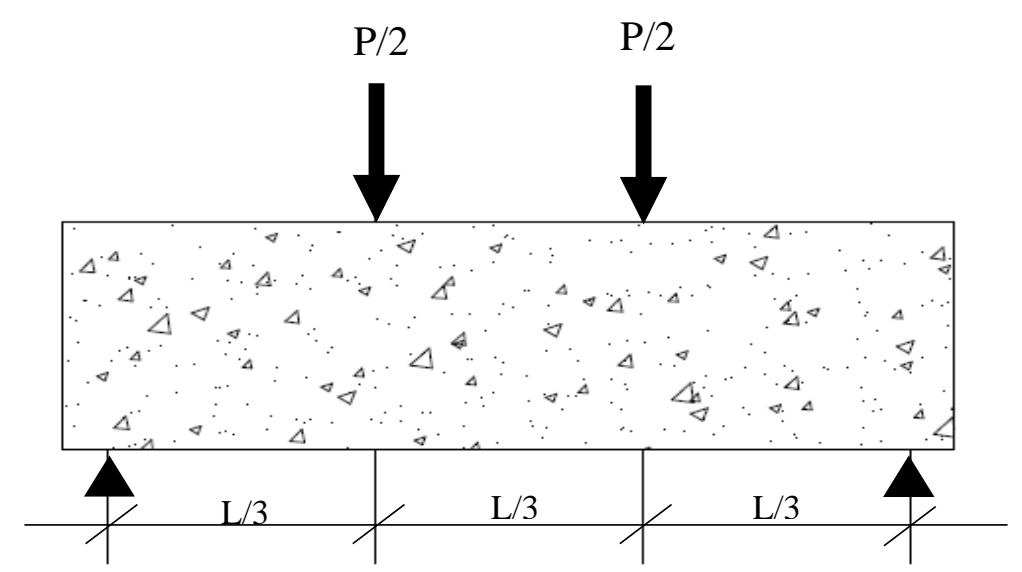

Figure 3.13 Schematic drawing for concrete flexural strength test 
The modulus of rupture $(\mathrm{R})$ is defined as the tensile stress when the concrete cracks and the specimen fails. It is calculated using the simple linear equation for stresses as shown below. The dimensions ( $\mathrm{b} \times \mathrm{h} \times \mathrm{L}$ ) of the specimens were $6 \times 6 \times 18$ in., as specified by ASTM Standard C78 (2008). Table 3-6 shows the experimental and ACI values for the modulus of rupture.

Stress at the bottom of the concrete section $=\mathrm{Mc} / \mathrm{I}=\mathrm{R}$

$\mathrm{R}=\mathrm{P} \mathrm{L} / \mathrm{b} \mathrm{h}^{2}$

Where:

M: The applied moment $=(\mathrm{P} / 2)(\mathrm{L} / 3)$

c: The distance from the centroid of the concrete cross section to the extreme bottom fiber $=\mathrm{h} / 2$

I: The moment of inertia $=\mathrm{bh}^{3} / 12$

$\mathrm{R}$ : The modulus of rupture

P: The maximum applied load

L: The span length of the specimen

b: The cross section width at the location of failure

$\mathrm{h}$ : The cross section height at the location of failure 


\begin{tabular}{cccccc}
\hline Beam label & $\boldsymbol{f}_{\boldsymbol{c}}^{\prime}$ (psi) & $\mathrm{b} \times \mathrm{h}$ (in.) & $\boldsymbol{P}_{\boldsymbol{m a x} .}(\mathrm{Ib})$ & $\mathrm{R} *(\mathrm{psi})$ & ACI 318-11** \\
\hline B2-4-55 & 7637 & $6.25 \times 5.94$ & 5030 & 822 & 655 \\
\hline B3-4-60 & 7158 & $6.40 \times 6.00$ & 4,450 & 698 & 635 \\
\hline B4-4-60 & 7518 & $6.00 \times 6.00$ & 4,633 & 722 & 650 \\
$* R=$ Modulus of Rupture & & & \\
$* *$ ACI modulus of rupture $=7.5 \sqrt{f_{c}^{\prime}}($ psi).
\end{tabular}

Table 3-6 Modulus of rapture

Figure 3.14 shows some photos of the three mechanical tests for concrete as described above.
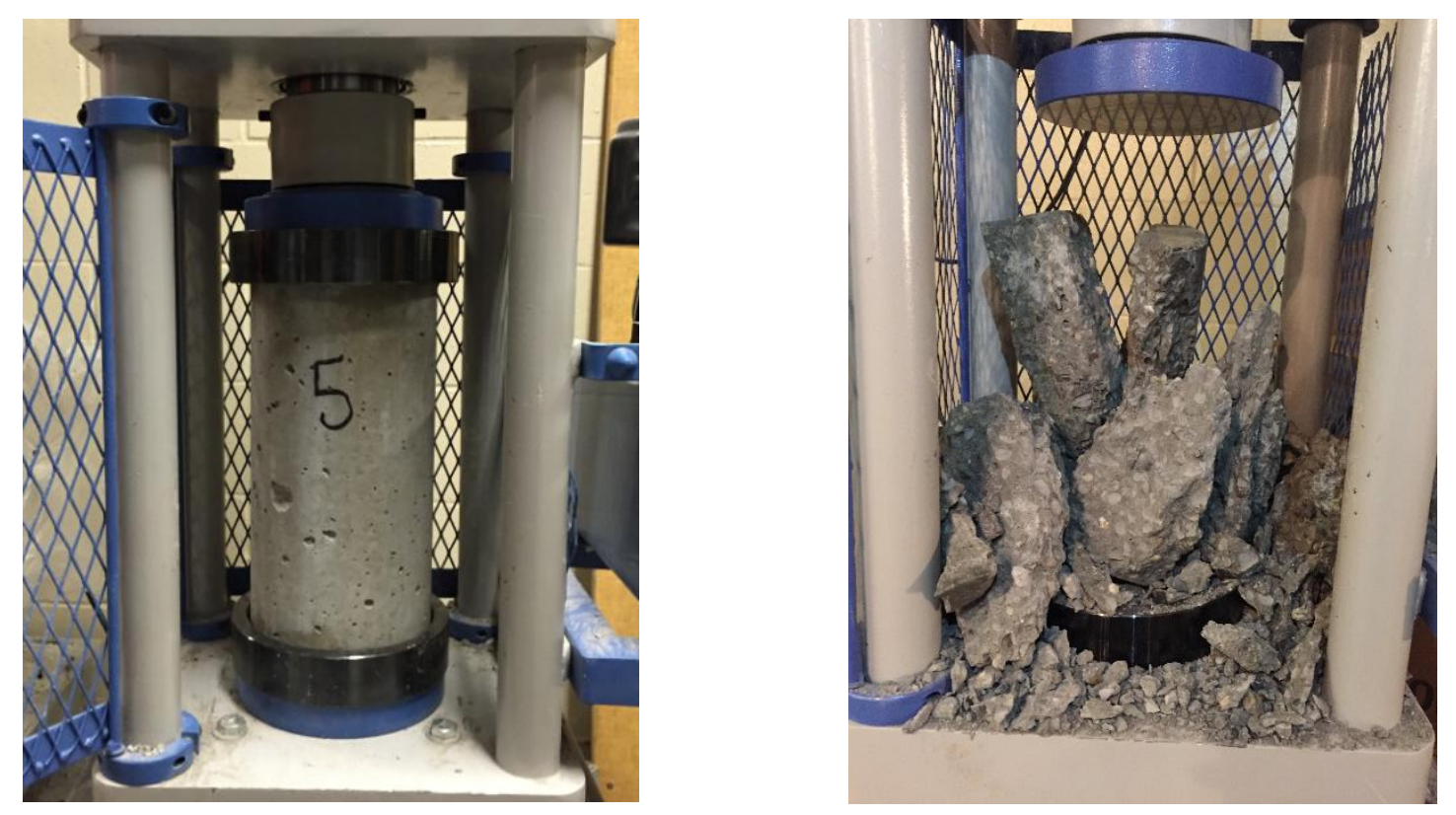

(A) Concrete compressive strength

Figure 3.14 Mechanical tests for concrete 

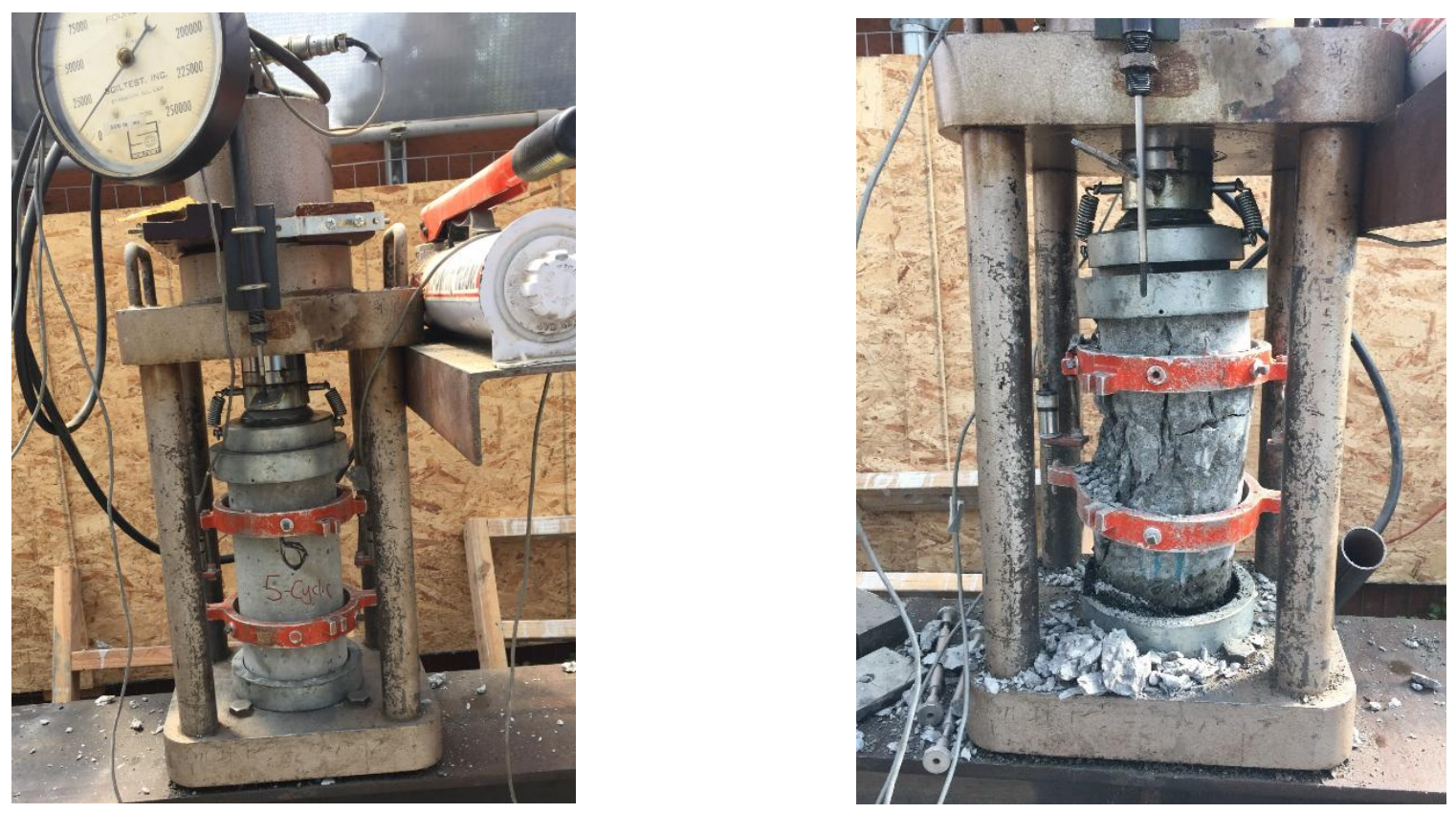

(B) Modulus of Elasticity
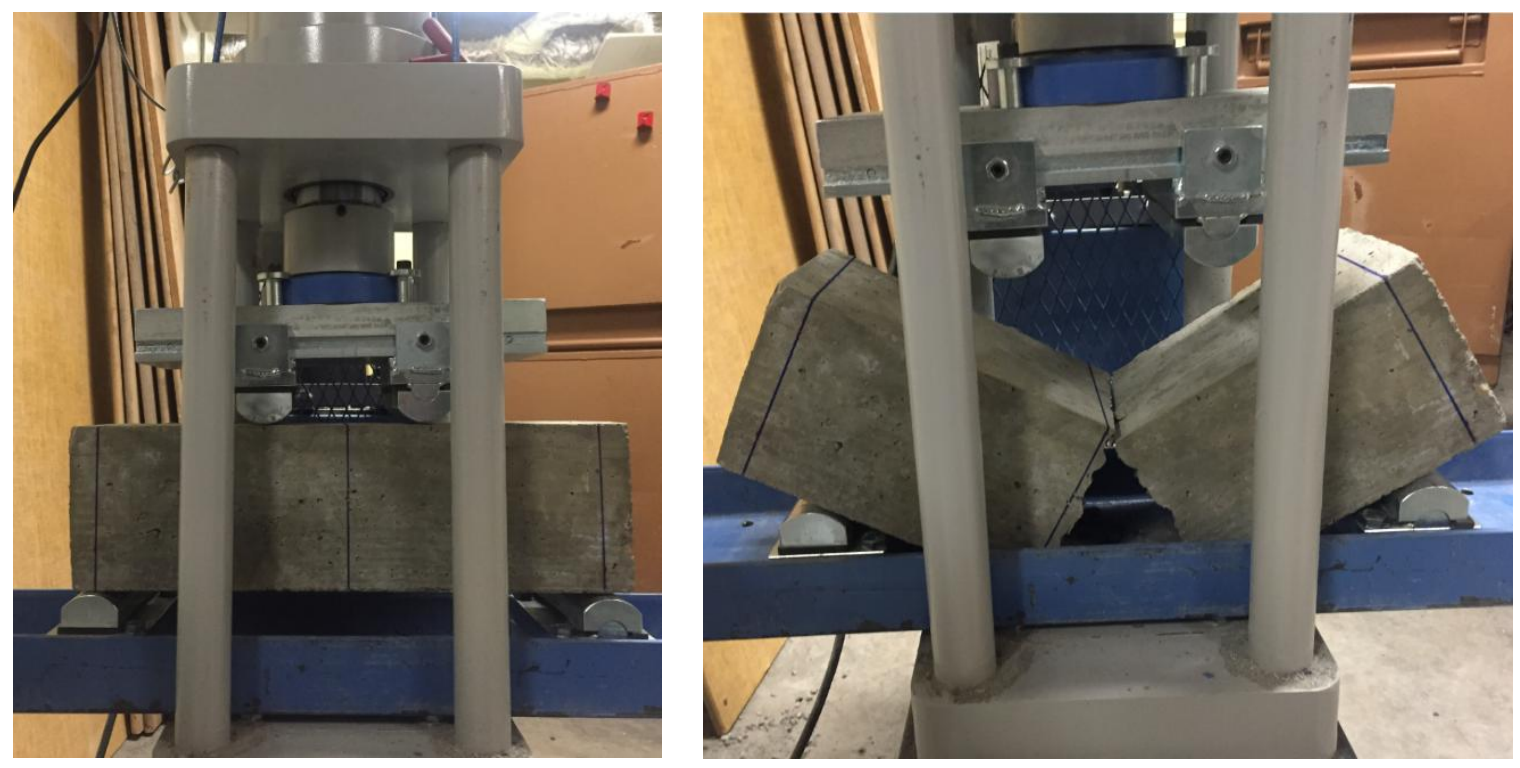

(C) Flexural Strength of Concrete

Figure 3.14 Continued 


\subsubsection{CFRP Strands}

The CFRP strands that were used for prestressing the concrete beams were the same as those used for anchorage system test as previously described in section 3.3.2. The properties of each strand used for each beam were determined during the pre-tensioning process. The length of each strand was $18.5 \mathrm{ft}$., including the two steel anchors at the ends. During the pre-tensioning process, the data of the force and strain were collected. The readings of the jacking force versus an average of nine strain gauges were recorded until the desired jacking force level was achieved. These data were used to determine the stressstrain relationship of each strand for each beam as shown in Figure 3.15. In Figure 3.15, the solid lines represent the measure stress vs. the strain, while the dotted lines are based on constant $\mathrm{E}$ values depending on the slope between the strain of $0.1 \%$ and $0.3 \%$, as specified by ASTM Standard D7205/D7205M (2011). The guaranteed capacity by the manufacturer (300 ksi) and the actual test value (330 ksi) are shown. 
(A) Beam1-4-65

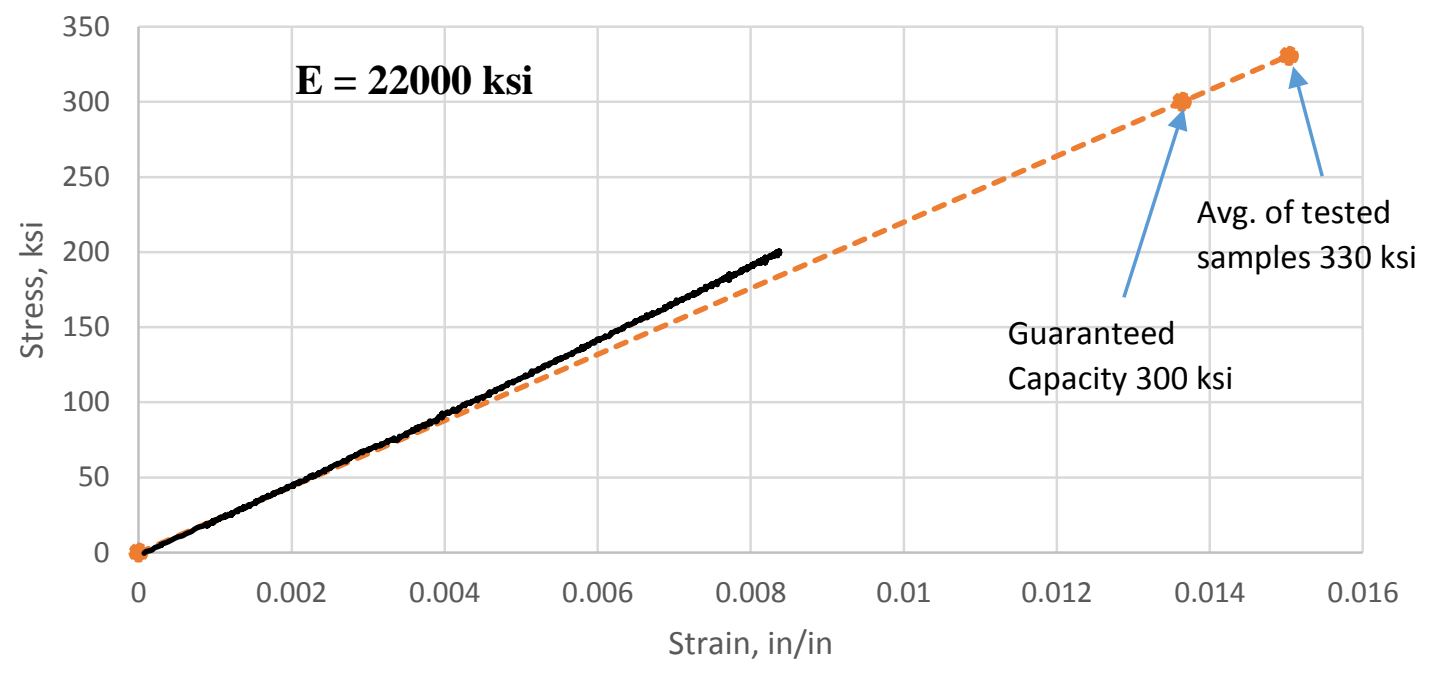

$--\cdot$ Constant $\mathrm{E} \longrightarrow$ Avg. of strain gauges

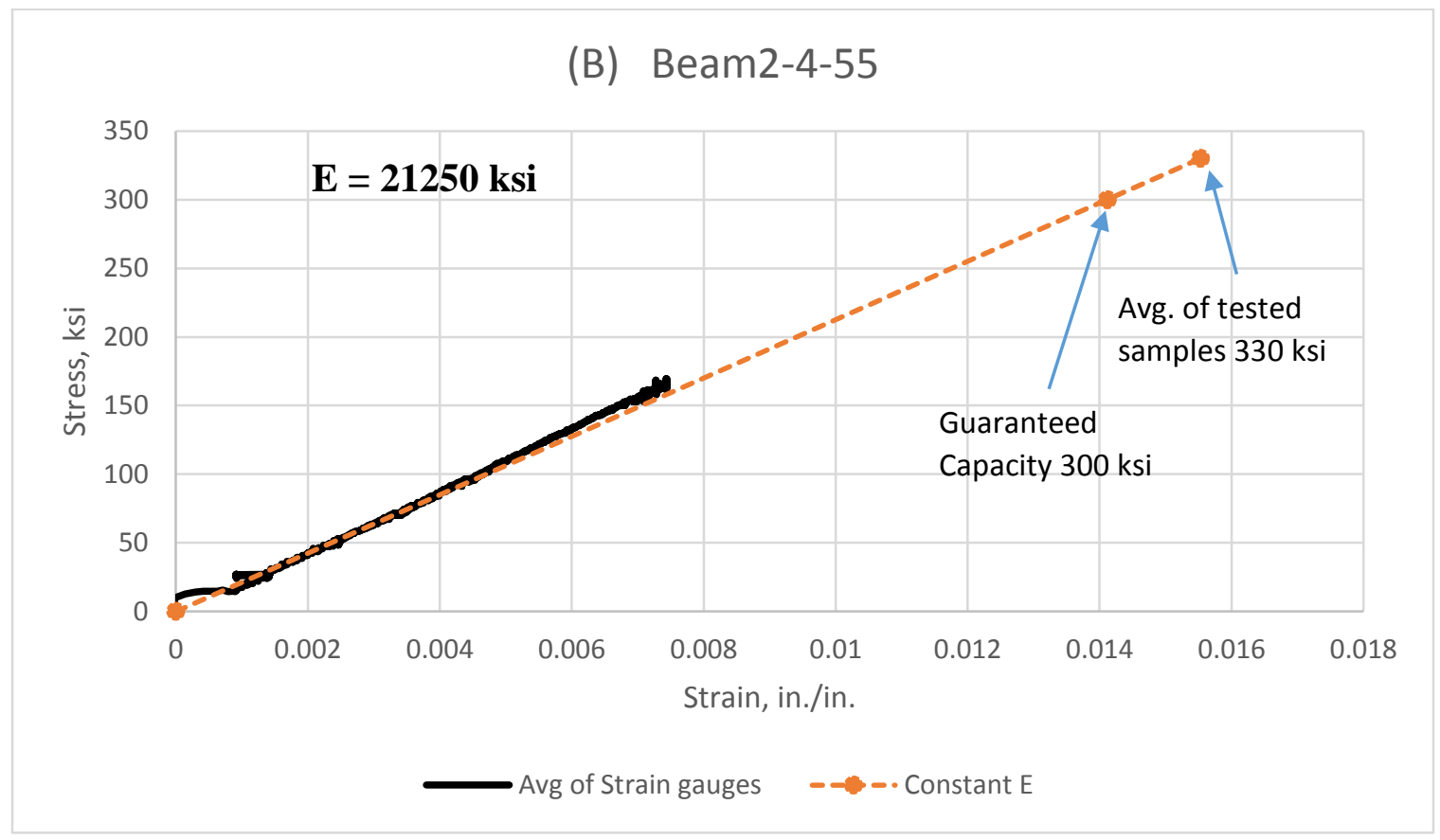

Figure 3.15 Stress-strain relationship for CFRP strands during the pre-tensioning process 
(C) Beam3-4-60

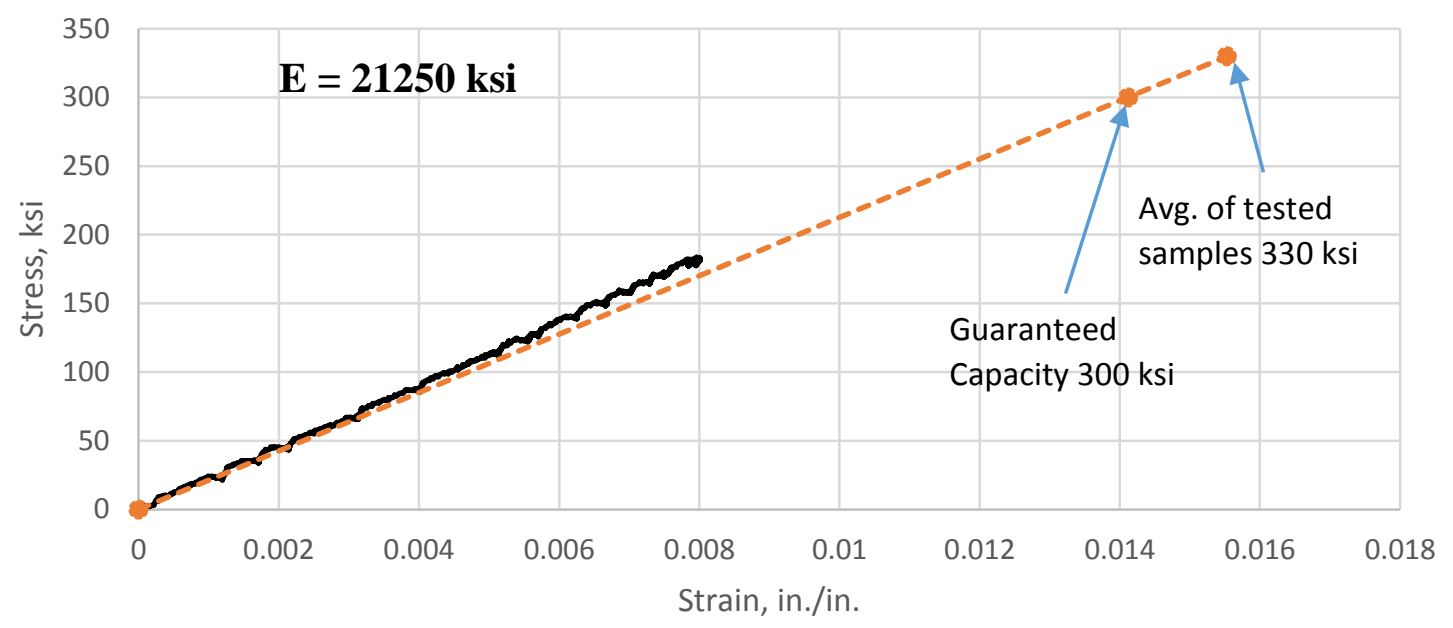

$\longrightarrow$ Avg. of strain gauges $\quad-\infty-\cdots$ Constant $E$

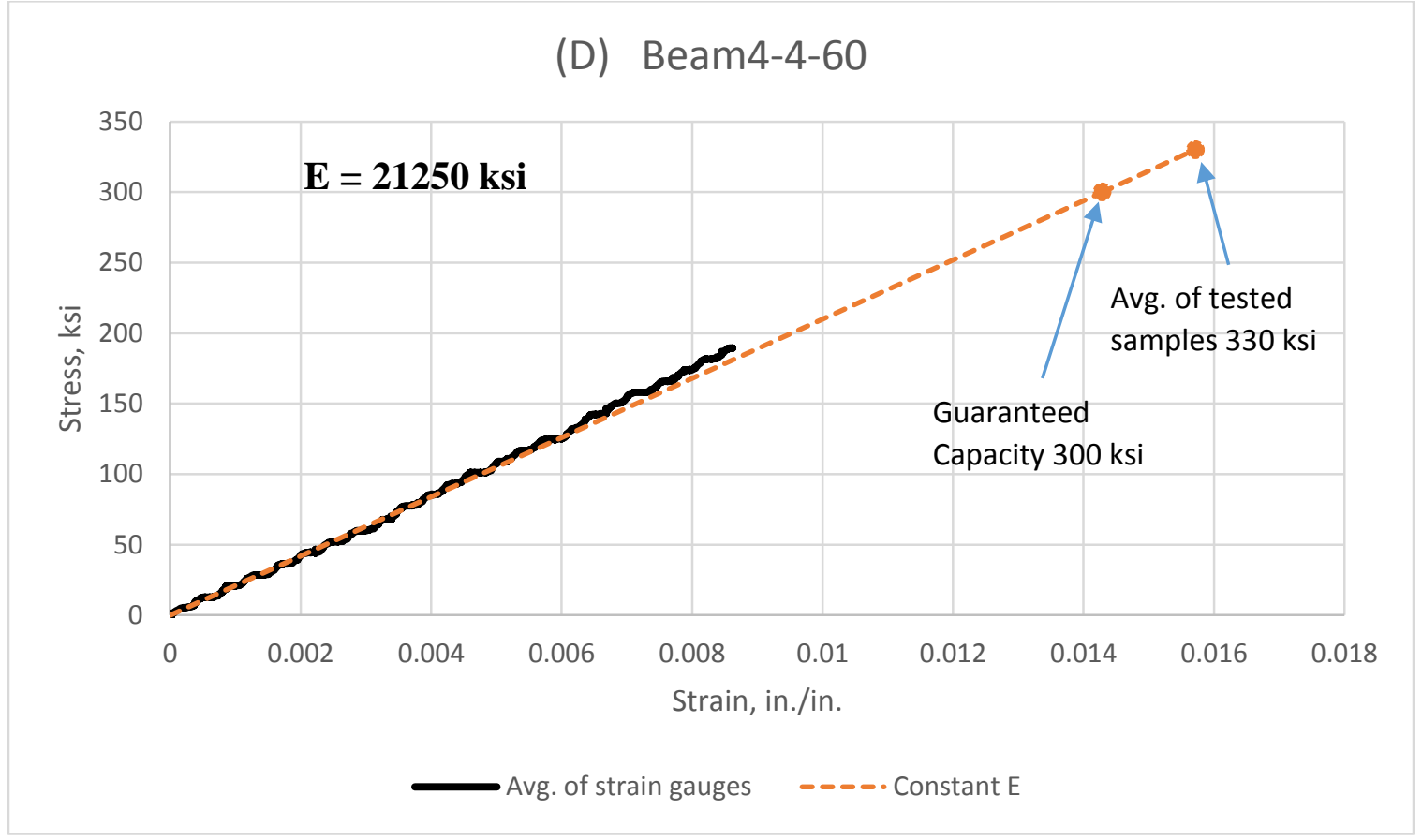

Figure 3.15 Continued 


\subsubsection{Steel Rebars (D5) for Shear Reinforcement}

Deformed steel reinforcement bars (rebars), commercially known as D5, were used to create the steel cage for shear reinforcement. The letter " $\mathrm{D}$ " means that the rebars are deformed. The diameter of D5 rebars is 0.25 in. D5 rebars were used for both the stirrups and the longitudinal reinforcement in the steel cage. The provider has tested this material and reports that the breaking capacity of D5 is $109 \mathrm{ksi}$. To the author's knowledge, there have been no previous reports about its yielding strength.
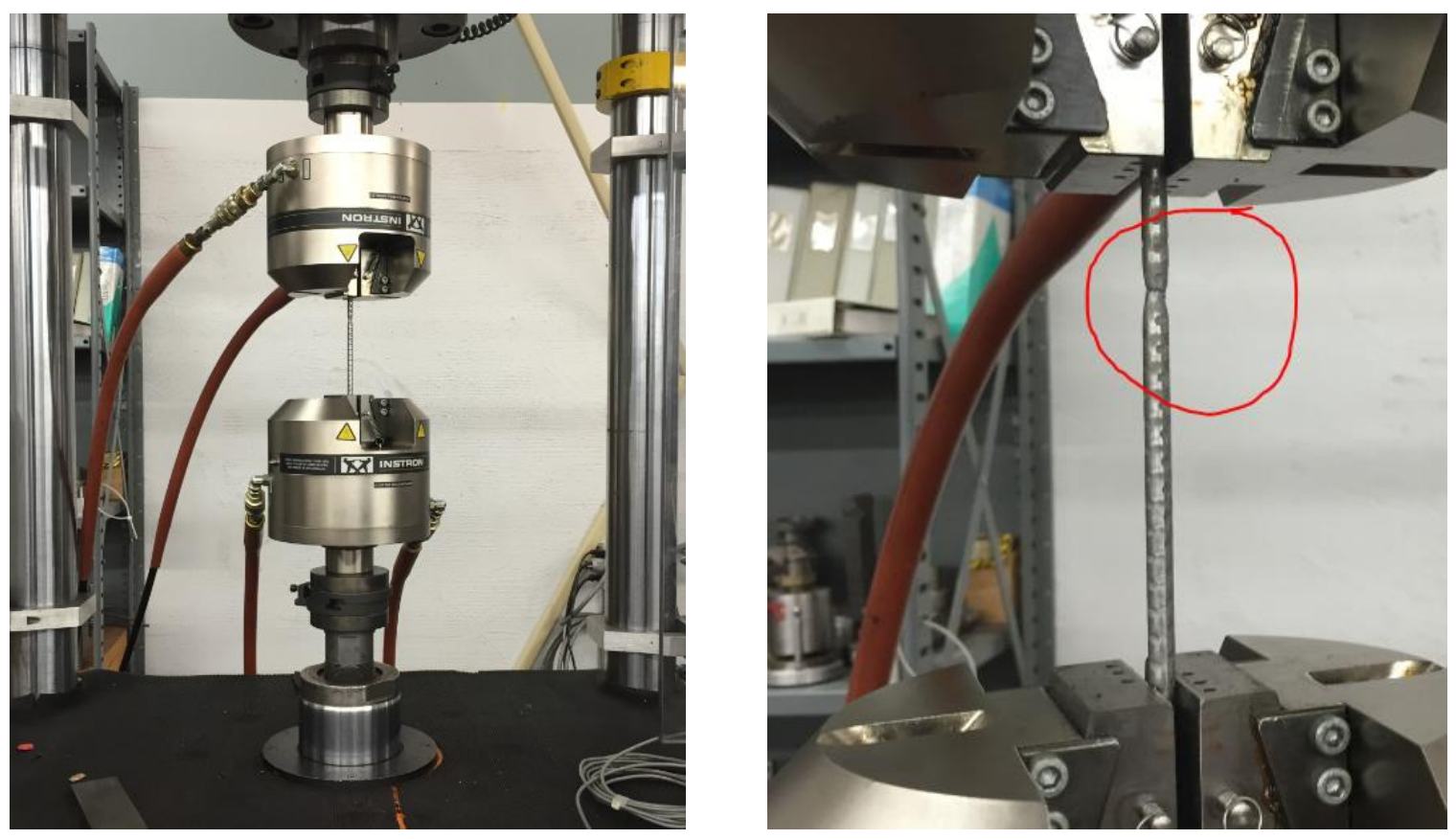

Figure 3.16 Test set-up for D5 stress strain tests 
ASTM tensile tests for the steel rebar (D5) were conducted in the laboratory of Mechanical and Materials Engineering/ Portland State University. The test was performed using a 100kip loading frame. The top grip was fixed, but the bottom grip moved downward while the load was increased. The strain was measured by determining the stroke displacement. Figure 3.17 presents the stress-strain curves for two samples. The results show that the breaking strength was about $100 \mathrm{ksi}$, which was close to the value reported by the supplier. It can be observed from the test results that the yielding strength of D5 was around $70 \mathrm{ksi}$. However, the design of shear reinforcement of the specimens assumed the yielding stress of $60 \mathrm{ksi}$.

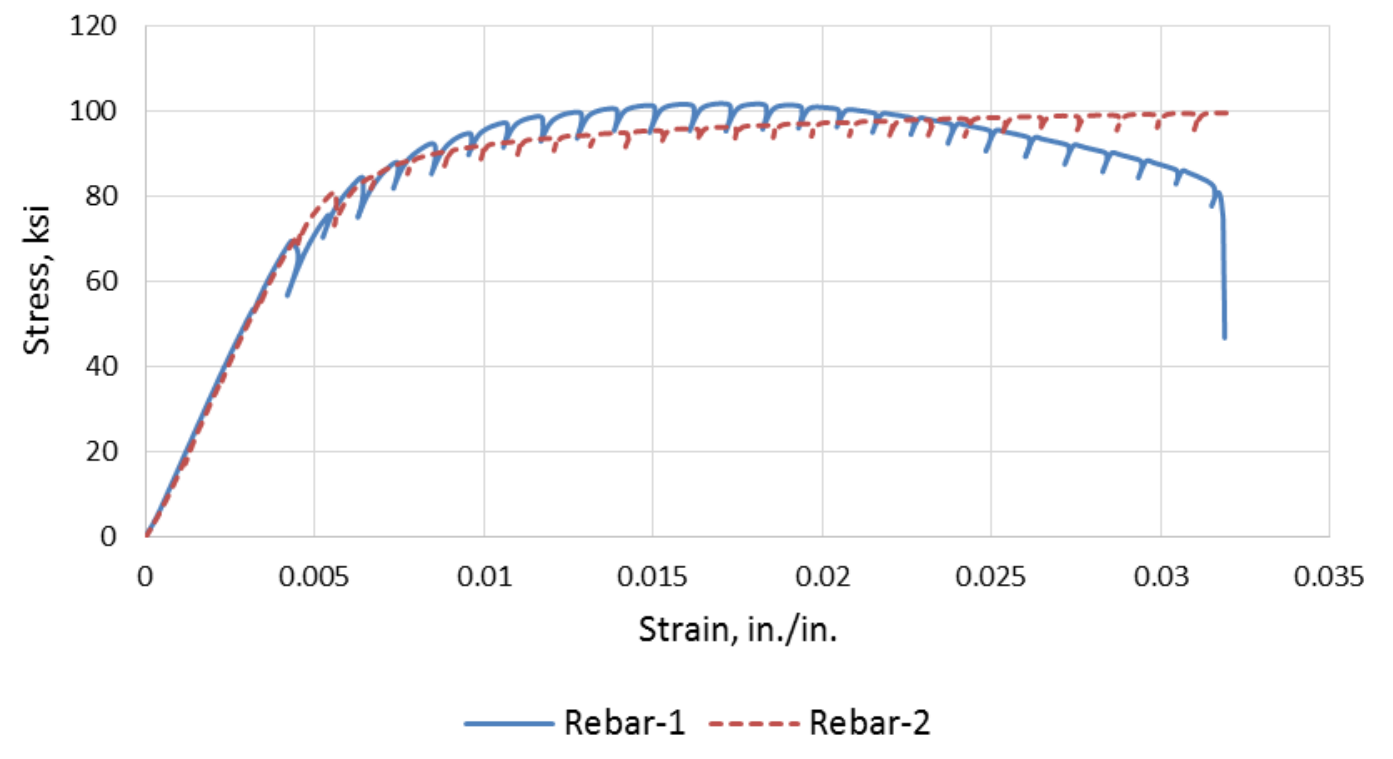

Figure 3.17 Stress-strain curve for D5 shear reinforcement 


\subsubsection{Formwork, Casting, and Curing}

The formwork was made separately for each beam. This was because the prestressing bed could only hold one beam at a time. As a result, only one beam was fabricated each time. Figure 3.18 shows a series of photographs related to formwork, casting, and curing of the prestressed concrete beams.

All beams had the same manufacturing procedure. The only differences were the stirrup spacing and the prestressing level. However, Beam \#4 was the only beam having anchors at the ends as shown in Figure 3.18-C.

The sides and the bottom of the formwork was made from 1.5-in.-thick wood panels. Wood screws were used to connect the wood panels to each other as shown in Figure 3.18. The interior surface of the wood was brushed with oil in order to easily disconnect the formwork after casting. In addition, the oil kept the wood sealed so that the wood panels didn't soak up water from the fresh concrete.

The entire steel cage was made from 0.25 steel bars (D5). The stirrups, and the top and bottom steel bars were connected using steel wire ties. The bottom concrete cover was maintained using pieces of plastic tubes, one-inch long, at the bottom of the steel cage. On the sides, U-shaped pieces of plastic with small screws that were originally made as a holder for electrical wires were used to provide the side cover of 0.75 in. as shown in Figure 3.18-D.

Once the formwork was ready, the steel cage correctly placed, and the CFRP strand pretensioned, fresh concrete was moved from the concrete mixer to the mold. Because there 
was no room for a vibrator, a couple of steel rods, (same that are used for slump test) were used to free the concrete from air bubbles. Finally a trowel was used for finishing.

After twelve hours, the concrete beam was covered by wet burlap sheets to keep the moisture in the concrete. Starting from the third beam (B3-4-60), the beams were covered by wet burlap sheets and plastic covers to protect them from the hot weather. This method of curing seemed to be an effective way to keep the beams moist in hot weather.

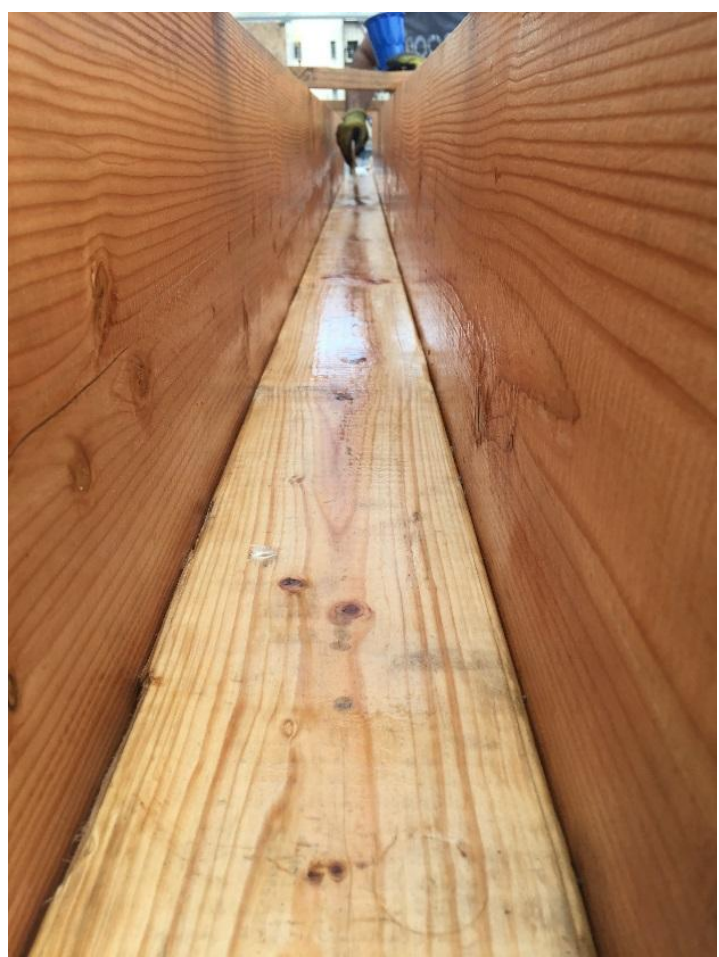

(A) Formwork/ oiling the interior surfaces.

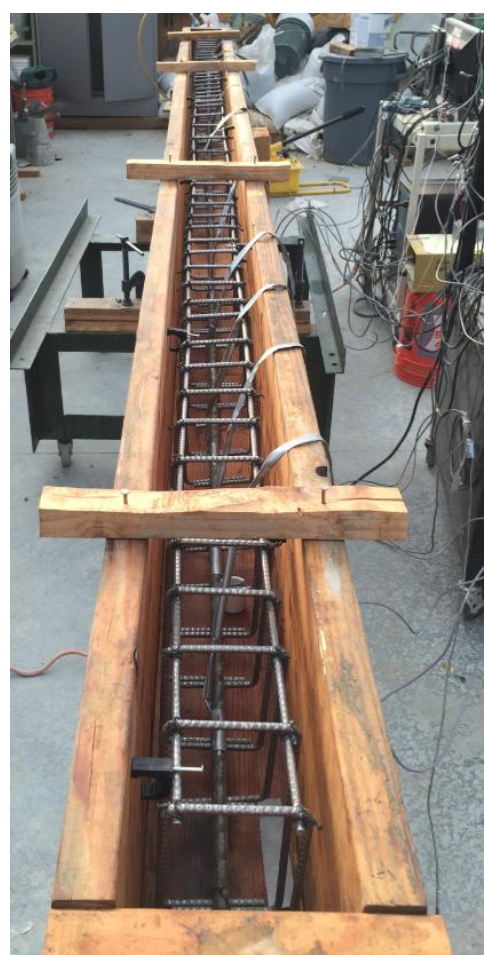

(B) Steel cage inside the wood frame

Figure 3.18 Formwork, Casting, and Curing of the prestressed concrete beams 


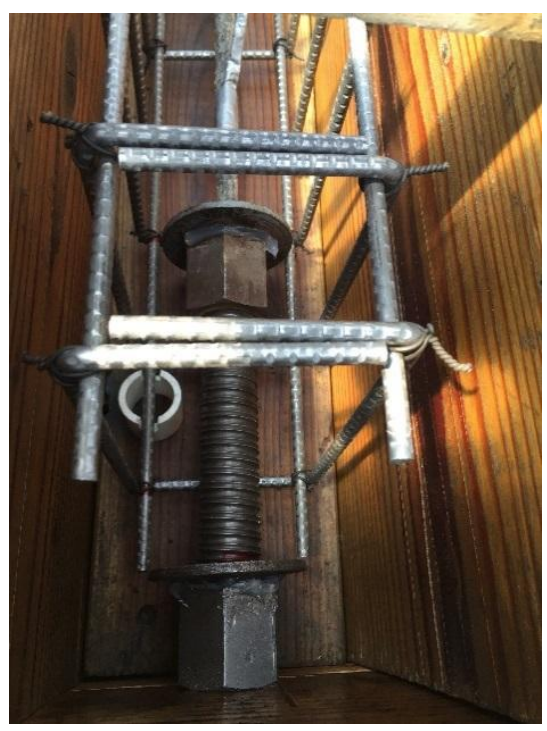

(C) The end anchors for Beam \#4

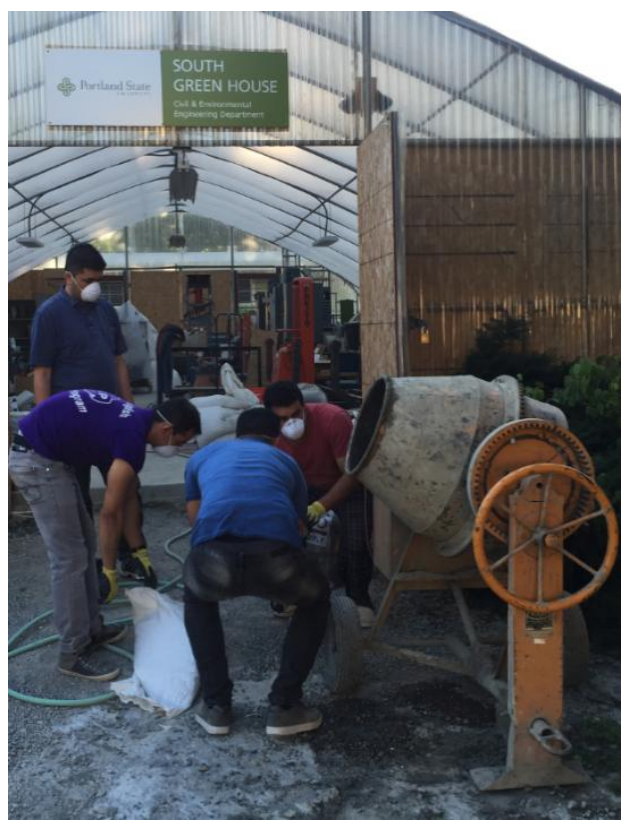

(E) Mixing concrete

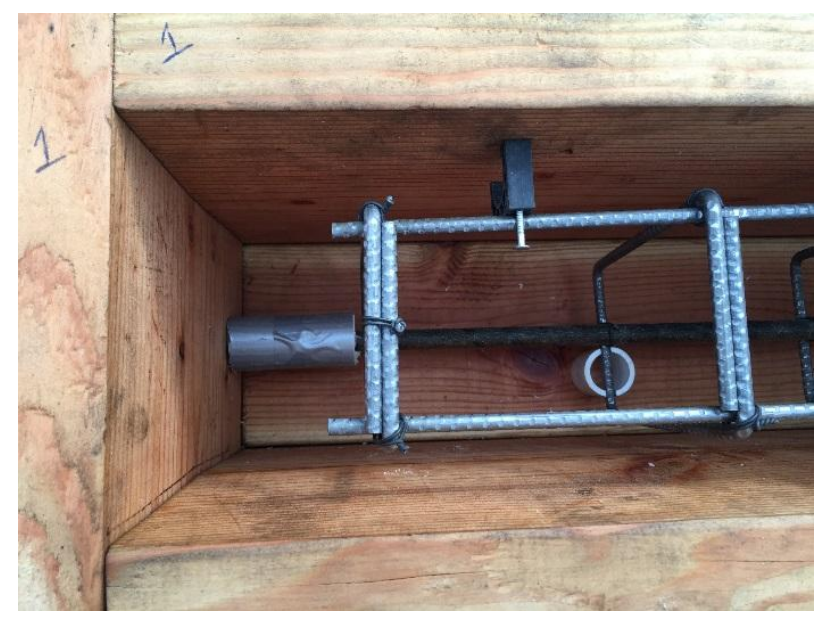

(D) Close view showing the side concrete cover and the unbounded end of CFRP strand

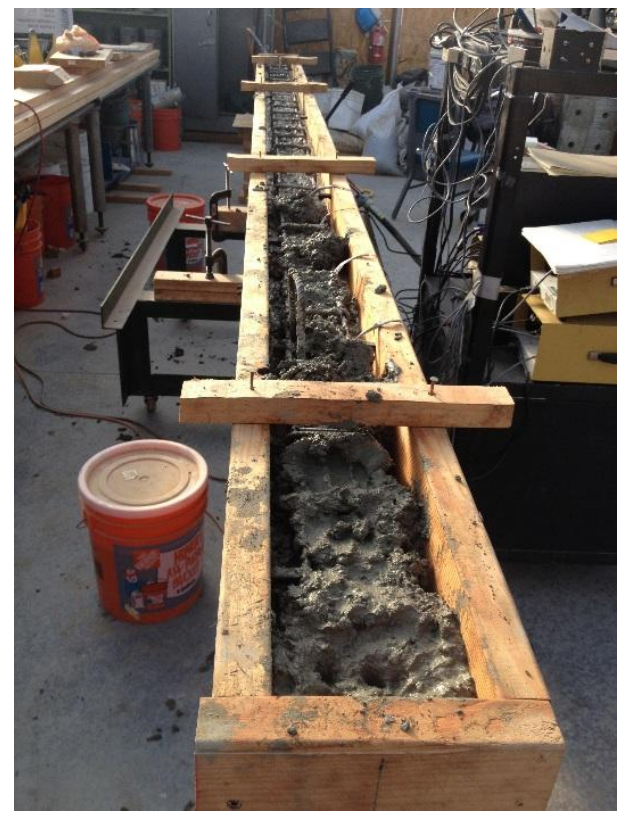

(D) Casting concrete

Figure 3.18 Continued 


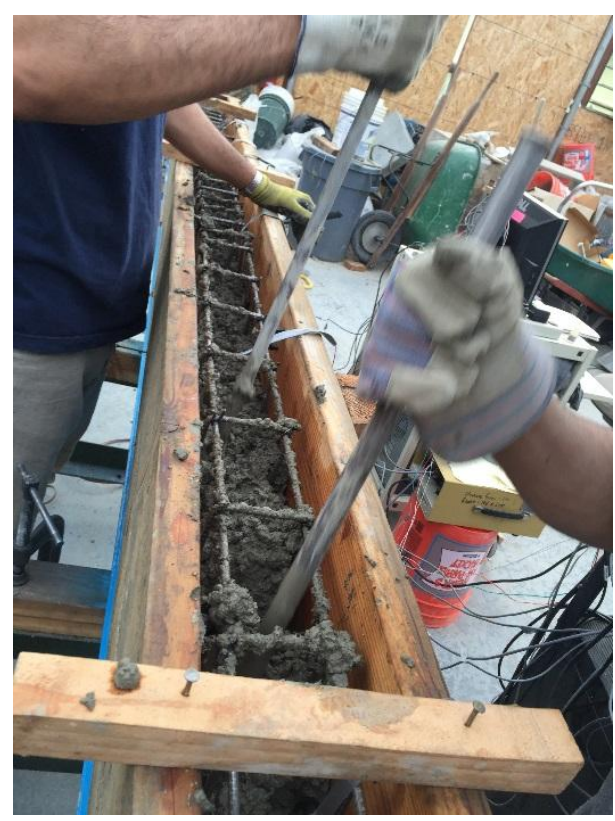

(E) Compaction using steel rods

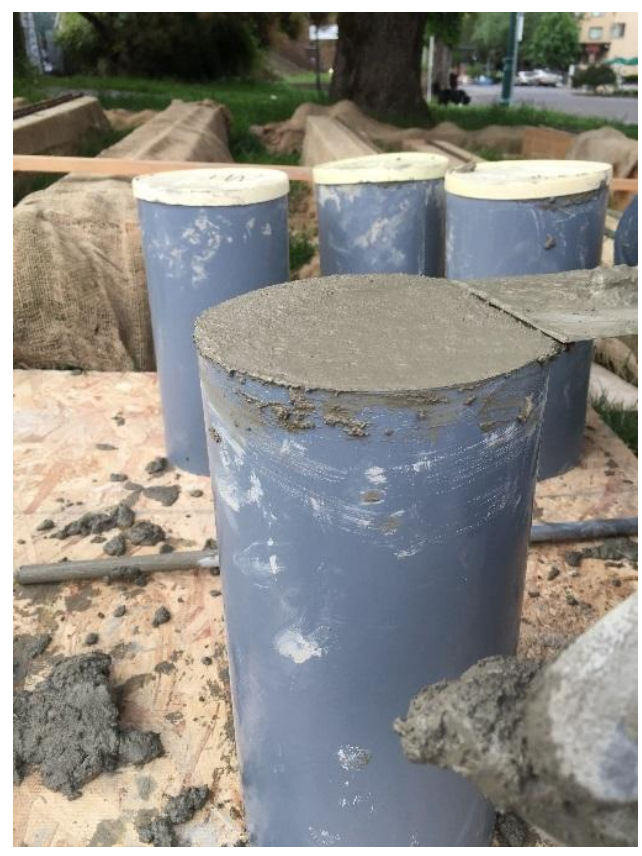

(G) Casting Cylinders

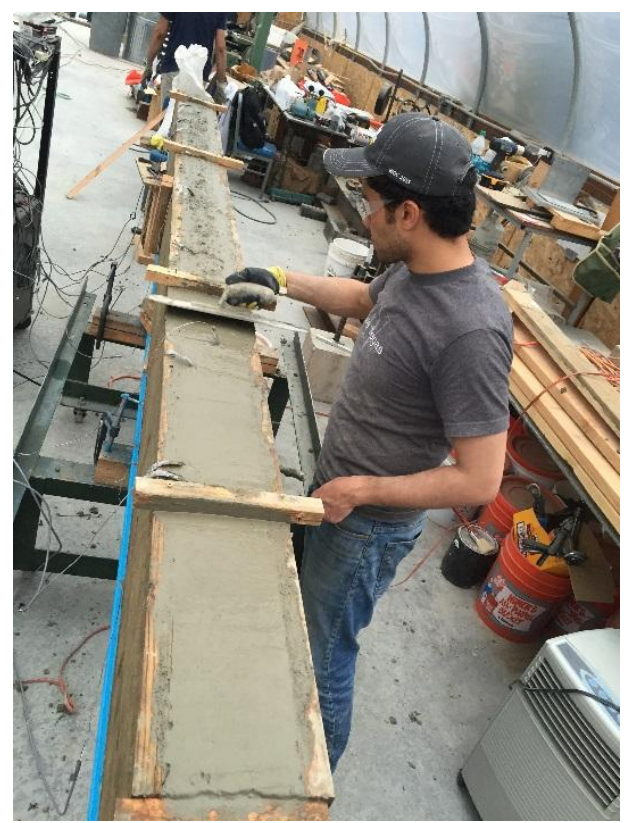

(F) Surface finishing using a trowel

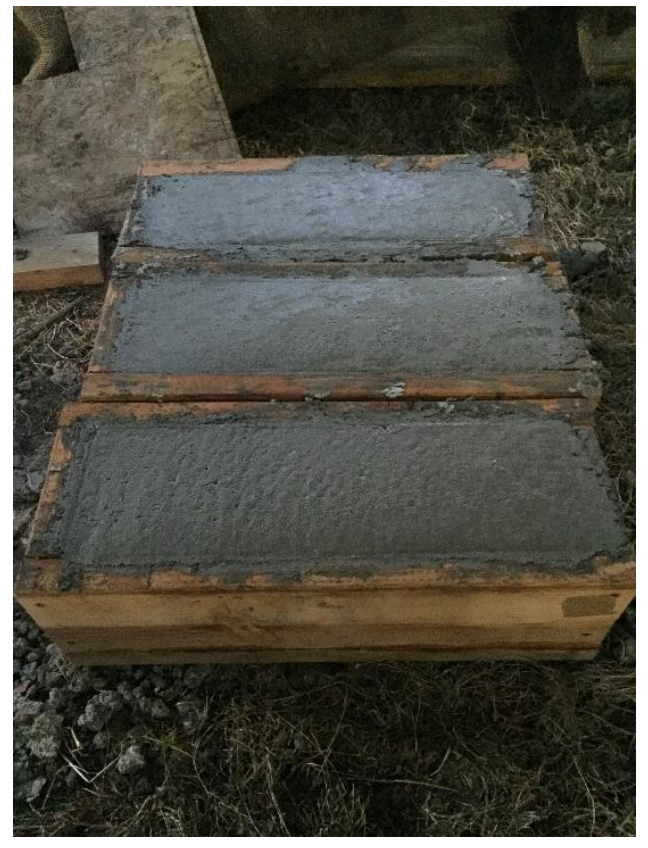

(H) Plain concrete beam for flexural strength test

Figure 3.18 Continued 


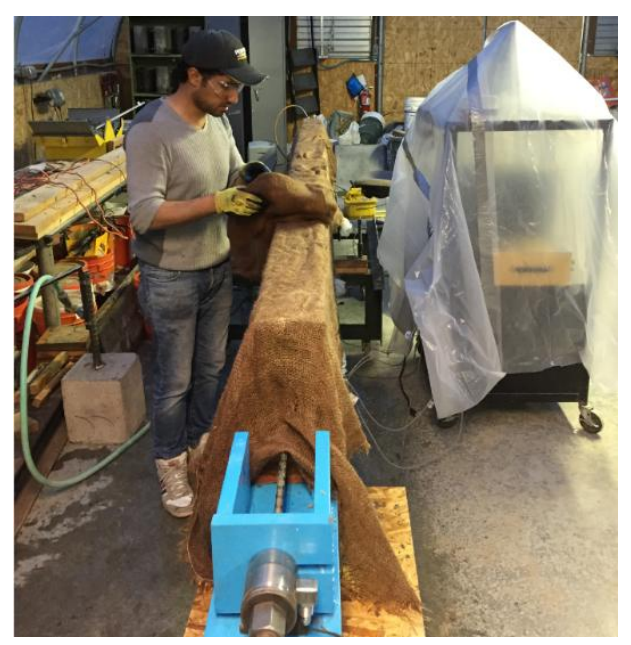

(I) Covering the concrete with wet burlap

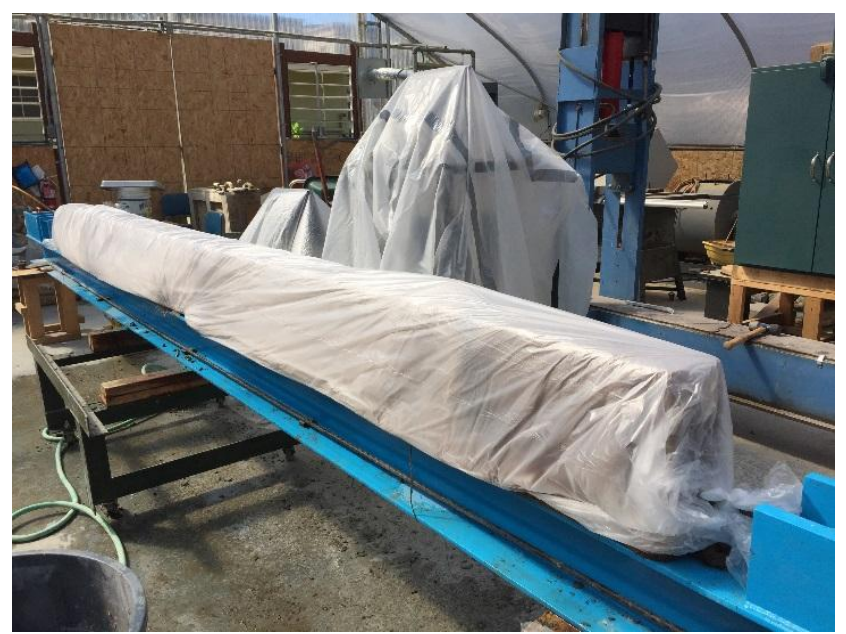

(J) Plastic covers in addition to the wet burlap
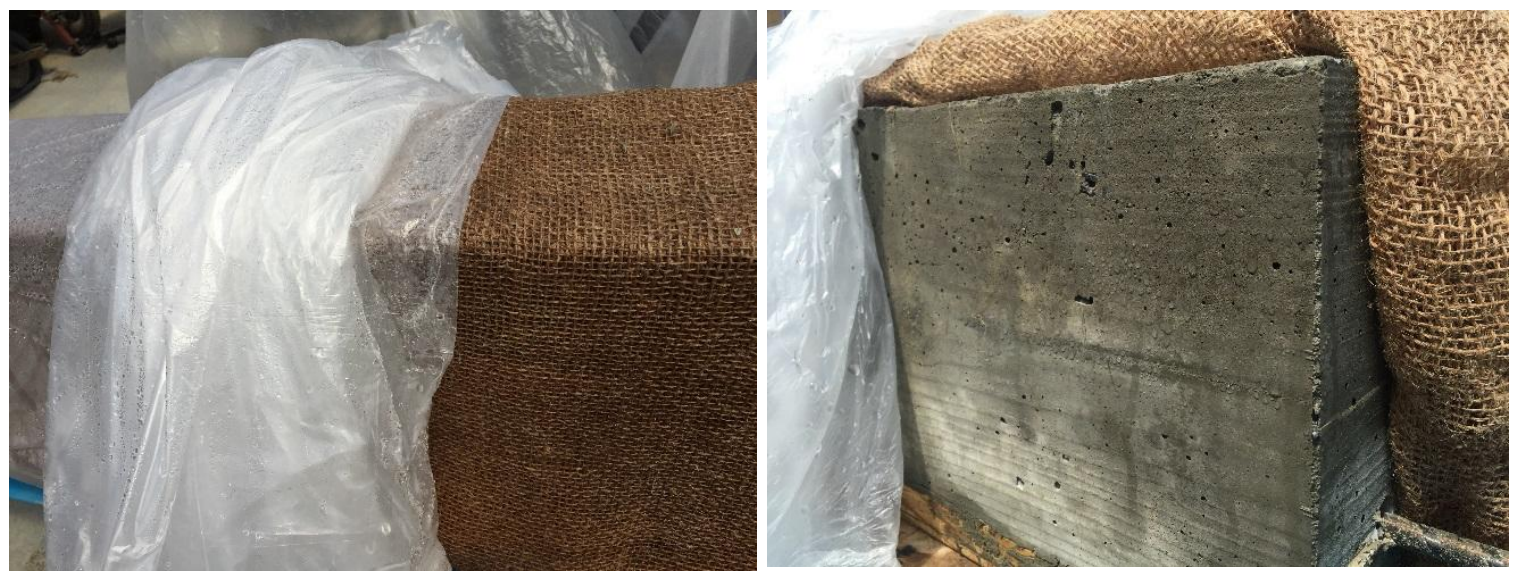

(E) Concrete condition after 12 hours of covering - still wet

Figure 3.18 Continued 


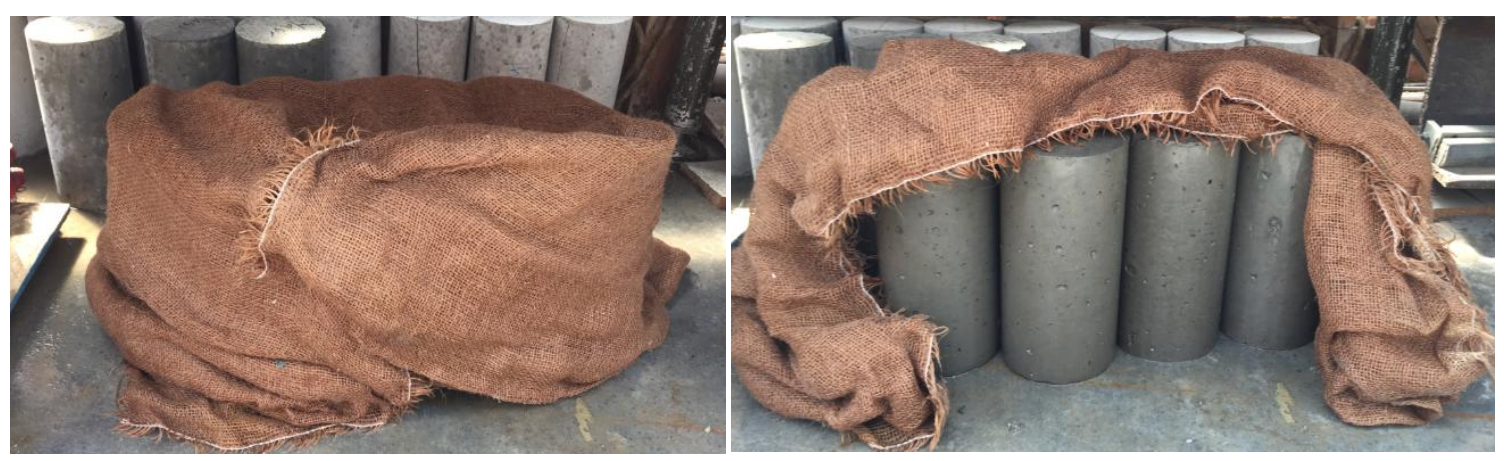

(E) Curing for cylinders

\section{Figure 3.18 Continued}

\subsubsection{Instrumentations and test set up}

\subsubsection{Installation of strain gauges}

Pre-wired electrical resistance strain gauges were used to measure the strain at predetermined locations in CFRP strands. The readings of these strain gauges were collected during pre-tensioning of the CFRP strands, while transferring the load to the concrete beam, and during flexural tests. These strain gauges provided real strain values that were developed in the CFRP strand during the test. Thus, the actual strain and stress profiles were developed along the length of each beam. The length of the strain gauges used for this project was $20 \mathrm{~mm}$. Figure 3.19 shows a series of photos for installation of strain gauge on CFRP strands. After installation, strain gauges and the wires were wrapped with duct tape in order to protect them during concrete casting. 


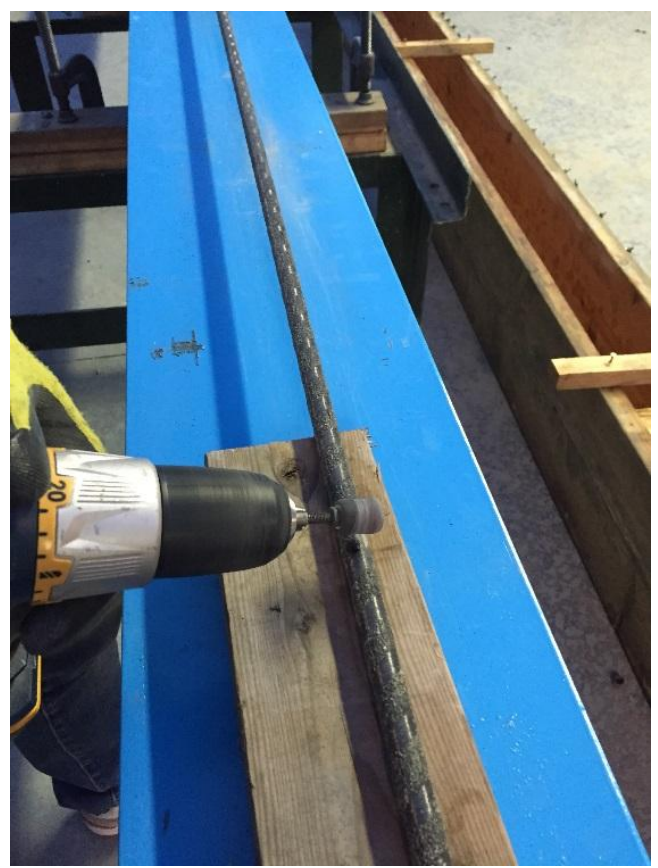

(A) Grinding: creating smooth area on the surface of CFRP strand

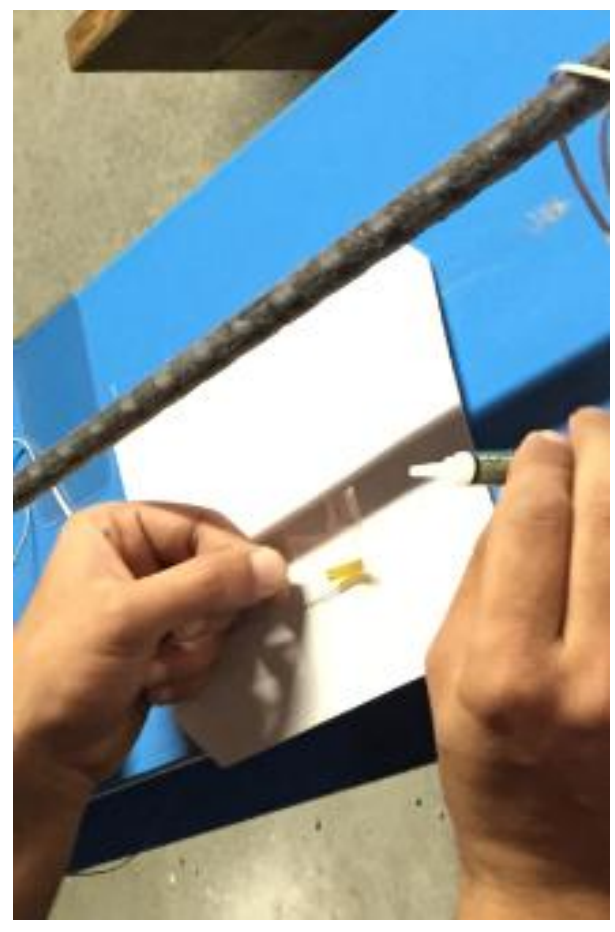

(C) Applying the glue

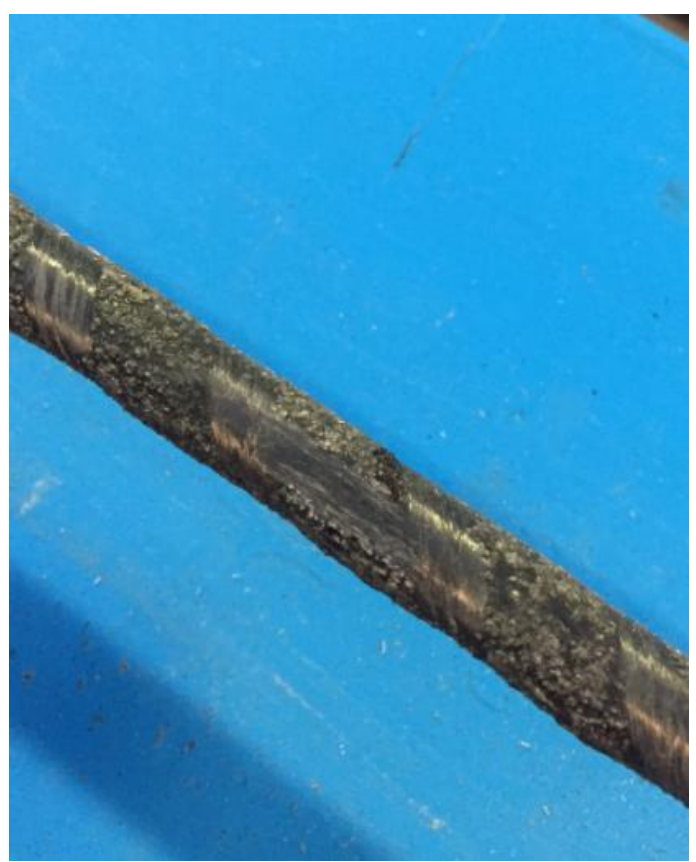

(B) Clean surface for s strain gauge to be installed

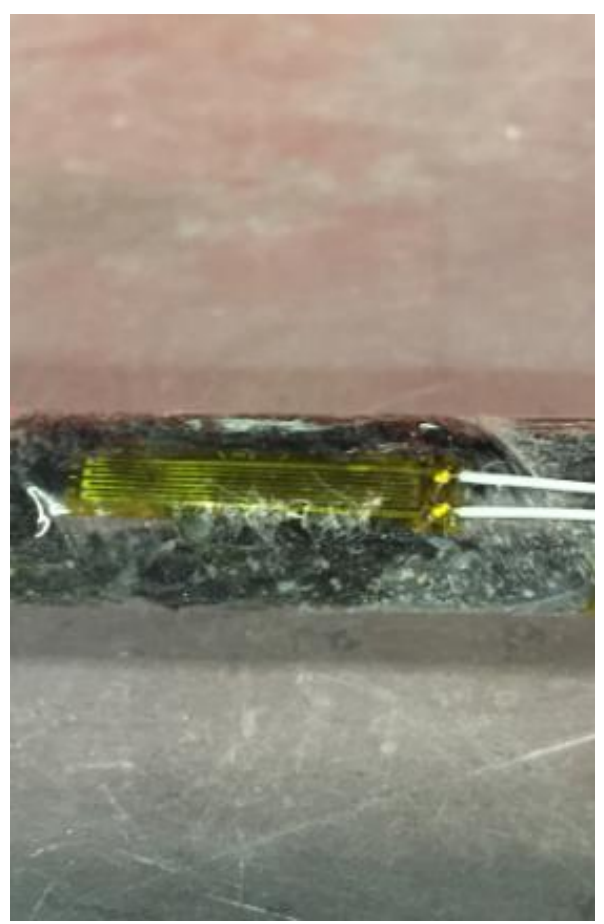

(D) A strain gauge is installed

Figure 3.19 Installation steps of the strain gauges on CFRP strands. 
In addition to the strain gauges that were mounted on CFRP strands, one or two strain gauges were installed on the concrete surface to measure the strain at the top fiber at midspan section of the beam. The strain was measured during the prestressing force transfer and during the cyclic flexural tests. Figure 3.20 shows the installation steps of strain gauges on concrete surface.
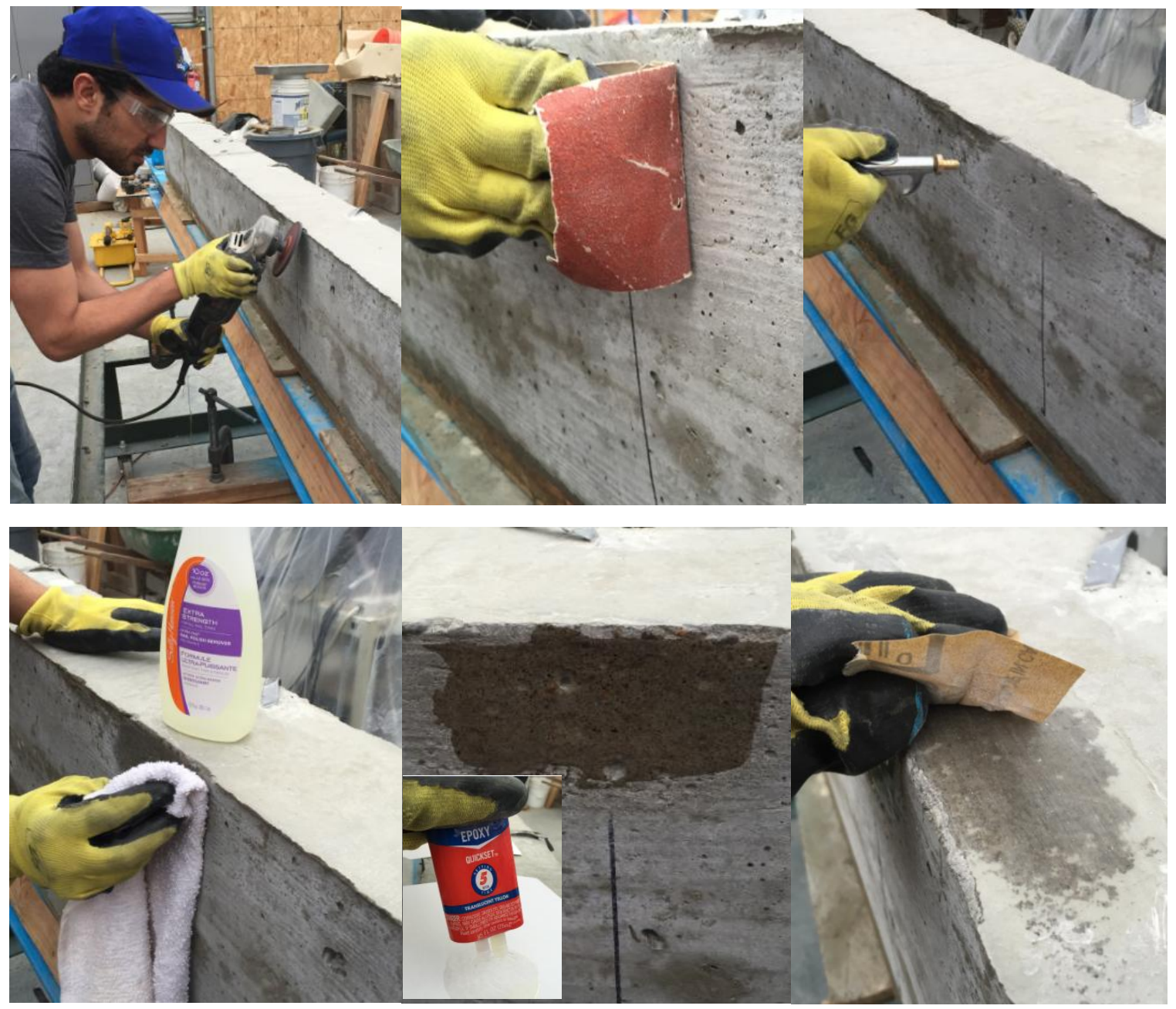

Figure 3.20 Installation steps of concrete strain gauges 


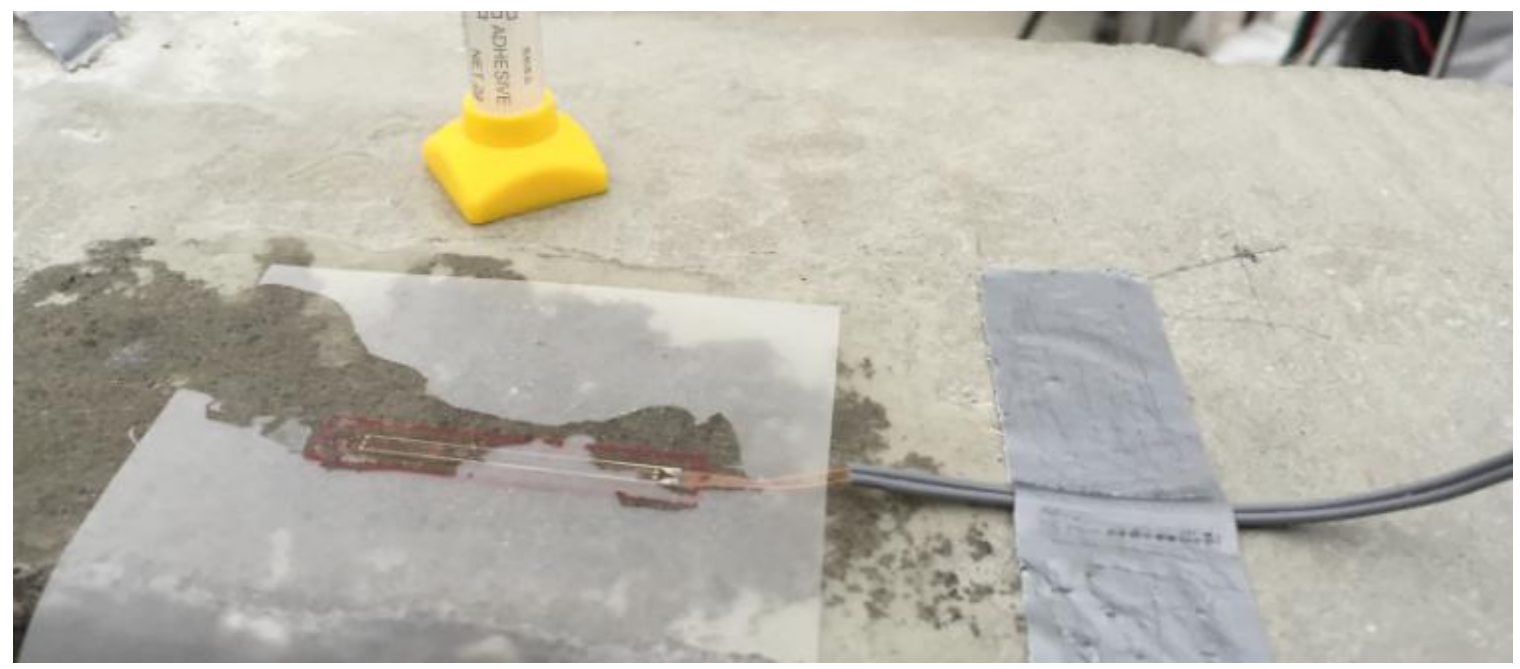

Figure 3.20 Continued

Figure 3.21shows typical locations and number of strain gauges that were installed along the beam.

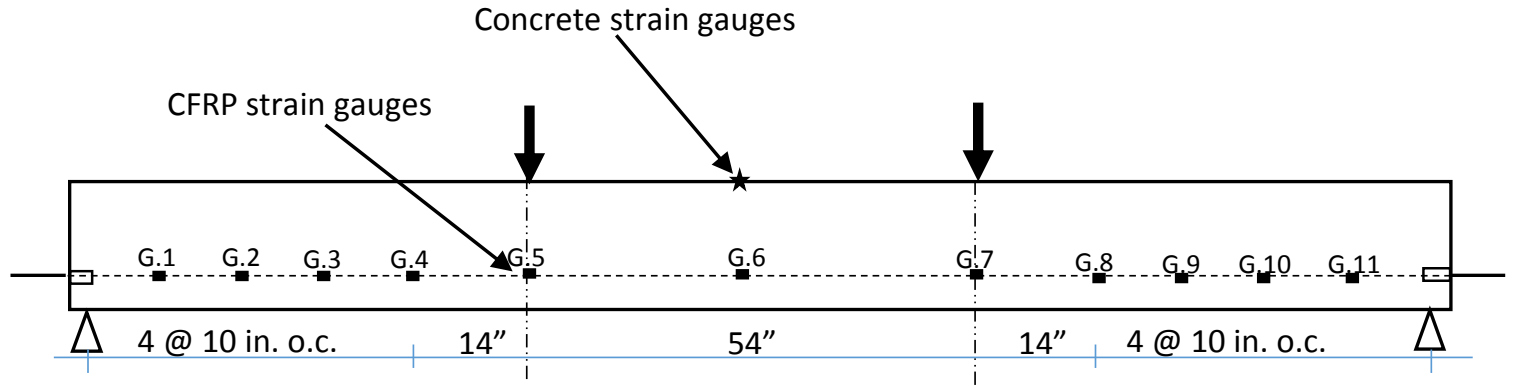

Figure 3.21 Typical locations and number of strain gauges along the beam 


\subsubsection{Pre-tensioning}

The first stage of instrumentation was made for the pre-tensioning of the CFRP strands. Part of the requirement for this project was to design and build a prestressing bed so that the CFRP strands could be pre-tensioned, and the concrete beams could be cast. Figure 3.22 shows photographs of the prestressing bed. The prestressing system was modeled using Abaqus/ CAE 6.13-2 computer program in order to observe and check the stresses developed due to the prestressing operation.

A wide flange section, W8 x 35, steel beam was used as the bed to handle the end moments caused by prestressing force and the weight of the concrete beam. Steel plates were welded to create the jacking end and dead end systems. The jacking end was where the hydraulic ram was placed and the pre-tensioning force was applied. The jacking end was designed so that the force could be locked mechanically, and so that the hydraulic jack could be released during curing period. On the other side of the steel beam, the dead end system was welded. The dead end system was just two one-inch-thick plates welded parallel to the direction of force. An additional free one-inch-thick plate with a slot in the middle of the plate was used to transfer the load from the anchor to the two steel plates that were welded on the steel beam, as shown in Figure 3.22. 


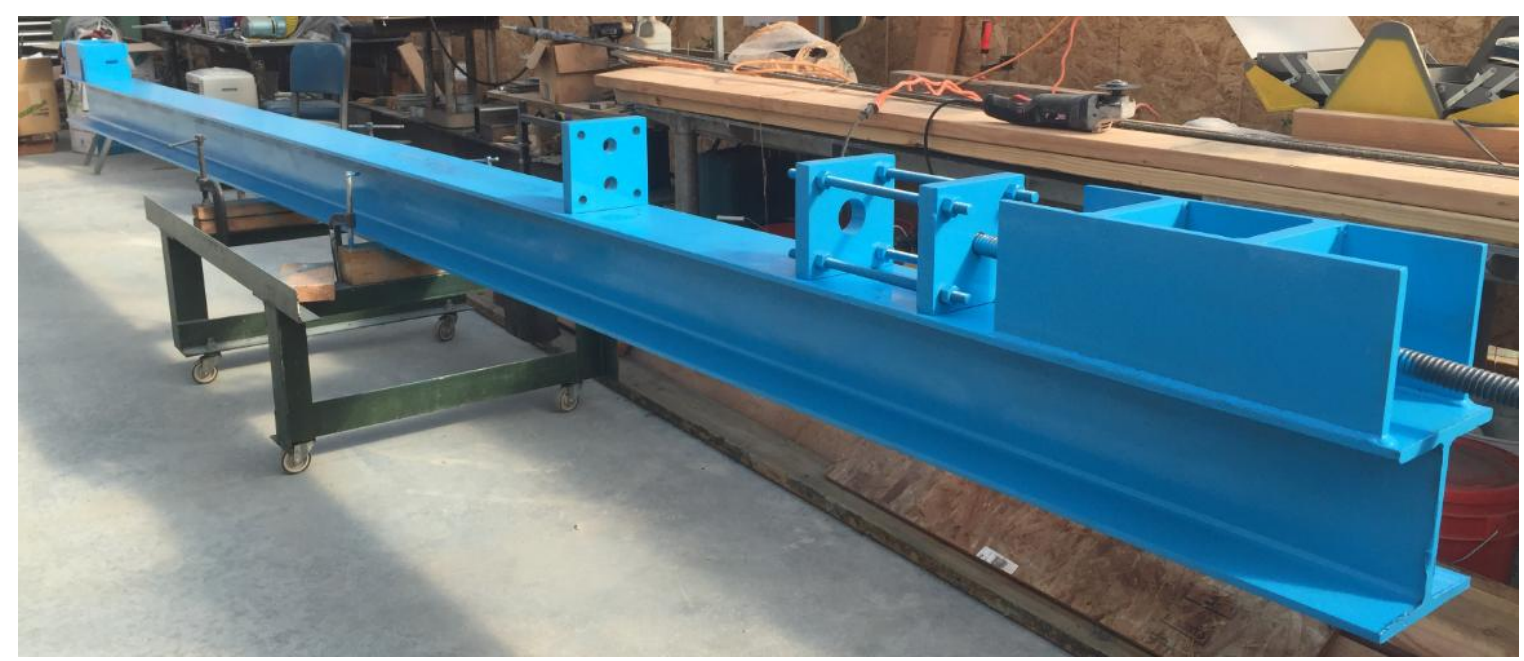

Prestressing bed

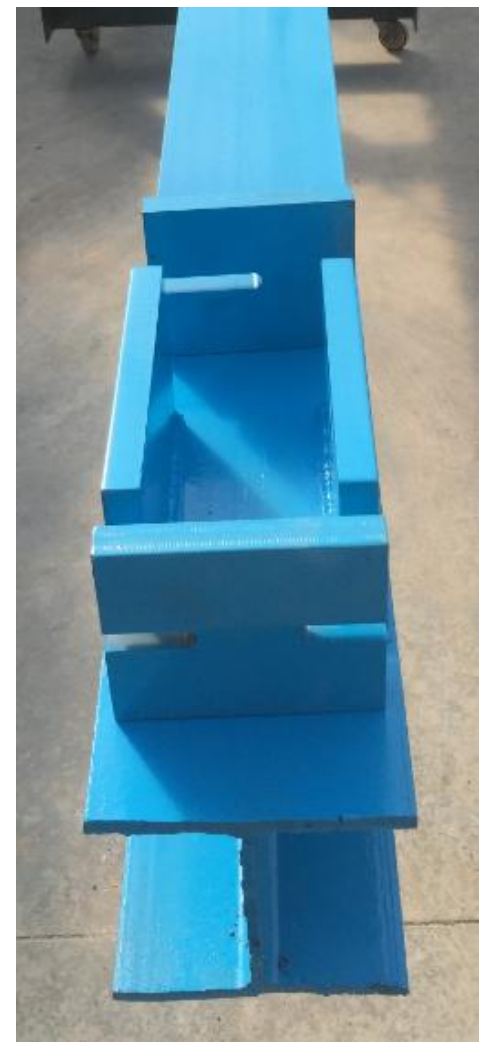

Dead end

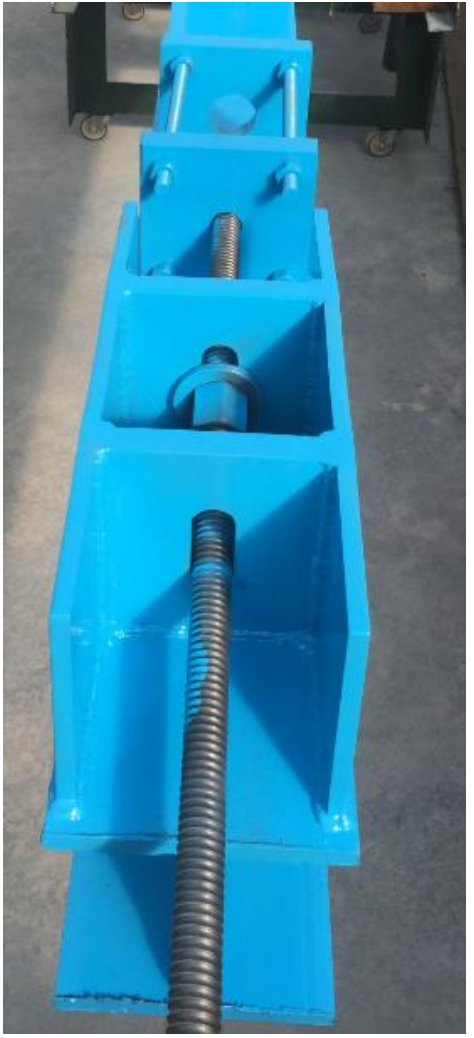

Jacking or live end

Figure 3.22 Prestressing bed system 
When the pre-tensioning force was applied, the readings of the nine-to-eleven electrical strain gauges attached to the surface along the CFRP strand were collected using eightchannel USB data loggers. The equivalent jacking or pre-tensioning force was recorded by a 150-kip compression load cell. Since it was a through-hole load cell, the steel tube that was used as an end anchor for CFRP strand went through the load cell. Then the load cell was locked by a nut at the dead end of the prestressing bed as shown in Figure 3.23.

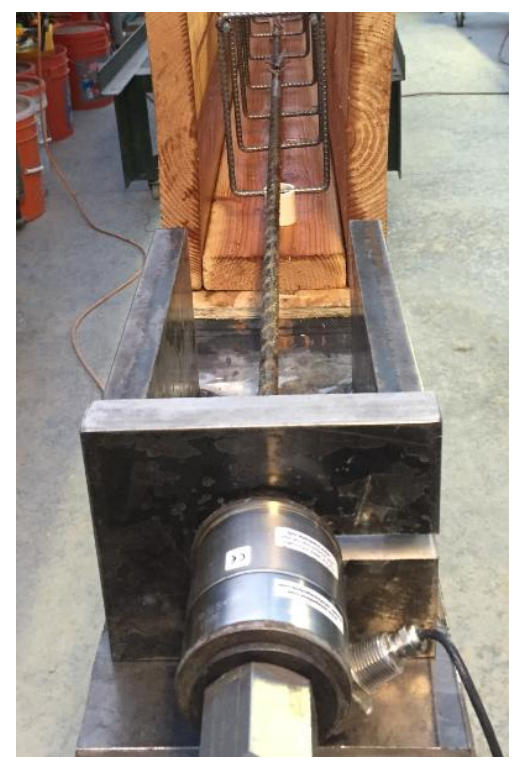

Figure 3.23 Locking the CFRP strand with the load cell at the dead end

\subsubsection{Prestressing Force Release}

The next stage of test set up, which started when the concrete strength reached the desired capacity, was releasing the prestressing force. At this stage, the prestressing load was transferred to the concrete beam. The operation of this stage started by a re-load of the 
CFRP with just one kip or less more than the force that the CFRP strand already had. This allowed hex nut to unlock. Once the nut was unlocked, the hydraulic ram was released slowly until all the load was transferred to the concrete beam. During this process, the readings of the strain gauges, which were installed along the CFRP strand, were collected along with the corresponding force.

In addition, two Linear Variable Differential Transformers (LVDTs) were installed at the ends, as shown in Fig. 3.24. These LVDTs measured the slippage of the CFRP strand relative to the concrete at the time of transferring the load. The slippage data was then used to calculate the transfer length; the required length from the beginning of the bond between the concrete and CFRP strand to the point where full transferred stress is developed.

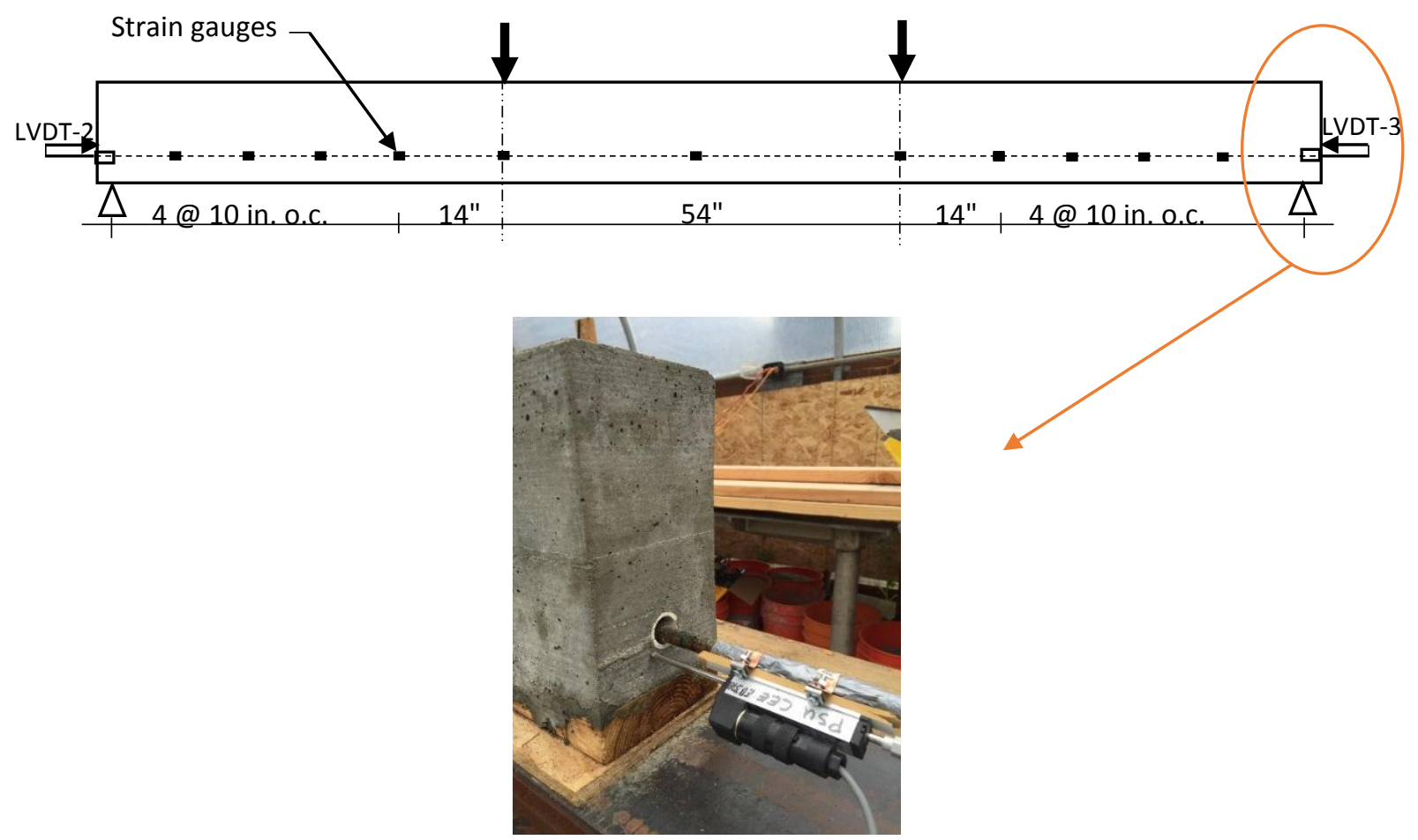

Figure 3.24 Force transferring operation 


\subsubsection{Flexural test of the prestressed concrete beams}

Another part of this project's requirements was to re-design a self-sustained load frame that could be used to test the 14 -ft long prestressed concrete beams until failure. The frame was designed to be strong enough so that there was almost no deformation produced in the frame elements during the tests. The reactional steel beam of the load frame originally was a $2 \mathrm{C} 10 \times 15.3$ (AISC), shaped as shown in Figure 3.25. The upgrading design for the reaction beam called for two 5/8-thick steel plates to be welded along the entire beam from top and bottom. The widths of the top and bottom plates were 12 and 9 in., respectively. The upgrading design of the loading frame also included a re-design top support of the hydraulic cylinder as the cylinder was changed to larger one. Figure 3.26 presents some of the work that was done for upgrading the loading system.
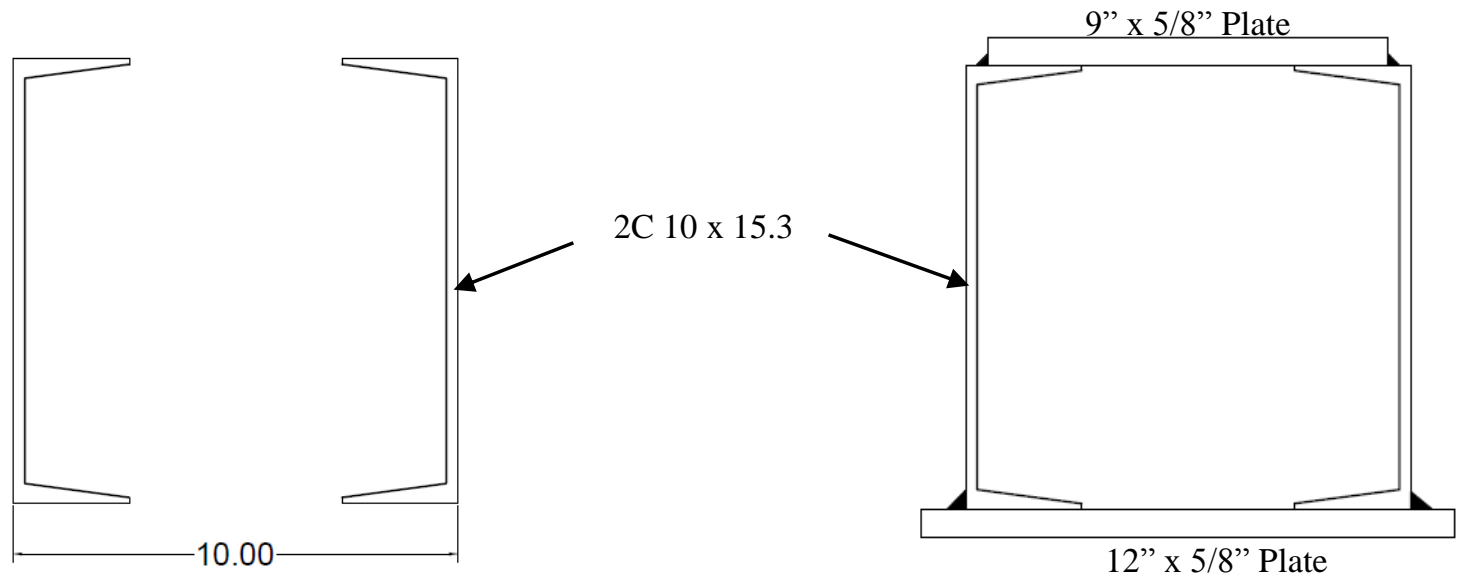

Figure 3.25 The reaction beam of the loading frame before and after upgrading 

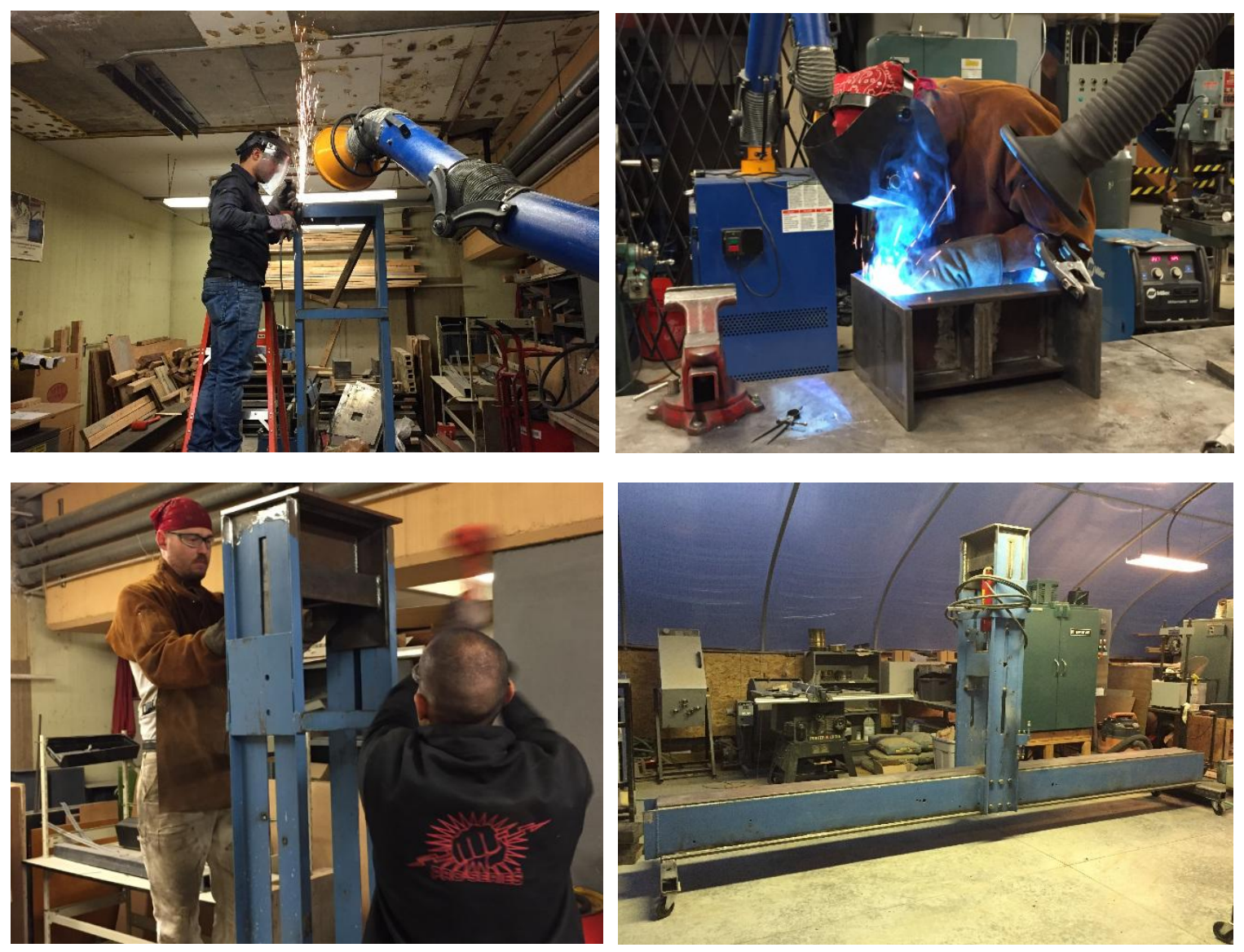

Figure 3.26 Upgrading of the loading frame

Four flexural tests in total were carried out in order to investigate the flexural behavior of prestressed concrete beams using CFRP strands. Figureshows 3.27 the experimental setup for flexural tests. All the beams were loaded with two equidistant point loads and were simply supported. The shear span for all the beams was $4.5 \mathrm{ft}$. The nominal cross section dimensions of all beams was $5.5 \times 10$ in. ( $\mathrm{b} \times \mathrm{h}$ ). Only one strand, 0.5-in. diameter, was used for all beams.

The loading frame that is described above was used to test all the specimens. A compression load cell with a capacity of 150 kips was used to determine the applied load. 
The readings of the applied load, the strain in the CFRP strand, the strain in concrete at mid-span, the CFRP slippage at both ends of the concrete beam, and the mid-span deflection were collected every 0.2 second (five times per second).

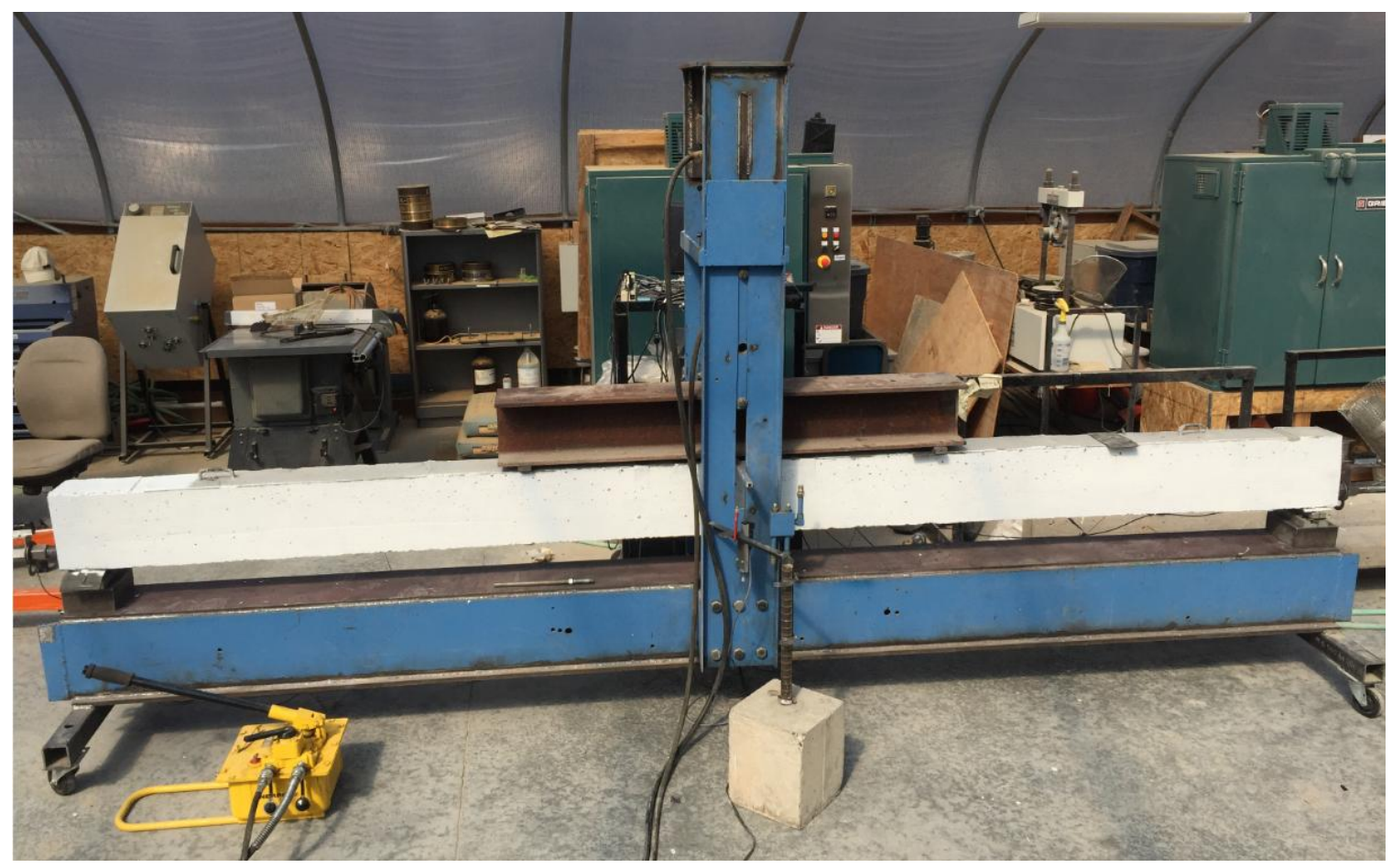

Figure 3.27 Set-up for flexural tests

The test procedure contained five cycles of loading and unloading and one last cycle continued monotonically until failure. The limit of the first five cycles was either 60 to $65 \%$ of the expected failure load, or when the strain in the CFRP strand reached 0.01 , which is also about 60 to $65 \%$ of the ultimate tensile strength. During each cycle of loading, the cracks' patterns were marked and the crack widths were measured. Figures 3.27 and 3.28 present the test set-up and instrumentations. 

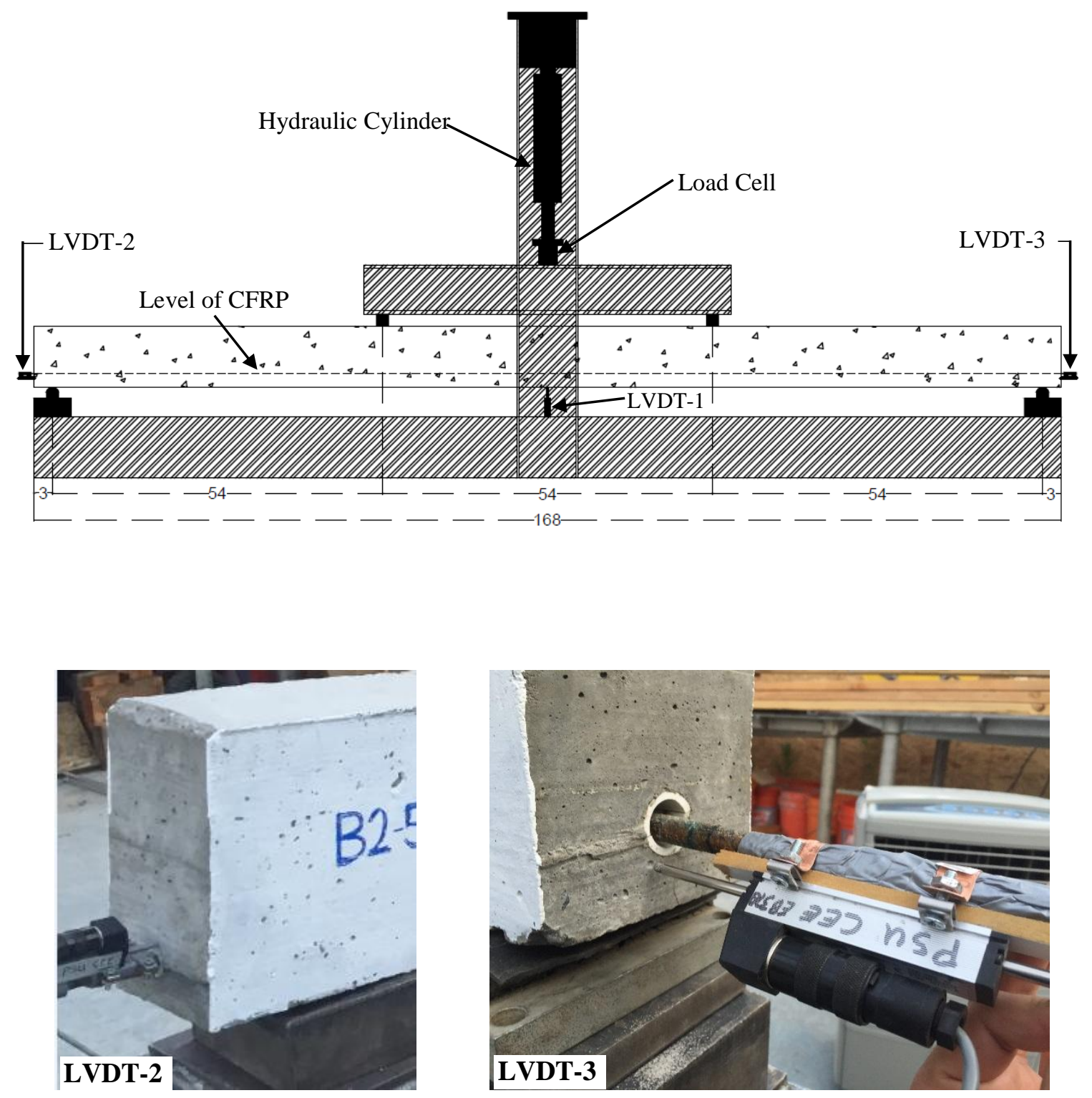

Figure 3.28 Flexural test set-up and instrumentations 


\section{Chapter 4: $\quad$ Results and Discussion of CFRP Prestressed Concrete Beams}

\subsection{Introduction}

A total of four prestressed concrete beams were fabricated and tested in the laboratory. All beams were prestressed with one \#4 (0.5-in. diameter) Carbon Fiber Reinforced Polymer (CFRP) strands. The prestressing level, represented by the jacking force, ranged from 55\% to $65 \%$. D5 bars (0.25-in. deformed steel bars) were used for steel cage reinforcement. A different number of stirrups (by changing the distance between stirrups, $(\mathrm{S})$ were used for each beam in order to investigate the effects of confinement on bonding. The mechanical properties of CFRP strands, concrete, and D5 steel bars are presented in Chapter 3.

This chapter presents the test results for all beams. The experimental results start with the bond properties including the transfer length, development length, and bond stress profile at transfer and during flexural tests. Then, the experimental results of flexural tests of the beams will be presented by examining the load-deflection curves for each beam. Finally, the analysis of the results and discussion will be presented.

\subsection{Jacking Force}

As previously mentioned, the jacking force also represents the prestressing level in this paper. The jacking forces are $65 \%, 55 \%, 60 \%$, and $60 \%$ for beams I, II, III and VI, respectively. At the beginning of this research, the aim was to look at the beams' ductility for different prestressing levels. However, bond issues between the CFRP strand and concrete resulted in early failure. It was impossible to evaluate the ultimate performance 
of the beams without solving the bond issues. As a result, the prestressing levels were kept almost the same in order to examine the effects of changing the stirrups spacing on the bond between the CFRP strand and the concrete.

Seven to eleven strain gauges were mounted on the surface of CFRP strand to measure the strain while prestressing. The collected data was used to develop the stress-strain relationship for each CFRP strand associated with each beam. This was used to predict the theoretical beams' responses as it was the actual stress-strain relationship for the same CFRP strand that was modeled. In addition, four pullout ASTM-based samples, the total length of which was three feet including the two gripping anchors, were tested in the Mechanical laboratory at the University of Portland to determine the stress-strain relationship of CFRP strands. The results from both the ASTM-based samples and the long actual strand are reasonably close, as shown in Figure 4.1.

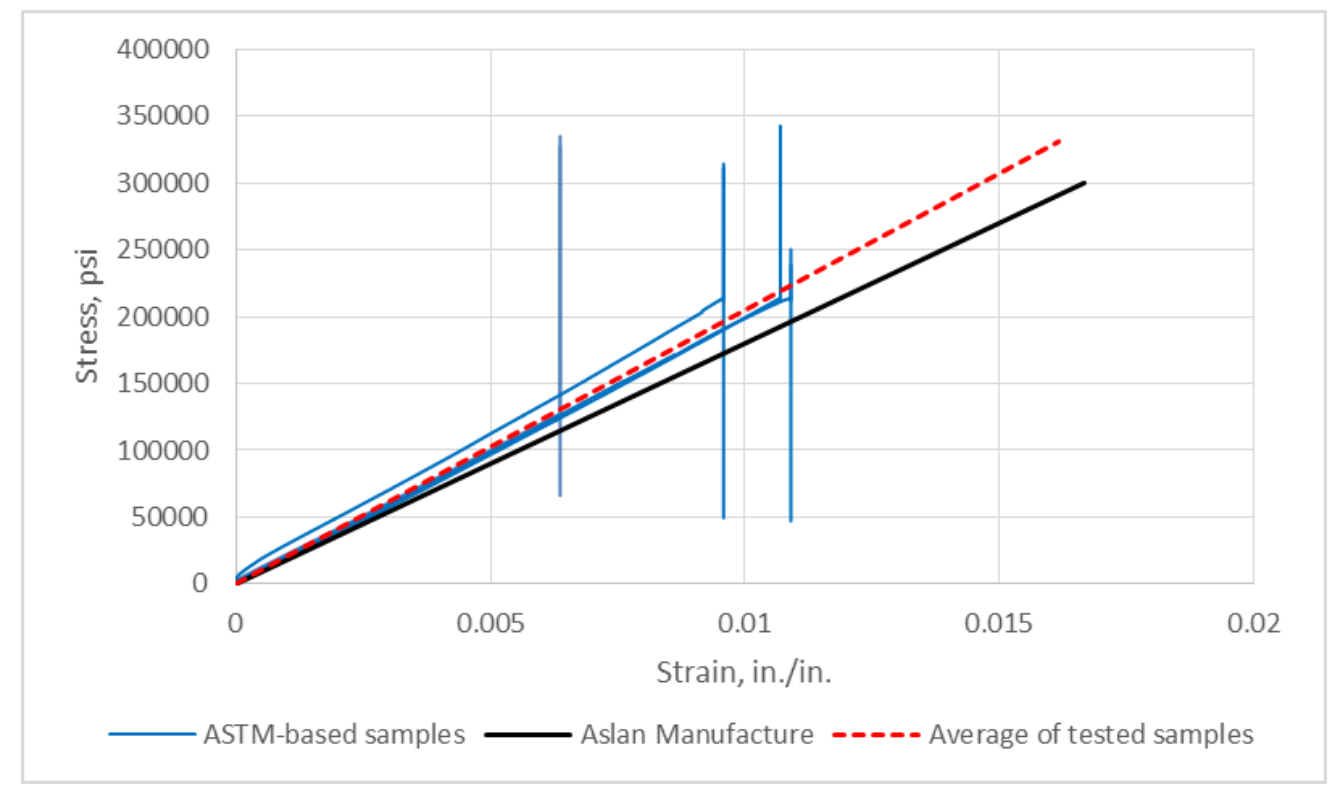

Figure 4.1 Stress-strain relationship for CFRP strands; comparing the tested samples to the manufacturer's guaranteed values 
An extensometer was used to measure the displacement in the ASTM-based tests. To protect the extensometer, it was removed when the tensile load reached $75 \%$ of the guaranteed tensile capacity of CFRP strand. This explains the stop in strain readings in Figure 4.1.

The average of the ASTM-based samples provided an ultimate tensile stress of $330 \mathrm{ksi}$. The associated average ultimate strain would be 0.0162 , assuming that the average modulus of elasticity is $20,500 \mathrm{ksi}$, as presented in Chapter 3/ Table 3-2. The manufacturer guaranteed stress and strain are $300 \mathrm{ksi}$ and 0.0167 strain, with an associated modulus of elasticity of $18000 \mathrm{ksi}$. Herein, the prestressing level (jacking force) depended on the guaranteed values. For instance, $60 \%$ prestressing level produced pre-tensioned stress of $0.6 * 300=180 \mathrm{ksi}$

Figure 4.2 shows the beams' label terminology. The prestressing measurements (stressstrain relationship for CFRP strands during prestressing process) for each beam are presented in Figure 4.3.

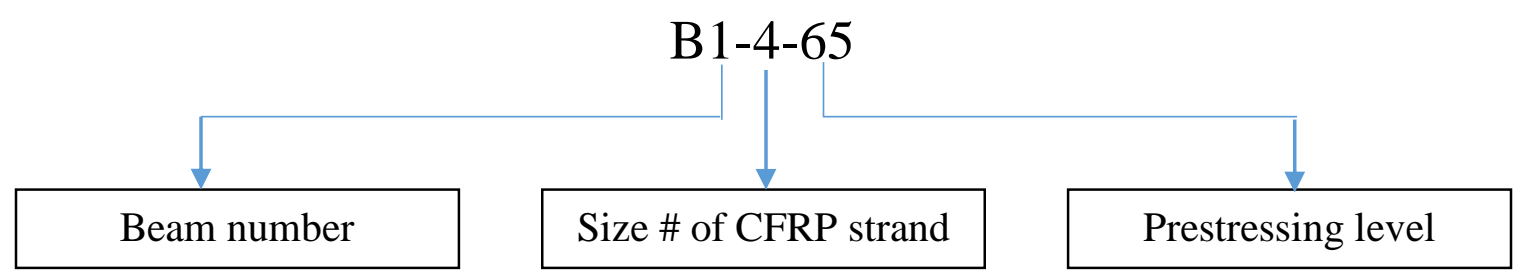

Figure 4.2 Beams' label terminology 

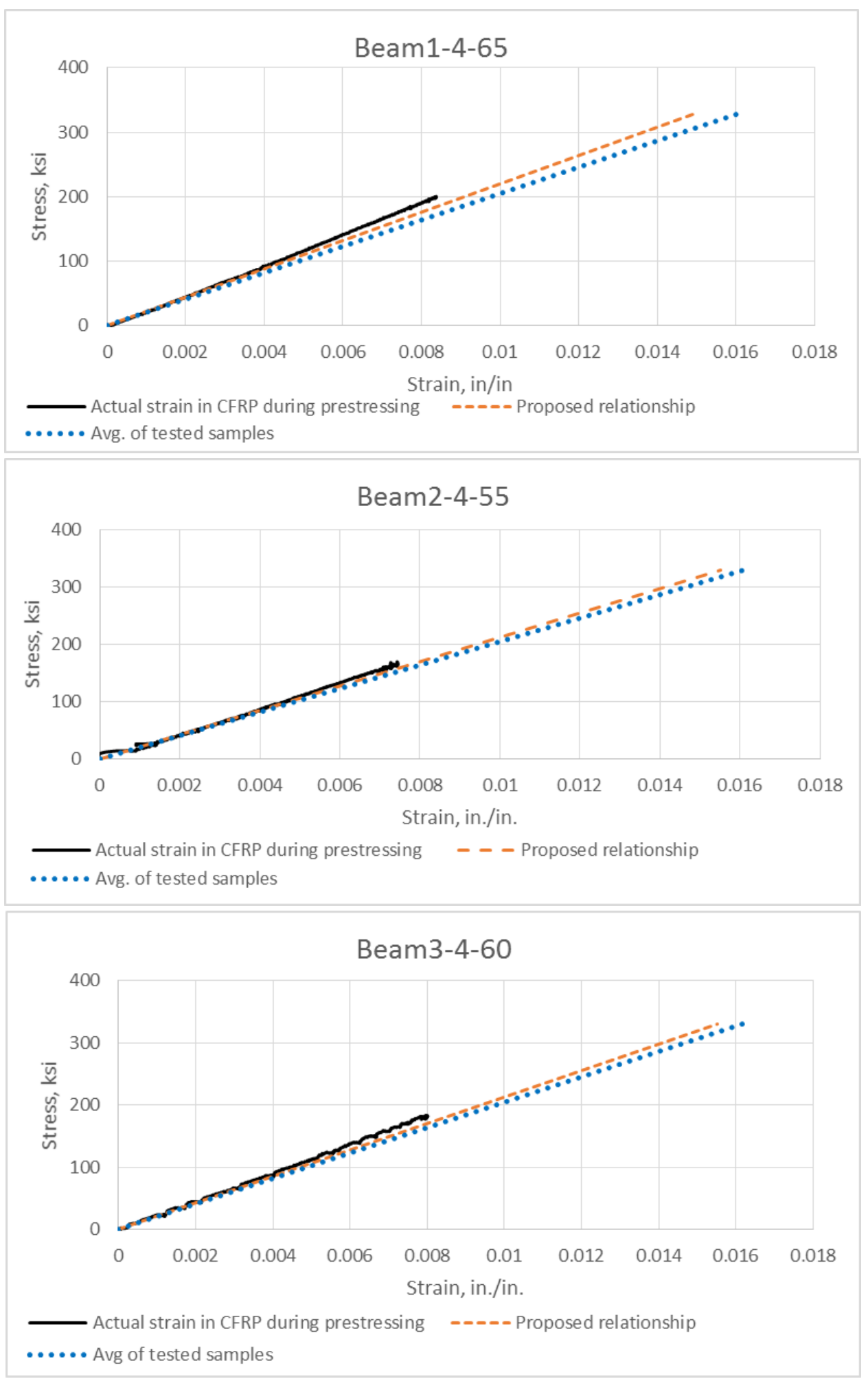

Figure 4.3 Stress-strain relationship for CFRP strands during prestressing process 


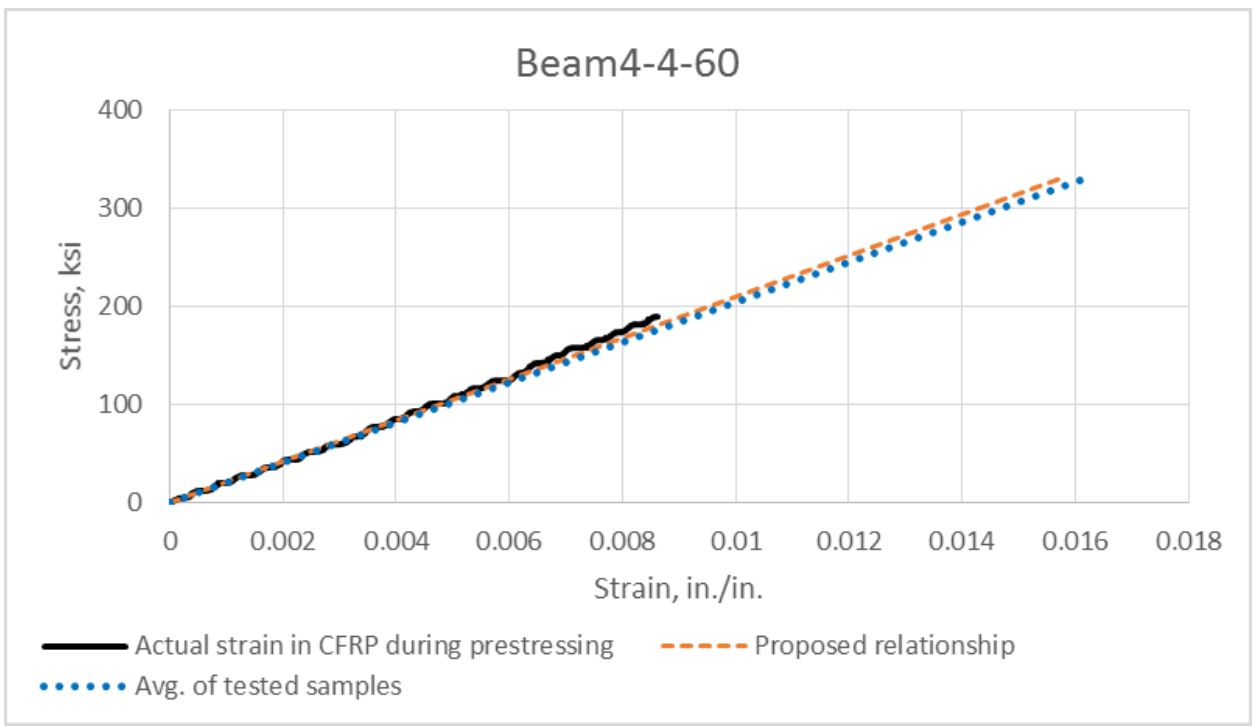

Figure 4.3 Continued

\subsection{Force Releasing Results}

The jacking force applied to the CFRP strand was released two weeks after casting when the concrete strength reached 6500 psi or more. The load and strain in CFRP were measure immediately before and after transfer. The load was measured by a load cell mounted at the dead end of the prestressing system, as described in Chapter 3. The strain in CFRP strand was measured by seven to eleven strain gauges mounted on different locations along the CFRP strand, as shown in Figure 4.4. The initial prestressing stress was the axial stress on CFRP strand measured immediately before transfer. The initial losses were the difference in the axial stress between the measured stress right after locking the jacking force and the initial stress immediately before transfer. Additionally, there were more losses leading to the effective stress. The effective prestressing stress was the stress measured immediately before the beam flexural test began. The elastic shortening of the 
prestressing system, the relaxation of the CFRP strand, and the shrinkage and creep of concrete affected the amount of losses. Table 4-1 shows the jacking force, the initial and effective stresses, the total losses in CFRP stress from jacking to effective stress, and concrete compressive strength at transfer and at the day of flexural test.

\begin{tabular}{ccccccc}
\hline Beam & Prestressing & Jacking & Initial stress, & Effective & \multicolumn{2}{c}{ Compressive } \\
label & level $(\%)$ & stress & $\boldsymbol{f}_{\boldsymbol{i}}$ & stress, $\boldsymbol{f}_{\boldsymbol{e}}$ & \multicolumn{2}{c}{ Strength (psi) } \\
& & $(\mathbf{k s i})$ & $(\mathbf{k s i})$ & $(\mathbf{k s i})$ & $f_{c i}^{\prime}$ & $f_{c}^{\prime}$ \\
\hline B1-4-65 & 65 & 195 & 184.4 & 178.2 & 6581 & 7183 \\
\hline B2-4-55 & 55 & 165 & 163.2 & 156.5 & 6950 & 7637 \\
\hline B3-4-60 & 60 & 180 & 172.1 & 163.4 & 6790 & 7269 \\
\hline B4-4-60 & 60 & 186 & 181.8 & 174.1 & 7351 & 7518 \\
\hline
\end{tabular}

Table 4-1 Prestressing data

\subsubsection{Transfer Length}

The transfer length is the length required for the concrete beam to develop the stress transferred by the prestressed CFRP strand. It is also equal to the length starting from the point where the CFRP and concrete meet up to the point where the strain at the level of CFRP is equal to the initial prestressing stress. Experimentally, the transfer lengths were determined using the data from strain gauges along the length of the beams. The strain gauges were mounted on the surface of CFRP strand. Once the strain profile was determined the transfer length, $l_{t}$, was easily determined. The bond behavior from both 
dead-end and live (jacking)-end was assumed to be symmetrical, especially when the data on a specific location was provided from one side only. For all beams, the strain gauges were mounted on both ends as shown in Figure 4.4. For instance, if the readings of gauge no. 1 were missing, it is assumed that the strains at the location of gauge no. 1 were the same as the readings of gauge no. 11 because both locations were $10 \mathrm{in}$. away from the support. Fewer number of strain gauges (7 ones) were used for beam \#1 (B1-4-65) because the instrumentation equipment was not enough to accommodate more strain gauges. However, eleven strain gauges were used for beam \#2 (B2-4-55) as more conditioner boxes for strain gauges were provided. For beams \#3 (B\#-460) and \#4 (B4-4-60), nine strain gauges were used, gauge \#4 (G.4) and gauge \#8 (G.8) were eliminated. Even though the installation of strain gauges was very carefully processed, sometimes the readings of the strain gauges could be lost. This loss might be because the gauge wires were cut during casting the concrete, the strain gauge readings were maxed out early (below the standard), or a good attachment was not created between the CFRP surface and the strain gauge.

Figure 4.4 shows the strain profiles along the beams. The arrangement of the strain gauge locations was the same for beams B2-4-55, B3-4-60, and B4-4-60. However, Beam \#1, B14-65 was the only beam which had a different distribution pattern. The square-dot line represents the level of strain immediately before transfer, measured by a load cell and an average of the strain gauge readings. The blue dots with the attached numbers represent the actual gauge readings immediately after transfer. The solid-orange line represents the best fit line for the readings immediately after transfer. When there is a strain gauge, but no 
reading is provided in the strain profile plot, this means the readings associated with this gauge are lost (For example; G.5 and G.7 in beam \#1).

For B1-4-65, the transfer length was experimentally determined by drawing a straight line from zero strain at the support to an actual strain measured by strain gauge G.1 and equal to 0.00454 at $13.5 \mathrm{in}$. from the support. This line can be extended with the same slope to reach the average initial strain of 0.00804 (stress $=176.9$ ) at $23.9 \mathrm{in}$. As a result, the transfer length for Beam \#1 was 23.9 in., which is equal to $47.8 \mathrm{~d}_{\mathrm{b}}$. As expected, when the prestressing level decreased, a shorter transfer length was needed. Beams B2-4-55 and B34-60 had transfer lengths of 21.0 and 19.5 in., respectively. It can be observed that the transfer length for $55 \%$ and $60 \%$ prestressing level was between $41 d_{b}$ and $42 d_{b}$. Further investigation was required in terms of the effects of prestressing level on the required transfer length because here the prestressing levels for all beams were close to each other.

The other main factor that affected the transfer length was the confinement amount provided by the steel stirrups. The number of stirrups used for Beam \#2 (B2-4-55) was twice the number used for Beam \#1 (B1-4-65). As a result, not only did the lower prestressing level lead to a shorter transfer length, but the confinement also enhanced the bond and led to shorter transfer length. In order to verify this concept, Beam \#2 (B2-4-55) and Beam \#3 (B3-4-60) were compared. The steel stirrups for Beam \#2 and Beam \#3 were spaced at $3.0 \mathrm{in}$. and $2.0 \mathrm{in}$. on centers, respectively. Therefore, the confinement was more for Beam \#3. Even though the prestressing level for Beam \#3 was higher than that of Beam $\# 2$, the results from strain gauge measurements and LVDTs indicated that the transfer length was shorter for Beam \#3. It can be concluded that the confinement, represented by 
the number (or frequency or spacing) of stirrups that were used for each beam, played a significant role in bond behavior between concrete and CFRP rods.

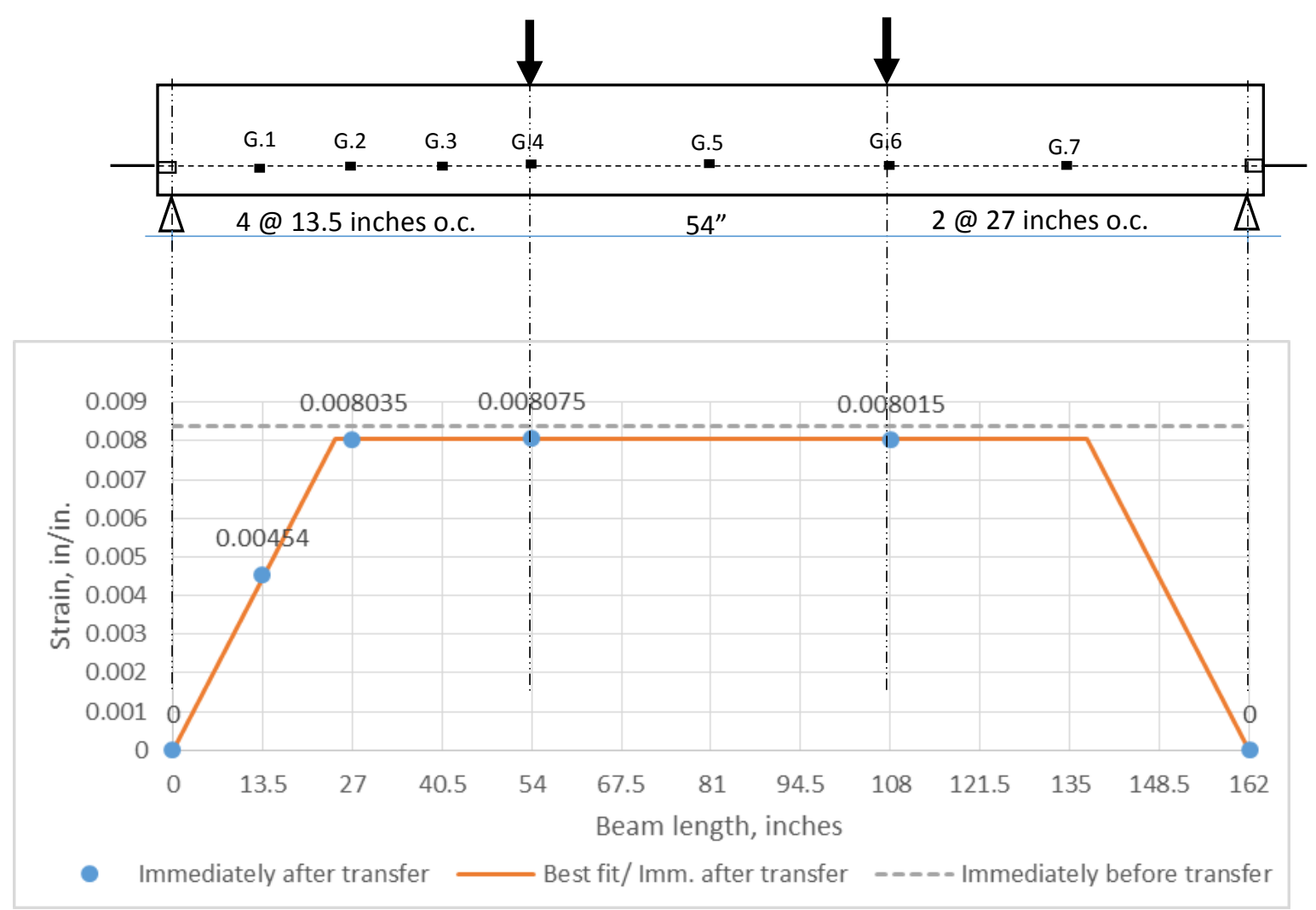

(a) Beam \#1 (B1-4-65)

Figure 4.4 Force releasing data; before \& after 


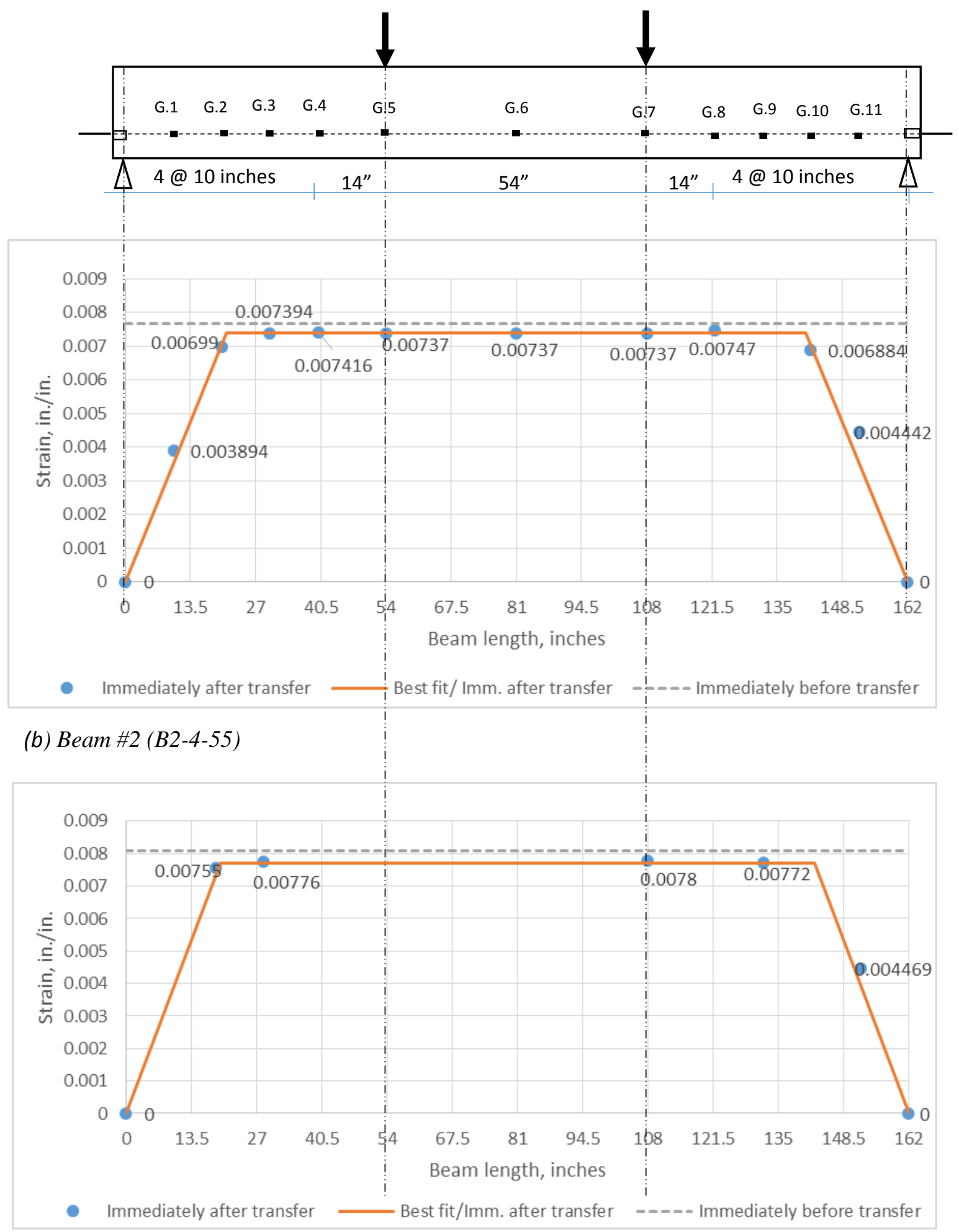

(c) Beam \#3 (B3-4-60)

Figure 4.4 Continued 


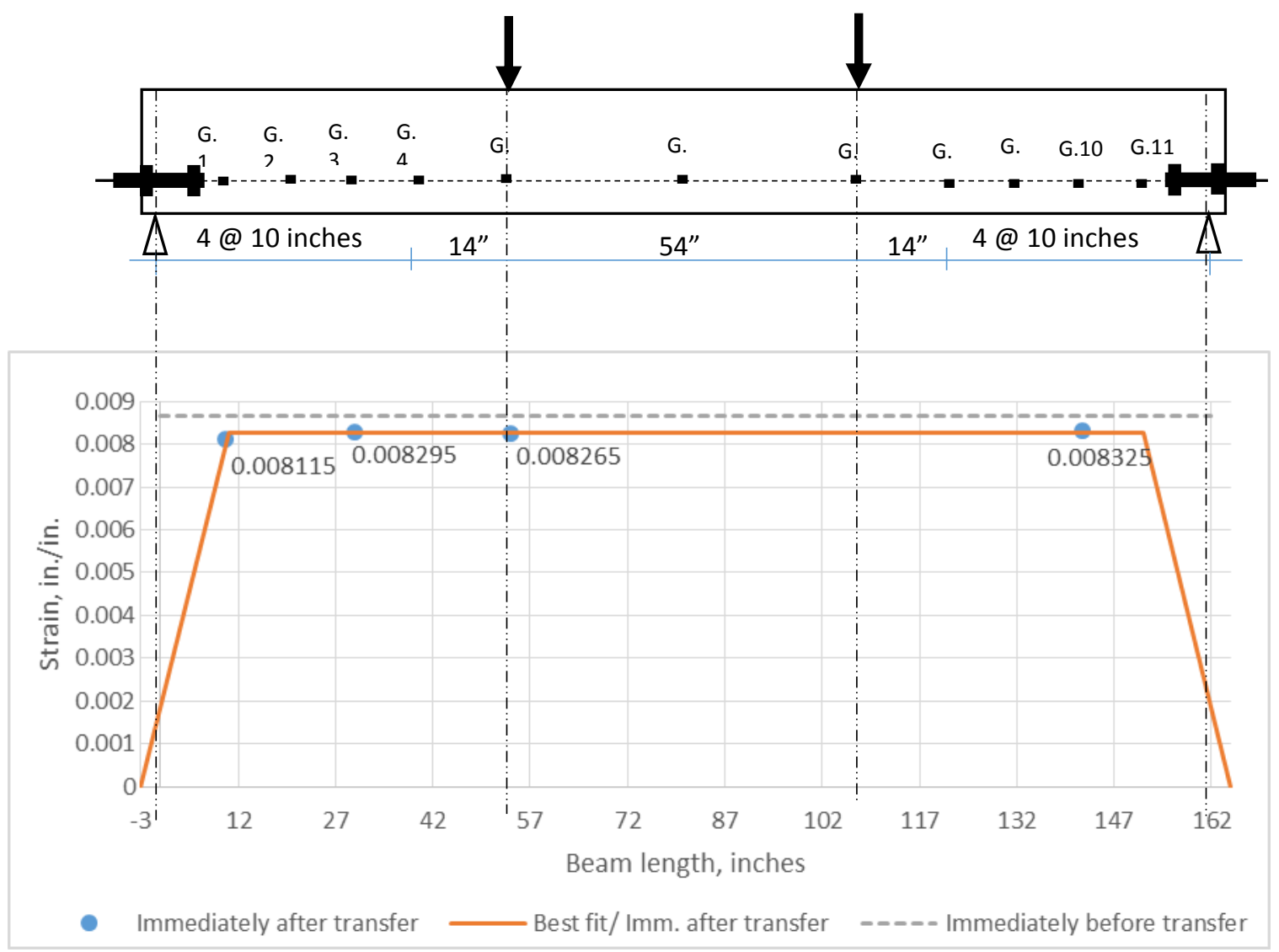

(d) Beam \#4 (B4-4-60)

Figure 4.4 Continued

For Beam \#4, B4-4-60, the results could not be used for transfer length investigation between CFRP strand and concrete because 9 in. of steel tube anchors were embedded inside the concrete at the beam ends. The steel tube was threaded from outside, so that the bond would be even higher. This was confirmed by looking at the plot for Beam \#4 where transfer length was only 13.5 in., which is equal to $27 \mathrm{~d}_{\mathrm{b}}$. Using the steel tube anchor at the ends approximately dropped the transfer length by almost a half. It was assumed that the full initial force had been developed in the steel tube. Therefore, the transfer length was 
achieved by the end of the tube length. It should also be mentioned that the concrete compressive strength might affect the results. It is true that all the beams were designed for the same compressive strength, but the actual compressive strengths were slightly different.

Another method is used to determine the transfer lengths for the first three beams. The results of this method depend on two LVDTs attached to the CFRP at both ends. The principle behind this method is based on measuring the slippage of the CFRP strand inside the concrete due to force releasing. By knowing the slippage of the CFRP relative to the concrete due to force releasing, the transfer length can be estimated as the length required to accommodate this deformation (Krem, 2013). The deformation can be calculated as the following:

$$
\Delta i=\frac{P L}{A E}=\frac{1}{E} * \text { Stress Function } * l_{t}=\frac{1}{E} f_{p i} * l_{t} \quad \ldots . E q .(4-1)
$$

This is the deformation of the length $\mathrm{L}=l_{t}$ when the stress is equal to the prestressing stress before transfer. After transfer, the stress at the ends is equal to zero and the stress at the transfer length is equal to the initial stress. If the function is assumed to be linear, as shown in Figure 4.5, equation 4-1 can be written as the difference between the initial and final deformations $\Delta$ (which is the measured value by the end LVDTs):

$$
\Delta=\left(\frac{1}{E} f_{p i} * l_{t}\right)-\left(\frac{1}{E} * \frac{f_{p i}}{2} * l_{t}\right)=\frac{1}{E} * \frac{f_{p i}}{2} * l_{t} \quad \ldots . E q .(4-2)
$$

So,

$$
l_{t}=\frac{2 E \Delta}{f_{p i}} \quad \ldots . E q .4-3
$$


Where:

$\Delta$ is the CFRP strand deformation.

$\mathrm{P}$ is the prestressing force

$\mathrm{L}$ is the length of the CFRP strand within the transfer length.

A is the cross-sectional area of the CFRP strand.

$\mathrm{E}$ is the modulus of elasticity of the CFRP strand.

$l_{t}$ is the transfer length

$f_{p i}$ is the initial prestressing stress representing the top horizontal line of the strain profile curves for the data collected immediately after transfer, see Figure 4.5 below.

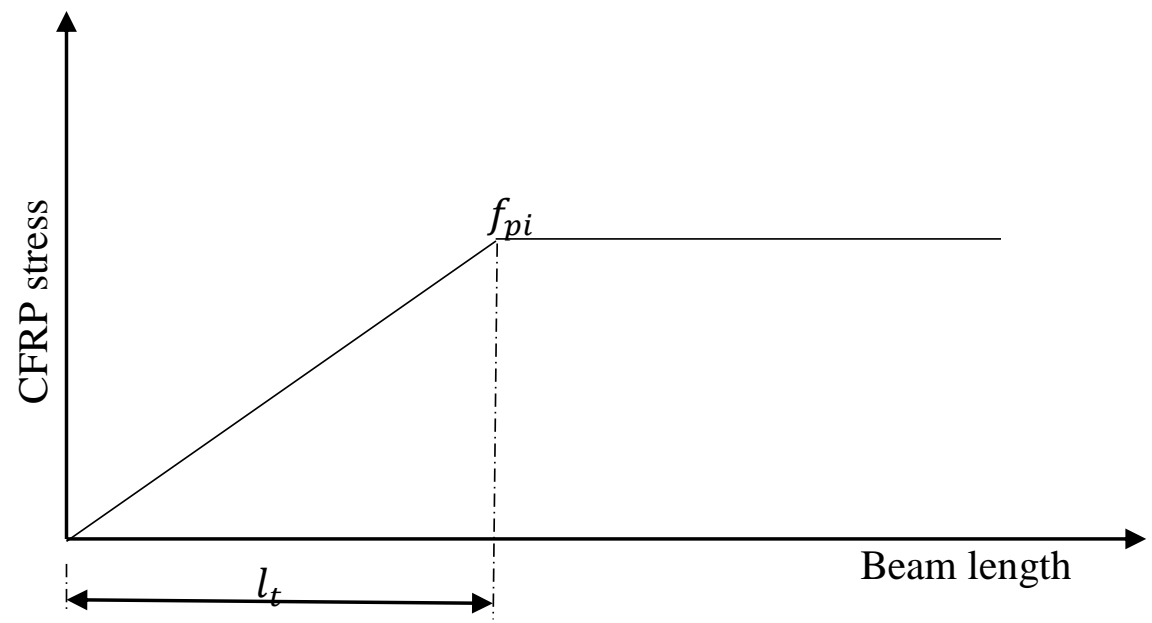

Figure 4.5 Schematic drawing showing the stress development at the ends 
The results are shown in Table 4-2 for both dead and jacking ends as the measurements of the LVDTs were collected from both ends. As it is mentioned in Chapter 3, a 3-in. of CFRP strand was kept not bonded at each end of the beam by using PVC tubes. The elastic deformation of the free length of CFRP strand was counted and subtracted from LVDTs' readings. It can be seen that the transfer lengths estimated by LVDTs' measurements are all less than those measured by strain gauges. However, the difference between the two methods was not significant. It can be stated that the results from both methods were reasonably close. Another observation was that LVDTs' measurements indicated that the transfer length was a little shorter when measured at the dead end.

\begin{tabular}{|c|c|c|c|c|c|c|}
\hline \multirow[t]{2}{*}{ Label } & \multirow{2}{*}{$\begin{array}{c}f_{p i}, \\
\text { ksi }\end{array}$} & \multirow{2}{*}{$\begin{array}{l}f_{c i}^{\prime}, \\
\text { psi }\end{array}$} & \multirow{2}{*}{$\begin{array}{c}\text { Stirrups } \\
\text { spacing, in. }\end{array}$} & \multirow{2}{*}{$\begin{array}{c}l_{t} \text { (in.) } \\
\text { Strain gauges }\end{array}$} & \multicolumn{2}{|c|}{$l_{t}$ (in.), LVDTs } \\
\hline & & & & & Dead end & Jacking end \\
\hline B1-4-65 & 176.9 & 6581 & 6 & 23.9 & 22.3 & 22.3 \\
\hline B2-4-55 & 157.3 & 6950 & 3 & 21.0 & 19.6 & 21.0 \\
\hline B3-4-60 & 163.6 & 6790 & 2 & 19.5 & 18.4 & 18.8 \\
\hline B4-4-60 & 173.3 & 7351 & 3 & 13.5 & - & - \\
\hline
\end{tabular}

Table 4-2 Transfer lengths as a result of LVDTs' \& strain gauges' measurements

\subsubsection{Total and Immediate Losses}

In this particular work, the time between prestressing force releasing and the flexural destruction test was too short in order to investigate the long-term losses. The necessary information here was for the immediate and total losses. The immediate loss in stress was the difference between the prestressing force immediately before and after force releasing. 
The stress immediately before transfer was determined by the load cell and the strain gauges. The stress immediately after transfer was measured by the strain gauges at the middle, usually gauges G.3 to G.9, where the transfer length was already achieved. Although the total losses usually associated with $t=5+$ years, the total losses in this study refer to the difference between the jacking force and the force in CFRP immediately before the flexural test, which is a span of three to four weeks. Table 4-3 summarizes the loss results.

\begin{tabular}{ccccccc}
\hline Beam & Jacking & \multicolumn{2}{c}{ Initial stress, $\boldsymbol{f}_{\boldsymbol{p} \boldsymbol{i}}(\mathbf{k s i})$} & Effective & Immediate & Total losses \\
\cline { 3 - 5 } Label & stress $(\mathbf{k s i})$ & $\begin{array}{c}\text { Imm. before } \\
\text { transfer }\end{array}$ & $\begin{array}{c}\text { Imm after } \\
\text { transfer }\end{array}$ & stress, $\boldsymbol{f}_{\boldsymbol{p} \boldsymbol{e}}(\mathbf{k s i})$ & losses $(\boldsymbol{\%})$ & $(\boldsymbol{\%})$ \\
\hline B1-4-65 & 195 & 184.4 & 176.9 & 178.2 & 4.1 & 8.6 \\
\hline B2-4-55 & 165 & 163.2 & 157.3 & 156.6 & 3.6 & 5.1 \\
\hline B3-4-60 & 180 & 172.1 & 163.8 & 163.4 & 4.8 & 9.2 \\
\hline B4-4-60 & 186 & 181.8 & 173.3 & 174.1 & 4.7 & 6.4 \\
\hline
\end{tabular}

Table 4-3 Immediate and total losses

\subsubsection{Average Bond Stress and Bond Stress Profile at Transfer}

The average bond stress at force transfer was assumed to be the bond stress resulting from dividing the initial force that was transferred to the beam by the contacting area between the concrete and the CFRP rod along the transfer length. It was decided to use the transfer length measured by strain gauges for this calculation. It can be observed from Table 4-4 that the average bond stress increased when the confinement increased by using more stirrups. Comparing Beam \#3 with Beam \#1 and Beam \#2, it can be observed that the 
average bond stress is higher for Beam \#3 because of the confinement provided despite the fact that Beam \#1 had a higher prestressing level and Beam \#2 had a lower prestressing level. The confinement effects on bond improvement was also confirmed by the beam flexural test results which are covered in section 4.4.

$$
\text { Avg.bond }=\frac{F_{i}}{\pi d_{b} l_{t}} \quad \text {.... Eq. }(4-4)
$$

\begin{tabular}{ccccccc}
\hline Beam \# & $\begin{array}{c}\text { Beam } \\
\text { label }\end{array}$ & $\boldsymbol{f}_{\boldsymbol{i}}$, ksi & Fi, kips & $\begin{array}{c}\text { Stirrups } \\
\text { spacing, in. }\end{array}$ & $\boldsymbol{l}_{\boldsymbol{t}}$, in. & $\begin{array}{c}\text { Avg. Bond } \\
\text { Stress, ksi }\end{array}$ \\
\hline 1 & B1-4-65 & 176.9 & 34.67 & 6 & 23.9 & 0.924 \\
\hline 2 & B2-4-55 & 157.3 & 30.83 & 3 & 21 & 0.935 \\
\hline 3 & B3-4-60 & 163.8 & 32.10 & 2 & 19.5 & 1.048 \\
\hline 4 & B3-4-60 & 173.3 & 33.97 & 3 & 13.5 & 1.602
\end{tabular}

Table 4-4 Average bond stress at transfer

Figure 4.6 shows the CFRP tensile stress development and bond stress profile at transfer for all the four beams. The tensile stress profile immediately before and after transfer is presented in Figure 4.6 for each beam. These stresses were measured by the strain gauges distributed along the CFRP strand. For the first three beams, 3 in. of the CFRP strand was unbonded at the ends. The zero points in x-axis of Figure 4.6 represent the beginning of the attachment between the CFRP strand and the concrete beam, and also represents the location of the left support. This is partially true for Beam \#4. Although the zero point in Figure 4.6 (d) represents the location of the left support, it does not represent the point where the beginning attachment occurs. 

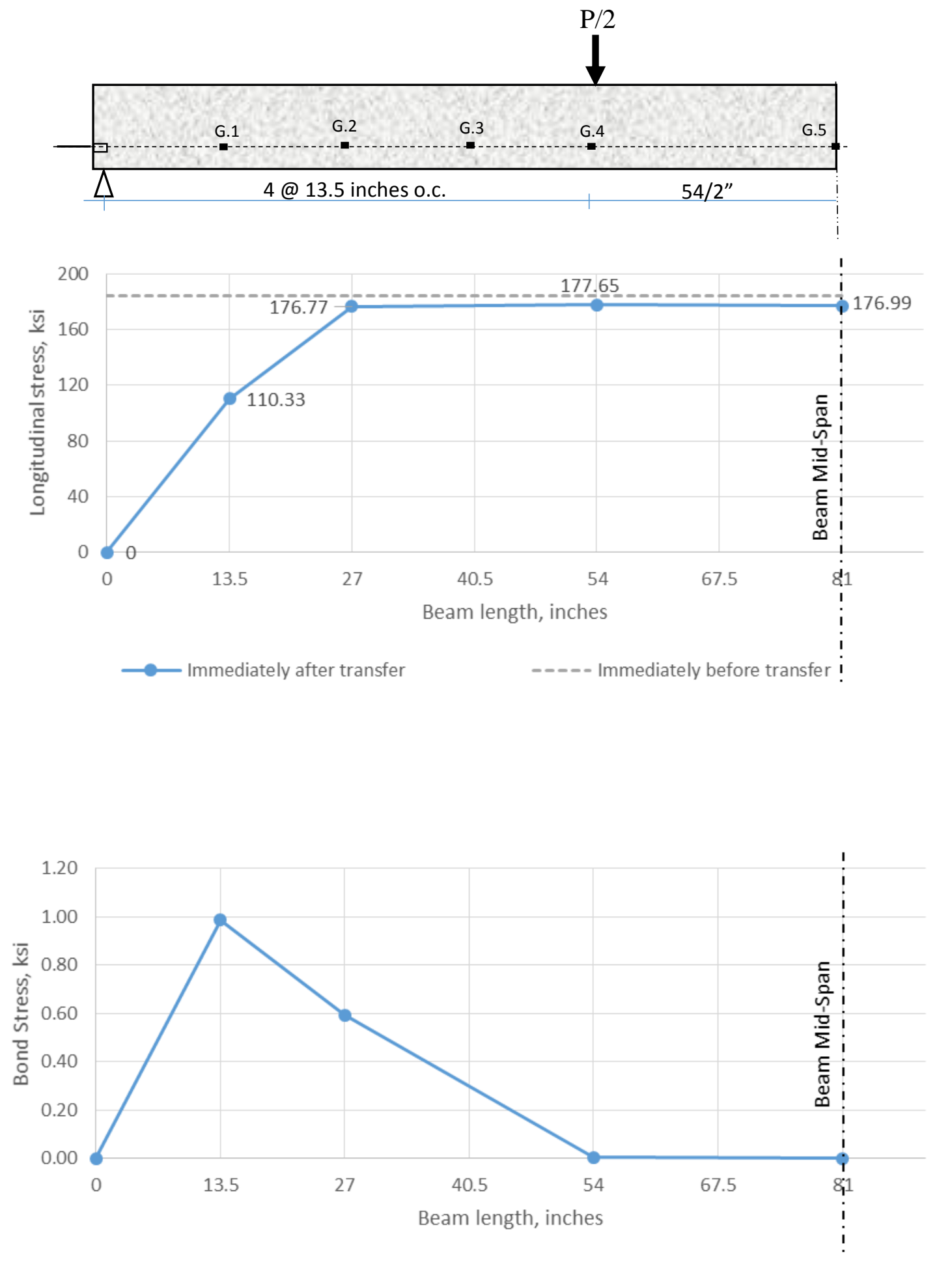

(a) Beam \#1 (B1-4-65)

Figure 4.6 CFRP tensile stress development and bond stress profile at transfer 

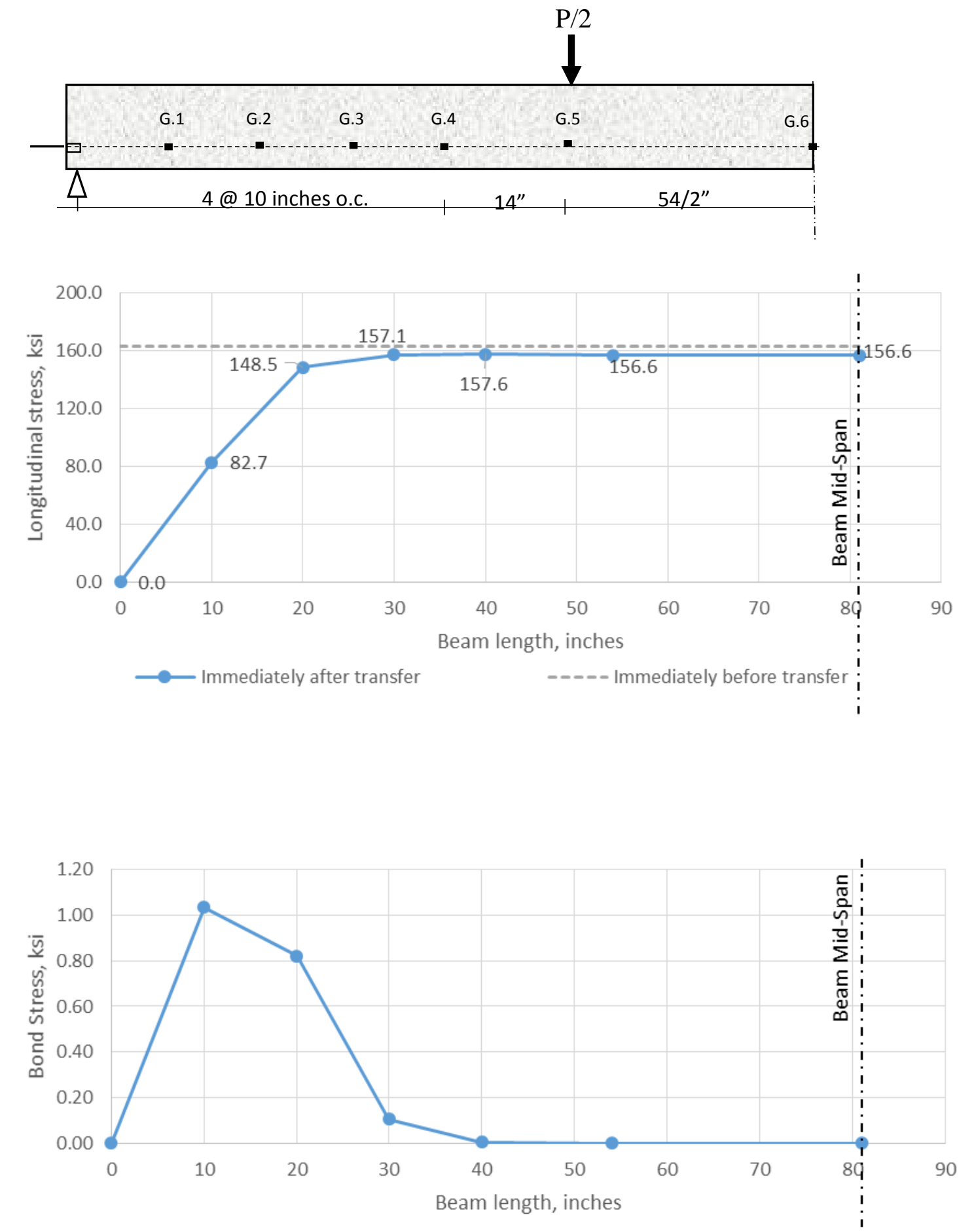

(b) Beam \#2 (B2-4-55)

Figure 4.6 Continued 

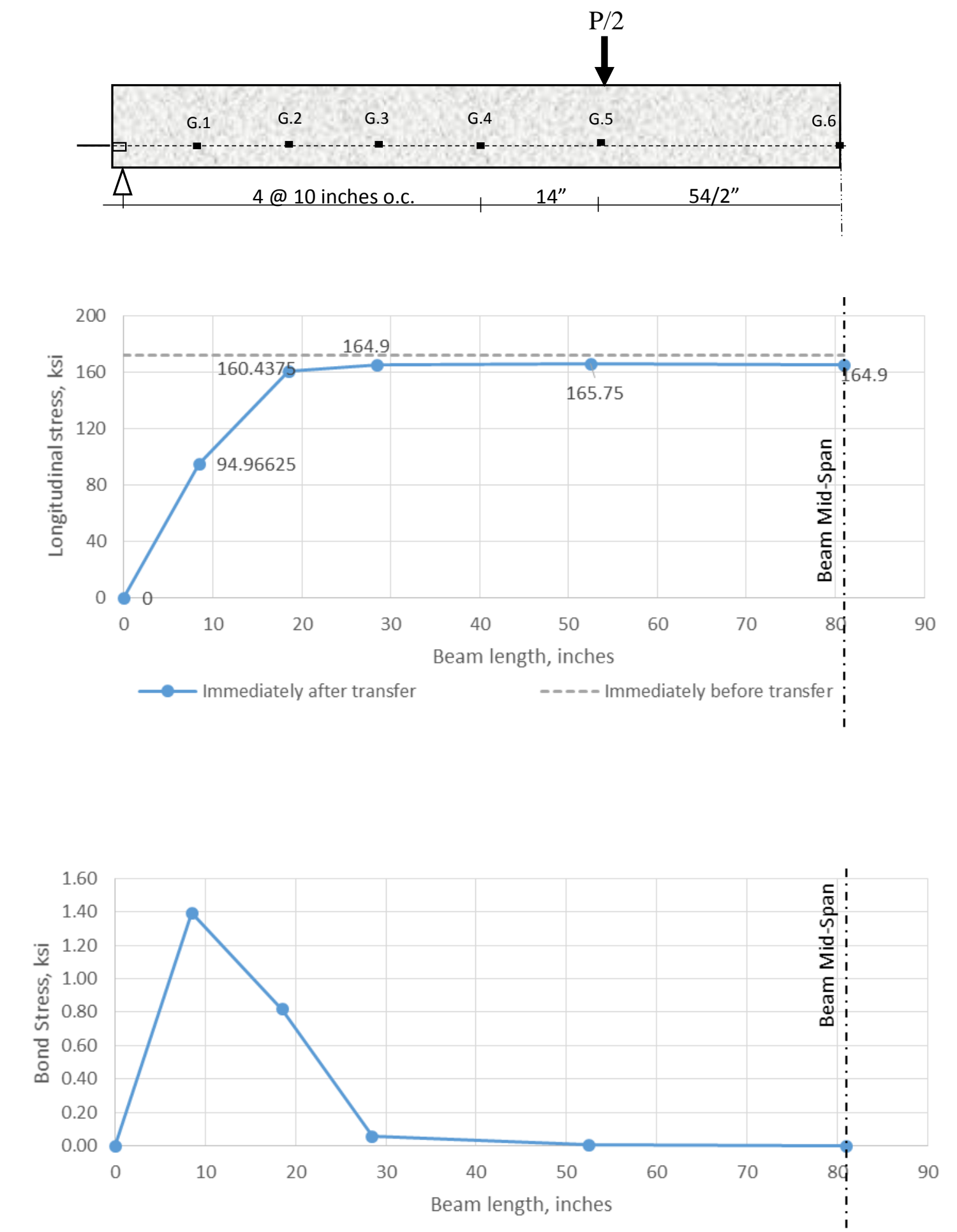

(c) Beam \#3 (B3-4-60)

Figure 4.6 Continued 

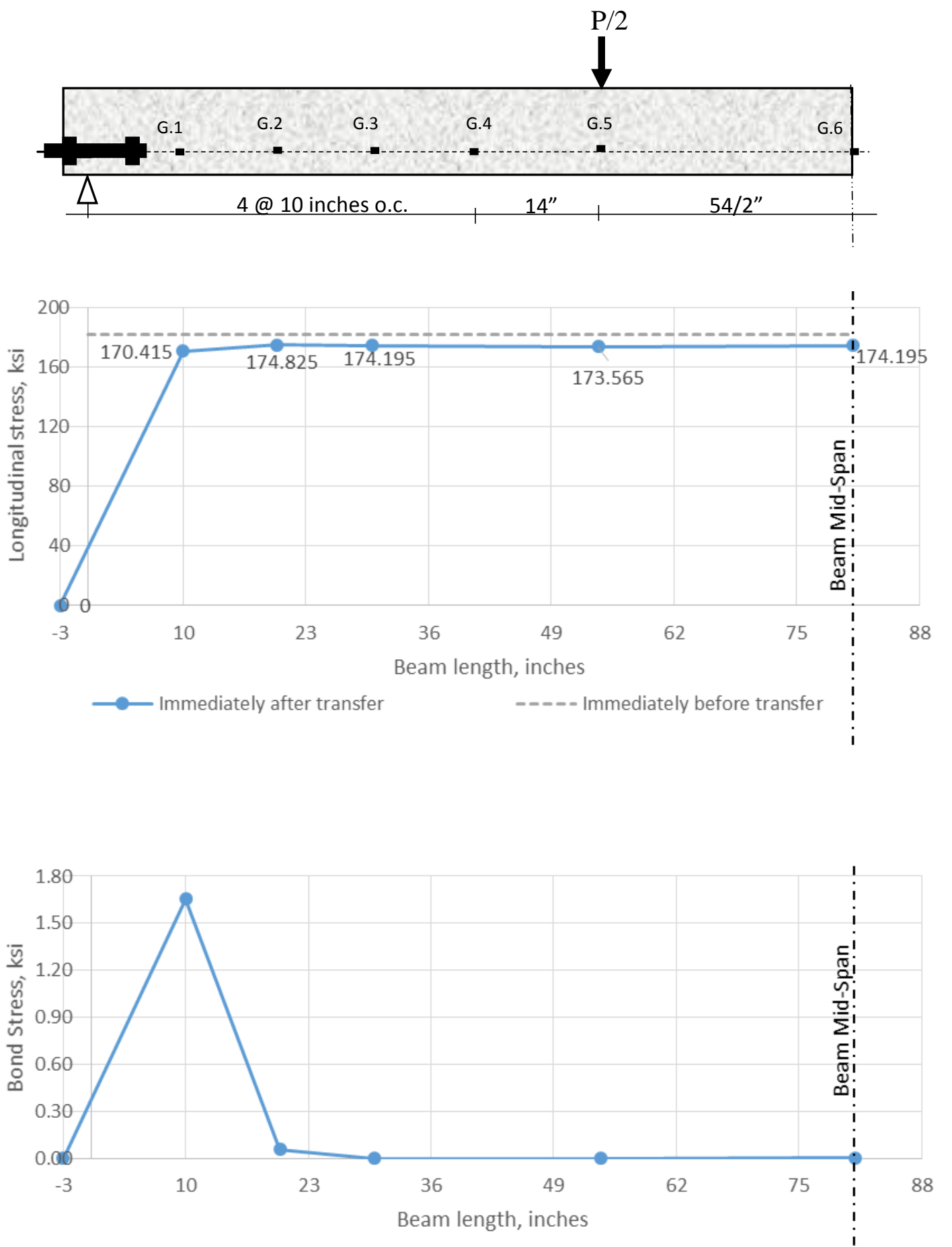

(d) Beam \#4 (B4-4-60)

Figure 4.6 Continued 
Since Beam \#4 had anchors at the ends, the attachment between the CFRP and concrete began at the beam ends. This is further illustrated in Figures 4.7 and 4.8 below.
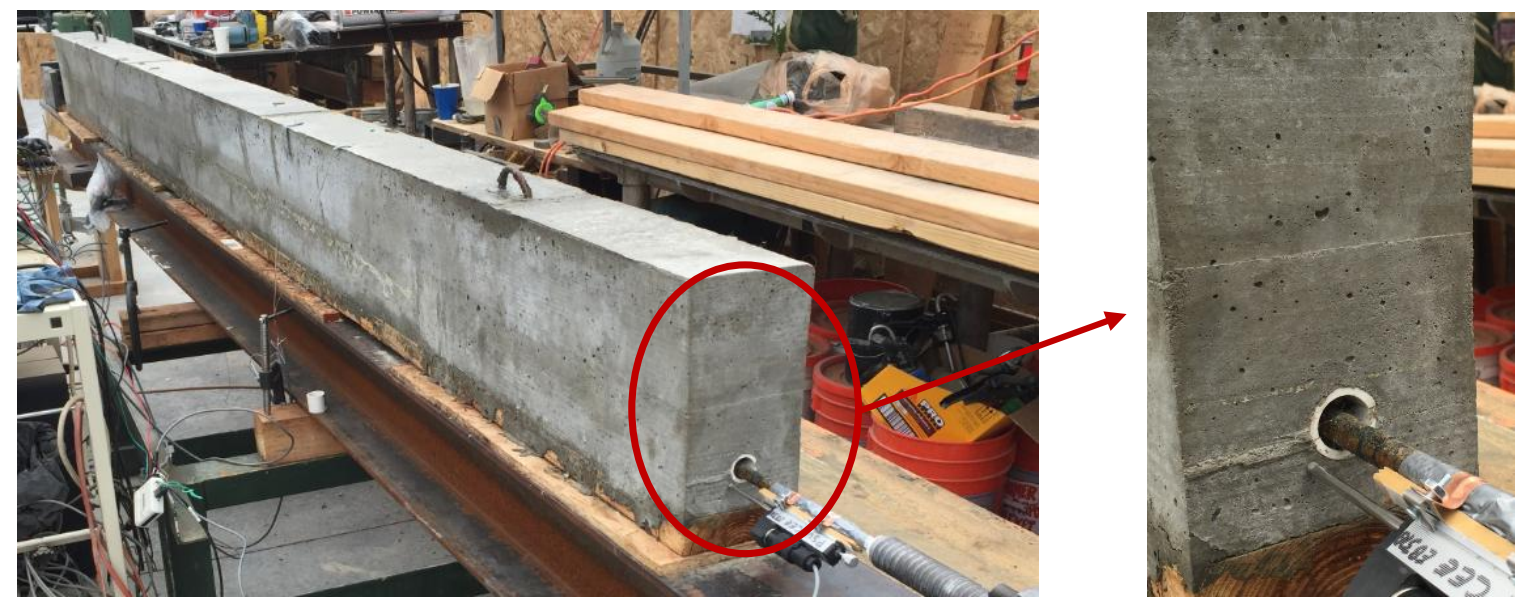

Figure 4.7 Typical view for Beams \#1 to \#3 showing the un-bonded technique for CFRP at the ends.

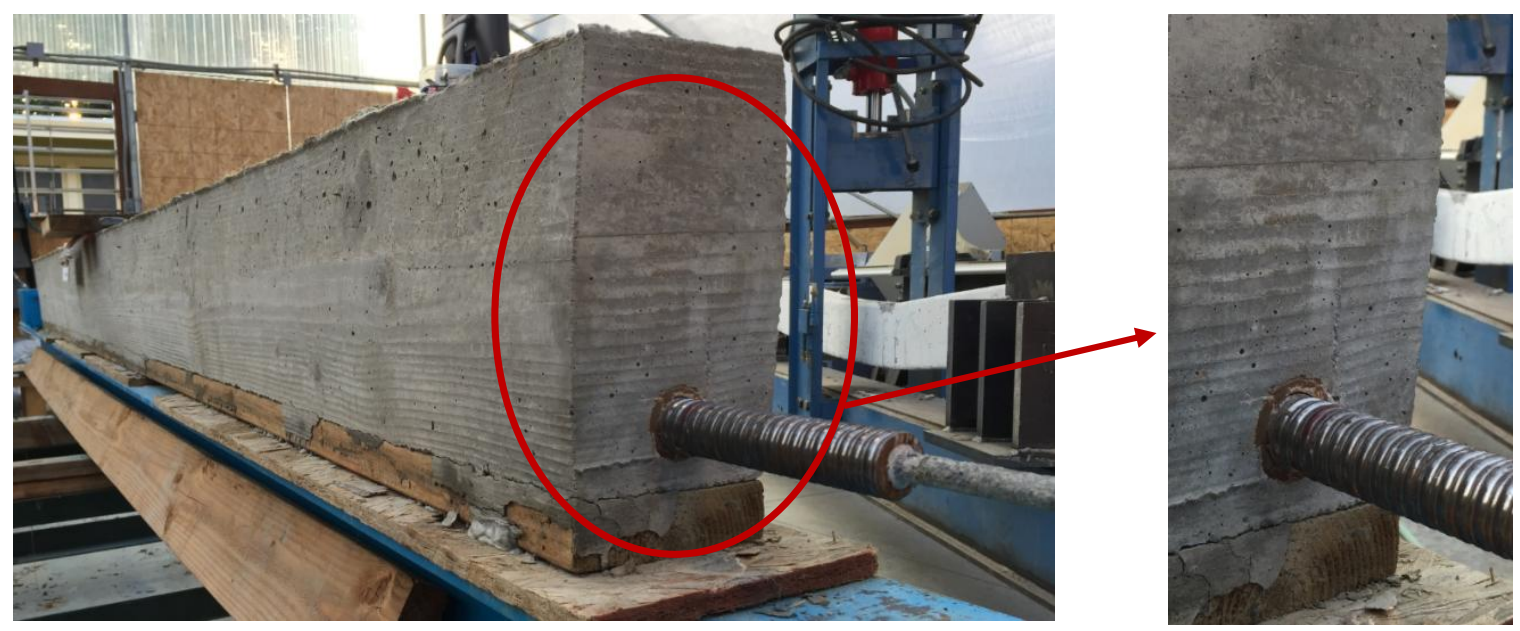

Figure 4.8 Typical view for Beam \#4 showing the anchoring technique of CFRP strand at the ends. 
Even though the stress development in transmission zone (the zone of transfer length) was assumed to be linear in transfer length calculations, Figure 4.6 shows that some stress nonlinearly developed from zero at the ends to the initial stress at the transfer length. The tensile stress developed from zero to certain length represents the transfer length. As described before, the transfer length was shorter when the bond performance was increased by increasing the confinement. For beam \#4, the tensile stress reached the initial stress quickly not only because the bond performance had been enhanced by using steel anchors at the ends, but also the contribution of bearing stresses that was taken by the steel washers at the anchors, see Figure 3.18/ C.

With regard to the bond stress at transfer, in spite of the prestressing level, the bond stress was higher when more stirrups were used. More confinement led to a more rapid development of the stress over shorter length, which then led to higher bond stress for the same force. Generally, the peak of the bond stress at transfer was developed close to the transfer length. After the peak, the bond stress started to decease until it reached almost zero close to the maximum moment region. All beams showed the same pattern of bond stress profile. The results showed that the peak bond stress at transfer increased from 990 psi for Beam \#1 to 1,390 psi for Beam \#3 where the confinement, provided by steel stirrups, was increased three times. This confirmed that changing the stirrups spacing significantly affected the bond performance. For Beam \#4, the provided confinement was equal to what was used for Beam \#2, but CFRP was anchored by threaded steel tubes at the ends. This helped the bond performance significantly by leading to the largest "computed bond stress" of 1660 psi. It should be noted that the 1660 psi was calculated by dividing the CFRP 
tensile force by the contacting area between the concrete and CFRP along the transfer length ignoring the area of the steel tube. Also, the contribution from bearing stress provided by the steel washers of the anchors were neglected. On the other hand, even though the initial prestressing force for Beam \#1 was the largest, the bond stress for Beam \#1 was the lowest because the force was transferred over longer length.

\subsubsection{Theoretical Prediction of CFRP Transfer Length}

There are a number of equations in the literature for transfer length predictions. Table 4-5 compares the transfer length experimentally measured with the theoretical equations. The equations are listed, but their details and coefficients can be found in the reference sources. It can be seen that the experimental results of the transfer length of Aslan 200 CFRP bars agreed mostly with the transfer length results predicted by the equation recommended by ACI Committee 440 (2004). However this equation is recommended for Leadline ${ }^{\mathrm{TM}}$ rods and Carbon Fiber Composite Cables (CFCCs), which are also carbon FRP. Since the properties of Leadline ${ }^{\mathrm{TM}}$ are closer to Aslan 200 CFRP which was used for this work, the $\propto_{\mathrm{t}}$ factor used in the equation was assumed to be the same as used for Leadline ${ }^{\mathrm{TM}}$, which is 10. Although ACI 440.4R equation predicts the transfer length for Aslan 200 CFRP strands reasonably well, it does not account for confinement. This could be the reason why the equation overestimated the transfer length for Beam \#3. 


\begin{tabular}{|c|c|c|c|c|}
\hline Beam label & & Beam \#1 & Beam \#2 & Beam \#3 \\
\hline Experimentally Measured & & $l_{t}=24.4^{(1)}$ & $l_{t}=21.0^{(1)}$ & $l_{t}=19.5^{(1)}$ \\
\hline Source & Equation & & & \\
\hline ACI 440.4R & $l_{t}=\frac{f_{p e} d_{b}}{\alpha_{t} f_{c}^{\prime 0.67}}$ & 24.46 & 20.96 & 22.15 \\
\hline ACI 318-14 for steel & $l_{t}=f_{s e} d_{b} / 3$ & 29.48 & 26.21 & 27.27 \\
\hline Zia and Mostafa (1997) & $l_{t}=1.3\left(\frac{f_{s i}}{f_{c i}^{\prime}}\right) d_{b}-2.3$ & 15.17 & 12.41 & 13.36 \\
\hline Russell and Burns (1996) & $l_{t}=f_{s e} d_{b} / 2$ & 44.22 & 39.31 & 40.91 \\
\hline $\begin{array}{l}\text { Mitchell, Cook, and Khan } \\
\text { (1993) }\end{array}$ & $l_{t}=\frac{f_{s i} d_{b}}{3} \sqrt{\frac{3}{f_{c i}^{\prime}}}$ & 19.90 & 17.22 & 18.13 \\
\hline
\end{tabular}

(1): The experimental transfer length measure by strain gauges for each beam (inch).

Table 4-5 Theoretical vs. experimental transfer lengths

\subsection{Flexural Tests of the Prestressed Concrete Beams}

A total of four beams were tested until failure. All of them were subjected to five cycles of loading up to the minimum of either $63 \%$ of the predicted ultimate load or a strain in CFRP equal to $1 \%$. Then, the load was applied monotonically until failure at the sixth cycle. The parameters were mainly the amount of confinement, represented by the number of steel stirrups, and the prestressing level. At the beginning of this work, the aim was to change the prestressing level from as low as $30 \%$ to as high as $75 \%$ in order to see the effects of prestressing level on ductility. After testing the first beam, it was realized that the main issue with CFRP strands in prestressed concrete beams was the bonding issue. Therefore, 
the number of provided stirrups at the shear span region for the second beam was doubled in order to provide more confinement. However the bond issue was also the problem, and led to failure before reaching the predicted load. As a result, three times the number of stirrups used for the first beam were used for the third beam. The failure mode of the third beam was concrete crushing, but the maximum failure load did not go more than what was achieved from the second beam. Finally, it was decided to solve the bond problem by using two steel anchors at the ends. These anchors could prevent the slippage at the ends, thus solving the bond issues.

Table 4-6Table 4-6 summarizes the details of the four beams. During the flexural tests, the applied load, CFRP strain at the locations of interest, strain in concrete at the top fiber of the mid span section, mid-span deflection, and the CFRP slippage at both ends were recorded. The aim of this section is to analyze and discuss these collected data.

\begin{tabular}{|c|c|c|c|c|c|}
\hline \multirow[t]{2}{*}{ Beam label } & \multirow[t]{2}{*}{ Prestressing (\%) } & \multicolumn{2}{|c|}{ Stirrups' spacing (in.)* } & \multirow[t]{2}{*}{ End anchors } & \multirow[t]{2}{*}{$f_{c}^{\prime}(\mathbf{p s i})$} \\
\hline & & Shear span & Mid-span & & \\
\hline B1-4-65 & 65 & 6 & 6 & No & 7183 \\
\hline B2-4-55 & 55 & 3 & 6 & No & 7637 \\
\hline B3-4-60 & 60 & 2 & 6 & No & 7269 \\
\hline B3-4-60 & 60 & 3 & 6 & Yes & 7518 \\
\hline
\end{tabular}

Table 4-6 Design details for the four beams 


\subsubsection{Load Deflection Responses}

As described before, the beams were subjected to cyclic loading. All of the beams were simply supported and subjected to two-point loading. The two points, where the point loads were applied, divided the beam into three equal lengths equal to span length divided by 3 (L/3). The clear span length was $13.5 \mathrm{ft}$., which led to a shear span of $13.5 / 3=4.5 \mathrm{ft}$. All the beams had the same shear span length. The applied moment, then, was equal to:

Applied moment $=\frac{P}{2} \cdot a \quad \ldots . E q \cdot(4-5)$

Where:

$\mathrm{P}$ is the total applied load (kips)

a is the shear span (ft.), which is equal to $4.5 \mathrm{ft}$. for all beams.

In terms of the applied moment, it should be mentioned that the dead load caused by beams' own weight was ignored here. It is assumed that the moment caused by beam's dead load was very small and did not affect the results. In terms of deflection, the camber deflection caused by prestressing force was not considered. Therefore, the zero deflection that was presented in the moment-deflection curves in this work was actually not the absolute zero. In reality, the zero deflection here represents a small value of upward deflection (camber). 
In general, the moment-deflection curves for all beams were bilinear. The first part of the moment-deflection curves was a linear line between zero moment to the cracking moment. The post cracking response, from the cracking moment to the ultimate moment, could also be assumed as a linear, but with reduced stiffness. Since the beams were subjected to cyclic loading, there was a small permanent deflection after the first cycle. Generally, each beam seemed to behave the same for the following five cycles and returned to its permanent deflection after releasing the load. The only noticeable reduction in stiffness was seen between the first cycle and the rest of the cycles. The flexural cracks were developed mainly at the maximum moment region for the first five cycles, where the maximum load applied was 60 to $65 \%$ of the maximum predicted load. The cracks closed when the load was released to zero. After loading and un-loading five cycles, the beam was subjected to a monotonic loading at the sixth cycle until failure. The cracks kept widening as the load increased. Also, new cracks developed in the shear span when the load increased. Before failure, in general, the cracks were distributed along $75 \%$ of the beam clear span. However, the widest cracks were flexural cracks and developed under the two point loads. The crack patterns and development of crack widths with the applied load will be discussed for each beam.

\subsubsection{Beam \#1 (B1-4-65)}

As mentioned before, it was decided to test the beams under cyclic loading. The aim was to push the prestressed concrete beams beyond the service load for five cycles. This would provide more information about the flexural behavior of CFRP prestressed concrete beams under high cyclic loading. Based on the predicted model, the CFRP would reach its 
guaranteed tensile strength (300 ksi) when the applied moment was $37 \mathrm{kip}$-ft. for this particular beam, the first five cycles went up to $75 \%$ of its ultimate strength. Figure 4.9 shows the moment vs. deflection curve for Beam \#1 (B1-4-65)

The initial prestressing force for Beam \#1 (B1-4-65) was the highest among all four beams, and its moment capacity was the lowest. In addition, its ductility was also the lowest. The steel stirrups' spacing for this beam was 6 in. on centers distributed along the entire span. This was the minimum shear reinforcement based on ACI 318-11. The steel stirrups worked as shear reinforcement, but also provided confinement that helped CFRP-concrete bonding behavior. The results indicated that with this amount of confinement, the provided concrete cover and the concrete compressive strength, the flexural bond length was much less than the required length in order to develop the ultimate CFRP force. Therefore, it can be stated that the reason for this early failure was that the concrete reached its maximum bond stress that it could handle, thus initiating the slippage of the CFRP strand. It can be seen from Figure 4.10 that the slippage at the ends started to increase when the load got close to the maximum. Suddenly, the concrete gave up and large amount of slippage occurred at the instant of failure. Once the slippage happened, the beam lost most of its prestressing force and could not behave as a prestressed concrete beam any more. It also could not be considered as an ordinary reinforced concrete beam because there was no bond between the CFRP rod and the concrete. As a result, the concrete beam collapsed. 


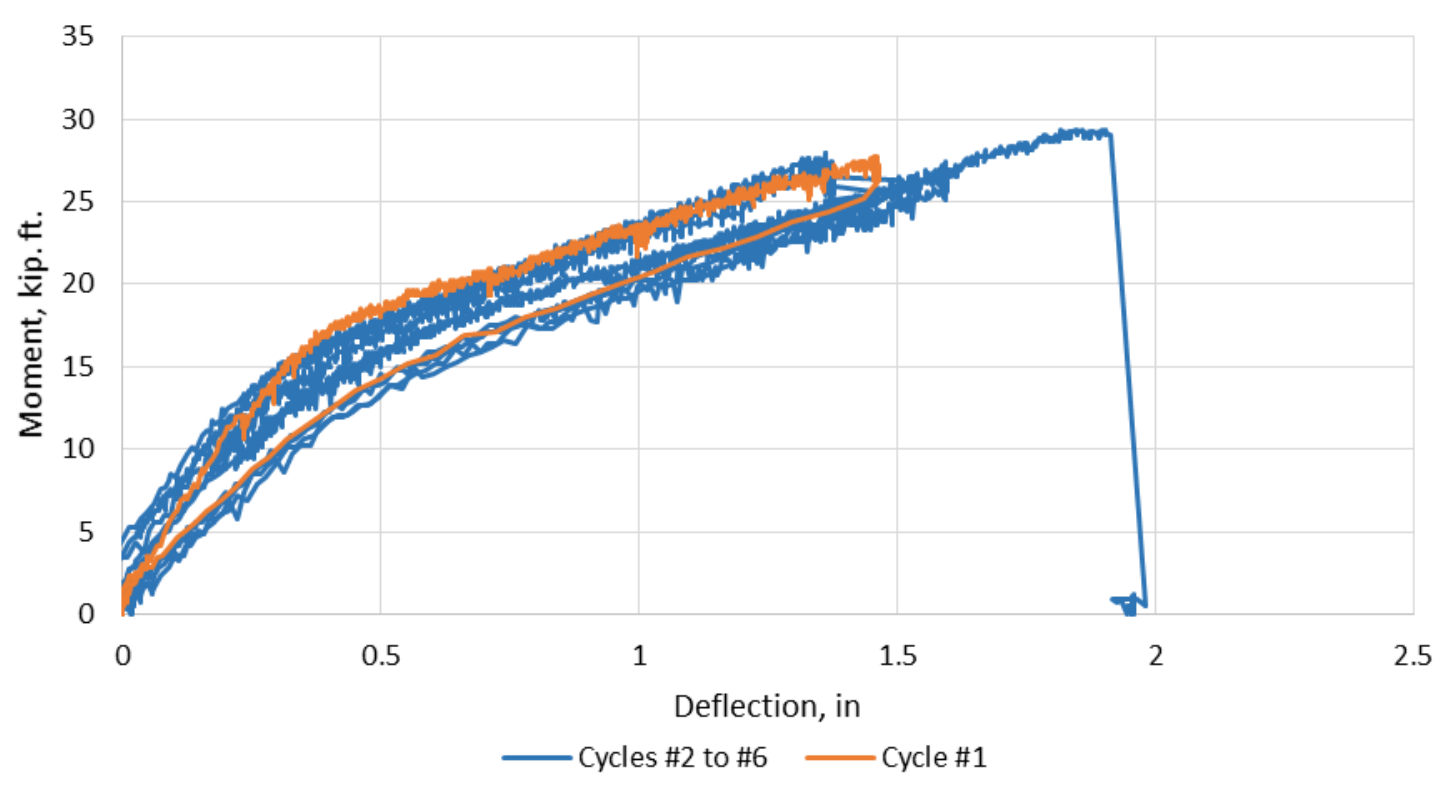

Figure 4.9 Moment vs. deflection for Beam \#1-Mode of failure is CFRP slippage

It can be observed from Figure 4.9 that the cracking moment was about 18 kip-ft. If it is assumed that the concrete cracks at a tensile stress equal to $6 \sqrt{f_{c}^{\prime}}$, then the expected cracking moment would be 19 kip-ft. After cracking moment, the stiffness dropped dramatically and continued linearly until the end of cycle one. The first cycle ended at a moment of $27 \mathrm{kip}-\mathrm{ft}$. and a deflection of $1.46 \mathrm{in}$. The following four cycles also ended at a moment equal to 27 kip-ft., or just a little less, but the deflection was $1.55 \mathrm{in}$. For one cycle shown in Figure 4.9, there is a "starting moment" which is because the load was not decreased to zero when the beam was unloaded. During testing, sometime the LVDT plunger position moves very slightly in the lateral direction and it can show a slightly lower than the actual deflection. The crack widths were measured, using crack width microscope, at different levels of loading. The maximum crack width at peak of cycle one was $0.5 \mathrm{~mm}$. 
It was recorded that the maximum crack width for the second and third cycle was $0.6 \mathrm{~mm}$. The fourth and fifth cycles exhibited a crack width of $0.7 \mathrm{~mm}$. No crack width was recorded for the last cycle as it was not expected that the beam would fail at 29 kip-ft. Figure 4.10 shows the load vs. end slippage at the ends for Beam \#1.

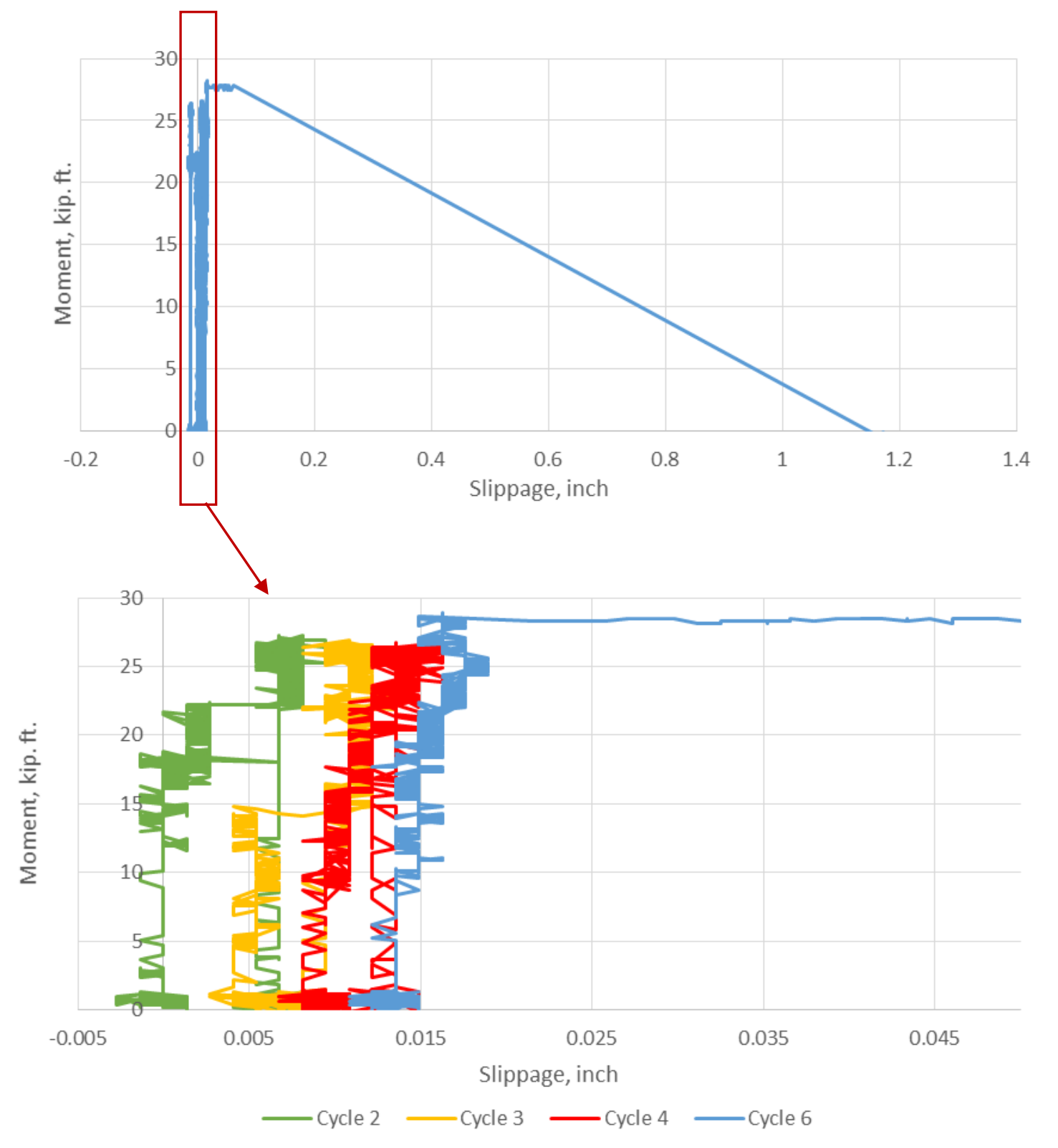

Figure 4.10 Load vs. end slippage at the ends - Beam \#1 
Figure 4.10 points to the probable cause of failure for Beam \#1. It can be observed how the slippage started growing cycle after cycle. The beam failed at the sixth cycle when the load was raised from $27 \mathrm{kip}-\mathrm{ft}$. to $29 \mathrm{kip}-\mathrm{ft}$. This can be described as poor bonding performance between the concrete and the CFRP strand. Since not enough bonding was provided, the CFRP strand slipped before developing its maximum capacity. Losing the CFRP force led to zero pre-compression stress in the concrete cross section, thus the beam acting as a plain concrete beam and losing its moment capacity.

Figure 4.11 shows moment vs. CFRP strain during flexural test for Beam \#1.
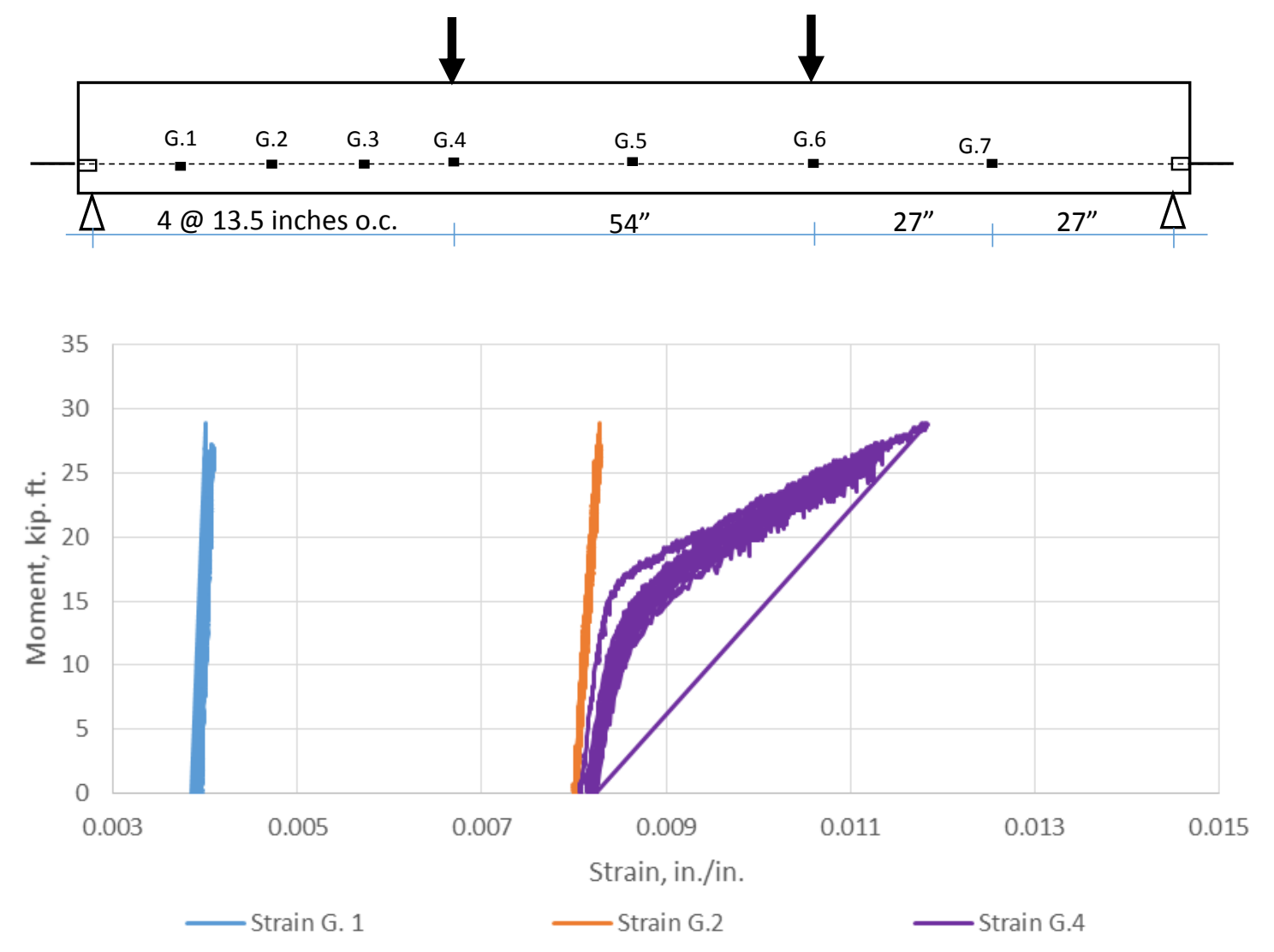

Figure 4.11 Moment vs. CFRP strain during flexural test-Beam \#1 
It can be observed from Figure 4.11 that the maximum strain in the CFRP strand at failure was 0.0118 . Therefore, the CFRP strand had not developed more than $85 \%$ of its guaranteed capacity and $79 \%$ of its actual capacity.

Figure 4.12 shows various photos of the flexural test of Beam \#1. The failure location, as shown in the Figure 4.12, was between the support and the point load, at the middle of the shear span. At this location, the applied shear was maximum, and applied moment was half the maximum. Therefore, it can be said that the concrete beam with de-bonded CFRP strand failed at this location because it could not handle the combination of maximum shear and half of the maximum applied moment. Theoretically, as will be discussed in more details in the following chapter, the moment capacity at the location of failure was only 7.0 kip-ft. based on the maximum stress experimentally recorded at the failure location (Strain G.2). However, the maximum applied moment at the location of failure was 14.5 kip-ft. This was again because of the slippage in CFRP. It can be clearly observed from Figure 4.11 that strain G.2 was not picking up any additional load. On the other hand, the CFRP force at the mid-span region, recorded by strain G.4, was developing while the applied load was increasing. At the failure load, the CFRP strain at mid-span, recorded by strain G.4, was 0.0118 . Theoretically, the moment capacity provided based on this strain was 31.0 kipft. The maximum applied moment was 28.9 kip-ft. This explains why the beam failed at the middle of the shear span (location of strain G.2), and did not fail at the maximum moment region. 


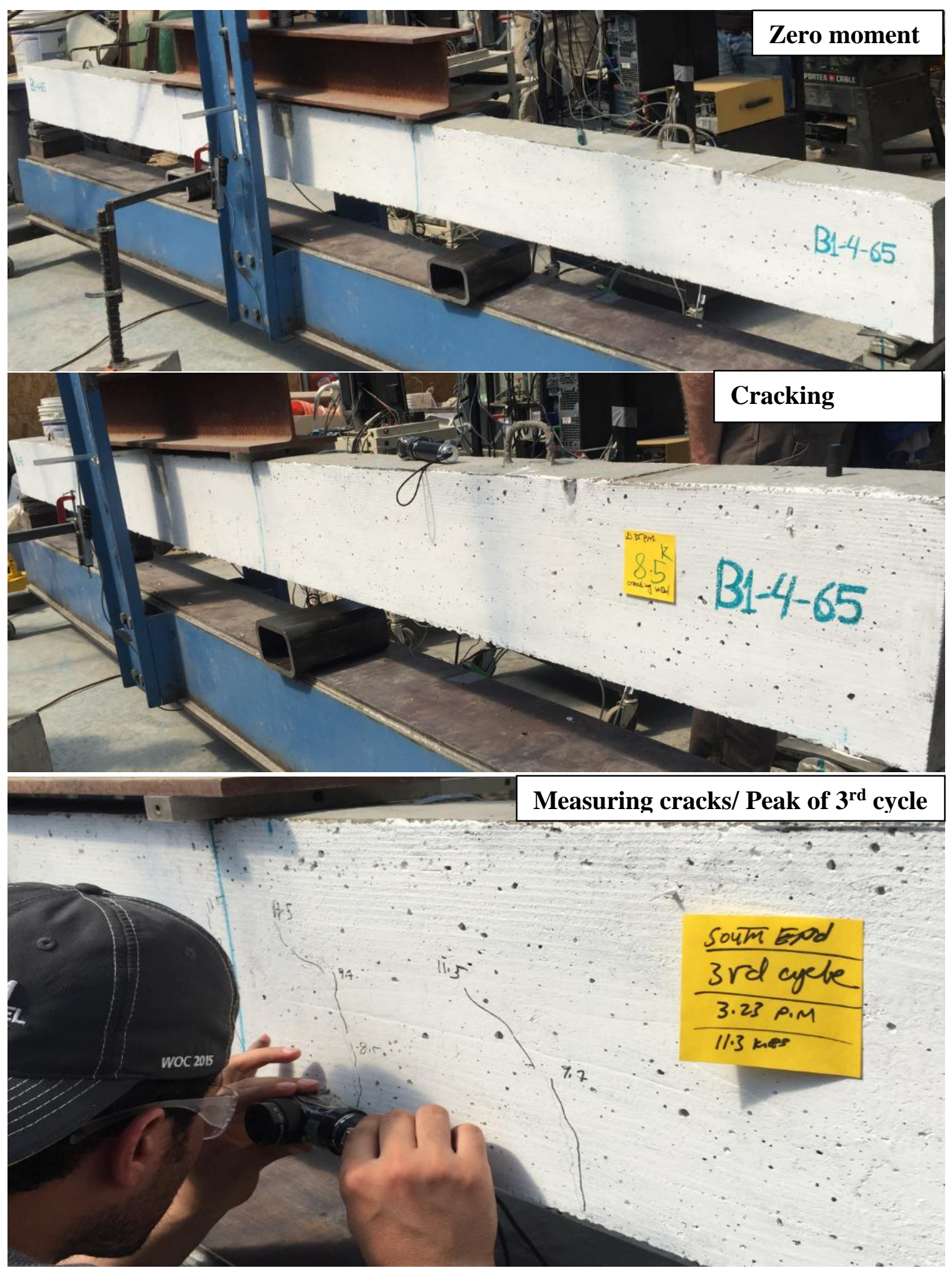

Figure 4.12 Photos of the flexural test of Beam \#1 

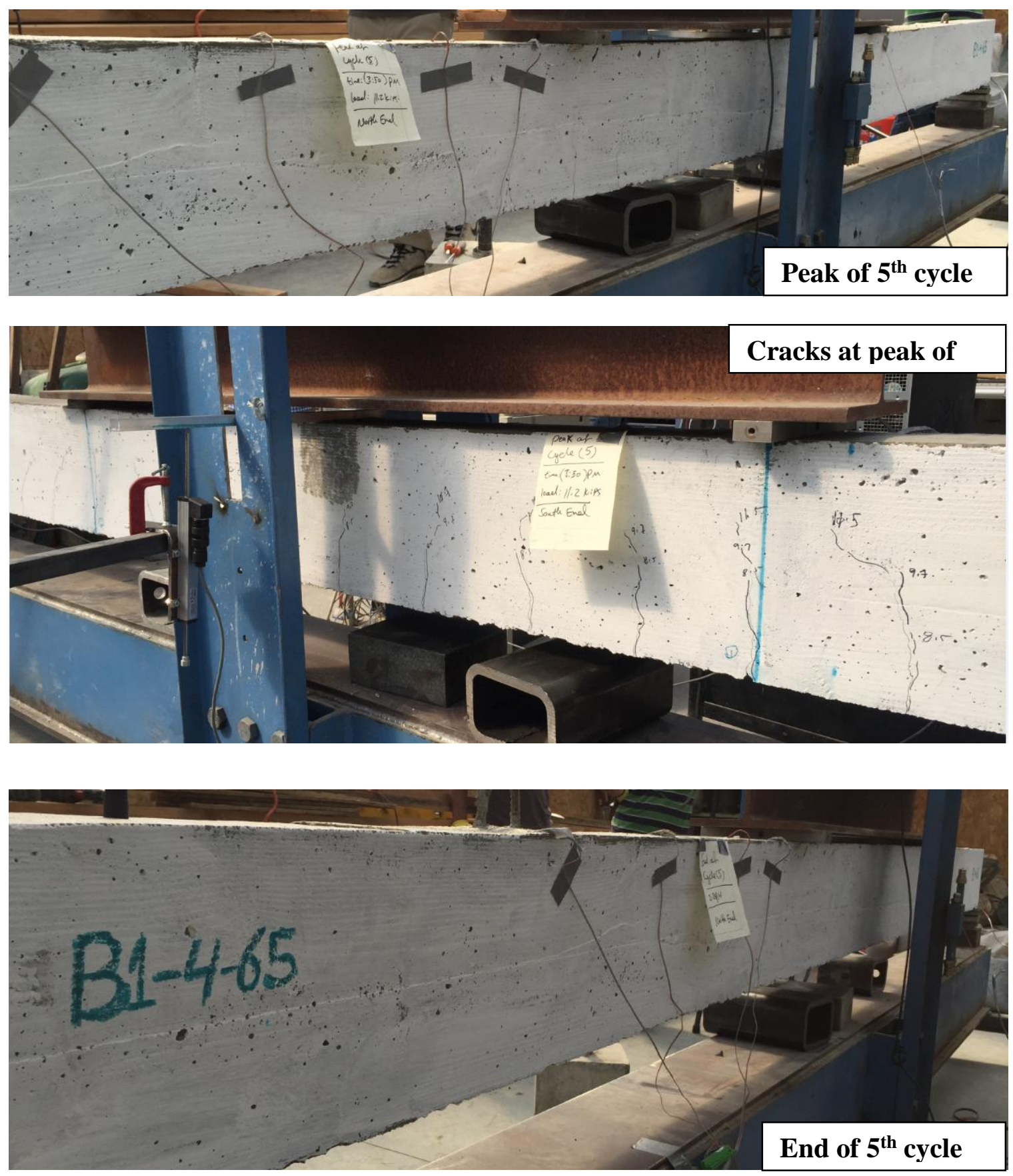

Figure 4.12 Continued 

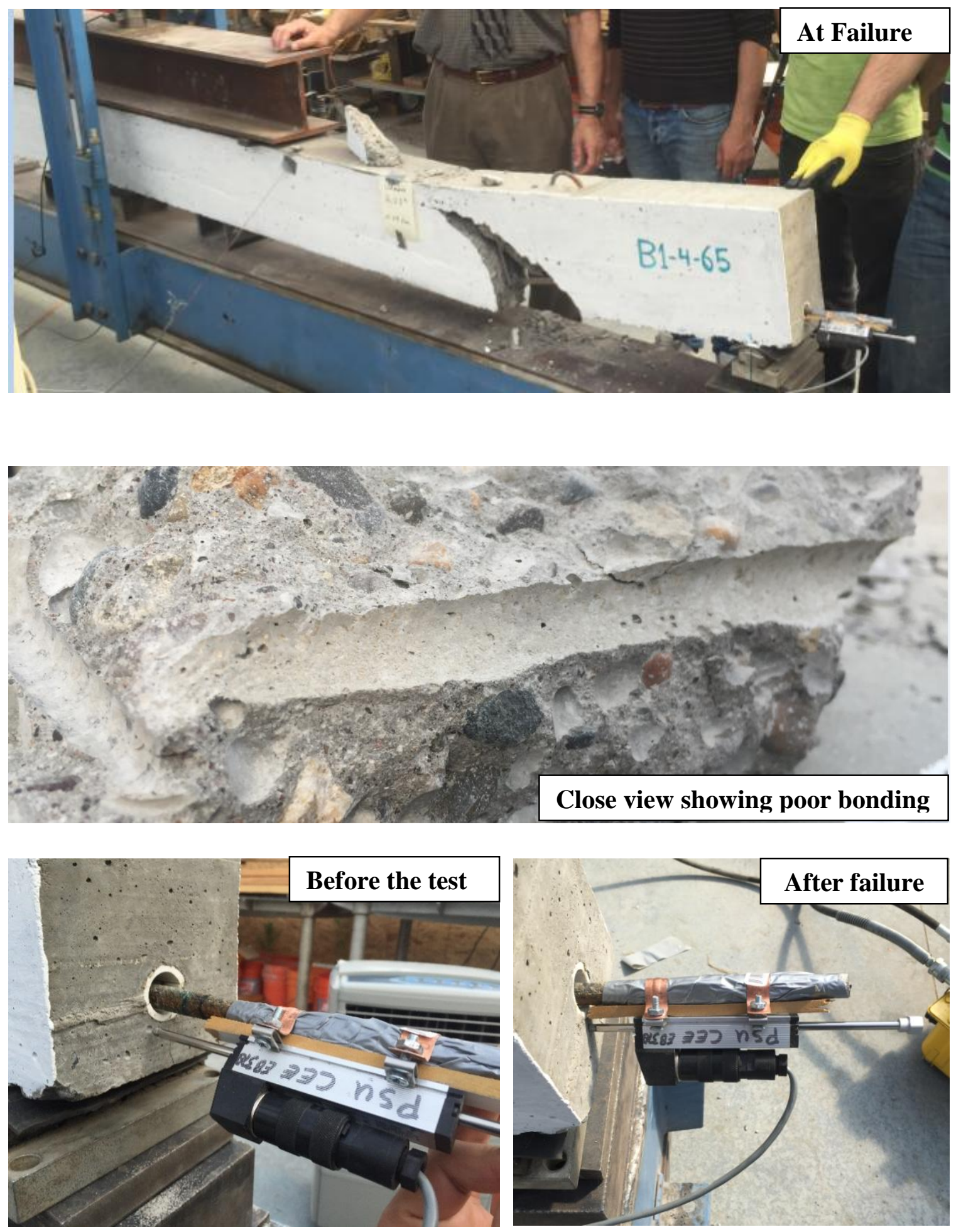

Figure 4.12 Photos of the flexural test of Beam \#1 


\subsubsection{Beam \#2 (B2-4-55)}

Knowing the bonding problem for Beam \#1, the confinement for Beam \#2 was increased by doubling the number of steel stirrups used as shear reinforcement. The number of stirrups at the maximum moment region, between the point loads, was kept 6 in. for all beams. The prestressing level was slightly reduced to $55 \%$ from the previous level of $65 \%$. All other beam properties were the same as Beam \#1.

Figure 4.13 shows moment vs. deflection for Beam \#2. The flexural capacity of Beam \#2 was 22\% higher than Beam \#1 (35.3 kip-ft. instead of 29.0 kip-ft. for Beam \#1). This increase can be attributed to better confinement leading to better bonding behavior between the CFRP strand and the concrete. Like Beam \#1, the first part of the moment-deflection curve (un-cracked section) was linear with a stiffness of EI. Experimentally, the first crack appeared when the applied moment reached approximately 14 kip-ft. Then the stiffness dropped as shown in Figure 4.13. Theoretically, and based on ACI 318-11 prediction of cracked section, the first crack occurred at a moment of $17.8 \mathrm{kip}-\mathrm{ft}$. It should be mentioned that the moment caused by the beam's own weight was ignored. Including the dead weight would have added a little more moment to the experimental cracking moment (14 kip-ft.), so the difference between the expected and the actual cracking moment would have been even less. The stiffness difference between the first cycle and the rest was also clear. The slope of the line was about the same for the first cycle and the following ones, but there was a permanent deflection of about 0.11 in. that was generated after the first cycle. In terms of crack width, the widest crack width recorded from the $1^{\text {st }}$ cycle was $0.5 \mathrm{~mm}$. when the applied load it was 10 kips. At the same load, the crack width was $0.6 \mathrm{~mm}$. for the $2^{\text {nd }}$ 
and $3^{\text {rd }}$ cycles. The width increased to $0.7 \mathrm{~mm}$. for the $4^{\text {th }}$ and $5^{\text {th }}$ cycles. When the load increased to 12 kips and 14 kips at the $6^{\text {th }}$ cycle, the crack widths were $0.9 \mathrm{~mm}$. and 1.2 $\mathrm{mm}$, respectively.

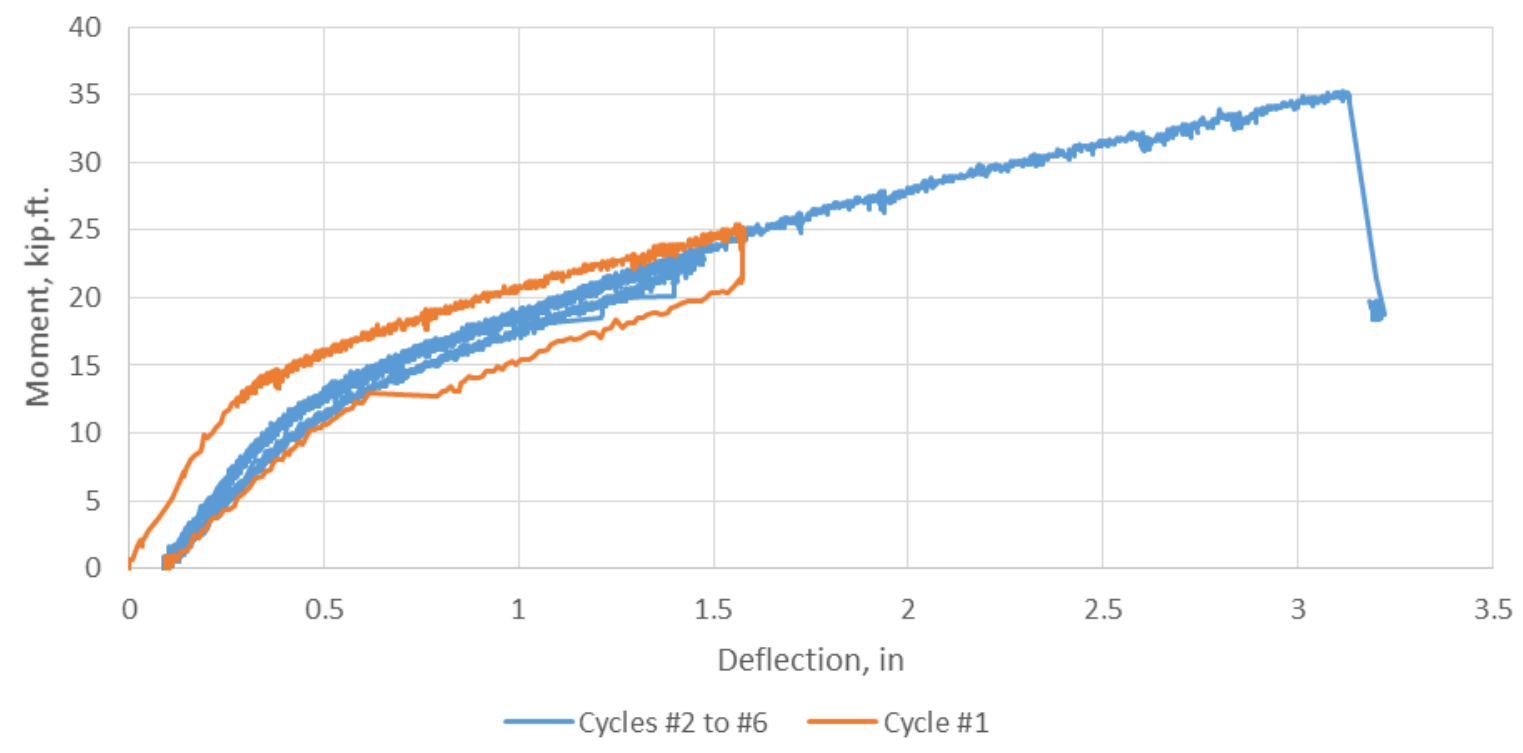

Figure 4.13 Moment vs. deflection for Beam \#2 - Mode of failure is CFRP slippage

The failure moment of Beam \#2 was 35.3 kip-ft. Similar to Beam \#1, the failure mode was pull-out of CFRP strand. Even though Beam \#1 and Beam \#2 still had the same failure mode, Beam \#2 failed at 22\% higher moment. Since the failure for both beams mostly depended on the bonding capacity of the CFRP with the surrounding concrete, the additional steel stirrups used for Beam \#2 seemed to provide more confinement, which helped the CFRP to develop more stress before debonding. This can be noticed by comparing the achieved strain, or stress, in CFRP for both beams. In Beam \#1, the maximum axial stress developed at the CFRP strand is $259.6 \mathrm{ksi}$, whereas the maximum 
stress developed at the CFRP strand for Beam \#2 is $318.8 \mathrm{ksi}$, assuming that the maximum strain recorded was 0.015 . The difference in the achieved forces was $22.6 \%$. The maximum achieved CFRP stress for Beam \#2 exceeded the maximum guaranteed capacity, but did not reach the actual capacity based on the laboratory tests (330 ksi).

The cause of failure of Beam \#2 can be observed from Figure 4.14. The slippage suddenly occurred when the load reached maximum. The location of the failure was also at the end of the transmission zone. A wide crack quickly developed at the middle of the shear span (20 to 30 in. from the left support). Based on the readings of the strain gauges (shown in Fig. 4.15) the stress at the failure location was about $167.6 \mathrm{ksi}$. This amount of stress at CFRP strand resulted in, theoretically, a moment capacity of 18 kip-ft. The applied moment at the location of failure was $17.7 \mathrm{kip}-\mathrm{ft}$. On the other hand, the amount of stress achieved at the CFRP strand at the maximum moment region, recorded by strain gauges G.5 and G.7, was $318.8 \mathrm{ksi}$. This stress theoretically provided more moment capacity than the maximum applied moment. This may explain why the beam failed at the zone of transfer length instead of the maximum moment region. In other words, the slippage prevented the CFRP from developing more stress as needed at the zone where the transfer length ends. 


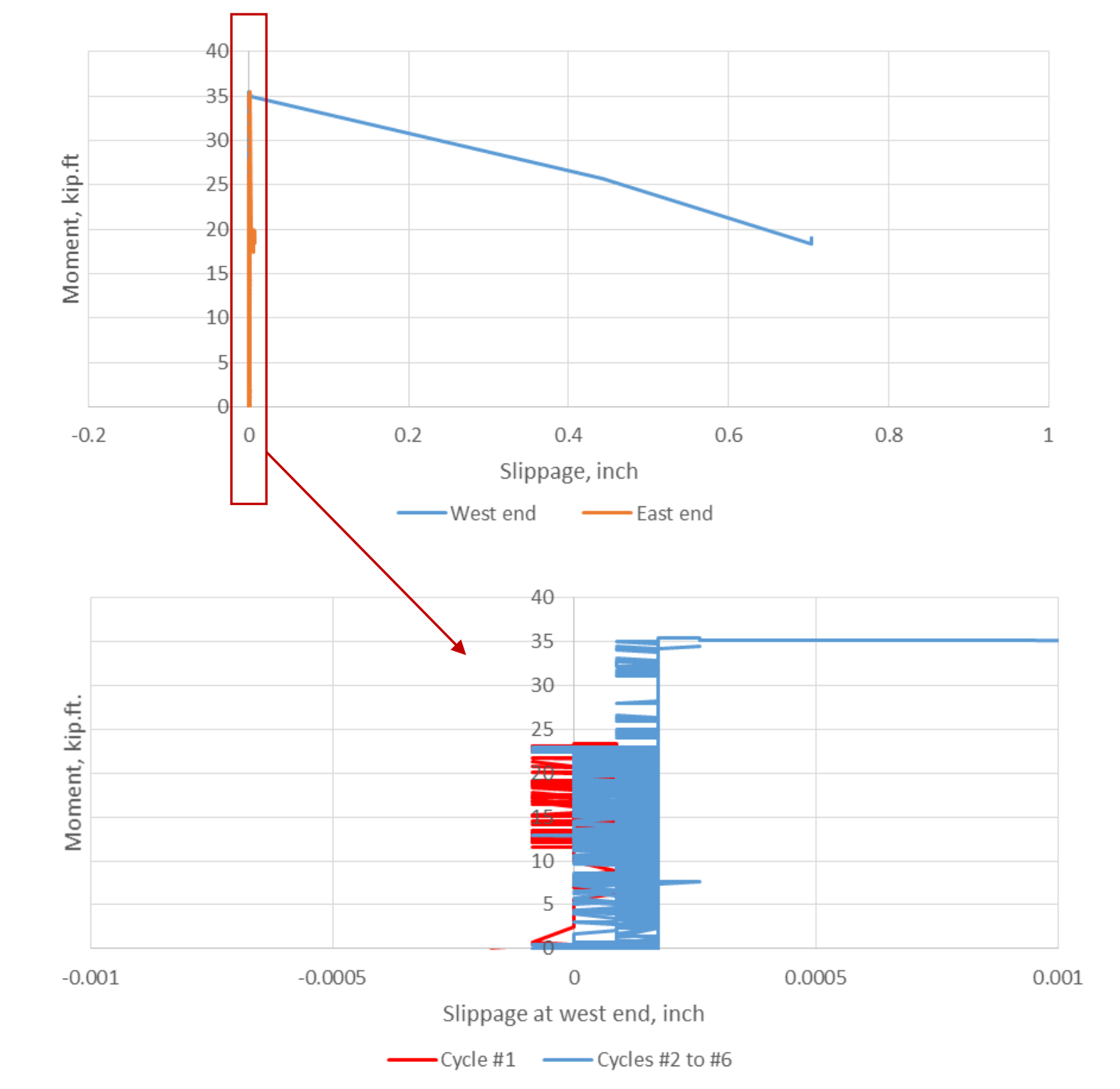

Figure 4.14 Load vs. end slippage at the ends - Beam \#2

Figure 4.15 shows the moment vs. strain for the concrete and the CFRP strands during the flexural test of Beam \#2. 

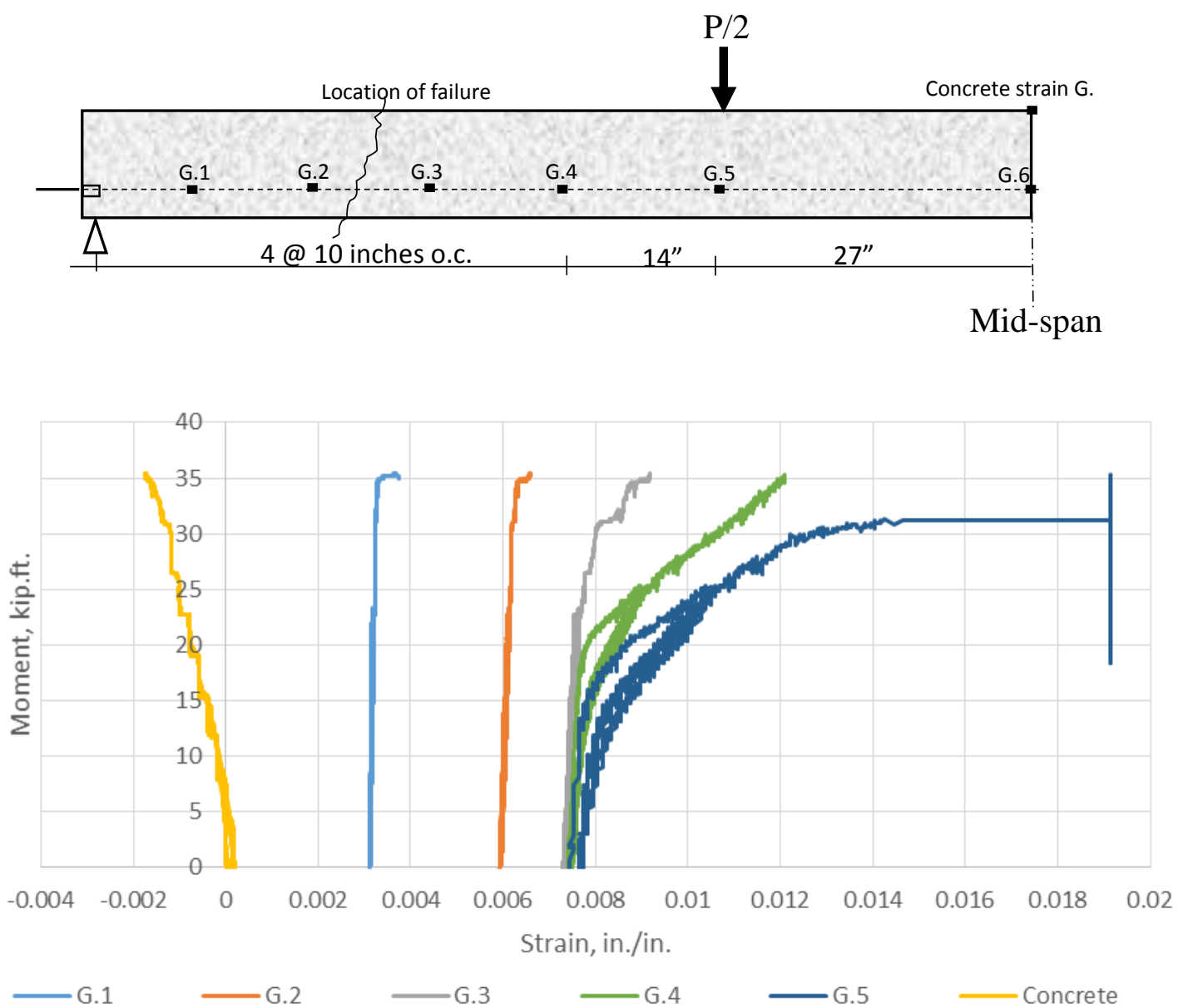

Figure 4.15 Moment vs. CFRP \& concrete strains during flexural test-Beam \#2

It can be concluded from here that the provided flexural bond length $(54-21=33$ in.), with this concrete strength, the provided confinement, and 55\% prestressing level was less than the required value in order to develop the full capacity of the CFRP strand. Finally, the maximum concrete strain measured at the top fiber of concrete cross section at mid span of the beam was 0.0017 . Theoretically, as will be discussed in the following chapter, the concrete strain was estimated to be 0.00225 .

Figure 4.16 shows various photos of the flexural test of Beam \#2. 

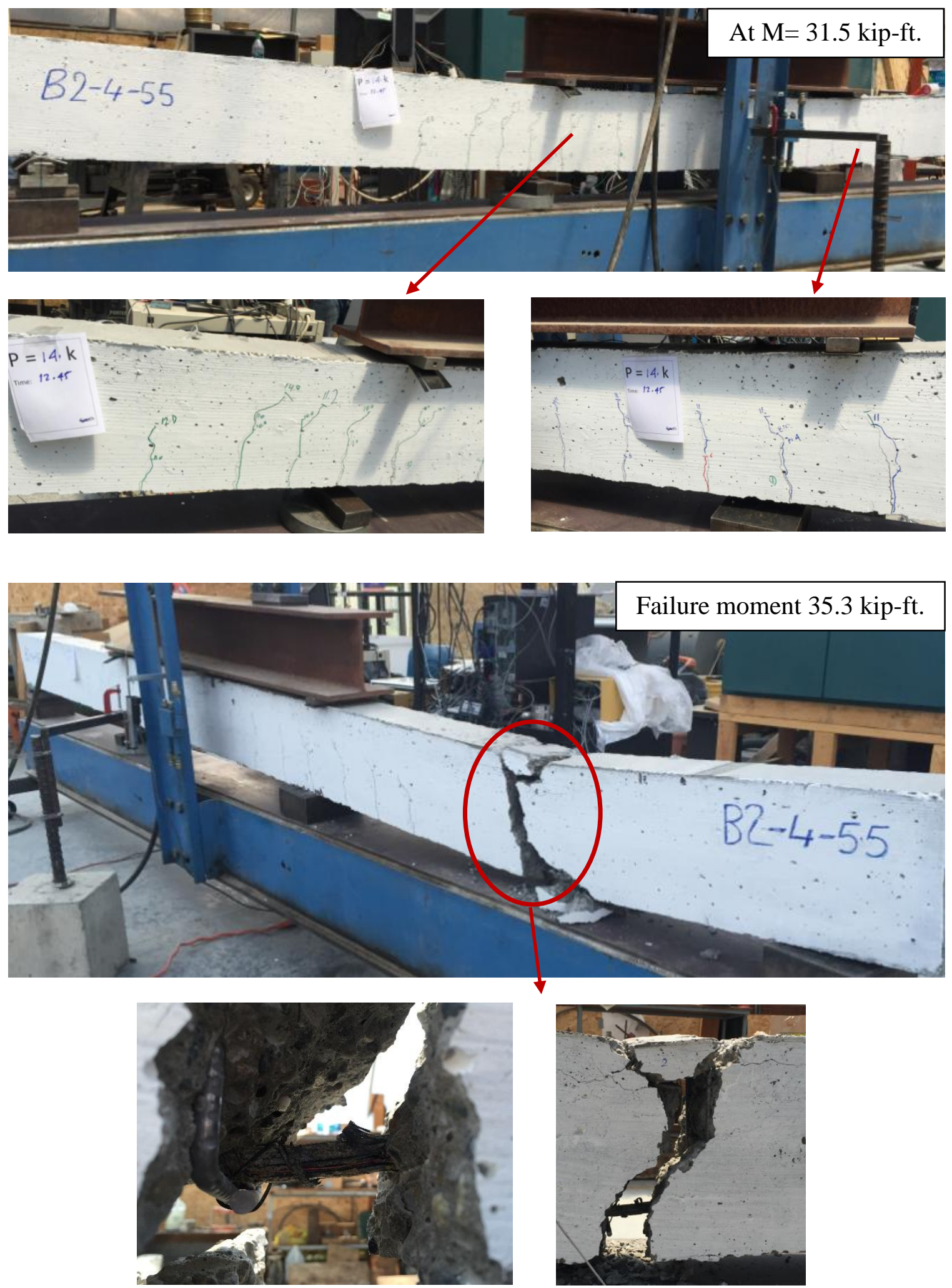

Figure 4.16 Photos of the flexural test of Beam \#2 


\subsubsection{Beam \#3 (B3-4-60)}

Because the use of more stirrups was observed by the results of Beam \#2 to improve the flexural response of the prestressed beam, and more confinement leads to better bonding between the CFRP strand concrete, it was decided to provide more stirrups for Beam \#3. For this beam the spacing of stirrups along the shear span was reduced to $2 \mathrm{in}$. on-centers. The prestressing level was $60 \%$ so that the results of this beam could be compared to the previous two beams. Every other parameter was kept the same.

Figure 4.17shows the moment vs. deflection for Beam \#3. The beam failed at 32.5 kip-ft. The maximum moment was less but close to what was achieved by Beam \#2. However, no slippage that can be considered as cause of failure was observed. It cannot be concluded that Beam \#3 had a better bonding performance because the maximum achieved CFRP force for Beam \#3 did not exceed what was gained from Beam \#2. However, the performance of Beam \#3 was definitely better than Beam \#1 proving what was concluded by Beam \#2, which was that the confinement helped bonding performance.

Figure 4.18shows load vs. end slippage at the ends and Figure 4.19shows moment vs. CFRP \& concrete strains during flexural test for Beam \#3. Even though the concrete capacity of Beam \#3 (7269 psi) was slightly less than that of Beam \#2 (7637psi), the beam was not expected to fail in compression until the CFRP stress (tension force) reached 328 ksi. In addition, the concrete was expected to fail at approximately 0.003 strain. However, and as shown in Figure 4.19 the concrete failed at a measured compressive strain between 0.002 to 0.0025 , which is generally close to the strain at peak concrete stress $\mathrm{f}_{\mathrm{c}}$. 


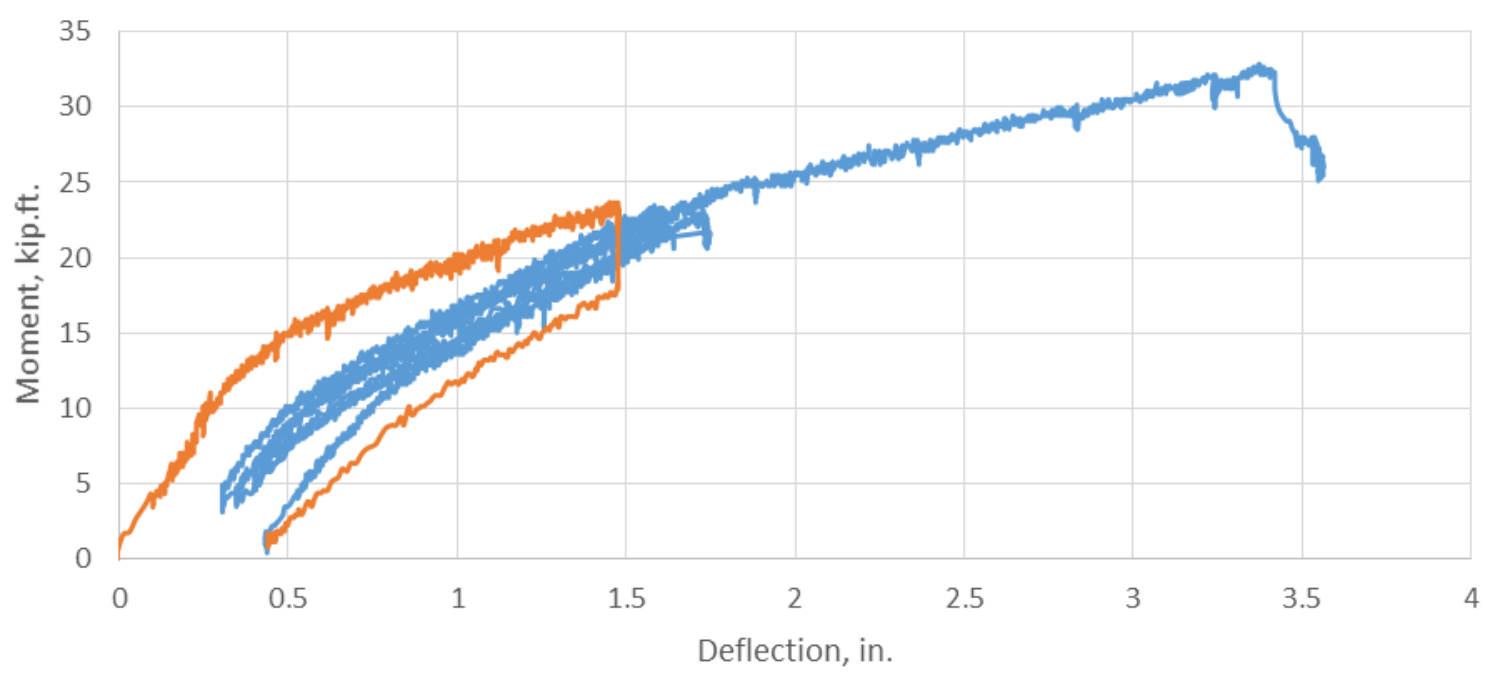

- Cycles \#2 to \#6 - Cycle \#1

Figure 4.17 Moment vs. deflection for Beam \#3 - Mode of failure is concrete crushing

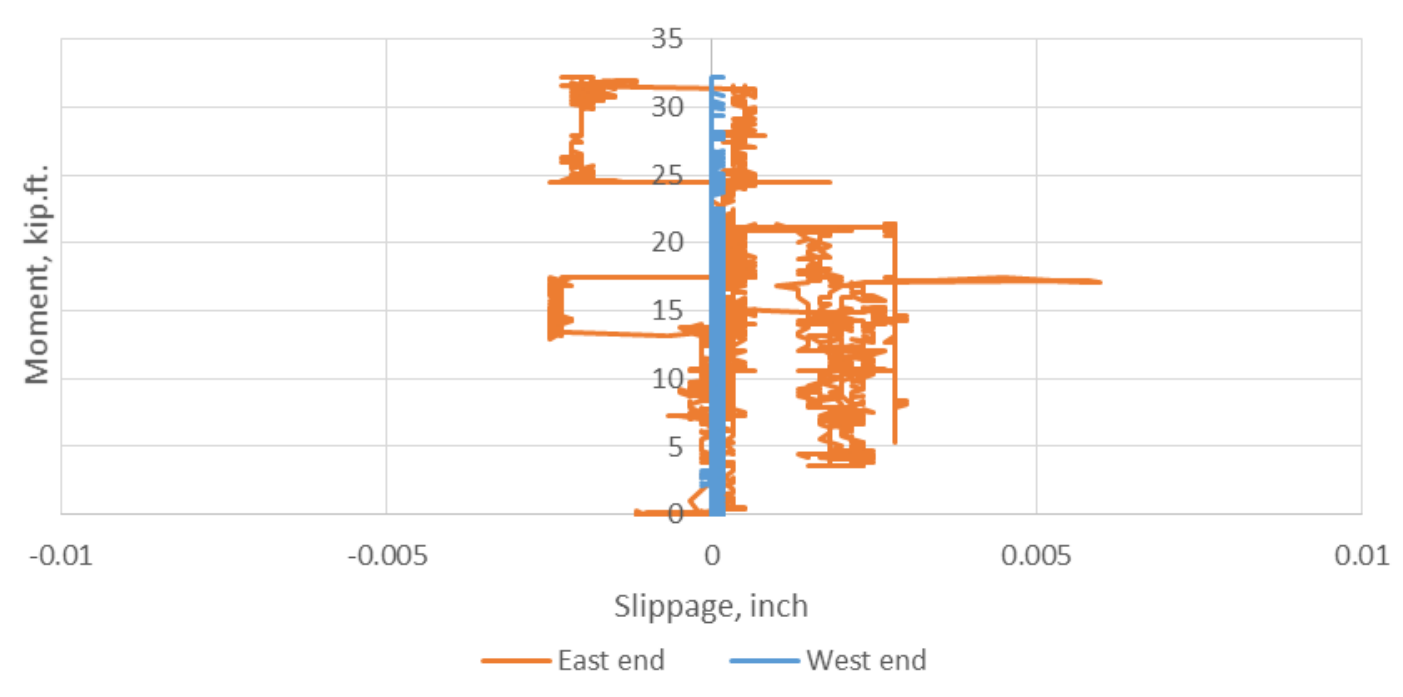

Figure 4.18 Load vs. end slippage at the ends-Beam \#3 

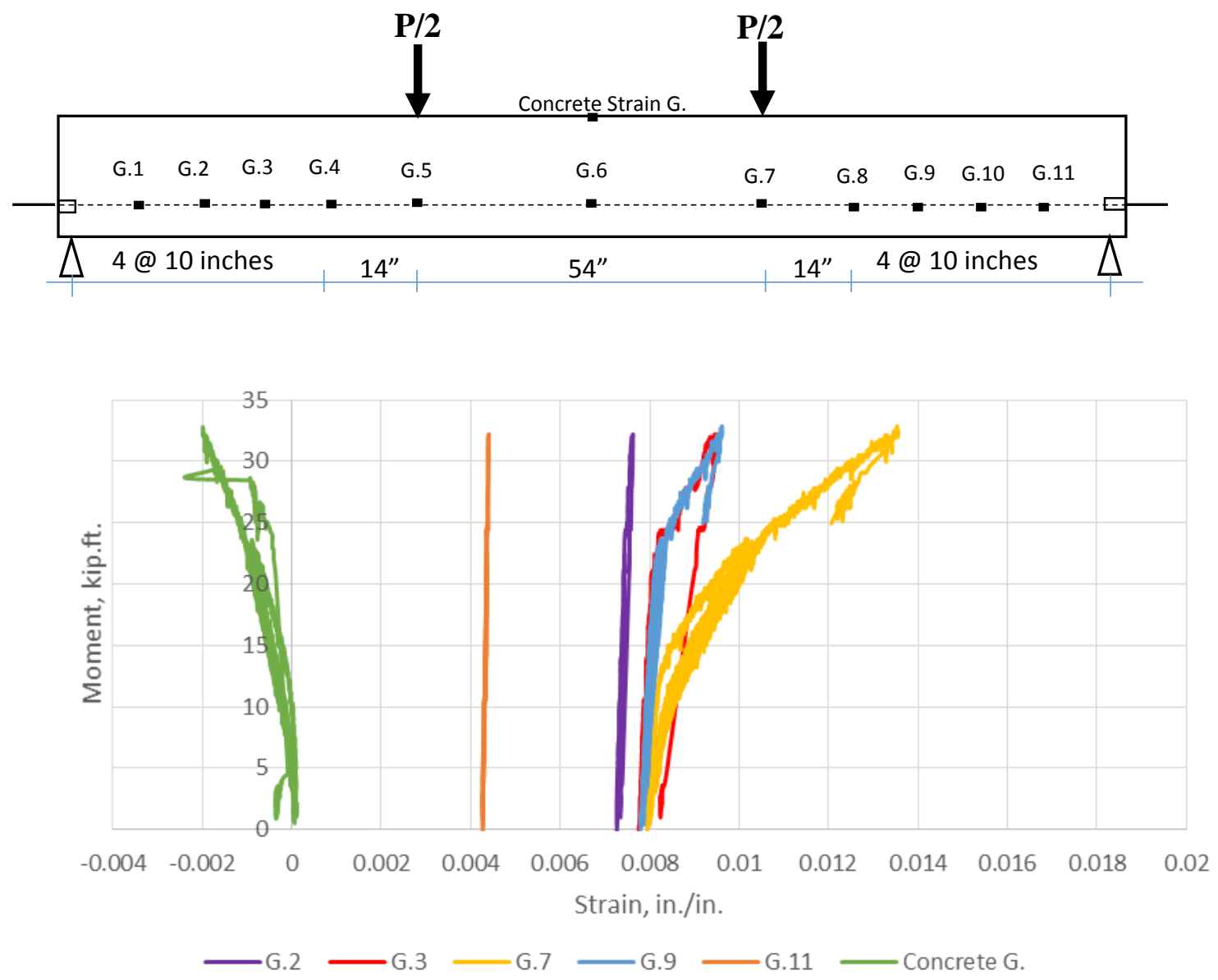

Figure 4.19 Moment vs. CFRP \& concrete strains during flexural test - Beam \#3

Although the maximum load for Beam \#3 (32.5 k-ft.) was somewhat less than that of Beam \#2 (35.3 k-ft.), the maximum deflection achieved by Beam \#3 was more than the maximum deflection of Beam \#2. This shows that the stiffness of Beam \#3 was less than the stiffness of Beam \#2. The reason for less stiffness can be attributed to the fact that concrete capacity of Beam \#3 (7269 psi) was less than that of Beam \#2 (7637psi). 
The concrete failed as a result of loading that produced a maximum strain of more than 0.002. The concrete beam went through six cycles of loading and unloading with a peak deflection of about $1.7 \mathrm{in}$. for each cycle. This peak deflection that Beam \#3 underwent for each cycle was the highest compared to other three beams. As expected, the cracks were wider and longer when the deflection was higher. As a result, the concrete compression force becomes smaller because the concrete un-cracked area in compression zone was smaller. It can be observed from Figure 4.19 and based on the CFRP properties that the CFRP stress at failure was $288 \mathrm{ksi}$. The maximum measured CFRP stress was $96 \%$ of the guaranteed CFRP capacity and $87 \%$ of the actual capacity. The bond capacity and bond improvement cannot be observed by this beam test since the failure happened (by concrete in compression) before bond stress reaching the maximum bond stress the concrete was expected to handle. Figure 4.20 shows various photos of the flexural test of Beam \#3.

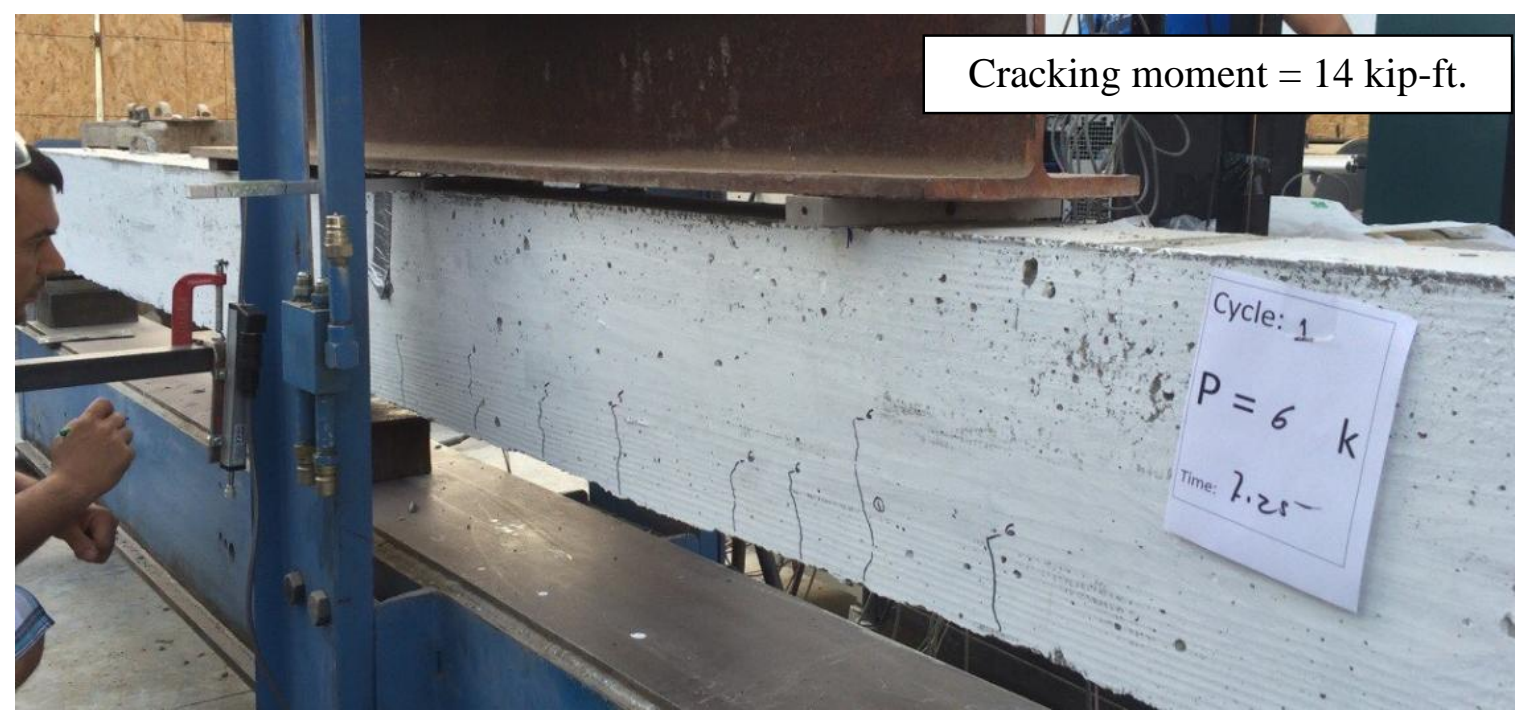

Figure 4.20 Photos of the flexural test of Beam \#3 

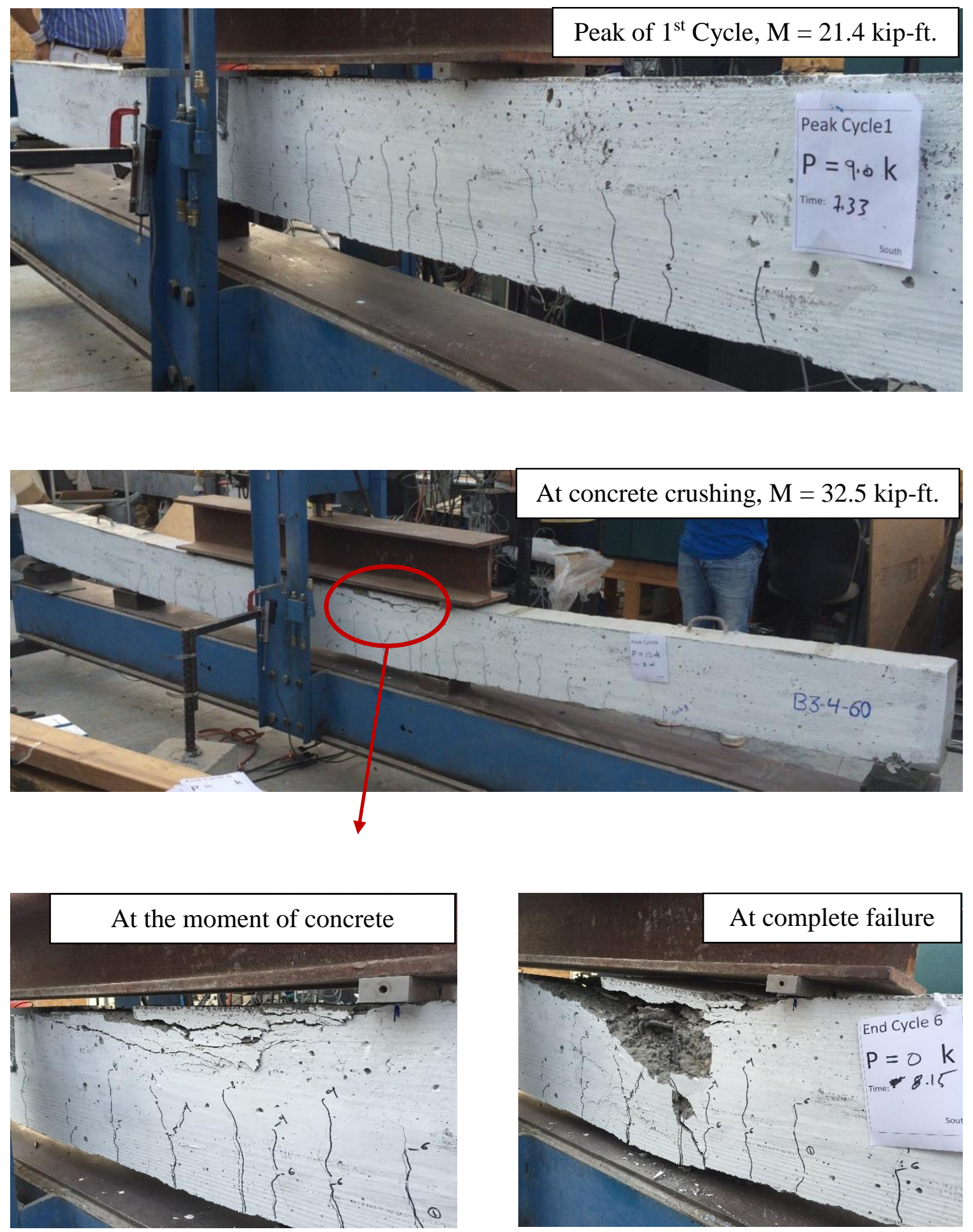

Figure 4.20 Continued 


\subsubsection{Beam \#4 (B4-4-60)}

The major problem faced by the previous beams was bonding issues between the CFRP strand and the surrounding concrete. It was concluded that the provided flexural bond length was not enough in order to develop the full capacity of the CFRP strand. As a result, a new idea was developed to solve the problem. New bond anchors were attached to the strand at both ends. Each anchor was a steel tube all-threaded from outside and smooth from inside, as described in Chapter 3. These two anchors were embedded nine in. inside the concrete. The anchors' job was to prevent CFRP slippage. They worked like locks holding the CFRP at the ends of the beam. Two hex nuts were used for each anchor in order to provide enough bearing capacity, in addition to the bond, to hold the CFRP force at transfer and at flexural test. The prestressing level was kept as $60 \%$ so that Beam \#4 could be comparable with the previous beams. For transverse reinforcement, the same number of steel stirrups were used as Beam \#2 ( $\mathrm{s}=3$ in. on centers). Beam \#2 failed because of the slippage problem. The aim of the new technique used on Beam \#4 was to prove that if slippage was prevented then the beam performance would be improved and the failure mode would not be due to the slippage of CFRP strand.

Figure 4.21 shows moment vs. deflection for Beam \#4. Since the prestressing level of Beam \#4 was $60 \%$, it was comparable to all previous beams. The collected data of deflection were lost after a deflection of about $2.6 \mathrm{in}$. because of a technical issue with the $100 \mathrm{~mm}$ LVDT recording equipment. The curve after that, as shown in Figure 4.21, was mathematically generated by determining and following the polynomial equation of the curve previous to the loss of data. 


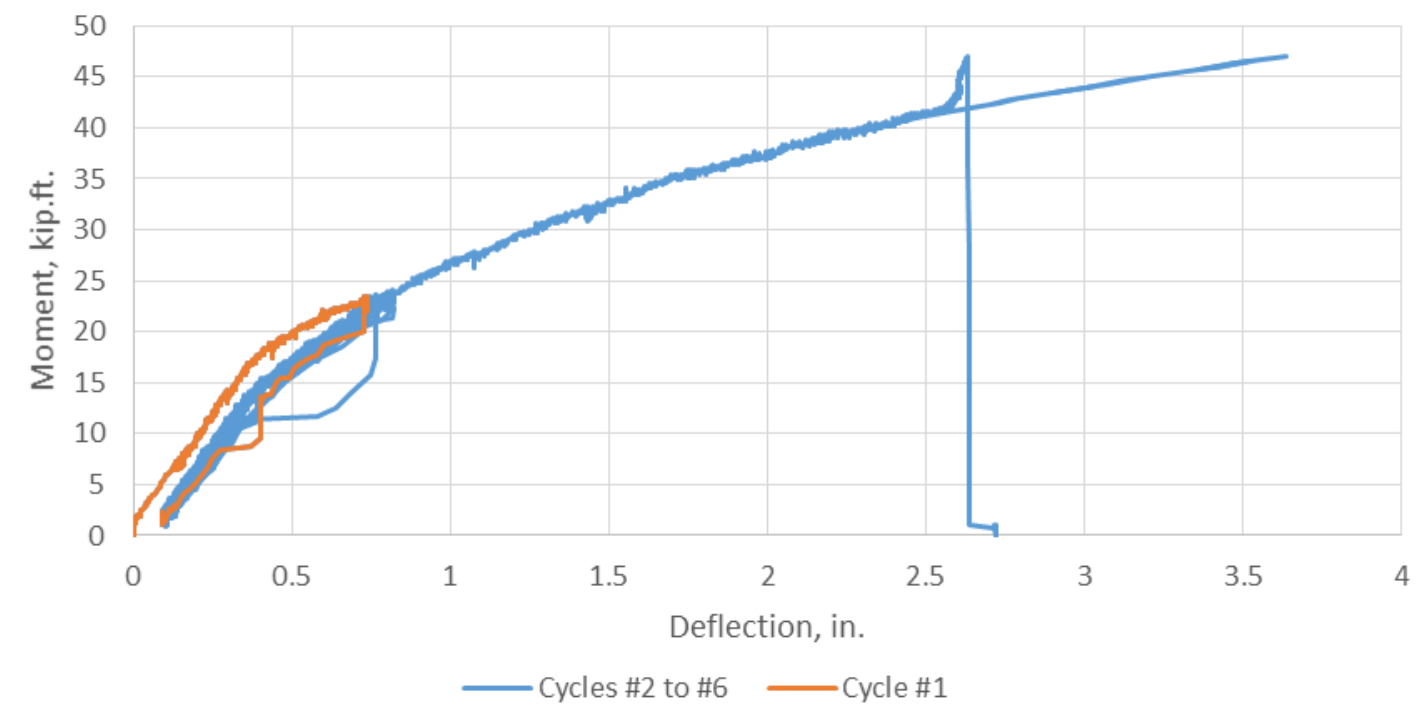

Figure 4.21 Moment vs. deflection for Beam \#4 - Mode of failure is concrete crushing

The maximum moment reached 47 kip-ft. The maximum moment capacity of previous beam was 35.3 kip-ft. (Beam \#2), which means the ultimate moment capacity improved $33 \%$ by using the new technique of Beam \#4. It can be concluded that the new technique of anchoring the ends significantly improve the flexural performance of the beam. In addition to gaining more moment capacity, Beam \#4 had better ductility, which can be noted by looking at the maximum deflection at failure compared to the deflection at cracking moment. The cracking moment was19 kip-ft., which was about the same as Beam $\# 1$. The decrease in the stiffness between the first cycle and the following ones can also be observed from the moment-deflection curve. The permanent deflection after releasing the first cycle of loading was $0.1 \mathrm{in}$. This value of permanent deflection was almost the same for the following cycles. 
Figure 4.22 shows moment vs. CFRP \& concrete strains during flexural test, and Figure 4.23 shows load vs. end slippage at the ends for Beam \#4. Figure 4.23 shows that there was no slippage observed at both ends. This also shows that there was no noticeable loss in the CFRP force during the test. No slippage means no force losses in the CFRP. The CFRP stress development during the test can be observed in Figure 4.22.

It is interesting to note that Beam \#4 was the only beam in which the CFRP force at a location 20 in. from the support had increased $15 \mathrm{ksi}$ when the applied load increased from zero to ultimate (the failure load). The location of 20 in. from the support was the end of transmission zone (the zone of transfer length), at which Beam \#1 and Beam \#2 failed because of slippage. In the previous beams, the CFRP stress at the location of strain gauges one and two did not increase when the applied load increased because of the slippage. When slippage of CFRP occurred, the CFRP strand could not develop the required stress in order to provide adequate moment capacity. In this case, the CFRP was locked at the ends, so that the CFRP force developed accordingly with the applied load. This was the benefit of the new technique of anchoring the CFRP strands in at the ends of prestressed concrete beams. 

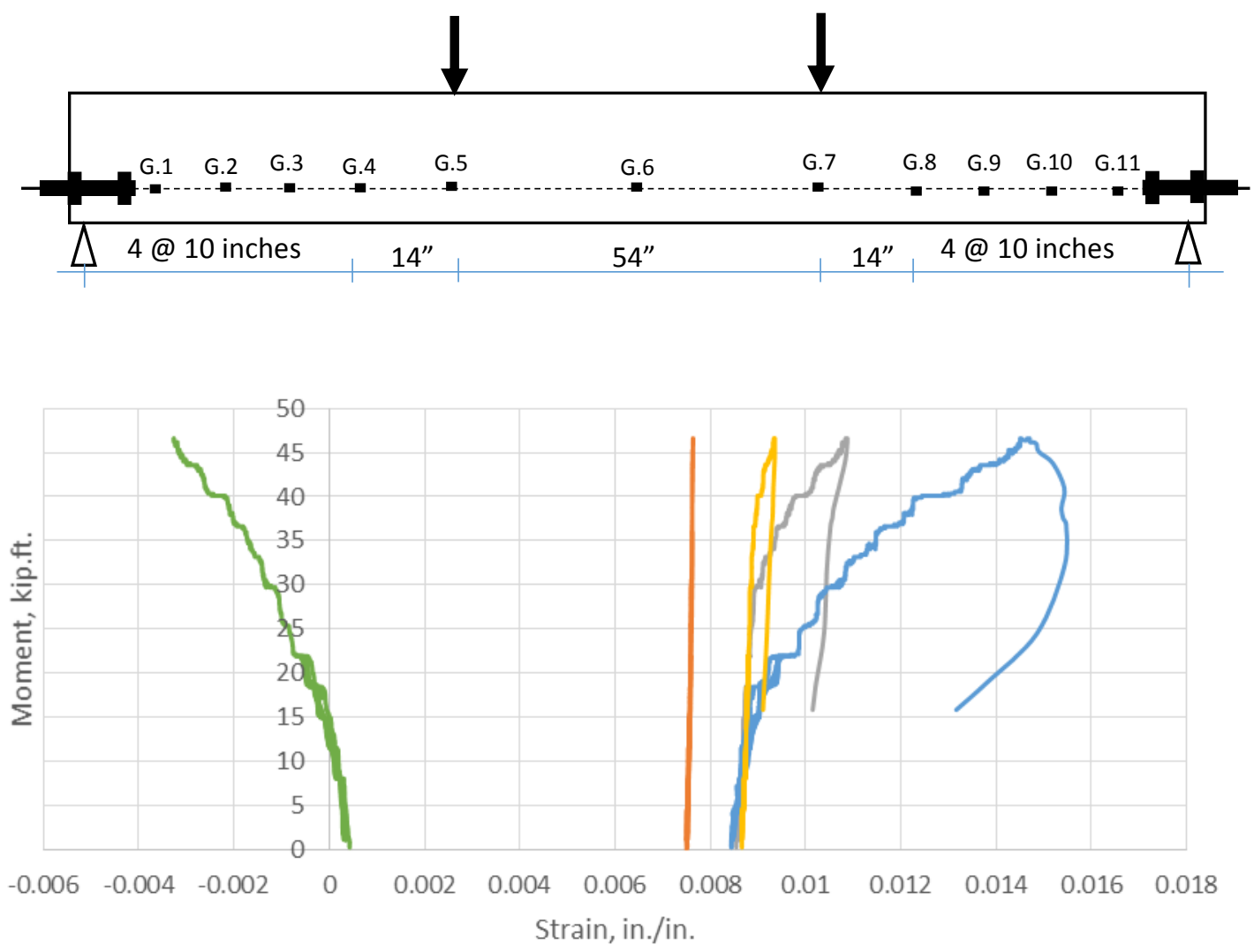

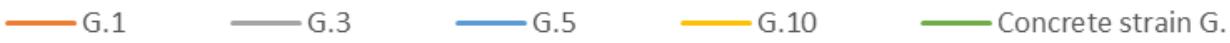

Figure 4.22 Moment vs. CFRP \& concrete strains during flexural test-Beam \#4

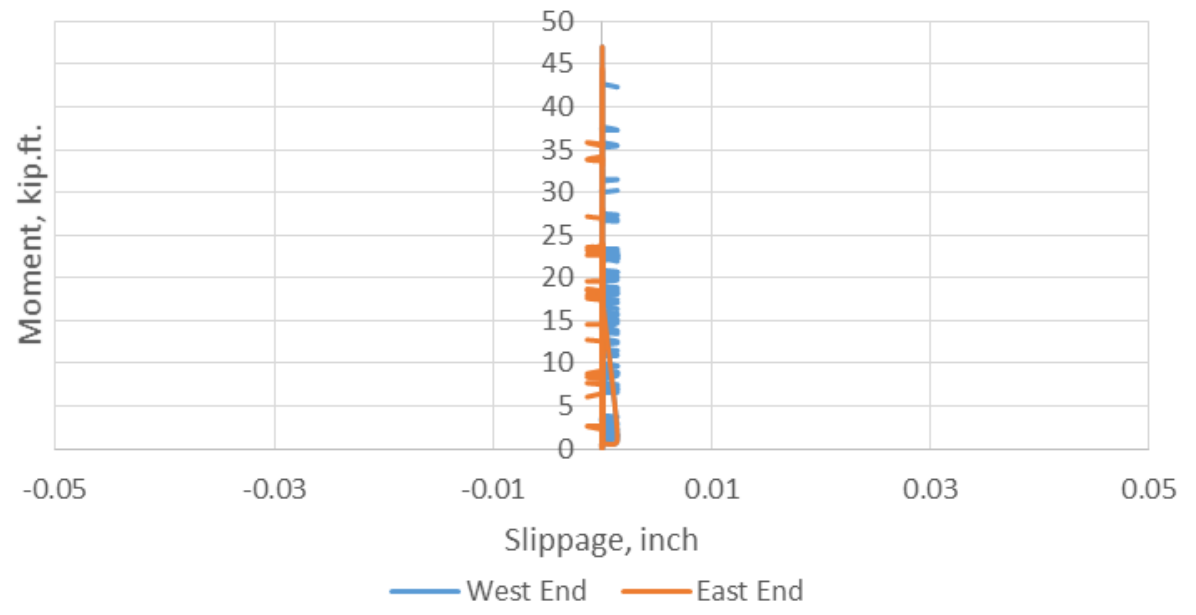

Figure 4.23 Load vs. end slippage at the ends - Beam \#4 
The failure mode was concrete crushing at compression zone. The concrete strain went up to 0.0033 at failure. It is reasonable to assume that the concrete at this level of strain had reached its full capacity, could not handle more stress and failed. This beam was designed so that the failure mode would be CFRP rupture. However, the CFRP strand was very close to rupture. The CFRP stress at failure was $325 \mathrm{ksi}$, whereas the failure tensile stress of the CFRP strand was $330 \mathrm{ksi}$. The force development at the end of transmission zone (the zone of transfer length) was the key for this improvement in the moment capacity. Unlike the previous beams, Beam \#4, with its new end anchorage technique, was able to develop the force at the CFRP strand from $184 \mathrm{ksi}$ to $198.5 \mathrm{ksi}$ at the end of transmission zone (location of strain gauge G.2). If the CFRP stress at this location had not been developed, the CFRP force would have stayed at $184 \mathrm{ksi}$, which was what happened to the previous beams. Theoretically, 184 ksi force at CFRP produces moment capacity of the beam section equal to 18.2 kip-ft. The applied moment at this location was 18 kip-ft., which was very close to the moment at failure stage. As a result, it would have been very possible to observe the same mode failure of Beam \#1 and Beam \#2 if the end anchors had not been used, and the CFRP stress at the end of transmission zone stayed the same without development. Herein, the CFRP stress at the end of transmission zone developed from $184 \mathrm{ksi}$ to $198.5 \mathrm{ksi}$, which theoretically produced a moment capacity equal to $22 \mathrm{kip}-\mathrm{ft}$.

Beam \#4 also showed improvement in terms of cracking behavior. Less crack width was observed compared to the previous beams. This can be attributed to no losses in the CFRP force. Since the CFRP strand was anchored at the ends, the tensile force at the bottom did not reduce over time due to cyclic loading. The tensile force in the CFRP was almost the 
same for all cycles with no losses. The tensile force in CFRP strand forced the cracks to be as thin as possible. Figure 4.24 shows various photos of Beam \#4 test.
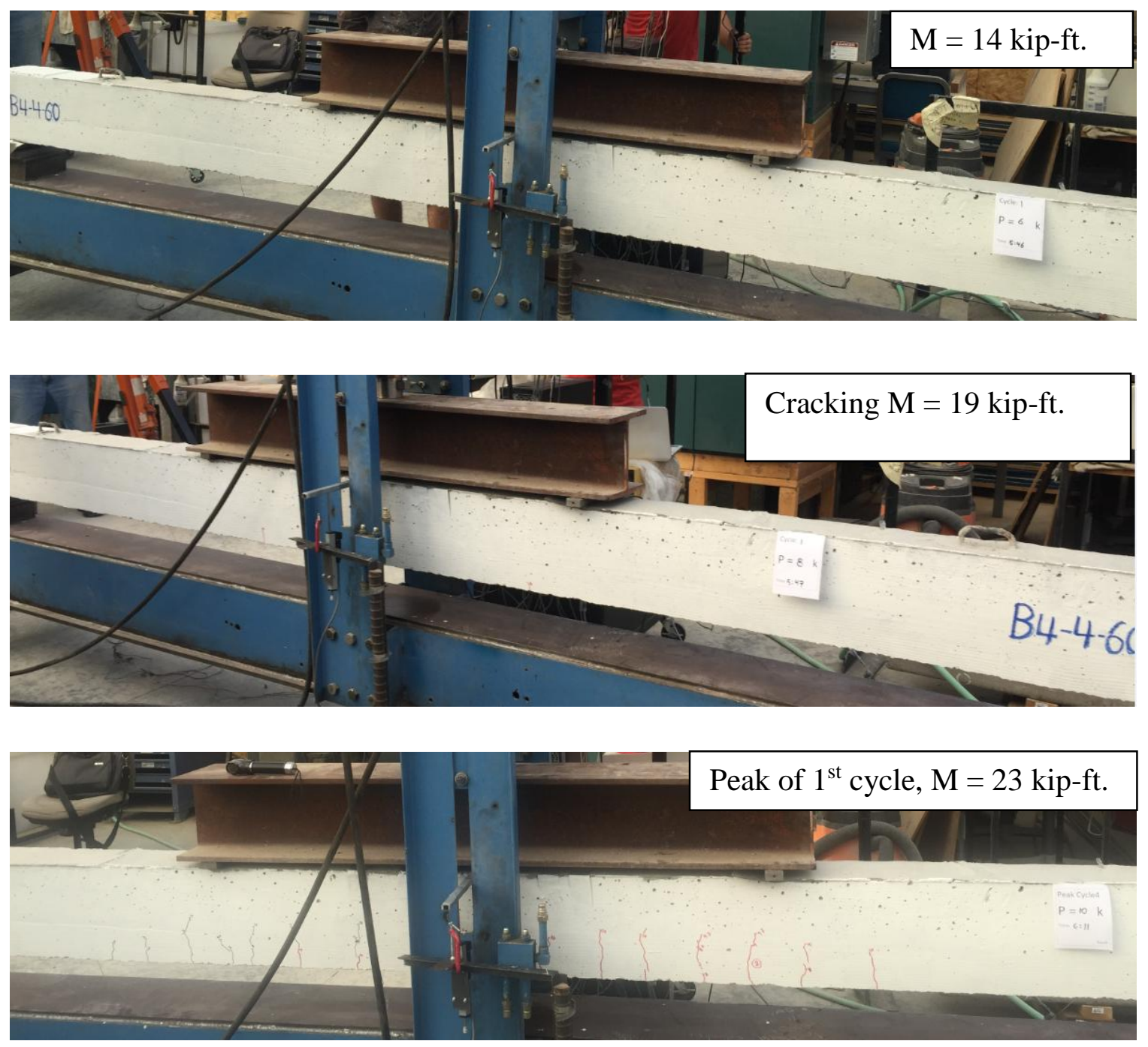

Figure 4.24 Photos of the flexural test of Beam \#4 

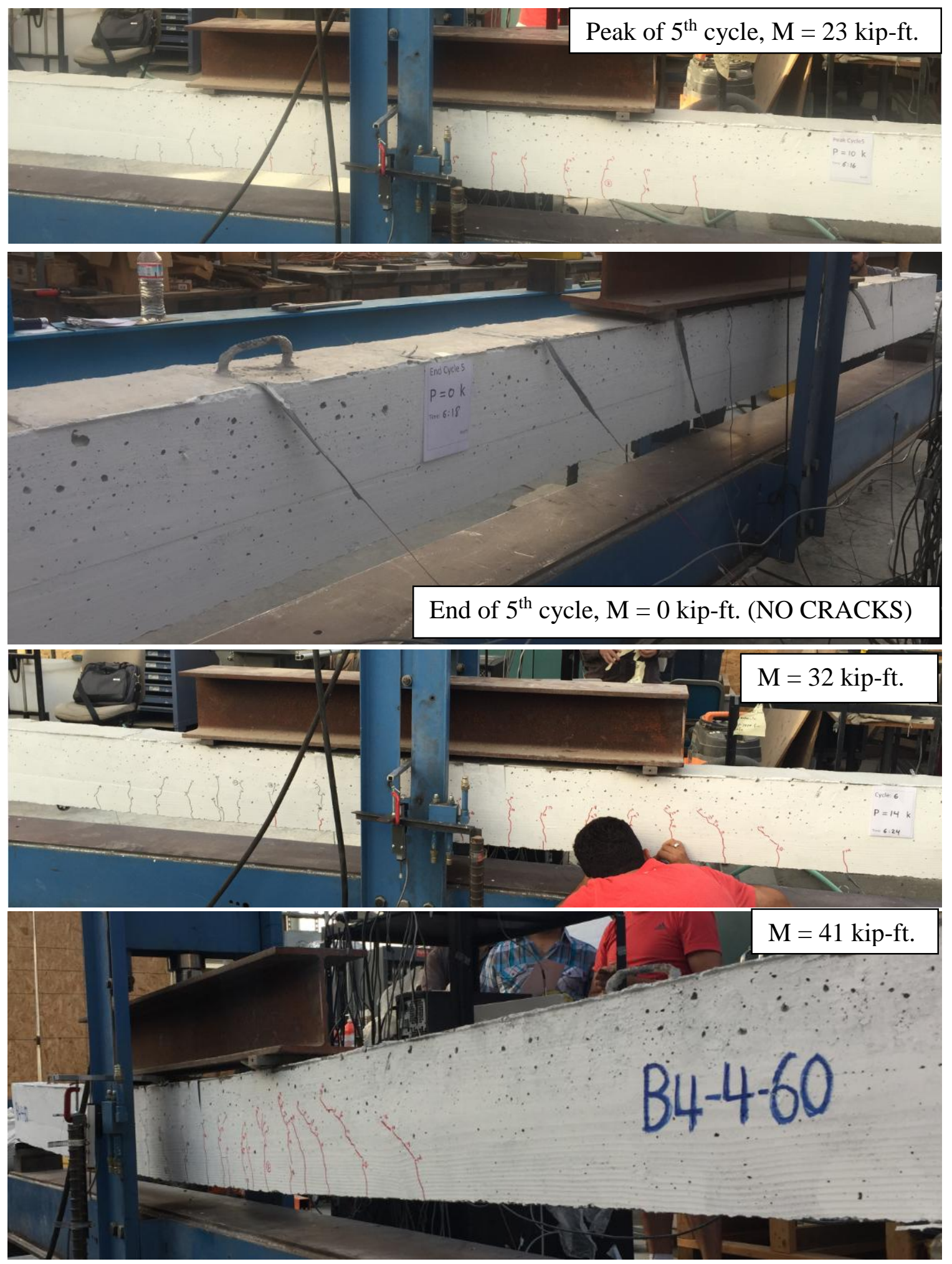

Figure 4.24 Continued 

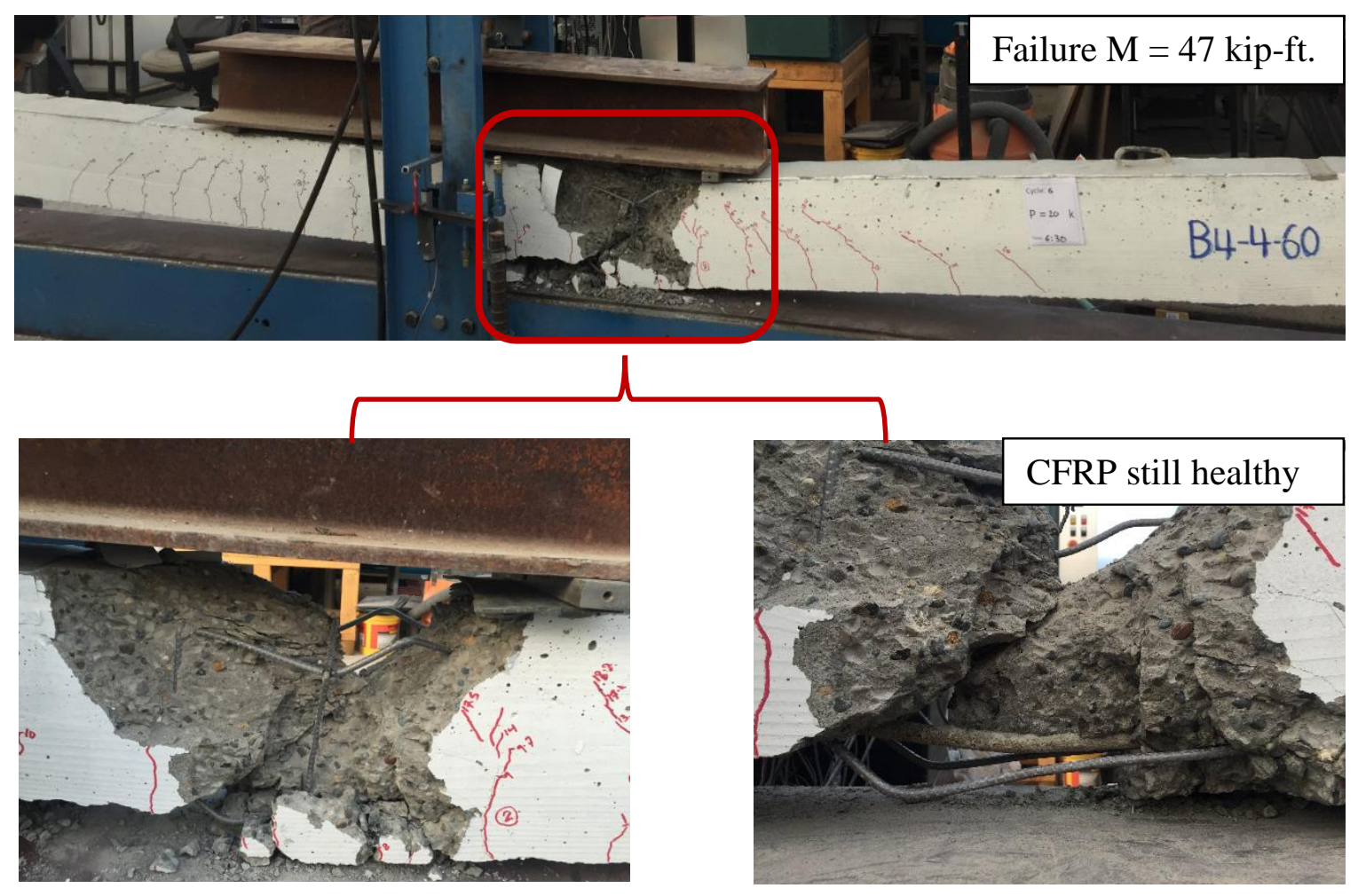

Figure 4.24 Continued

\subsubsection{Tensile \& Bond Stress Development during Flexural Tests}

Since none of the beams failed due to rupture of the CFRP strand, the flexural bond length cannot be experimentally determined. From the literature, the flexural bond length for CFRP strands could vary from $70 \mathrm{~d}_{\mathrm{b}}$ to $125 \mathrm{~d}_{\mathrm{b}}$ (ACI Committee 440, 2004). In this work, the average available flexural bond length was about 34 in., which is equal to the shear span (54 in.) minus the measured transfer length as given in Table 4-2. Based on previous experimental results (Krem, 2013), it has been concluded that all beams that were prestressed with $60 \%$ of the CFRP force or more needed more than 5.6 feet shear span in order for the concrete to provide adequate anchors. Regarding the current work, it can be 
stated that a shear span of 4.5 feet was not enough to provide the required flexural bond. Of course, this was only true with the same parameters and conditions of this work. Even though the flexural bond length cannot be experimentally determined herein, the bond stresses during the flexural tests can be plotted and investigated.

Figures 4.25 through 4.28 show tensile stress and bond stress profiles for four beams tested. The first parts of Figures 4.25 through 4.28 show the stress development in the CFRP strand during the flexural test for each beam. It can be clearly seen that the CFRP stress at ultimate was higher for the beams with higher moment capacity. The highest CFRP stress recorded was $325 \mathrm{ksi}$ for Beam \#4. The figures also show the stress development in particular loading stages. The selected stages were at release, at cracking moment, at peak of $1^{\text {st }}$ cycle, at peak of $5^{\text {th }}$ cycle, and finally at failure. The stress at peak of $5^{\text {th }}$ cycle was then replaced by $90 \%$ of the maximum moment as it looked more interesting for beams with higher moment capacity than the peak of $5^{\text {th }}$ cycle.

The second parts of Figure 4.25 through 4.28 present the bond stress profile during the same stages of loading starting from releasing the force with zero applied moment to the ultimate, or failure moment. It can be seen that the bond stress was gradually distributed over longer length while the applied load was increasing. For comparison purposes, the average flexural bond stress was calculated by dividing the increase in the axial force at CFRP, recorded by the strain gauges, by the contact area between the CFRP strand and the surrounding concrete, as shown in Eq. (4-6).

Table 4-7 presents the results of Eq. (4-6) compared to the bond stress at transfer as determined in section 4.3.3. It is observed that the bond stress at flexural bond length was 
much less than the bond stress at transfer. It is clear from the results shown in the table that the flexural bond stress for Beam \#2 (B2-4-55) was the highest. It was higher than that of Beam \#1 because beam \#2 was improved in confinement and carries more load. It would have been expected to have larger bond stress for Beam \#3 if the beam had continued to resist more load and did not fail in concrete compression. Beam \#4 had less average bond stress than Beam \#2 because most of the bond was provided by the anchors at the ends. As a result, the concrete participation in the flexural bond area was less, and more dependent on the help provided by the anchors.

Average flexural bond stress $=\frac{\left(F_{\text {max. }}-F_{i}\right)}{\left(\pi d_{b}\right) l_{f b}} \quad \ldots$. Eq. $(4-6)$

Where:

$F_{\max }$ is the maximum achieved force at the CFRP strand

$F_{i}$ is the CFRP initial force

$d_{b}$ is the diameter of the CFRP strand

$l_{f b}$ is the available flexural bond length which is equal to the distance from the end of transfer length to the nearest point load, which is 54 in - transfer length. 
It should be noted that for Beam \#4, the gripping force comes from two sources, bond around the anchor as well as the bearing that comes from the washer against the concrete. However, the computed avg. bond stress (1.628 ksi) is based on the bond around the anchor.

\begin{tabular}{cccccccc}
\hline Label & $\mathbf{F}_{\mathbf{i}}$ & $\mathbf{F}_{\max }$ & $\mathbf{F}_{\max }-\mathbf{F}_{\mathbf{i}}$ & $l_{t}$ & $l_{f b}$ & $\begin{array}{c}\text { Avg. bond stress } \\
\text { at transfer, ksi }\end{array}$ & $\begin{array}{c}\text { Avg. flexural bond } \\
\text { stress, ksi }\end{array}$ \\
\hline B1-4-65 & 34.67 & 50.88 & 16.21 & 23.9 & 30.1 & 0.924 & 0.343 \\
\hline B2-4-55 & 30.83 & 62.48 & 31.65 & 21.0 & 33.0 & 0.935 & 0.611 \\
\hline B3-4-60 & 32.1 & 56.44 & 24.34 & 19.5 & 34.5 & 1.048 & 0.449 \\
\hline B3-4-60 & 34.53 & 63.7 & 29.17 & 13.5 & 43.5 & 1.602 & 0.427 \\
\hline
\end{tabular}

Note: All units are in kip-in. system.

Table 4-7 Average bond stress at transfer and at flexural test 


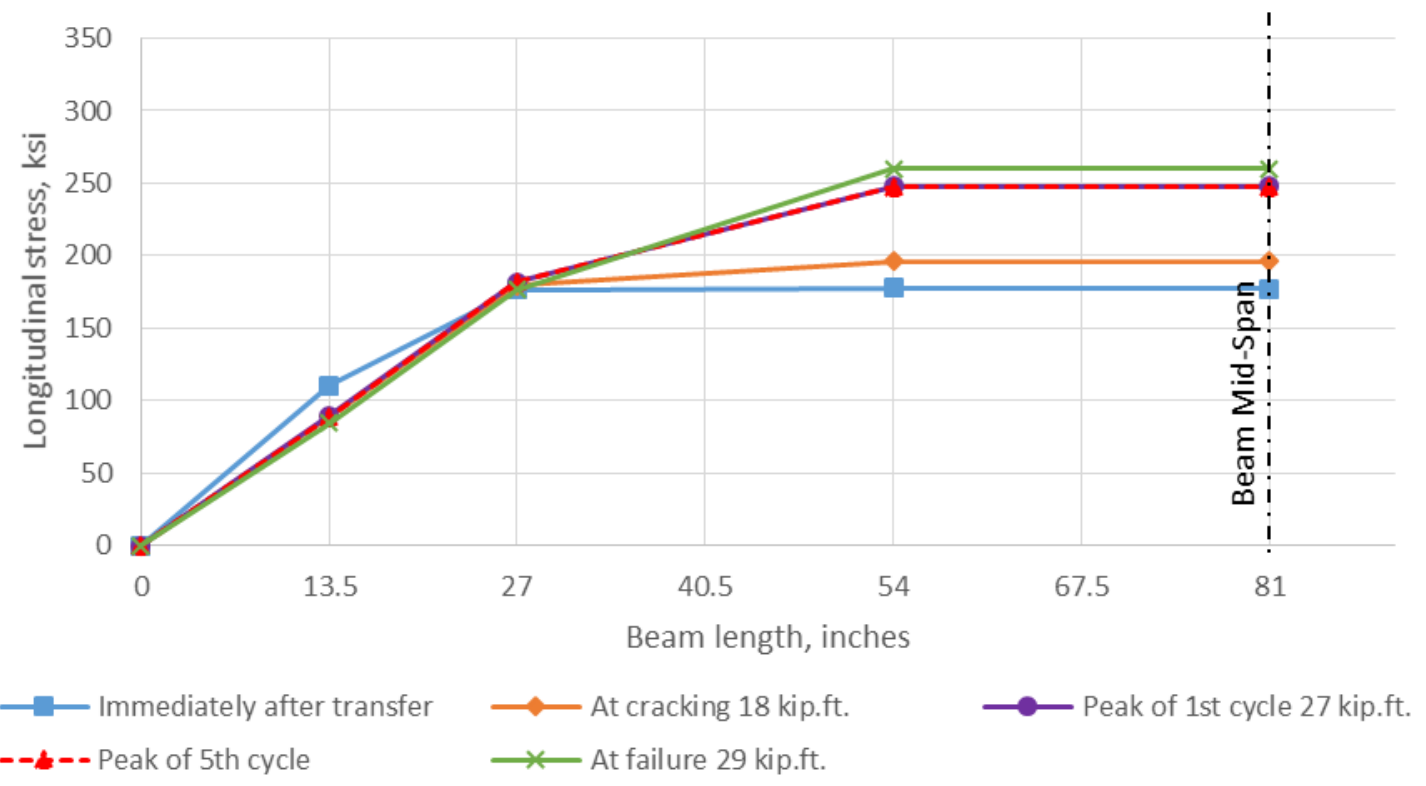

(1) CFRP tensile stress profile at specific load stages

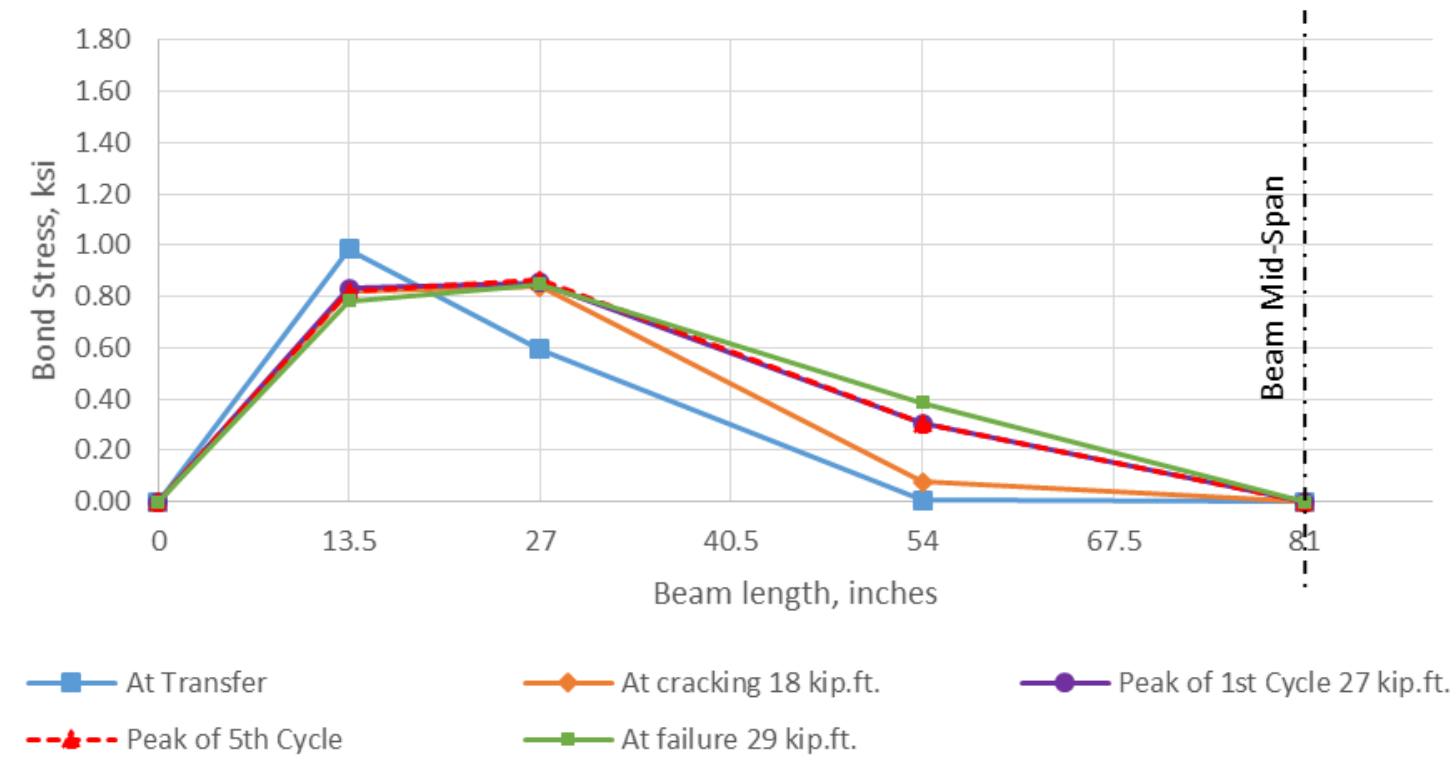

(2) Bond stress profile at specific load stages

Figure 4.25 Tensile stress and bond stress profiles - Beam \#1 


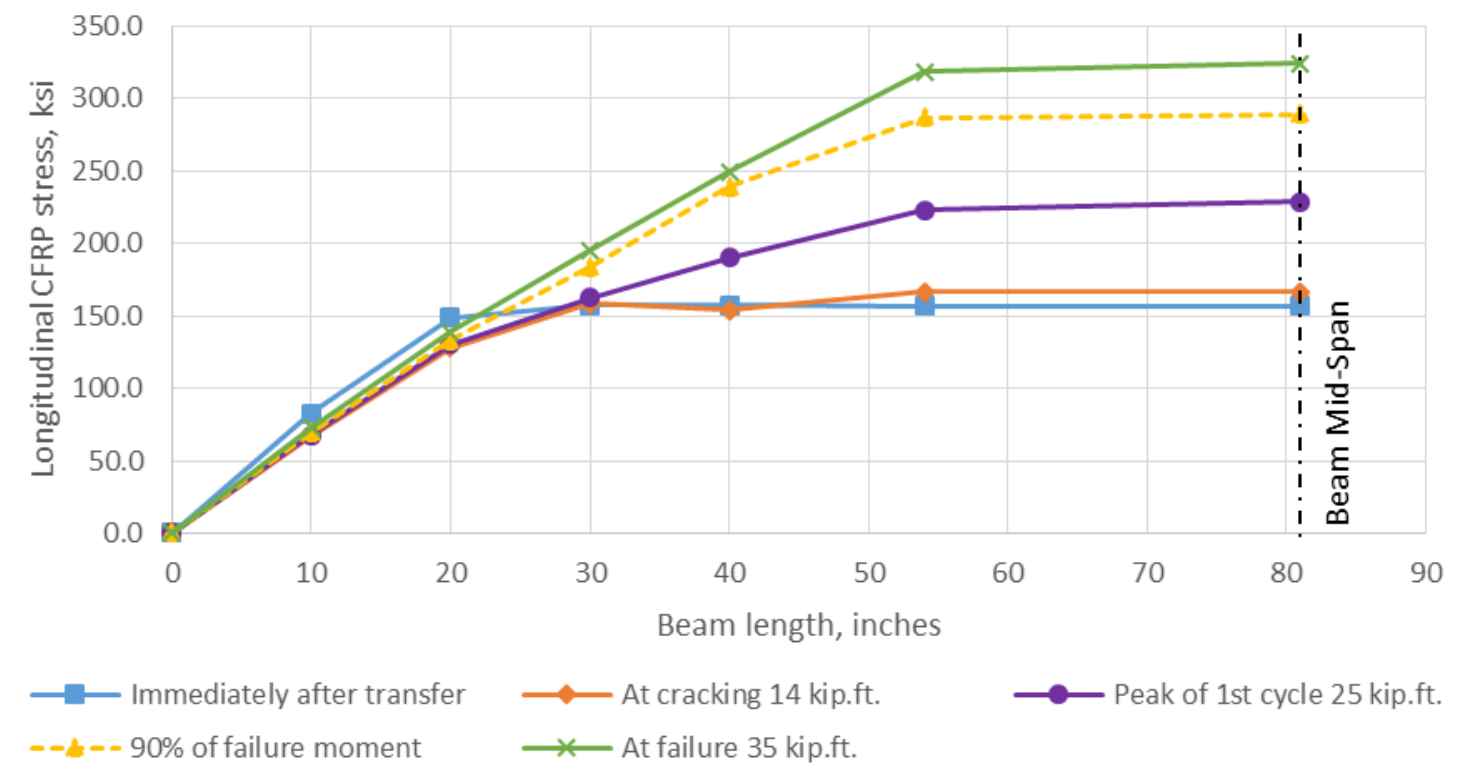

(1) CFRP tensile stress profile at specific load stages

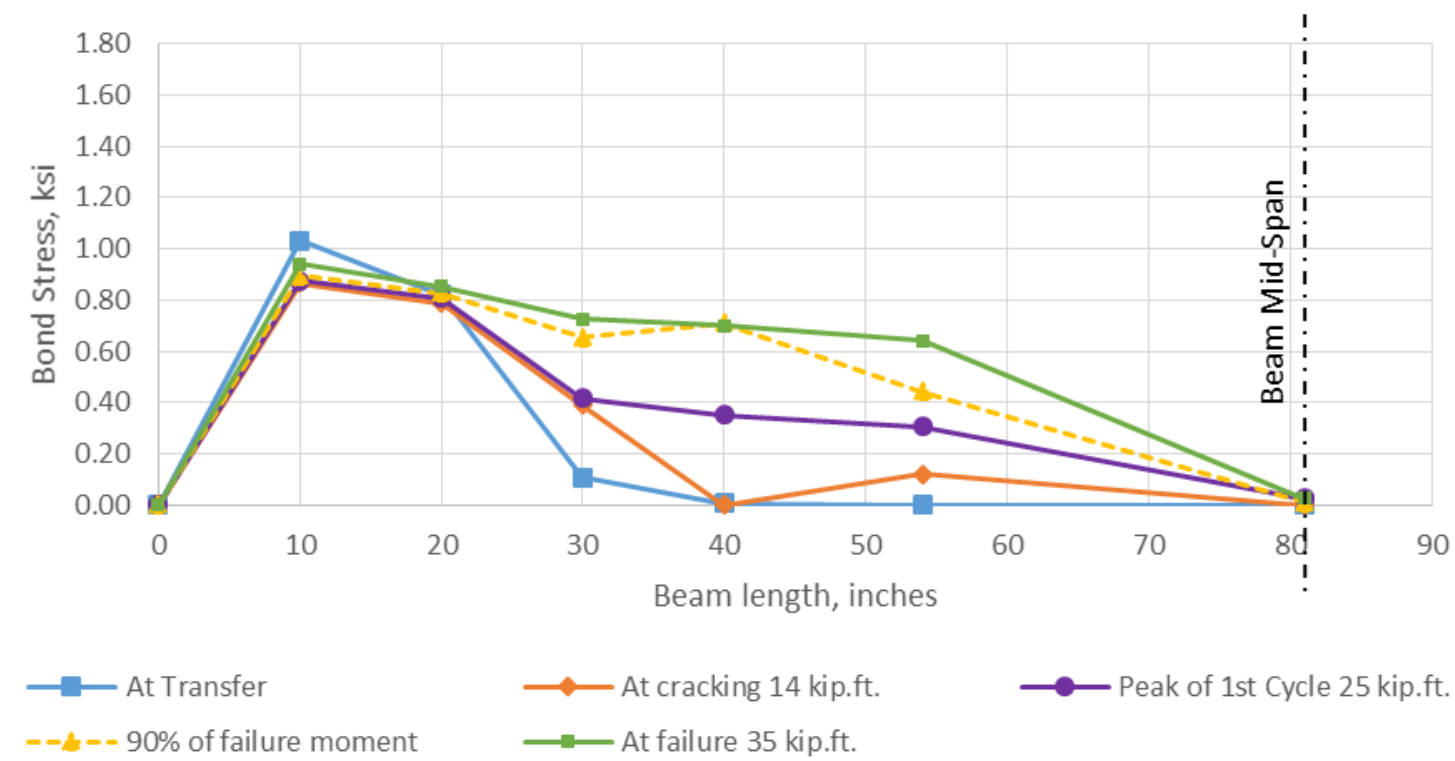

(2) Bond stress profile at specific load stages

Figure 4.26 Tensile stress and bond stress profiles - Beam \#2 


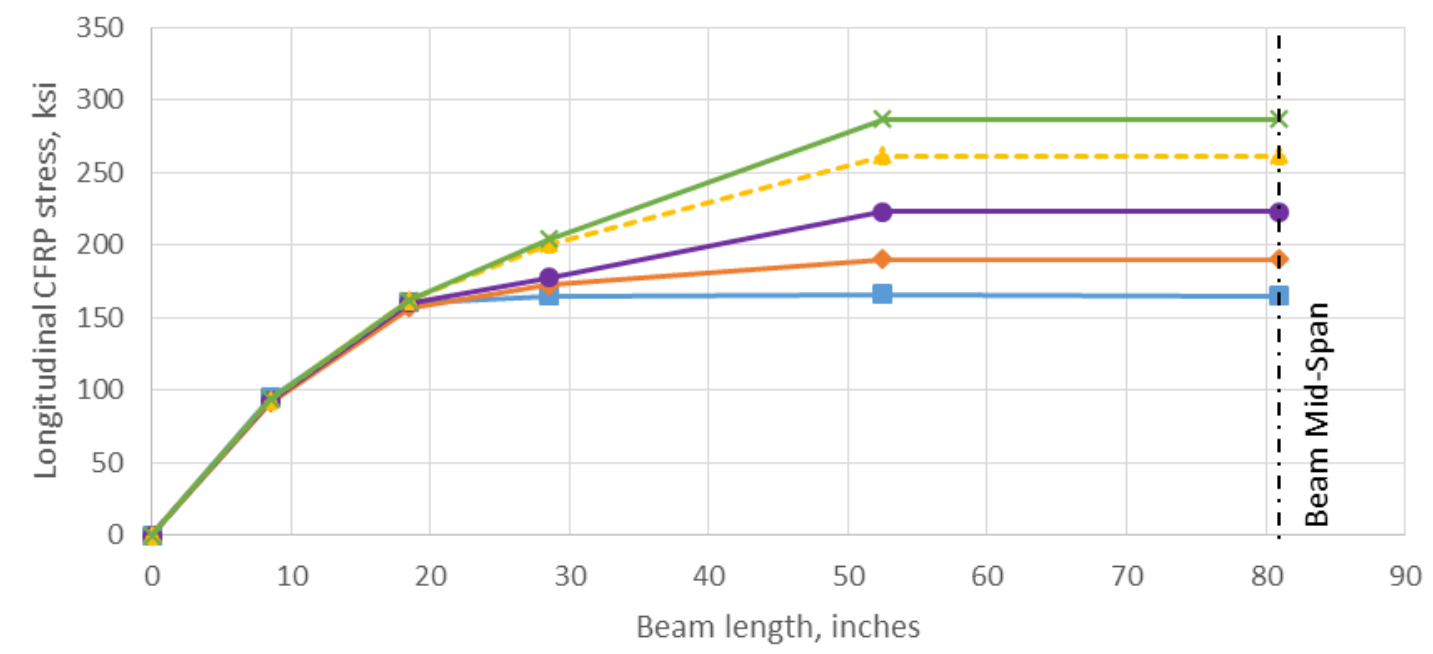

$\longrightarrow$ Immediately after transfer $\longrightarrow$ At cracking 13 kip.ft.
- At failure 32.5 kip.ft.

(c-1) CFRP tensile stress profile at specific load stages

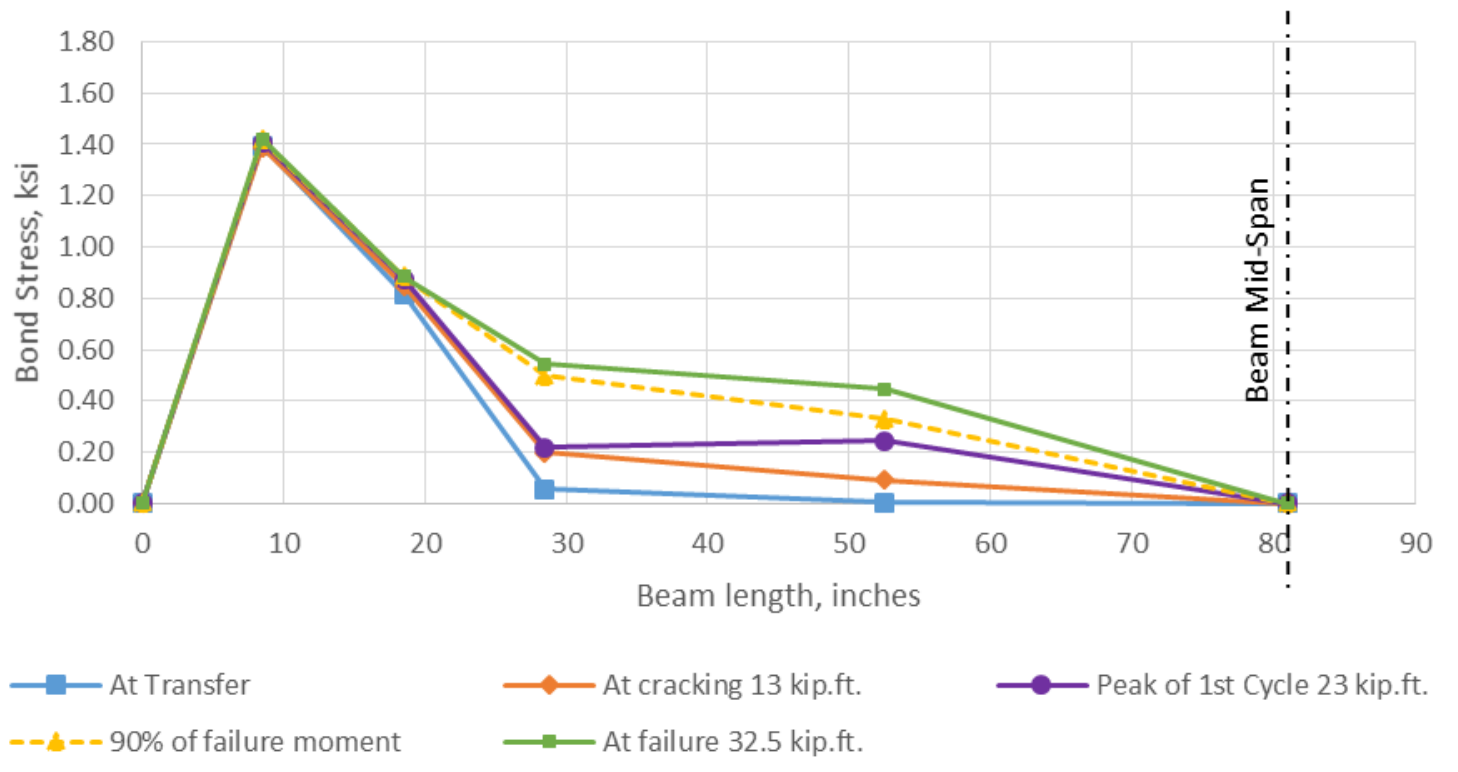

$(c-2)$ Bond stress profile at specific load stages

Figure 4.27 Tensile stress and bond stress profiles - Beam \#3 

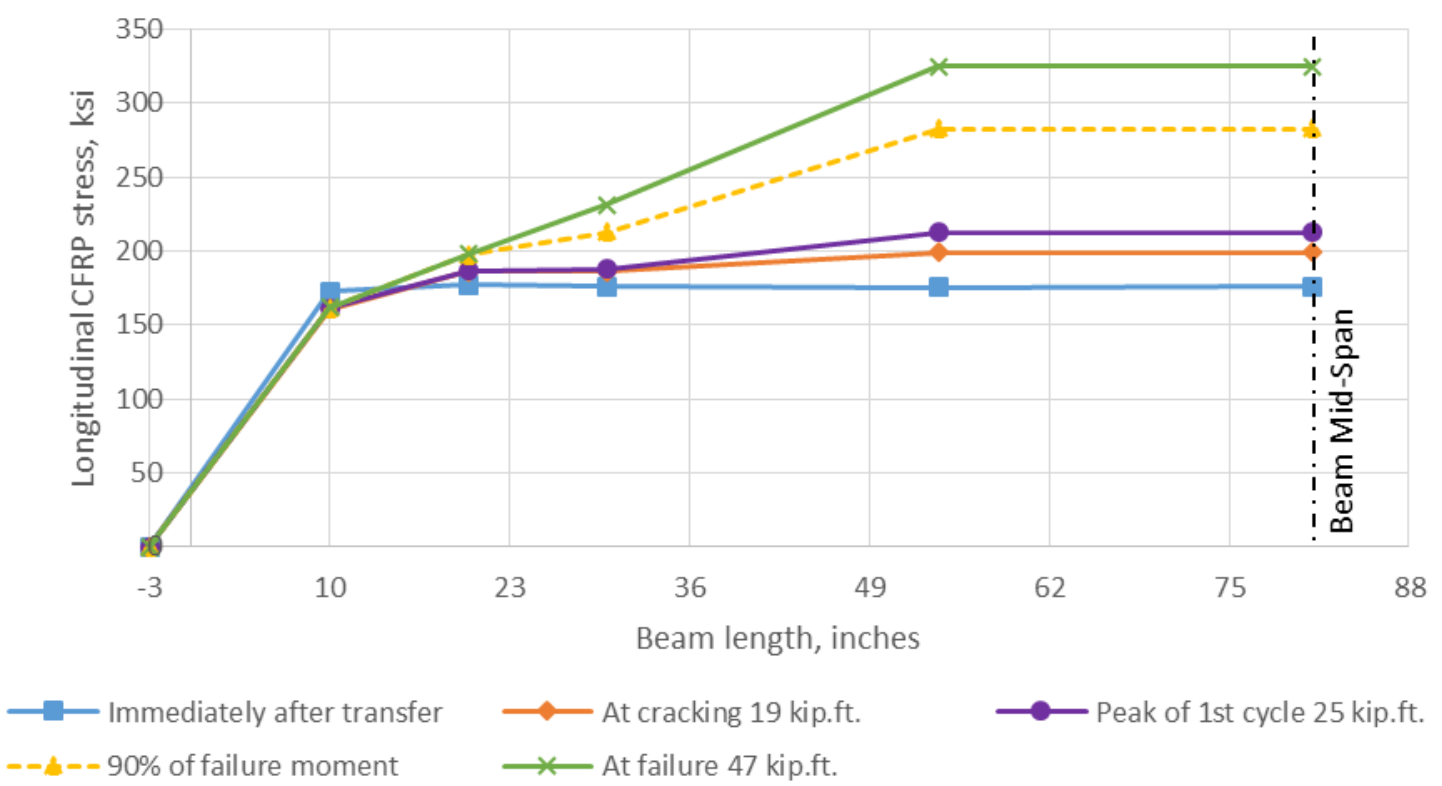

(1) CFRP tensile stress profile at specific load stages

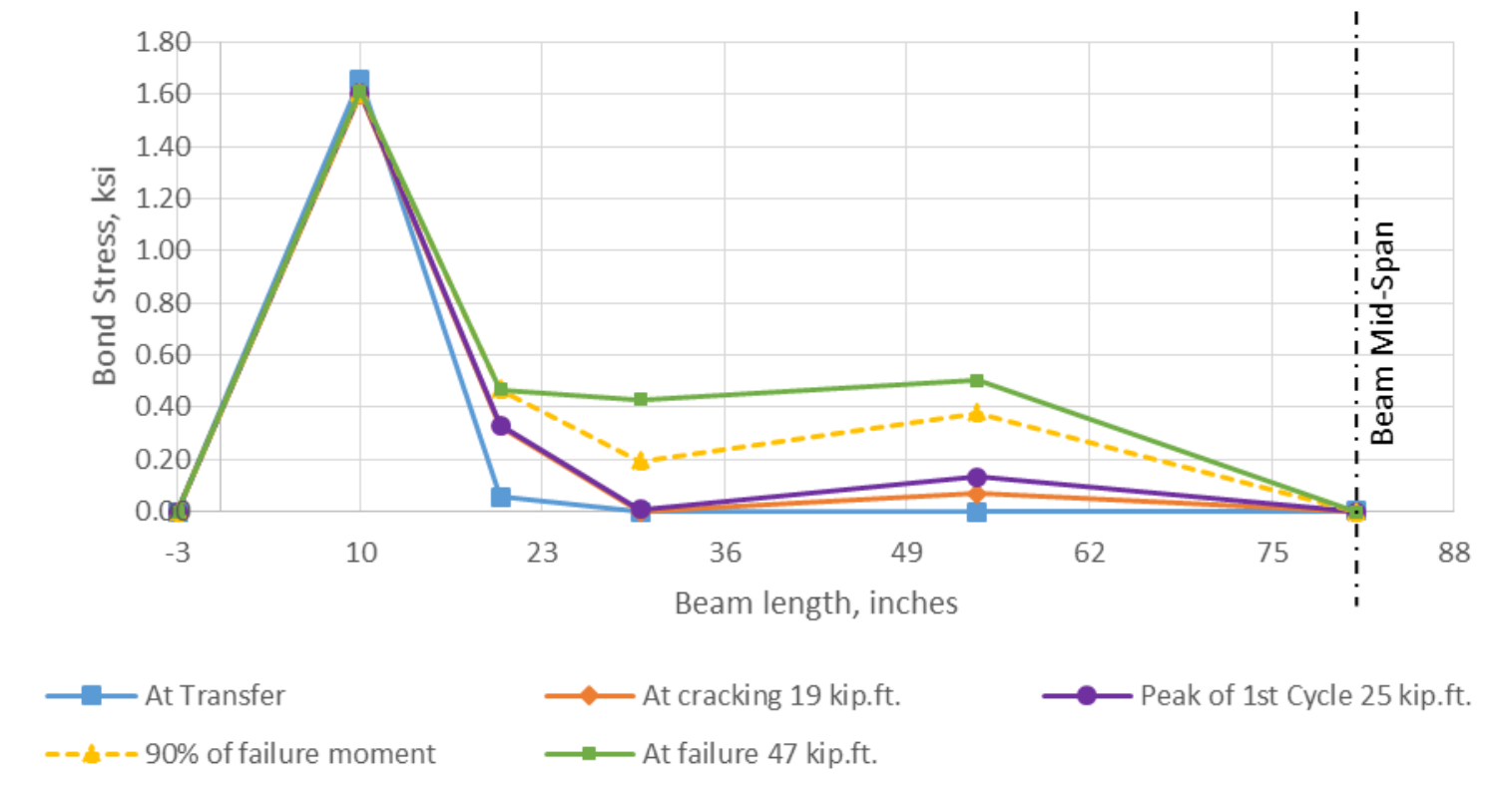

(2) Bond stress profile at specific load stages

Figure 4.28 Tensile stress and bond stress profiles - Beam \#4 


\subsubsection{Moment-Deflection Response Comparison}

The separate moment-deflection curves for all four beams presented in section 4.4.1 were combined in this section so that it would be easier to compare. Figure 4.29 shows momentdeflection curves for all four beams. It can be observed in this figure that the un-cracked section stiffness for all beams was about the same. However, the stiffness responses after the cracking and due to the cyclic loading were different. The post-cracking responses for the first three beams were close in terms of the slope of the curves (stiffness).

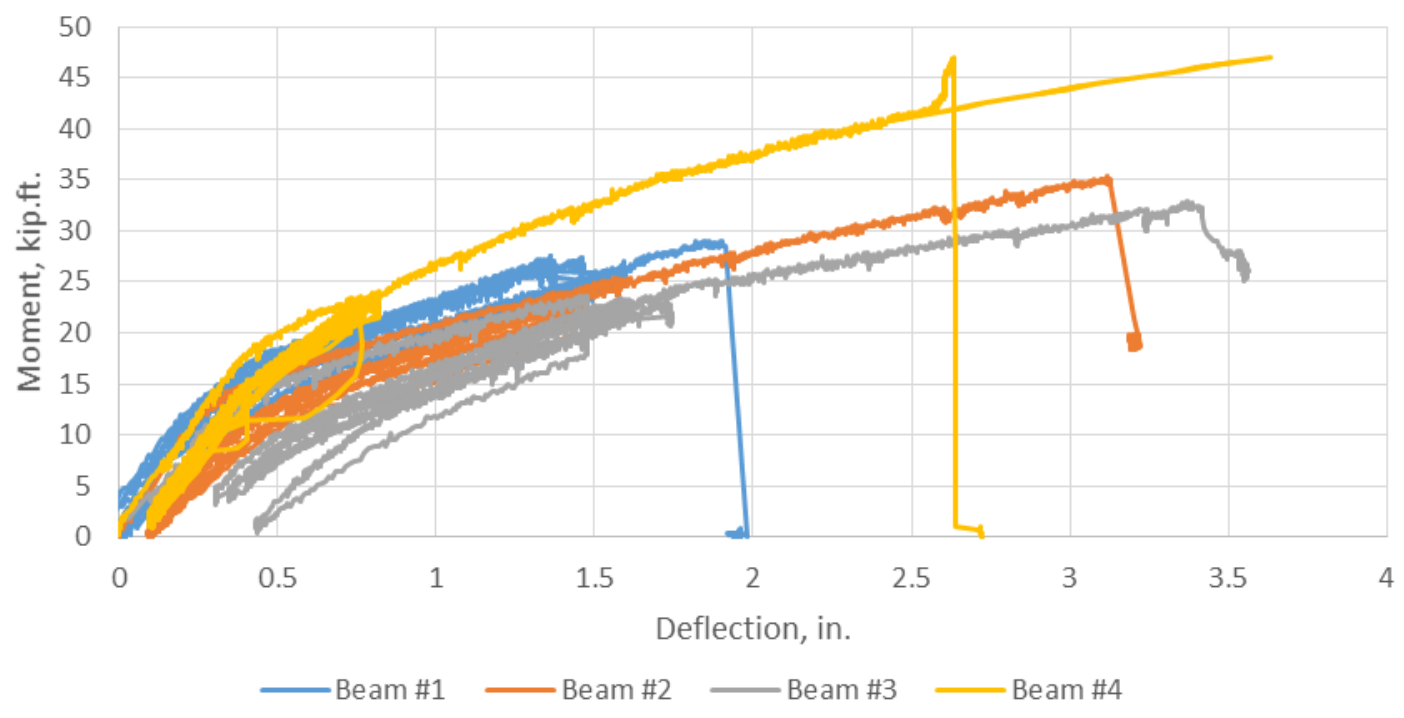

Figure 4.29 Moment-deflection curves comparison

Beam \#1 was the first to fail at $29 \mathrm{kip}$-ft. because of poor bonding between the CFRP strand and the concrete. Beam \#2 went up to $35 \mathrm{kip}-\mathrm{ft}$. with an approximately linear stiffness. Although Beam \#3 failed at 32.5 kip-ft., which was less than failure load for Beam \#2, it 
accommodated more deflection. This means that the overall stiffness of Beam \#3 was less than the stiffness of Beam \#2. On the other hand, the response of Beam \#4 was significantly improved by using the new technique of anchoring the ends. The post cracking stiffness was significantly higher than all of the other beams. The results also show that Beam \#4 provided very good ductility associated with its maximum moment capacity. The new anchoring technique not only improved the moment capacity, but also improved the ductility, or deformability of the beam.

Since FRP materials do not yield, the ductility of beams reinforced or prestressed with FRP were called deformability to make it different from beams reinforced with steel, as described in ACI 440R-07 (ACI Committee 440, 2007). There are a number of proposals in the literature about how to determine the deformability of beams reinforced with FRP materials, but herein only two approaches are used for comparison. The first approach is proposed by Abdelrahman, Tadros, and Rizkalla (1995) . Either deflection or curvature can be used to determine the deformability factor. Abdelrahman proposes the following equation:

$\mu_{\Delta}=\frac{\Delta_{2}}{\Delta_{1}} \quad$... Eq. $(4-7)$

Where:

$\Delta_{1}$ is the assumed deflection of the beam pretending un-cracked section at a load equal to the failure load. 
$\Delta_{2}$ is the actual maximum deflection, as shown in Figure 4.30 below.

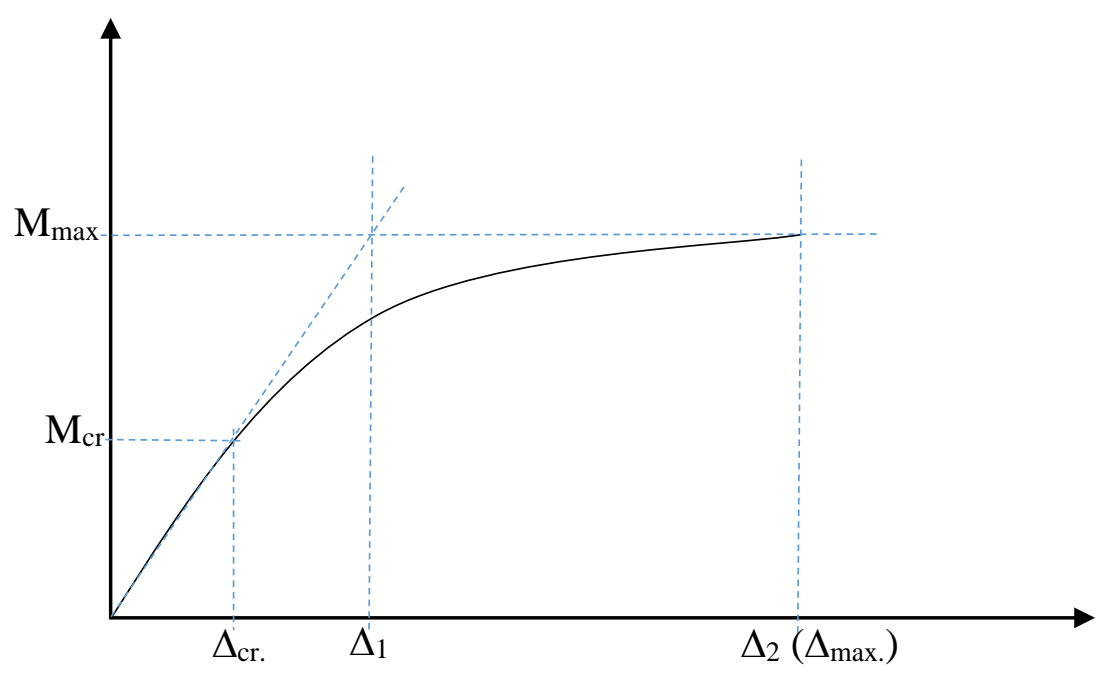

Figure 4.30 Schematic drawing showing the points of interest for deformability calculations

Another approach is proposed by Zou (2003), especially for FRP prestressed concrete beams. The deformability index is as shown in equation Eq. (4-8).

The results of both approaches are presented in Table 4-8. Beam \#2 and Beam \#4 showed the highest ductility, but Beam \#1 showed the least performance in terms of ductility compared to its maximum moment capacity.

$Z=\frac{M_{\max } .}{M_{c r}} \frac{\Delta_{\max .}}{\Delta_{c r .}} \quad \ldots . E q .(4-8)$ 


\begin{tabular}{cccccccc}
\hline Label & $\mathbf{M}_{\mathbf{c r}}$ & $\Delta_{\mathbf{c r}}$ & $\mathbf{M}_{\max .}$ & $\Delta_{\text {max. }}$ & $\Delta_{\mathbf{1}}$ & $\boldsymbol{\mu}_{\Delta}$ & $\mathbf{Z}$ \\
\hline B1-4-65 & 18 & 0.55 & 28.9 & 1.9 & 0.75 & 2.53 & 5.55 \\
\hline B2-4-55 & 14 & 0.38 & 35.3 & 3.12 & 0.78 & 4.00 & 20.70 \\
\hline B3-4-60 & 14 & 0.47 & 32.5 & 3.4 & 0.9 & 3.78 & 16.79 \\
\hline B4-4-60 & 19 & 0.44 & 47 & 3.63 & 0.95 & 3.82 & 20.41 \\
\hline
\end{tabular}

Table 4-8 Deformability comparison based on moment-deflection responses

\subsubsection{CFRP vs. Steel Strands}

In this section the behavior of tested CFRP prestressed concrete beams vs. the behavior of a prestressed concrete beam designed for the same span, cross-sectional area, and service load, but with steel strands is investigated. The purpose is to examine the ductility and the service load deflection of the CFRP beams with those of a comparable beam but with steel strands.

The experimental results of beams prestressed with CFRP strands for the current study were compared to the results of a computer model for prestressed concrete beams pretensioned with 7-wire steel strands G 270 . The beams with steel strands were designed to carry the same service load obtained from beams with CFRP strands. The procedure started with determining the service load for each CFRP prestressed beams (Beam \#2 and Beam \#4 were chosen for this comparison) based on the experimental data and ACI un-cracked 
(Class U) section. Then, prestressed concrete beams pre-tensioned with conventional 7wire steel strands G.270 were designed based on that service load determined from CFRP beams (serviceability limit states following ACI 318-14).

It was assumed that the initial stress of the steel strand was $70 \%$ of the maximum tensile stress $(270 \mathrm{ksi})$. Most of the losses, commonly calculated when designing prestressed concrete beams were ignored to make this beam comparable with the CFRP beams. The CFRP beams were generally tested after a week from force releasing. Therefore, the model for beams prestressed with steel strand assumed that the losses were minimum due to the short period of time between force releasing and flexural testing. The effective stress used for steel strand was $180 \mathrm{ksi}$. However, the same prestressing force was applied for CFRP beams as well as beams with 7-wire steel strand. In this case, both types of prestressed beams would have approximately the same response before cracking. After cracking, the difference was more obvious as a result of different modulus of elasticity of CFRP compared to that of steel strands. The beams with steel strands showed nonlinear behavior with larger deflection, whereas the CFRP beams showed higher stiffness as the stress-strain relationship of CFRP linearly went up until failure.

Figures 4.31 and 4.32 show the difference between the experimental moment-deflection curve for beams pre-tensioned with CFRP strands and the predicted moment-deflection curve for beams pre-tensioned with 7-wire steel strands for the same service load. Figure 4.32 presents the same comparison but for Beam \#4. It can clearly be seen that CFRP beams could handle more load as tensile strength of CFRP was higher than that of steel strands. However, the prestressed concrete beams with steel strands had better behavior in terms of 
ductility. This difference in flexural behavior significantly related to the difference in material properties between steel and CFRP strands.

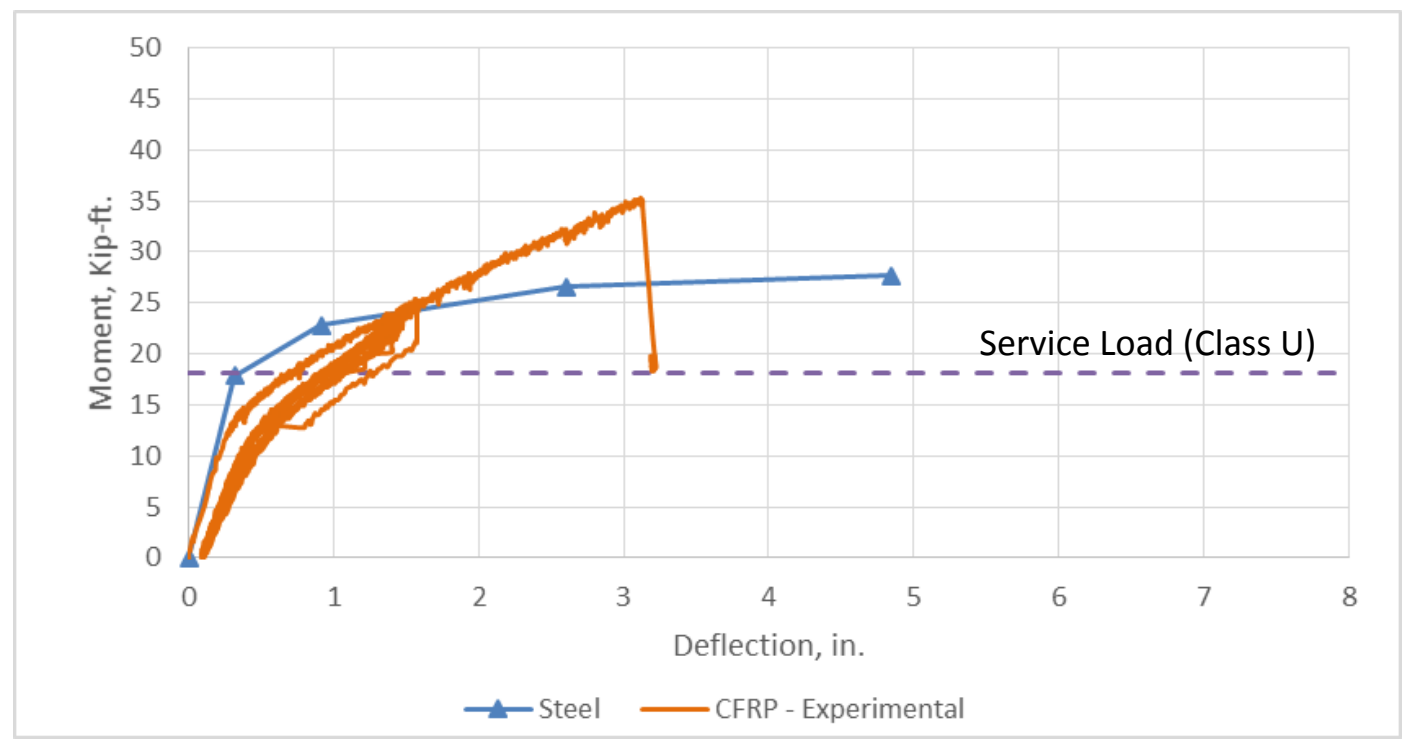

Figure 4.31 Comparison between prestressed concrete beams pre-tensioned with CFRP or steel strands - Beam\#2

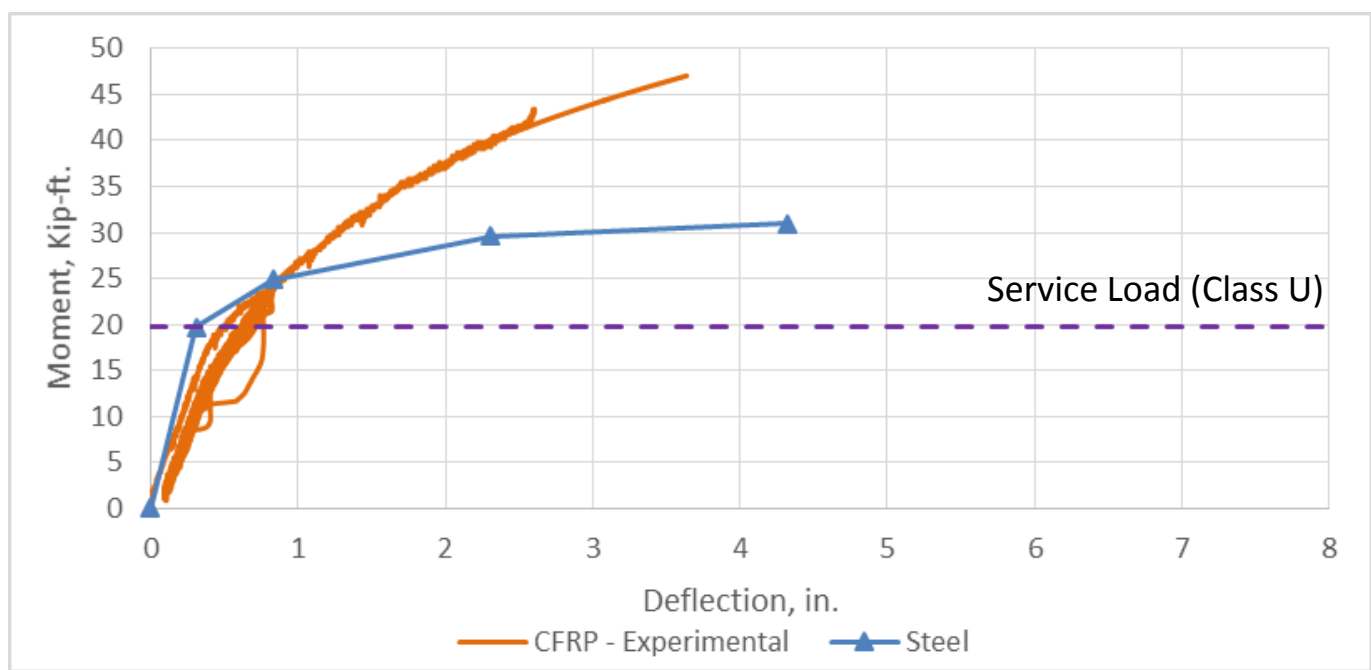

Figure 4.32 Comparison between prestressed concrete beams pre-tensioned with CFRP or steel strands - Beam\#4 
Table 4-9 shows concrete stress, moment and deflection at service load, as well as the maximum moment and deflection for CFRP beams and beams prestressed with steel strands. Table -410 shows the ratios of moments and deflections obtained experimentally from CFRP beams over the values obtained using the computer model for beams prestressed with steel strands. As shown in Table 4-10, the ratios of service load deflection and maximum moments are higher for CFRP beams while deflection under maximum loads are lower.

\begin{tabular}{lcccc}
\hline Beam label: & \multicolumn{2}{c}{ Beam \#2 } & \multicolumn{2}{c}{ Beam \#4 } \\
\hline Strands used: & CFRP & Steel & CFRP & Steel \\
\hline $\begin{array}{l}\text { Concrete stress under service } \\
\text { load }\end{array}$ & 655 & 655 & 650 & 650 \\
\hline $\begin{array}{l}\text { Service M (k-ft.) } \\
\text { Mid-span deflection under }\end{array}$ & 18 & 18 & 20 & 20 \\
$\begin{array}{l}\text { service load (in.) } \\
\text { Maximum M (k-ft.) }\end{array}$ & 0.70 & 0.32 & 0.51 & 0.31 \\
\hline $\begin{array}{l}\text { Mid-span deflection under } \\
\text { max. load (in.) }\end{array}$ & 3.12 & 4.84 & 3.6 & 31 \\
\hline
\end{tabular}

Table 4-9 CFRP beams vs. beams prestressed with steel strands

\begin{tabular}{ccccc}
\hline & Service M & $\begin{array}{c}\text { Mid-span deflection } \\
\text { under service load }\end{array}$ & Maximum M & $\begin{array}{c}\text { Mid-span deflection } \\
\text { under max. load }\end{array}$ \\
\hline Beam\#2 & 1.0 & 2.19 & 1.25 & 0.64 \\
\hline Beam\#4 & 1.0 & 1.65 & 1.52 & 0.84 \\
\hline
\end{tabular}

Note: All ratios CFRP Beam/Steel Strand Beam

Table 4-10 The ratios of moments and deflections obtained from CFRP beams over the values obtained from beams prestressed with steel strands 


\subsubsection{Crack width}

The crack widths were measured using a crack width microscope. Generally, it was aimed to record the crack widths at an increment of $4.5 \mathrm{kip}-\mathrm{ft}$. The procedure was to pick the widest two cracks from both sides of the beam, and to follow the development of crack widths until the load was close to failure. The best data recorded were for Beam \#2 and Beam \#4. For Beam \#1, the crack widths were only recorded at the peak of the loading cycles.

Figures 4.33 and 4.32 show moment vs. crack width for Beam \#2 and Beam \#4. The first observation that can be made from Figures 4.33 and 4.32 is that the crack width was slightly affected by the cyclic loading. It is also noted that in every other cycle the crack width slightly increased. However, the increase in the width was not significant when compared with the applied loading. The beams were pushed to about $65 \%$ of their predicted capacity during every cycle of loading. As a result, an increase of $0.05 \mathrm{~mm}$ was considered small compared with the resistance provided by the beams. The second observation was clear when the two beams were compared. It was obvious that Beam \#4 had better performance in terms of cracking. This was also as a result of using the end anchors. Since there was no loss in the tensile force at the bottom of the concrete section, the cracks could always be closed to micro-crack width once the applied load was removed. In addition when the beam was loaded again, the CFRP tensile force would always put pressure on the concrete thereby causing the cracks to be as thin as possible. 


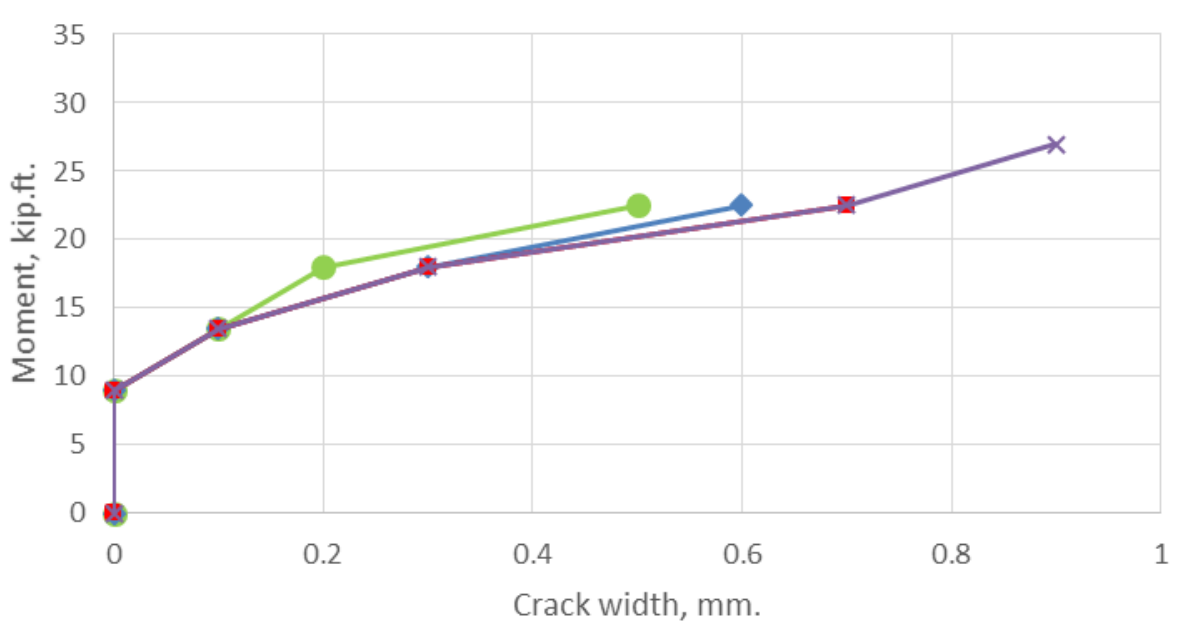

- Cycle \#1 - Cycles \#2 \& \#3 $\longrightarrow$ Cycles \#4 \& \#5 $\longrightarrow$ Cycle \#6

Figure 4.33 Moment vs. crack width for Beam \#2

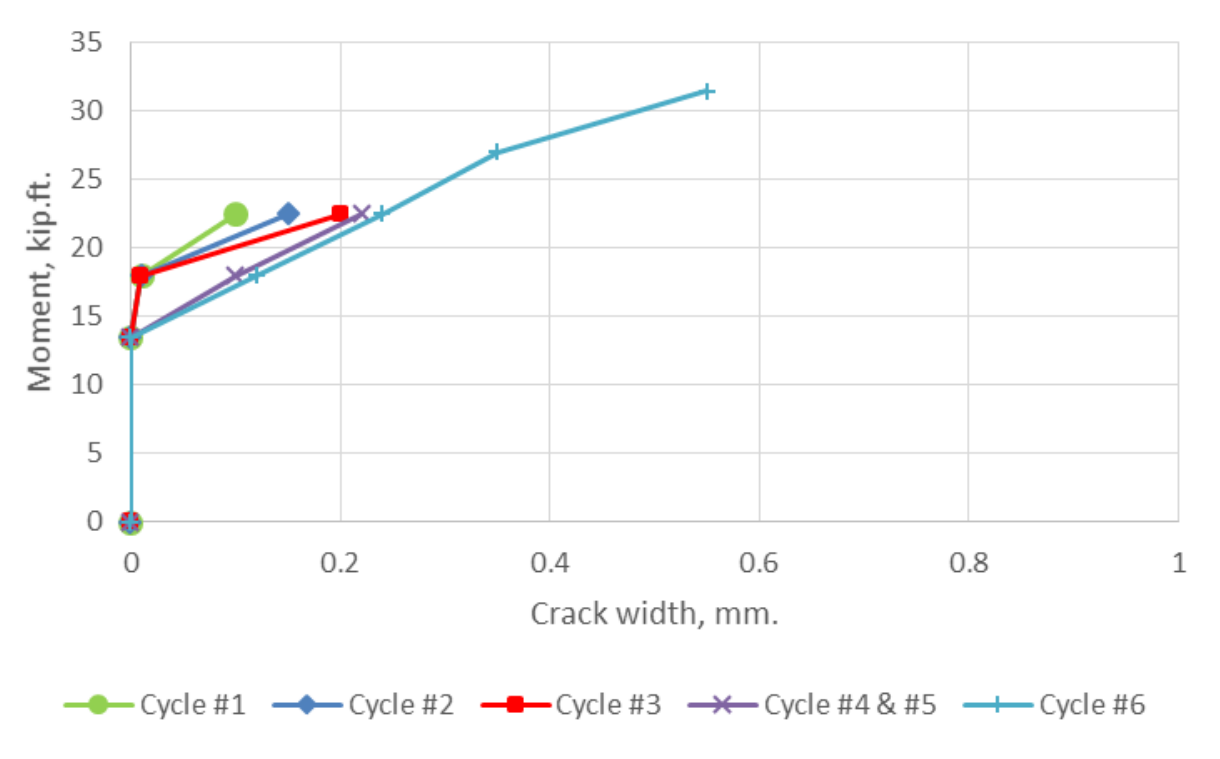

Figure 4.34 Moment vs. crack width for Beam \#4 


\subsubsection{Bond Concrete Behavior of the D5 Steel Wire Embedded}

In order to make sure that the deformed steel wires (commercially known as D5) used for shear reinforcement had enough bond with the concrete, two pull-out tests were conducted. The 0.25-in.-diameter steel wires were embedded inside a cylinder of concrete. The embedment length was 5 in. The five-inch embedment length was chosen to simulate half of the height of the beam cross section. Even though the actual provided bond length for each steel stirrup was about 4 in. (the total length of each stirrup was 8 in.), a five-inch embedment length was chosen for the bond test because the steel wire used in the bind test was straight. In the flexural tests, the closed shape of the stirrups helped with bonding. As a result, it was thought that adding one more inch to the bonding length would equalize the differences. The results showed that there was enough bond between the D5 steel wires and the concrete. The shear reinforcement was designed based on $60 \mathrm{ksi}$ yield of steel. For 0.25 steel wire, the provided force at yield was 2.95 kip. Figure 4.36 shows that the concrete could hold the steel wire for up to an average of $4.8 \mathrm{kips}$. It is interesting to note that the tensile capacity of 0.25 -in. D5 was 4.95 kips (101 ksi), which was slightly higher than the maximum pull-out load. Chapter 3 presents the results of the tensile test conducted for D5 steel wires. 

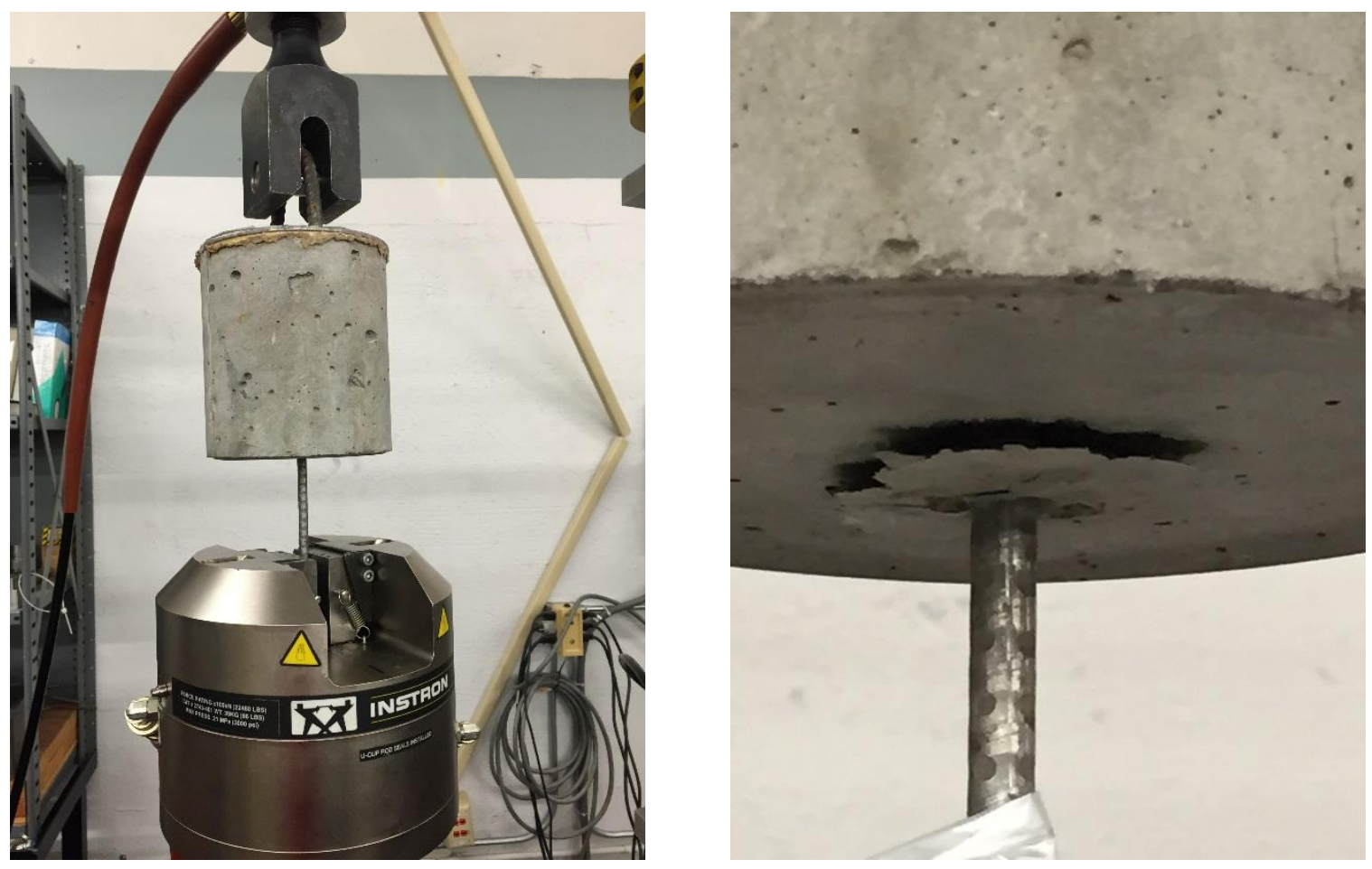

Figure 4.35 D5 vs. concrete bond test

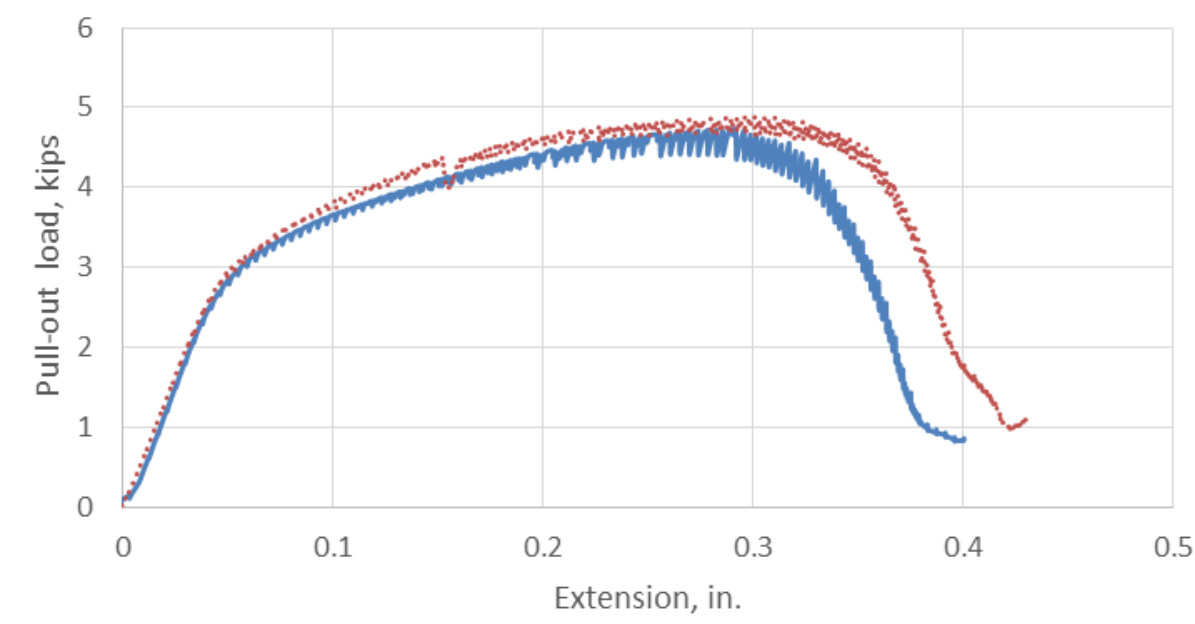

Sample-1

Sample-2

Figure 4.36 Pull-out load vs. extension of D5 rebar bonded in concrete 


\subsection{Test Results of the Anchorage System}

Although the anchorage system at the ends of the prestressed concrete beams showed desire performance in the flexural tests, the tensile response of the anchors themselves needs to be investigated. Based on the beams' flexural tests, the bond between the concrete and the steel tubes provided the required anchor. However, the bond between the CFRP bar and the cementitious grout, or between the grout and the inner face of the steel tube, was still unknown. The tensile tests for the anchors have been carried out as described in Chapter 3. Two bond lengths, which were equal to the steel tube length, were investigated. Figure 4.37 presents the results of the tensile tests. Figure 4.37 shows that the 15 -in. long anchors provided better stiffness and more tensile capacity. On the other hand, the 12-in. anchors achieved more than the maximum guaranteed capacity of the CFRP strand. Based on the literature, an anchor can be described as successful if it achieves $95 \%$ of the guaranteed value of the bars (Schmidt et al., 2010). Herein, both types of anchors failed due to rupture of CFFRP strand at the free length of CFRP bar, which is the recommended failure mode based on (ASTM Standard D7205/D7205M, 2011). Finally, it is interesting to look at the difference in the stiffness between the two kinds of the anchors. The three inches of additional length for the fifteen-inch length anchors significantly affect the anchorage stiffness. Having shown the results, the anchors can be confidently used for FRP

prestressing purposes. However, the author acknowledges that more investigation needs to be done in order for these anchors to be used in a practical setting. 


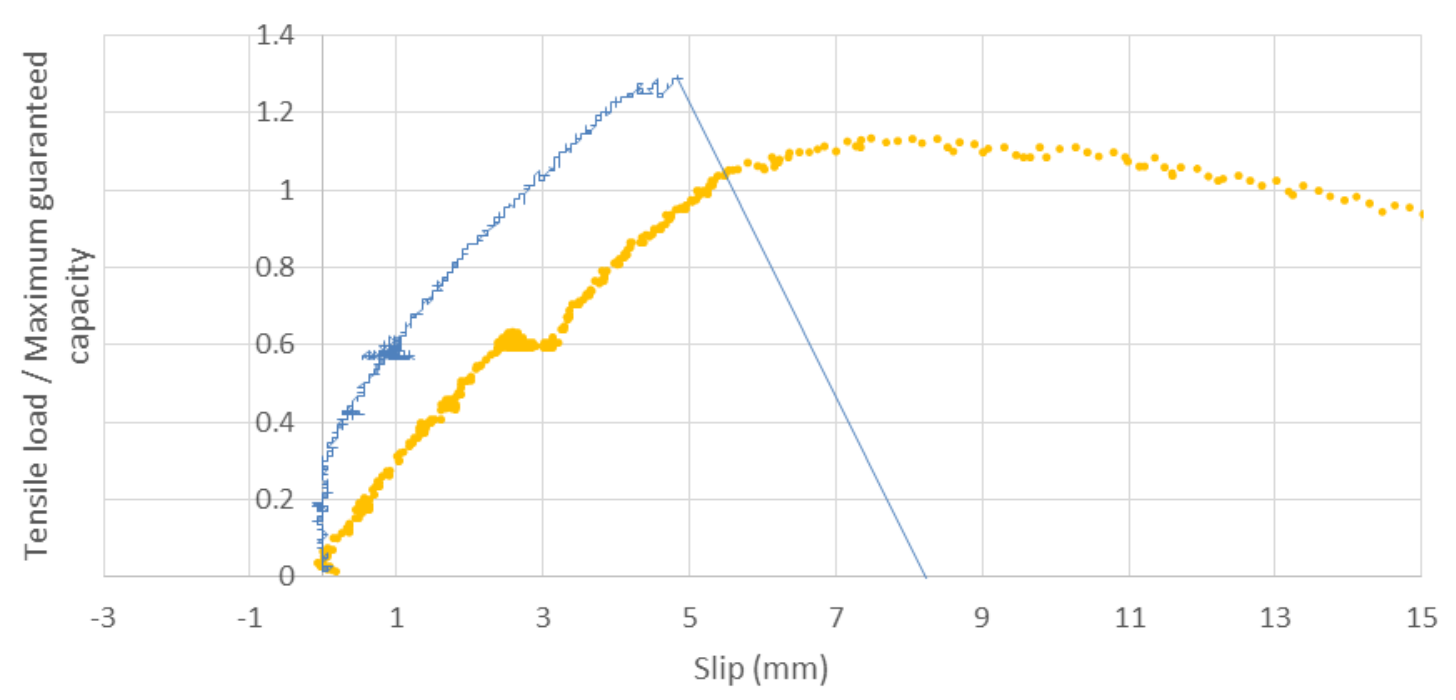

$\ldots$ 12-inch anchor $\quad$ 15-inch anchor

Figure 4.37 Load vs. slip for the anchorage system tensile tests
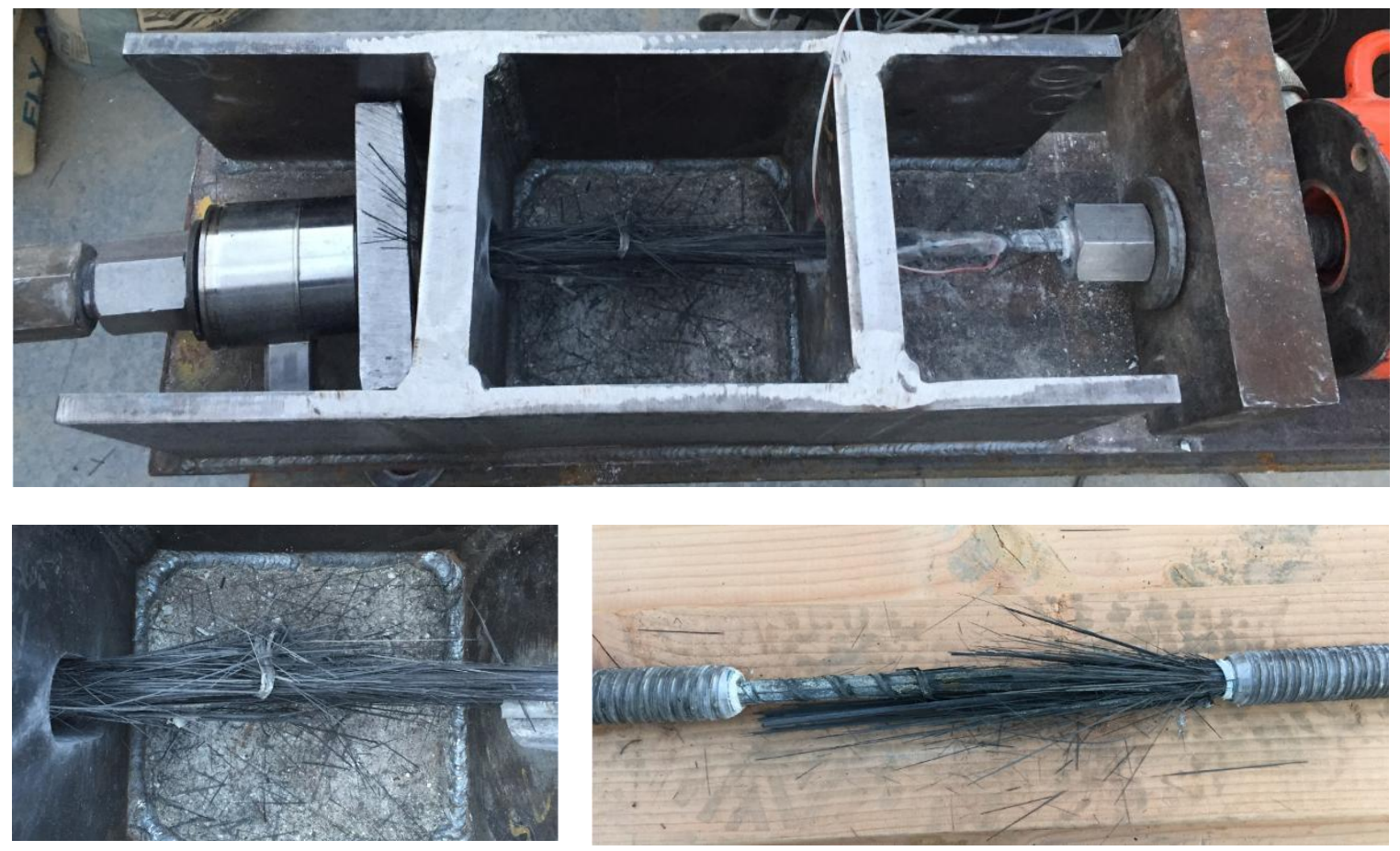

Figure 4.38 Photos at instant of failure of the anchorage system tensile tests 


\section{Chapter 5: Theoretical Prediction of Flexural Response of Beams Pre-tensioned with CFRP Strands}

\subsection{Introduction}

This chapter presents the theoretically derived moment curvature $(M-\varphi)$ relationships for the beams used in the experiment presented in the previous chapter. Then, the M- $\varphi$ relationships are used to compute the deflection of beams under an increasing load. A numerical model was developed to predict the flexural behavior based on strain compatibility principles. The properties of the materials used in modeling the beams are based on the experimental tests. The model predicts the moment curvature for each beam separately as the inputs for each beam are deferent. The analytical results of beam load vs. deflection will be presented and compared to the experimental results at the end of this chapter.

\subsection{Assumptions}

The theory behind this analytical model is based on the idea of strain compatibility. The analysis of the prestressed concrete section was divided into two main stages. The first stage was before cracking while the beam was still in the elastic region. It was assumed that no cracks would develop during this stage, and that the tensile force at the bottom of the concrete section was provided by the composite material consisting of FRP and concrete. The cross-sectional area was transformed to an area representing both materials based on the modulus of elasticity of each material. Generally, the FRP material was transferred to concrete. During the elastic stage, the deflection could be determined based 
on the principles of mechanics of materials. There would be two values of deflection. One value would be for upward deflection due to prestressing force, and the other value would be downward deflection due to applied load (Nawy, 2009).

The second stage started after concrete cracking. The response of a prestressed concrete beam was not elastic anymore. At this stage, the concrete force in tension was ignored. It was assumed that the only force below the natural axis was the CFRP force. The strain distribution was assumed to be linear along the height of the section. At this stage, the analysis mostly depended on the stress strain relationship of the concrete and the CFRP strand. The beam was considered failed when either the strain at the CFRP reached the ultimate, or the concrete strain reached 0.003 . It should be mentioned that perfect bonding was assumed between the CFRP strand and the surrounding concrete.

\subsection{Material Properties}

\subsubsection{CFRP Strands}

The mechanical properties of the CFRP strands were based on the tensile tests that had been carried out on four samples. The maximum tensile strength was determined. The actual ultimate strain could not be determined because there was no measurement of strain after $75 \%$ of the ultimate in order to protect the accelerometer. The ultimate CFRP strain was assumed based on the determined modulus of elasticity. The data collected from prestressing the strand during the manufacturing of the beams were used to determine the stress-strain relationship. The stress-strain relationships for each CFRP strand associated with each beam were presented in Chapter 4 . 


\subsubsection{Concrete}

The stress-strain relationship of concrete was determined using equation 5.1, which was originally proposed by Hognestad in 1951 (Wee, Chin, \& Mansur, 1996). Figure 5.1 shows a schematic drawing of typical concrete stress-strain relationship commonly used in analysis of beam behavior.

$$
f_{c}=f_{c}^{\prime}\left[2\left(\frac{\varepsilon}{\varepsilon_{o}}\right)-\left(\frac{\varepsilon}{\varepsilon_{o}}\right)^{2}\right] \quad \quad \ldots . E q \cdot(5-1)
$$

Where:

$f_{c}$ is the concrete stress

$f_{c}^{\prime}$ is the maximum concrete compressive strength

$\varepsilon$ is the concrete strain

$\varepsilon_{o}$ is the concrete strain associated with the maximum concrete stress. 


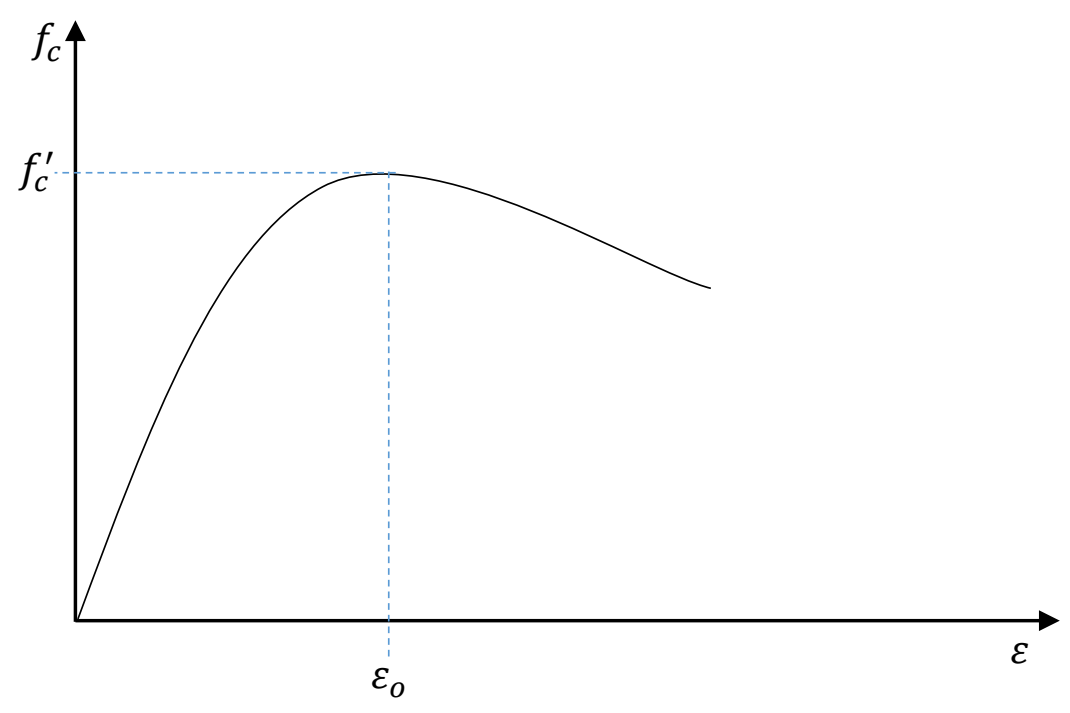

Figure 5.1 Schematic drawing for typical concrete stress-strain relationship

In this study, concrete samples were experimentally tested to determine the actual stressstrain relationship. The experimental results are shown in Figure 5.2. Even though based on the equation proposed by Hogesestad, the value of the concrete strain $\left(\varepsilon_{o}\right)$ at peak concrete stress was fixed at $0.002, \varepsilon_{o}$ used for theoretical analysis here was based on the experimental results. It was found that the fixed value of 0.002 for $\varepsilon_{o}$ worked well if the effect of concrete creep was ignored. Since flexural tests of the beams took more than 90 minutes, it was more reliable to take the $\varepsilon_{o}$ results from the compression tests considering the creep effects on concrete. Generally, when the creep effects were considered, the $\varepsilon_{o}$ value was more than 0.002 . The theoretical stress-strain curves were verified by comparing them to the test results as shown in Figure 5.2. 
Figure 5.2 shows the experimental results of the concrete stress strain relationship, as well as the stress-strain curves using equation 5-1. In Figure 5.2, there are two curves based on equation 5-1. One, called Theoretical-1, uses the experimental $\varepsilon_{o}$, and the second one, called Theretical-2, uses a fixed value of $\varepsilon_{o}$ equal to 0.002 . The average concrete compressive strength, resulted from testing at least three cylinders on the day of the flexural tests, is used for both equations. The figures below also present the effects of concrete creep on the concrete modulus of elasticity.

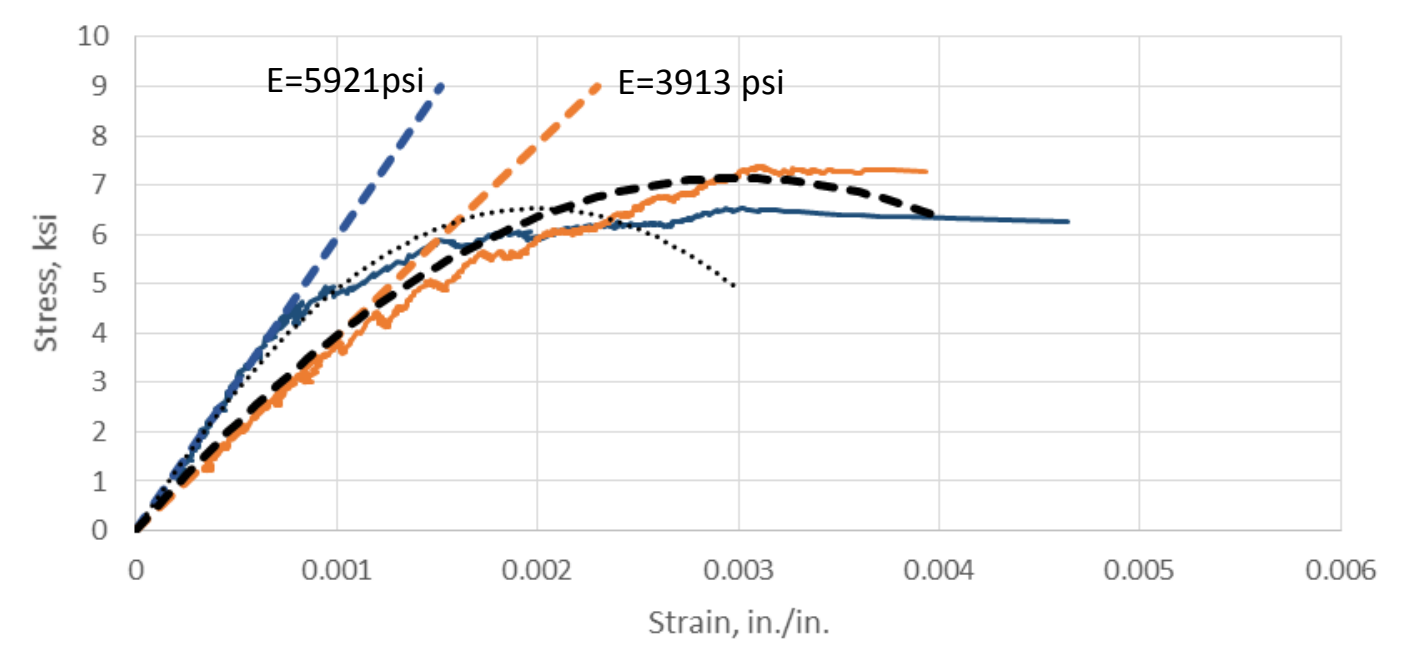

Short-time test

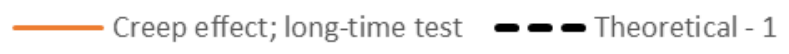

(a) Beam \#1 (B1-4-65)

Figure 5.2 Concrete stress-strain relationships ... short time and creep effects 


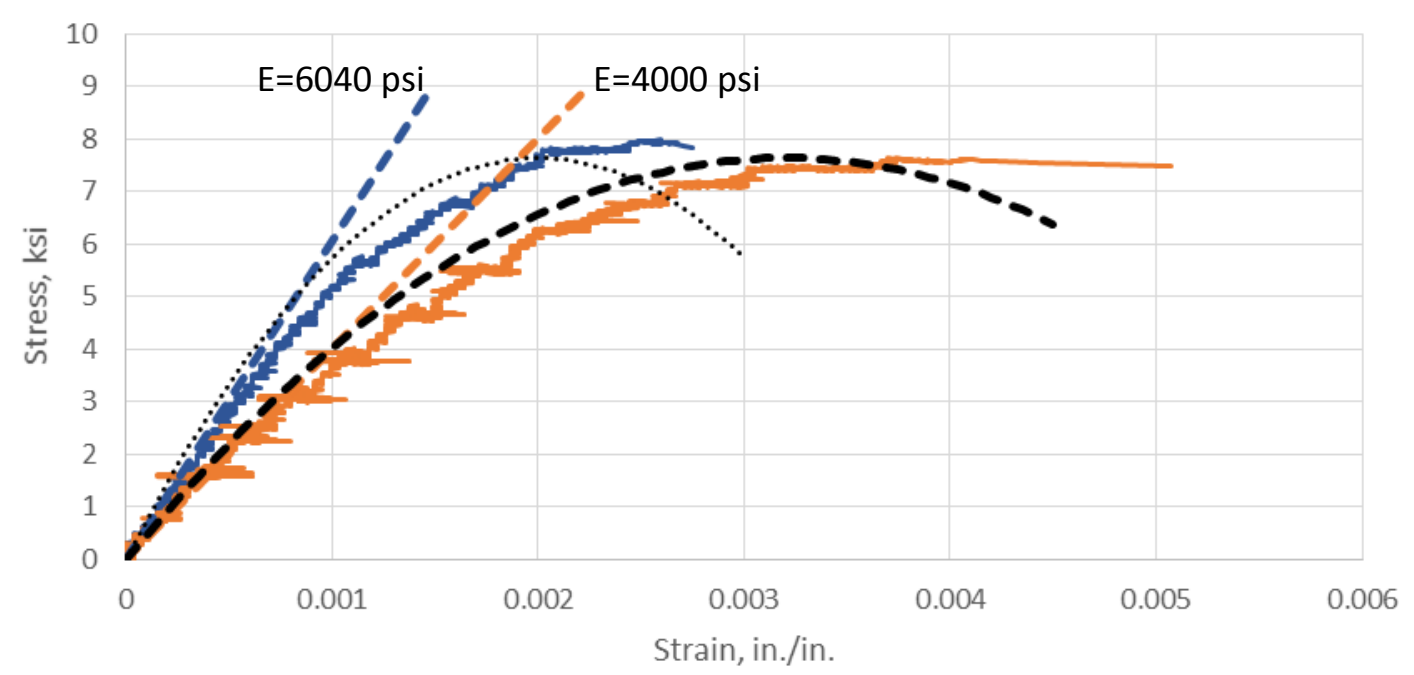

- Short-time test $\longrightarrow$ Creep effect: long-time test $\quad$ - Theoretical-1 $\quad \cdots \cdots \cdot \ldots$ Theoretical-2

(b) Beam \#2 (B2-4-55)

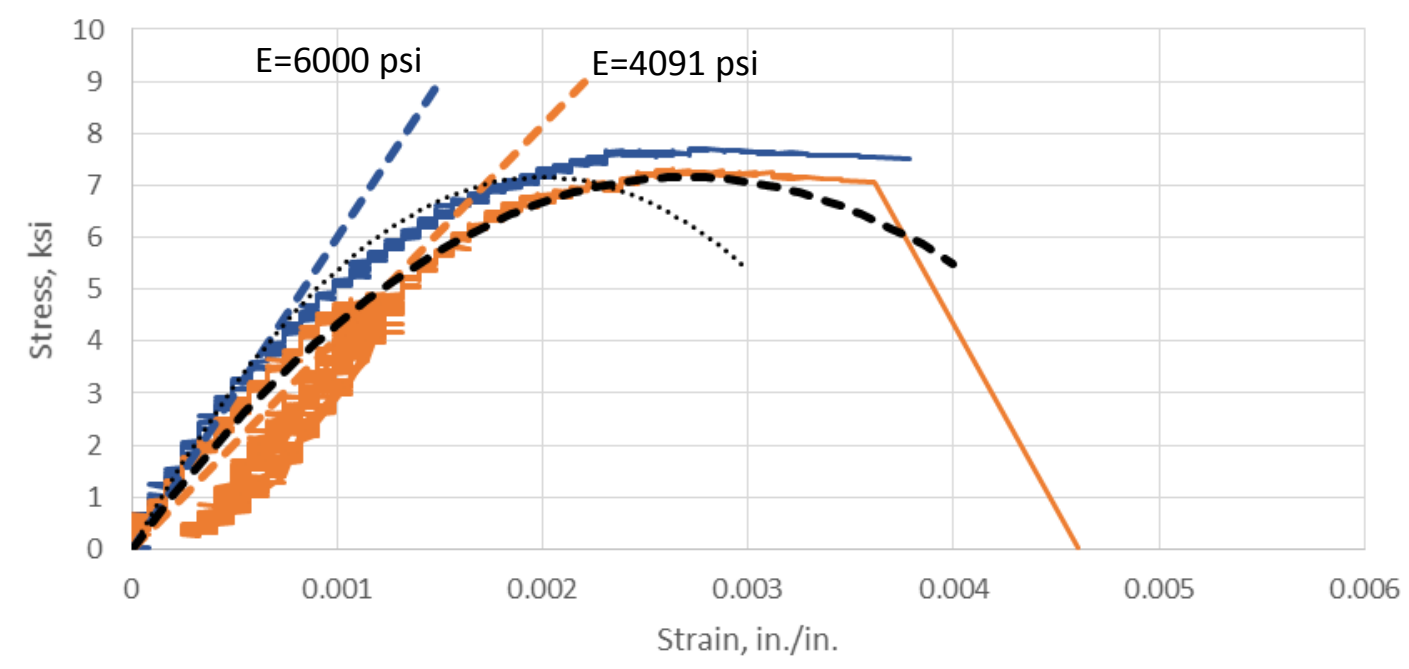

Short-time test Cyclic loading; long-time test $\quad$ - $\quad$ Theoretical-1 …..... Theoretical-2

(c) Beam \#3 (B3-4-60)

Figure 5.2 Continued 


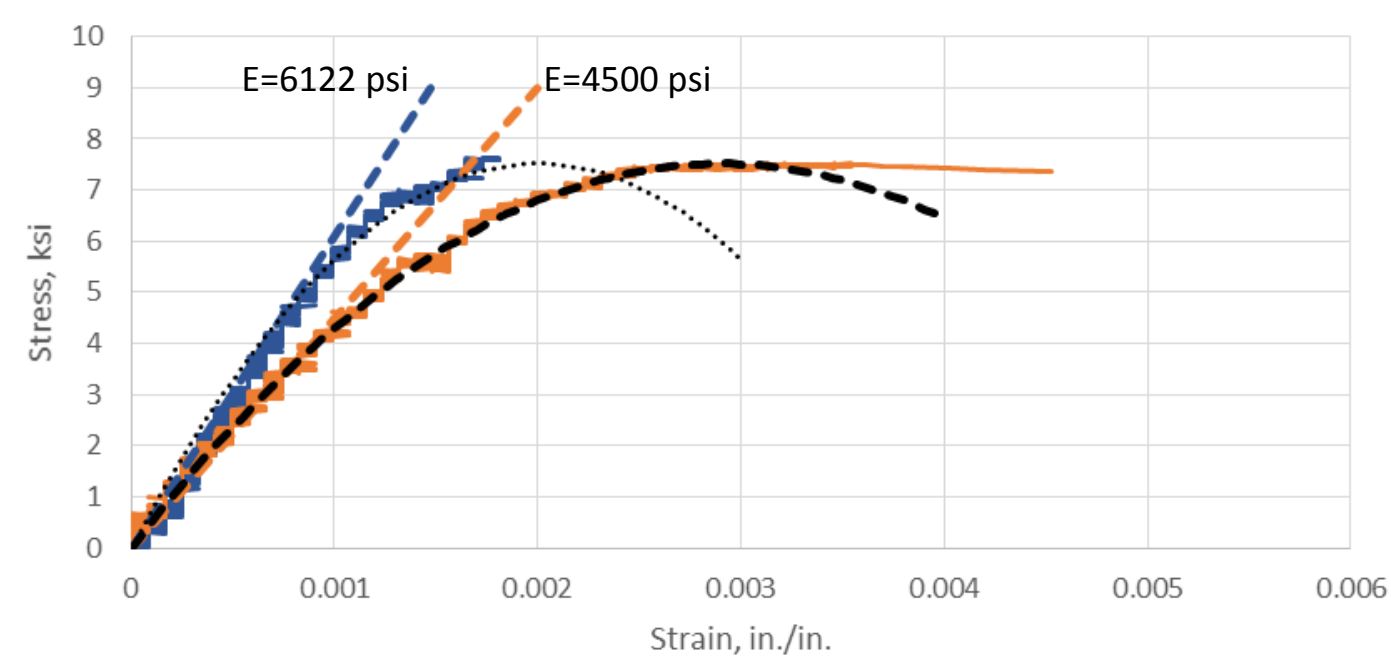

Short-time test

Creep effect: long-time test

(d) Beam \#4 (B4-4-60)

Figure 5.2 Continued

\subsection{Analytical Procedure}

The resources used to create the analytical model were Bank (2006), Nawy (2009), Zoghi (2014), ACI Committee 440 (2004), ACI Committee 440 (2006), and an online presentation ("Moment - Curvature: Bonded Tendons," 2015). A computer model was developed to first compute moment-curvature relationship of the beam cross-section and then compute the load (or moment) vs. deflection response of the beam.

Full details of the analysis procedure (computer model) are presented in Appendix A.

\subsection{Theoretical vs. Experimental Moment-Deflection Curves}

Based on the procedure mentioned in section 5.4 (details presented in Appendix A), the theoretical moment-deflection curves were developed for each beam. Figure 5.3 shows 
theoretical (analytical) vs. experimental moment-deflection curves. There are two labeled points on the curves. One is when the CFRP reaches the guaranteed tensile capacity (300 ksi). The other one, which is considered as failure point, will be either the CFRP strand reaches the actual rupture stress, or the concrete reaches a strain of 0.003 . As shown by the experimental results, the moment-deflection curves are essentially bilinear with a short transition between the straight lines. First linear portion is from zero moment to the cracking moment, followed by a second linear portion with less stiffness from cracking to ultimate moment.

The theoretical model overestimates the flexural capacity for the first three beams. This may be because of assuming perfect bonding between the CFRP and the concrete in the model. The theoretical calculations do not account for the de-bonding effects. Once the bonding problems were solved in Beam \#4, the actual capacity went beyond the predicted value. In this case, the theoretical model slightly underestimated the flexural capacity of Beam \#4. It can be stated that if the first three beams had not had the slippage issues, the experimental results of the first three beams would be closer to the predicted capacity. Additionally, even though the model overestimated the flexural capacity of the first three beams, the theoretical moment-deflection curves are still reasonably close to the experimental results, considering that the beams were made of concrete, a composite nonhomogenous material. Strain compatibility equations have to be modified to take into account the fact that some bond will be lost as the load increases. This is true for Beams $\# 1,2$, and 3 where slippage was observed. However, the computer model here assumed fully bonded strands. 


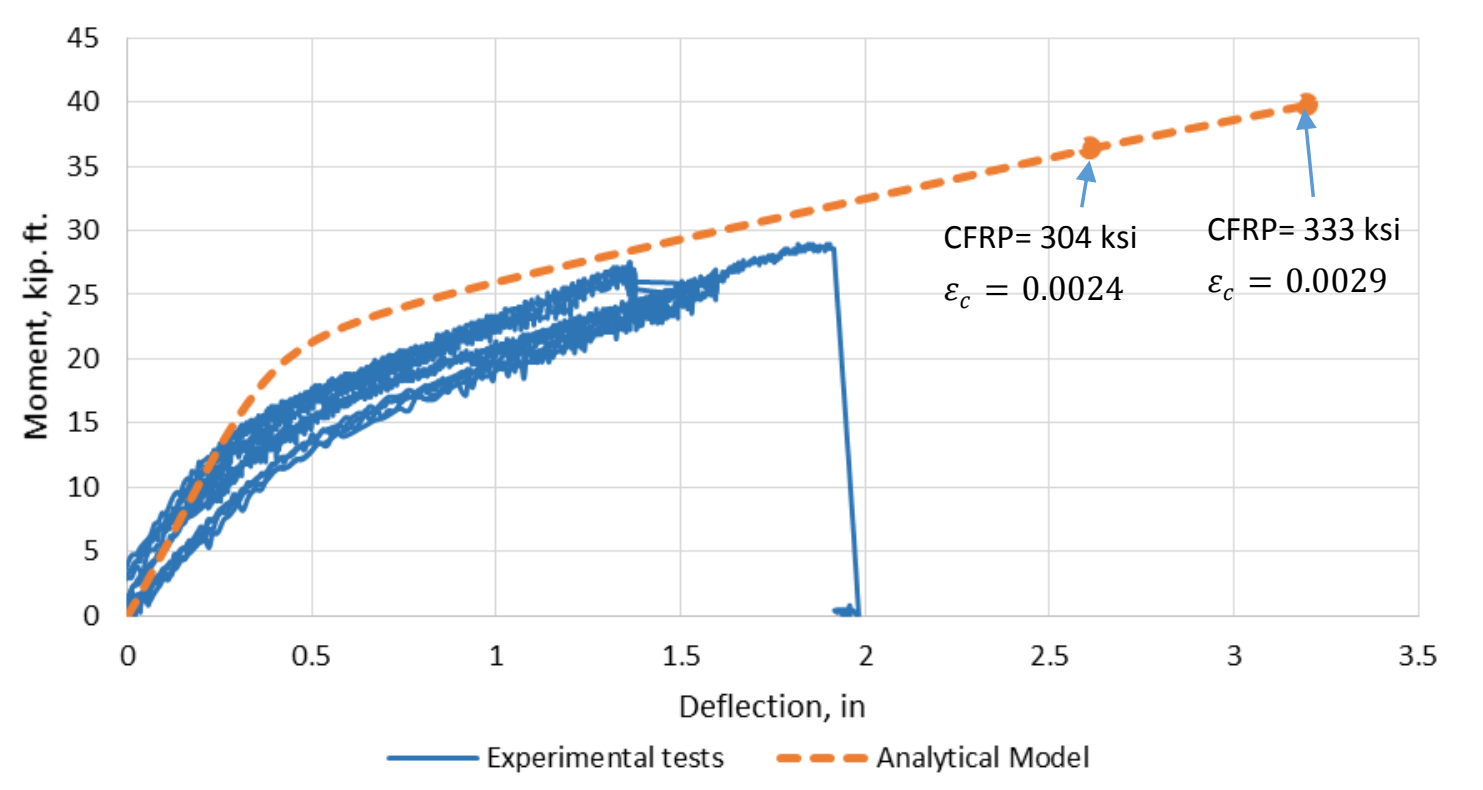

(a) Beam \#1

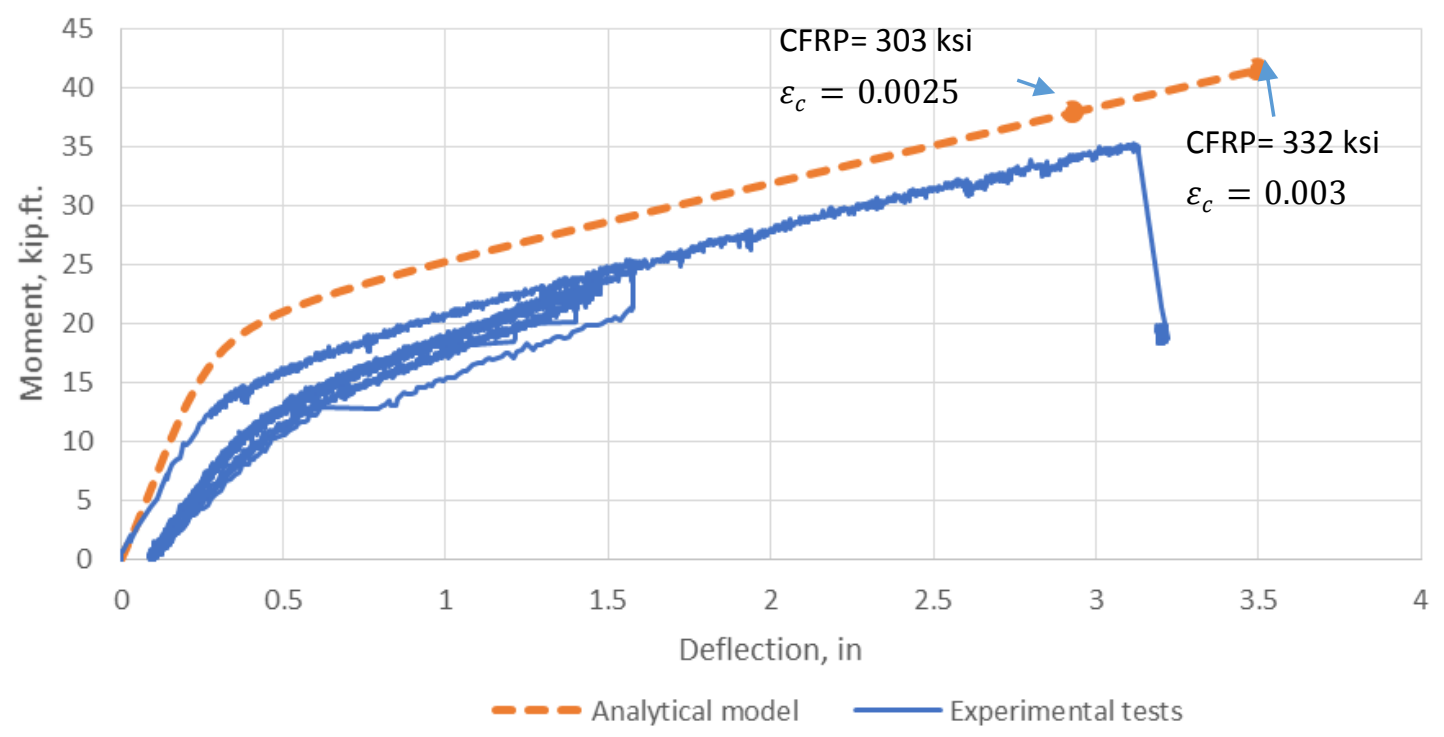

(b) Beam \#2

Figure 5.3 Theoretical vs. experimental moment-deflection curves 


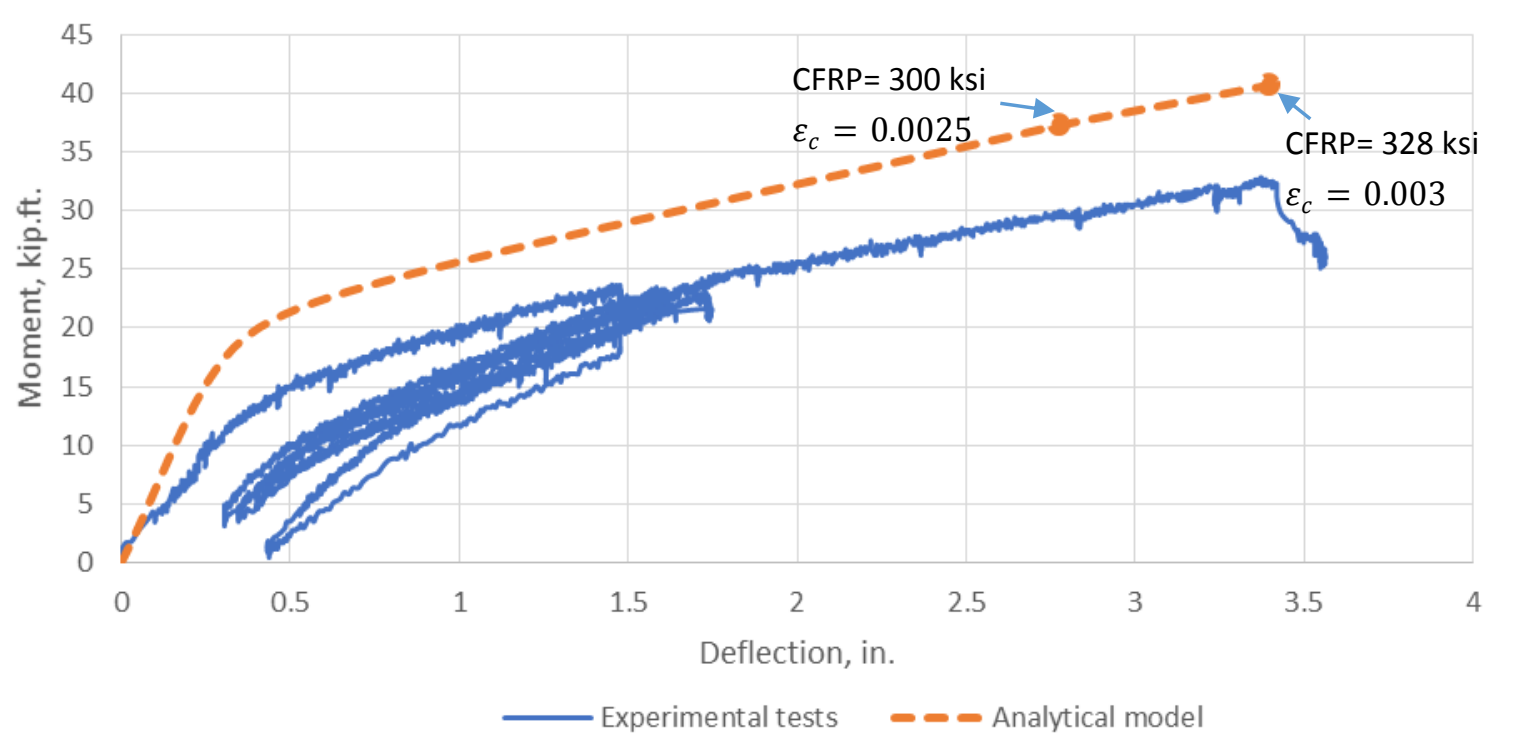

(c) Beam \#3

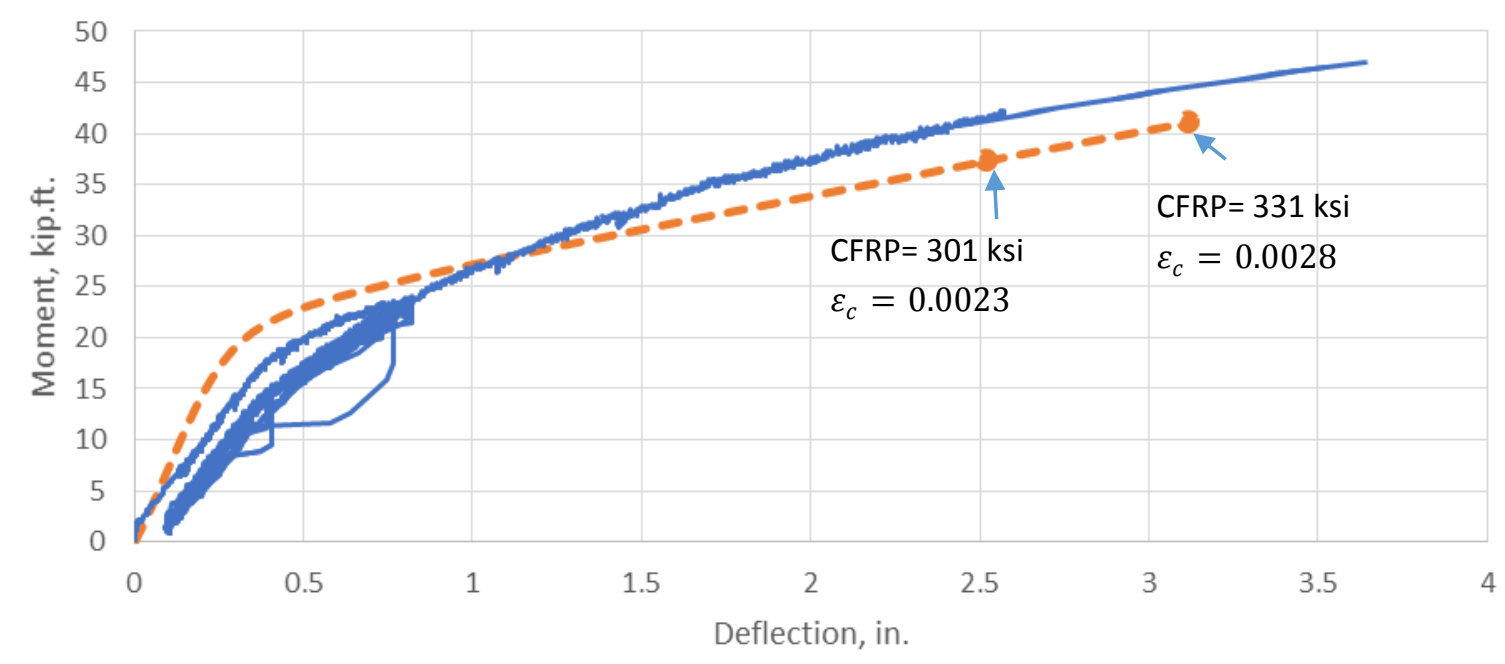

Analytical model Experimental tests

\section{(d) Beam \#4}

Figure 5.3 Continued 


\section{Chapter 6: Conclusions and Recommendations}

\subsection{Introduction}

This chapter presents a summary of this work, conclusions drawn from the results, and recommended future studies. The first section will summarize the work that has been done in this study. The second section contains the conclusions covering the significant findings and observations that can be made based on this research. The last section will cover the recommended future research.

\subsection{Summary}

A total of four prestressed concrete beams were fabricated and tested in this study. Although it was designed for the same capacity, the concrete compressive strength of beams ranged from 7100 psi to 7600 psi. The cross sectional dimensions for beam specimens were $5.5 \mathrm{in}$. wide and $10 \mathrm{in.} \mathrm{deep.} \mathrm{The} \mathrm{total} \mathrm{length} \mathrm{for} \mathrm{all} \mathrm{beams} \mathrm{was} 14 \mathrm{ft}$., the clear span of which was $13.5 \mathrm{ft}$. The beams were simply supported with two-point loads dividing the clear span into three equal lengths of $4.5 \mathrm{ft}$. All beam specimens were prestressed with one 0.5-in.-diameter Carbon Fiber Reinforced Polymer (CFRP) strand, which gives a reinforcement ratio of 0.0042 . The prestressing level ranged from $55 \%$ to $65 \%$ of the guaranteed ultimate strand capacity. The shear reinforcement was provided using 0.25 -in. deformed steel wires. The spacing of the stirrups at the shear span region were $6,3,2$, and 3 in. for beams \#1, 2, 3, and beam \#4, respectively. The variation in stirrups spacing was used to investigate the effects of confinement on FRP-concrete bonding behavior. A new technology was used for beam \#4. A steel-tube anchorage system 
was provided at the ends in order to provide an effective anchorage and reduce bond slippage.

Generally the prestressing force was released after two weeks from concrete casting, or when the concrete compressive strength became equal to or more than $6500 \mathrm{psi}$. Then, the prestressed concrete beams were flexurally tested at twenty-one days or when the concrete compressive strength went over 7000 psi. All of the specimens were subjected to five cycles of loading up to the peak load of 60 to $65 \%$ of the expected ultimate load. Then, the load was increased monotonically at the sixth cycle until failure. In addition to the flexural tests, pullout tests were carried out for the bond-type steel tube anchorage system. The results were collected, analyzed, and compared to the predicted behavior. The following section of this chapter highlights the findings of these results.

\subsection{Conclusions and Observations}

The following are the main findings that can be drawn based on this study:

- The mechanical properties of Aslan 200 Carbon Fiber Reinforced Polymer (CFRP) bars reported by the manufacturer were less than the average value for the specimens tested in the lab. The reported modulus of elasticity was $18,000 \mathrm{ksi}$ for both \#3 and \#4 strands, while the average modulus was 19,000 and 20,500 ksi for \#3 and \#4 CFRP strands tested, respectively. The maximum guaranteed tensile capacity reported by the manufacturer was $300 \mathrm{ksi}$ for \#4 CFRP strands, while it was $330 \mathrm{ksi}$ based on the laboratory tests for the same bar size. However, the manufacturer's values agreed with the guaranteed values specified by ACI Committee 440. 
- The expansive grout (Bustar), used as the filler material for the anchorage system, provided adequate pressure which maintained the CFRP strand inside the steel tube until the full tensile strength of CFRP was achieved. This resulted in a successful steel tube anchorage system used in one beam.

- Both lengths (15 in. and 12 in.) of the CFRP anchors achieved more than the guaranteed tensile capacity of the CFRP strand. However, the 15-in. long anchorage system could sustain $130 \%$ the guaranteed capacity with a load-slip stiffness much higher than that achieved by 12-in.-long anchors.

- The confinement provided by lateral reinforcement significantly affected the CFRP strand-to-concrete bond characteristics. Although ACI 440.4R-04 includes the most accurate equation among the available equations in the literature to predict the transfer length for Aslan 200 CFRP strands, it does not count for confinement effects.

- Since ACI does not have equations for Aslan 200 CFRP bars, they can be treated as Leadline FRP bars in terms of calculating the transfer length using ACI 440 equation. It is recommended by this study to consider the numerical coefficient $\alpha$, equal to 10. The coefficient " $\alpha$ " is used in ACI equation to determine CFRP transfer length

- The transfer lengths measured at the live and dead ends were found to be almost the same.

- The average bond stress at transfer increased when the transfer length decreased as a result of adding more lateral reinforcement. 
- Adding the CFRP steel tube anchorage system at the ends increased the average bond stress at transfer by about $60 \%$ and decreased the transfer length by about $36 \%$

- The minimum shear reinforcement specified by ACI Committee for steelprestressed concrete members might not be adequate for CFRP-prestressed concrete members due to weak bonding issues. CFRP members need to have adequate lateral confinement in order to prevent early bond failures.

- Based on the experimental results, the average total losses in prestressing force from the jacking up to the flexural test day (typically an average of 25 days) can be estimated as $7.3 \%$ for CFRP strands.

- The devised technique of using steel tube anchorage system at the ends of CFRP strands prevented the end slippage. In this study, using steel tube anchorage system improved the member flexural capacity by $33 \%$.

- For prestressed concrete beams with $1 / 2$-in. diameter Aslan CFRP strands, the development length is more than $108 \mathrm{~d}_{\mathrm{b}}$ without end anchors.

- The average flexural bond stress is less than the average bond stress at transfer as the flexural bond length is longer than the transfer length.

- The strain compatibility and internal force principles used in the theoretical model for analyzing prestressed concrete beams reasonably predicted the behavior of CFRP prestressed concrete members assuming the bond between the reinforcement and concrete was adequate. For more accurate prediction, however, strain 
compatibility equations have to be modified to take into account the fact that some bond will be lost as the load increases

- Comparing CFRP beams with beams prestressed with steel strands, the CFRP beams showed higher strength but less ductility when both beams had the same cross-sectional area, prestressing force, span length, and designed for the same service load. It should be noted that this conclusion is only true if the design procedure is based on service stress limits provided by ACI-class U. Other cases were not investigated.

\subsection{Recommendations for Future Work}

- Further studies need to be done to investigate the transfer, flexural bond, and development lengths of Aslan CFRP strands.

- The new steel-tube anchor should be examined for long-term tests in order to investigate its potential application in practice.

- A database should be created on prestressed concrete beams pre-tensioned with various prestressing levels (a range of $30 \%$ to $70 \%$ is suggested) in order to determine the minimum and maximum limit states for CFRP prestressing that result in in a ductile behavior.

- Further work is recommended to investigate fatigue and sustained loading on CFRP prestressed concrete members.

- It is recommended to compare the proposed theoretical model and the experimental results to a finite element model that can more precisely predict the flexural 
behavior of concrete beams prestressed with CFRP strands. This model should take in account the bond characteristics between the concrete and CFRP strands.

- It is recommended to examine the effects of using more than one CFRP strands in beams. 


\section{References}

Abdelrahman, A. A., Tadros, G., \& Rizkalla, S. H. (1995). Test Model for the First Canadian Smart Highway Bridge. ACI Structural Journal, 92(4), 451-458.

ACI Committee 318. (2014). Building Code Requirements for Structural Concrete. Farmington Hills, MI: American Concrete Institute.

ACI Committee 440. (2004). Prestressing Concrete Structures with FRP Tendons. Farmington Hills, MI: American Concrete Institute.

ACI Committee 440. (2006). Guide for the Design and Construction of Structural Concrete Reinforced with FRP Bars. Farmington Hills, MI: American Concrete Institute.

ACI Committee 440. (2007). Report on Fiber-Reinforced Polymer ( FRP ) Reinforcement for Concrete Structures. Farmington Hills, MI: American Concrete Institute.

Alobaidi, S. (2015). Behavior of Reinforced Concrete Beams Retrofitted in Flexure Using CFRP-NSM Technique. Portland State University.

ASTM Standard C469. (2002). Standard Test Method for Static Modulus of Elasticity and Poisson's Ratio of Concrete in Compression. West Conshohocken, PA: ASTM International.

ASTM Standard C78. (2008). Standard Test Method for Flexural Strength of Concrete (Using Simple Beam with Third-Point Loading). West Conshohocken, PA: ASTM International.

ASTM Standard D7205/D7205M. (2011). Standard Test Method for Tensile Properties of Fiber Reinforced Polymer Matrix Composite Bars. West Conshohocken, PA: ASTM International.

Bank, L. C. (2006). Composites for Construction: Structural Design with FRP Materials. John Wiley \& Sons, Inc., Hoboken, New Jersy.

Cai, W., Zhang, J., Liang, S., \& Tu, Y. (2011). Study of Static Load Tests of Bond-Type Anchors for CFRP Tendons. In The 5th International Conference on FRP Composites in Civil Engineering (pp. 313-316). Beijing, China.

Domenico, N. G., Mahmoud, Z. I., \& Rizkalla, S. H. (1998). Bond Properties of Carbon Fiber Composite Prestressing Strands. ACI Structural Journal, 95(3), 281-290.

Du, X., Zuohu, W., \& Jingbo, L. (2011). Flexural Capacity of Concrete Beams Prestressed with Carbon Fiber Reinforced Polymer (CFRP) Tendons. Advanced Materials Research, 168-170, 1353-1362. 
Ehsani, M., Saadatmanesh, H., \& Thompson, C. (1997). Transfer and Flexural Bond Performance of Aramid and Carbon FRP Tendons. PCI Journal, 42(1), 76-86.

Fang, Z., Zhang, K., \& Tu, B. (2013). Experimental Investigation of a Bond-Type Anchorage System for Multiple FRP Tendons. Engineering Structures, 57, 364-373. Retrieved from http://linkinghub.elsevier.com/retrieve/pii/S0141029613004501

Harajli, M., \& Abouniaj, M. (2010). Bond Performance of GFRP Bars in Tension: Experimental Evaluation and Assessment of ACI 440 Guidelines. Journal of Composites for Construction, 14(December), 659-668. Retrieved from http://www.scopus.com/inward/record.url?eid=2-s2.078649293597\&partnerID=40\&md5=ba084f865ae3566ac36bbd9798819f61

Krem, S. (2013). Bond and Flexural Behaviour of Self Consolidating Concrete Beams Reinforced and Prestressed with FRP Bars. University of Waterloo.

Lees, J. M., Gruffydd-Jones, B., \& Burgoyne, C. J. (1995). Expansive Cement Couplers: A Means of Pre-tensioning Fibre-Reinforced Plastic Tendons. Construction and Building Materials. Retrieved from http://www.sciencedirect.com/science/article/pii/0950061895000704

Li, F., Zhao, Q. L., Chen, H. Sen, Wang, J. Q., \& Duan, J. H. (2010). Prediction of Tensile Capacity Based on Cohesive Zone Model of Bond Anchorage for FiberReinforced Polymer Tendon. Composite Structures, 92(10), 2400-2405. Retrieved from http://linkinghub.elsevier.com/retrieve/pii/S0263822310000954

Lu, Z., Boothby, T. E., Bakis, C. E., \& Nanni, A. (2000). Transfer and Development Length of FRP Prestressing Tendons. PCI Journal, 45(2), 84-95.

Mahmoud, Z., Rizkalla, S. H., \& Zaghloul, E. (1999). Transfer and Development Dengths of Carbon Fiber Reinforced Polymer Prestressing Reinforcement. ACI Structural Journal, 96(4), 594-602.

Mitchell, D., Cook, W. D., \& Khan, A. A. (1993). Influence of High Strength Concrete on Transfer and Development Length of Prestressing Strand. PCI Journal, 38, 52 66.

Moment - Curvature: Bonded Tendons. (2015). Retrieved from http://staff.fit.ac.cy/eng.ma/Aces480notes/Prestressed_Moment_Curvature.pdf

Nanni, Y. A., \& Tanigaki, M. (1992). Pretensioned Prestressed Concrete Members with Bonded Fiber Reinforced Plastic' Tendons: Development and Flexural Bond Lengths (Static). ACI Structural Journal, 89(4), 433-441.

Nawy, E. G. (2009). Prestressed Concrete: A Fundamental Approach (Fifth). Prentice Hall.

Noël, M., \& Soudki, K. (2013). Effect of Prestressing on the Performance of GFRP- 
Reinforced Concrete Slab Bridge Strips, (April), 188-196.

Okelo, R., \& Yuan, R. L. (2005). Bond Strength of Fiber Reinforced Polymer Rebars in Normal Strength Concrete. Journal of Composites for Construction, 9(3), 203-213.

PCA. (2002). Design and Control of Concrete Mixtures: The Guide to Applications, Methods, and Materials (15th ed.). Portland Cement Association.

Reda Taha, M. (2003). New Concrete Anchors for Carbon Fiber-Reinforced Polymer Post-Tensioning Tendons-Part 1: State-of-the-Art Review/Design. ACI Structural Journal, (1), 86-95.

Reda Taha, M., \& Shrive, N. G. (2003). New Concrete Anchors for Carbon FiberReinforced Polymer Post-Tensioning Tendons_-Part 2: Development/Experimental Investigation. ACI Structural Journal, 100(1). Retrieved from http://www.concrete.org/Publications/ACIMaterialsJournal/ACIJournalSearch.aspx? $\mathrm{m}=$ details $\& \mathrm{ID}=12443$

Russell, B. W., \& Burns, N. H. (1996). Measured Transfer Lengths of 0.5 and 0.6 in. Strands in Pretensioned Concrete. PCI Journal, 41, 44-65.

Schmidt, J. W., Bennitz, A., Täljsten, B., Goltermann, P., \& Pedersen, H. (2012). Mechanical Anchorage of FRP Tendons - A Literature Review. Construction and Building Materials, 32, 110-121.

Schmidt, J. W., Bennitz, A., Täljsten, B., \& Pedersen, H. (2010). Development of Mechanical Anchor for CFRP Tendons Using Integrated Sleeve. Journal of Composites for Construction, 14(4), 397-405. Retrieved from http://ascelibrary.org/doi/abs/10.1061/(ASCE)CC.1943-5614.0000096

Soudki, K. a., Green, M. F., \& Clapp, F. D. (1997). Transfer Length of Carbon Fiber Rods in Precast Pretensioned Concrete Beams. PCI Journal, 42(5), 78-87. Retrieved from http://cat.inist.fr/?aModele=afficheN\&cpsidt $=2853876$

Wambeke, B. W., \& Shield, C. K. (2006). Development Length of Glass FiberReinforced Polymer Bars in Concrete. ACI Structural Journal, 103(1), 11-17.

Wee, T. H., Chin, M. S., \& Mansur, M. a. (1996). Stress-Strain Relationship of HighStrength Concrete in Compression. Journal of Materials in Civil Engineering, 8(2), 70-76.

Zhang, B. B., Benmokrane, B., Chennouf, A., Mukhopadhyaya, P., \& El-safty, A. (2001). Tensile Behavior of FRP Tendons, (May), 85-93.

Zhang, B., \& Benmokrane, B. (2004). Design and Evaluation of a New Bond-Type Anchorage System for Fiber Reinforced Polymer Tendons. Canadian Journal of Civil Engineering, 31(1), 14-26. Retrieved from http://www.nrcresearchpress.com/doi/abs/10.1139/103-062 
Zhang, B., Benmokrane, B., \& Chennouf, A. (2000). Prediction of Tensile Capacity of Bond anchorages for FRP Tendons. Journal of Composites for Construction, 4(2)(May), 39-47.

Zia, P., \& Mostafa, T. (1997). Development Length of Prestressing Strands. PCI Journal, $22,54-65$.

Zoghi, M. (2014). The international handbook of FRP Composites in Civil Engineering. Boca Raton, FL: Taylor \& Francis Group, LLC.

Zou, P. X. W. (2003). Flexural Behavior and Deformability of Fiber Reinforced Polymer Prestressed Concrete Beams. Journal of Composites for Construction, 7(4), 275284. Retrieved from http://www.scopus.com/inward/record.url?eid=2-s2.013944269852\&partnerID=40\&md5=e1778e8ac4bab30a3a8738dc0eecc1eb 


\section{Appendix A}

Development of a Computer Model to Predict Load-Deflection Response of Prestressed Beam with CFRP or Steel Strands

The calculations started by assuming that the applied load was equal to zero. It should be mentioned that the dead load of the beam's own weight was ignored. Likewise, the dead load was also ignored in the experimental moment-deflection curves. Since the applied moment was zero (ignoring self-weight), the only moment on the beam was due to the effective pre-tensioning force, $P_{f e}$. The concrete stresses at top and bottom fibers could be determined as the following:

$$
\begin{array}{ll}
\sigma_{\text {top }}=-\frac{P_{f e}}{A}+\frac{P_{f e} \cdot e \cdot c}{I} & \text { Eq. }(A-1) \\
\sigma_{\text {bottom }}=-\frac{P_{f e}}{A}-\frac{P_{f e} \cdot e \cdot c}{I} & \text { Eq. }(A-2)
\end{array}
$$

Where;

$\sigma_{\text {top }}$ is the concrete stress at the top fiber of the beam cross section, ksi

$\sigma_{\text {bottom }}$ is the concrete stress at the bottom fiber of the beam cross section, ksi

$\mathrm{P}_{\mathrm{fe}}$ is the effective prestressing force, kips

$\mathrm{A}$ is the cross-sectional area of the beam 
$\mathrm{e}$ is the eccentricity of the CFRP strand to the natural axis

$\mathrm{c}$ is the distance from the centroid axis to the location of interest, where the stress is being determined

$\mathrm{I}=\frac{\mathrm{b} \mathrm{h}^{3}}{12}$

Once the top and bottom concrete stresses were known, the associated strains could be determined using the concrete modulus of elasticity. Then, the section curvature was found using simple geometric relations.

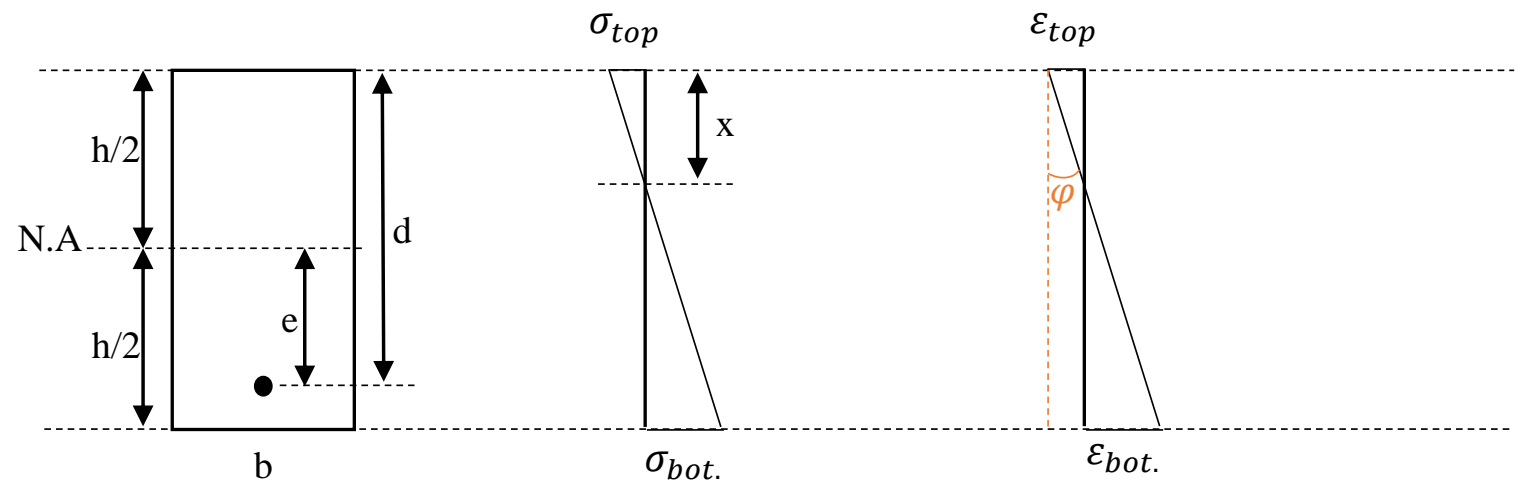

Figure A-1 Schematic drawings showing the concrete stresses and strains along the cross-sectional depth $(h)$.

$$
\varphi_{0}=\frac{\varepsilon_{b o t}-\varepsilon_{t o p}}{h} \quad \quad \ldots . E q .(A-3)
$$

Where; 
$\varphi$ is the section curvature

The curvature determined from Eq. (A-3) was associated with an applied moment due to external load equal to zero. At the same stage, the concrete strain at the level of CFRP strand, $\varepsilon_{c e}$, could be determined using the same principles of Eq. (A-1 \& A-2), but the value of "c" would be from the centroidal axis to the location of CFRP strand.

$$
\begin{array}{ll}
\sigma_{\mathrm{ce}}=-\frac{\mathrm{P}_{\mathrm{fe}}}{\mathrm{A}}+\frac{\mathrm{P}_{\mathrm{fe}} \cdot \mathrm{e} \cdot \mathrm{e}}{\mathrm{I}} & \ldots . \text { Eq. }(\mathrm{A}-4 \mathrm{a}) \\
\varepsilon_{\mathrm{ce}}=\frac{\sigma_{\mathrm{ce}}}{E_{c}} & \ldots . \text { Eq. }(\mathrm{A}-4 \mathrm{~b})
\end{array}
$$

In order to obtain the cracking moment, it was necessary to find the stress at the bottom fiber when the stress reached modulus of rupture. When the concrete strain at the level of CFRP became zero, additional stresses were added to the CFRP strand equal to $\sigma_{\text {ce }}$. As a result, the new CFRP strain was equal to the effective strain caused by the prestressing plus $\varepsilon_{\mathrm{ce}}$. Due to this process, a new point $\left(\varphi_{1}, M_{1}\right)$ on the moment curvature curve was obtained.

$$
\begin{array}{ll}
P_{f, 1}=P_{f e}+\sigma_{\mathrm{ce}} * A_{b} & \ldots . \\
\mathrm{M}_{1}=\frac{\mathrm{I} \sigma_{\mathrm{ce}}}{\mathrm{e}} & \ldots q .(A-5) \\
\end{array}
$$




$$
\begin{aligned}
& \sigma_{\text {top } 1}=-\frac{P_{f 1}}{A}+\frac{P_{f 1} \cdot e \cdot c}{I}-\frac{M_{1} \cdot c}{I} \quad \ldots . E q \cdot(A-7 a) \\
& \sigma_{\text {bot } 1}=-\frac{P_{f 1}}{A}-\frac{P_{f 1} \cdot e \cdot c}{I}+\frac{M_{1} \cdot c}{I} \quad \ldots . \text { Eq. }(A-7 b)
\end{aligned}
$$

Then, Eq. (A-3) was applied to obtain the curvature for this point, $\varphi_{1}$.

The difference between the bottom stress from previous stage, $\sigma_{\text {bot.1 }}$, and the cracking stress, assumed as $7.5 \sqrt{f_{c}^{\prime}}$, was the additional stress responsible for initiating the cracks. The additional moment caused by this additional stress was then obtained. The cracking moment was the moment associated with zero concrete strain at the level of CFRP plus the additional moment:

$$
\begin{aligned}
& \mathrm{f}_{\mathrm{cr}}=7.5 \sqrt{\mathrm{f}_{\mathrm{c}}^{\prime}} \quad \ldots . \mathrm{ACI} 318-11 \\
& \Delta \mathrm{f}=\mathrm{f}_{\mathrm{cr}}-\sigma_{\text {bot.1 }} \quad \text { so, } \Delta \mathrm{M}=\frac{\Delta \mathrm{f} . \mathrm{I}}{\mathrm{c}}
\end{aligned}
$$


Then, Eq. (A-3) was applied to calculate the curvature associated with $\mathbf{M}_{\mathrm{cr}}$. After cracking, the elastic equations are no longer applicable. The section was considered cracked, and the concrete force below the natural axis was ignored. The only force at the bottom was the CFRP force, which was obtained based on the linear stress-strain relationship that came from the experimental tests. The compressive force in the upper portion of the cross section (compression zone) was obtained from integrating the stress-strain relationship of the concrete based on Eq. (A-1). The centroid of the force is given by Eq. (A-14)

$$
\begin{array}{ll}
\mathrm{C}=\mathrm{b} \cdot \mathrm{f}_{\mathrm{c}}^{\prime} \cdot \frac{\varepsilon_{\mathrm{c}}}{\varepsilon_{\mathrm{o}}} \cdot \mathrm{x} \cdot\left[1-\frac{\varepsilon_{\mathrm{c}}}{3 \cdot \varepsilon_{\mathrm{o}}}\right] & \ldots . \\
\mathrm{y}^{\prime}=\mathrm{x} \cdot\left[\frac{8 \cdot \varepsilon_{\mathrm{o}}-3 \cdot \varepsilon_{\mathrm{c}}}{12 \cdot \varepsilon_{\mathrm{o}}-4 \cdot \varepsilon_{\mathrm{c}}}\right] & \ldots \mathrm{A}-13)
\end{array}
$$

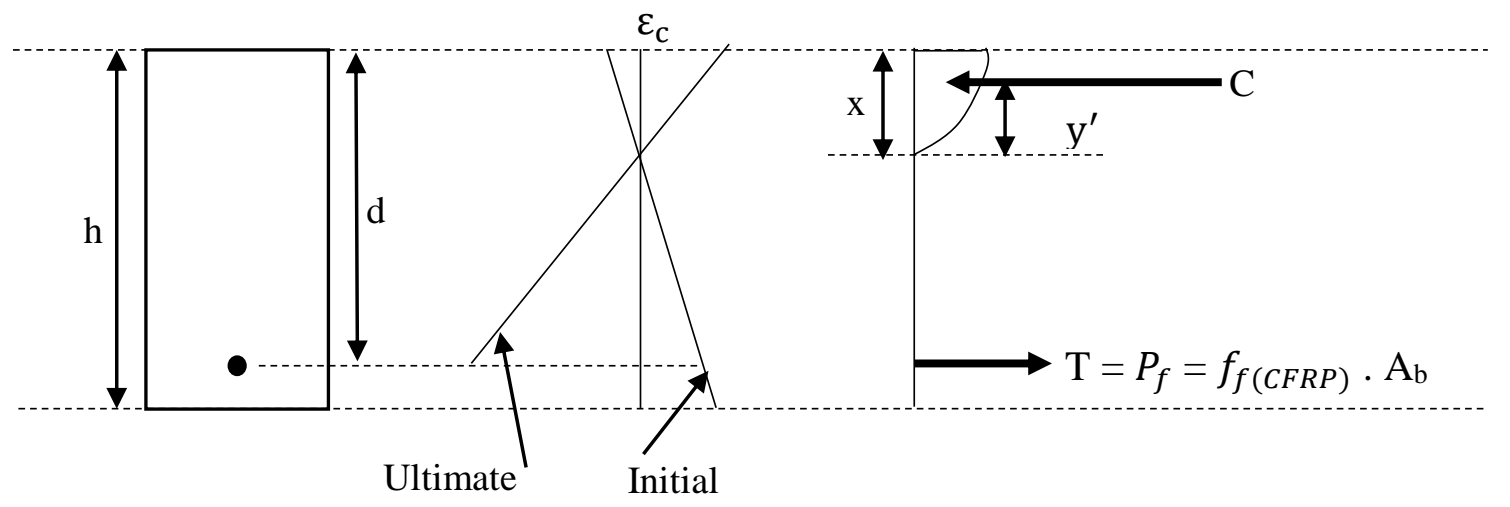

Cross Section Strain Stress

Figure A-2 Schematic drawings showing the tension and compression forces 
Beyond this point, the calculation was to follow a trial and error process starting by choosing a concrete strain at the top fiber $\left(\varepsilon_{c}\right)$. Then, a value for the depth of the neutral axis (x) was assumed. Having known the concrete strain at top fiber and the depth of the natural axis, the compression force $(\mathrm{C})$ and the tension force $(\mathrm{T})$ were calculated. If the forces were in equilibrium, the assumed value for the neutral axis depth was correct. Otherwise, another value of the neutral axis depth would be assumed and the forces recalculated until reaching the point where $\mathrm{T}=\mathrm{C}$. Once $\mathrm{T}$ and $\mathrm{C}$ were determined, and equal, the moment was easily determined. By continuing this process for several points, the moment-curvature curve was created.

In order to develop the moment-deflection curve at mid-span of the beam using the moment-curvature curve, the second moment-area theorem was applied to find the midspan deflection associated with each moment. Figure A-3 Shows the schematic drawing of the steps for calculating mid-span deflection. Area 1 , as shown in Figure A-3, multiplied by the distance from its centroid to point A gives the deflection associated with cracking moment. A similar procedure was carried out with Area 2 to obtain the ultimate deflection. Theoretically, the beam was considered failed if the concrete strain reached 0.003 , or if the CFRP reached the rupture stress.

The process described above is also applicable to modeling prestressed concrete beams with steel strands. The basic difference is that a stress-strain diagram for steel strand has to be assumed whereby strain values are converted to stress, based on the shape of the stress- 
strain relationship. This process was followed to determine the moment-deflection of a beam reinforced with steel strands and results are shown in Chapter 5.

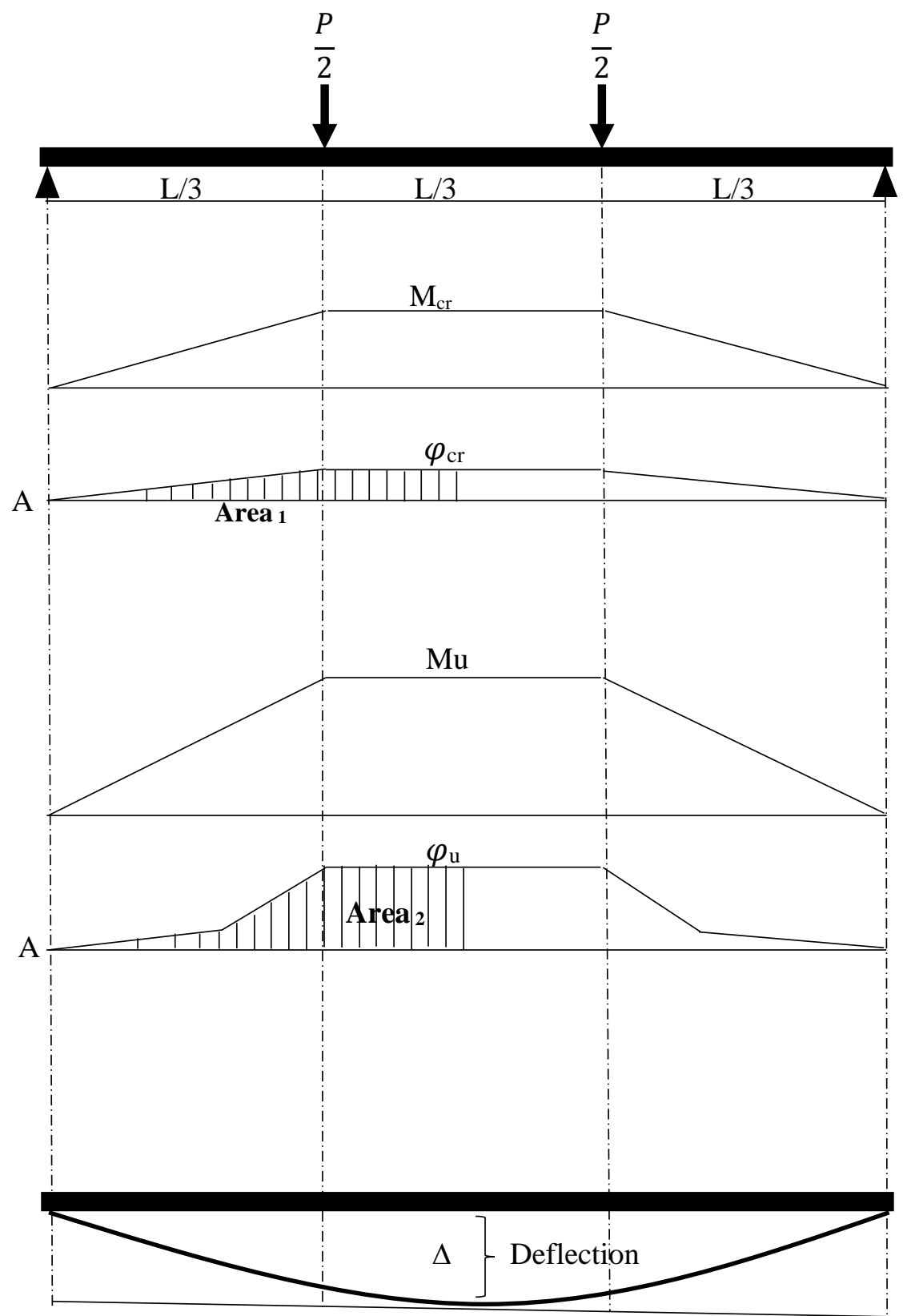

Figure A-3 Schematic drawings showing the steps of calculating mid-span deflection 